\title{
Functional Assessment of Biomarkers in Gemcitabine-Treated Pancreatic Cancer with Specific Focus on Nucleoside Transporter ENT1
}

\author{
Doctoral Thesis \\ In partial fulfillment of the requirements for the degree \\ "Doctor rerum naturalium (Dr. rer. nat.)" \\ in the Molecular Medicine Study Program \\ at the Georg-August University Göttingen
}

\author{
submitted by \\ Sebastian Roppel \\ from Rotenburg a.d. Fulda
}

Göttingen 2013 


\section{Members of the Thesis Committee:}

Supervisor

Name, Institute: Prof. Dr. med. Jürgen Brockmöller, Department of Clinical Pharmacology, Georg-August University Göttingen

Second member of the thesis committee

Name, Institute: Prof. Dr. Tim Beißbart, Department of Medical Statistics, Georg-August University Göttingen.

Third member of the thesis committee Name, Institute: Prof. Dr. Steven Johnsen, Department of Tumor Biology, Universitätsklinikum Hamburg-Eppendorf

Date of Disputation: 


\section{AFFIDAVIT}

Here I declare that my doctoral thesis entitled "Functional Assessment of Biomarkers in Gemcitabine-Treated Pancreatic Cancer with Specific Focus on Nucleoside Transporter ENT1" has been written independently with no other sources and aids than quoted.

Sebastian Roppel

Göttingen, August 2013 


\section{Table of Contents}

AFFIDAVIT .1

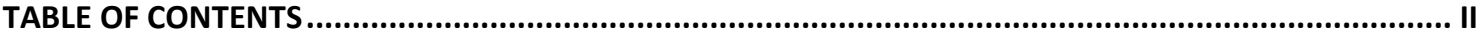

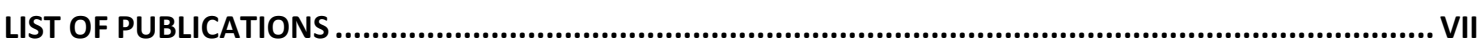

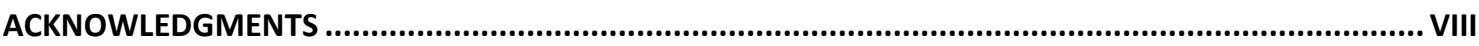

ABSTRACT

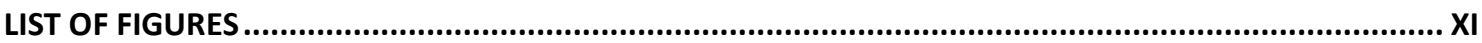

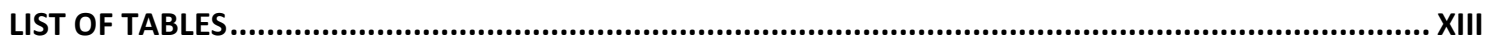

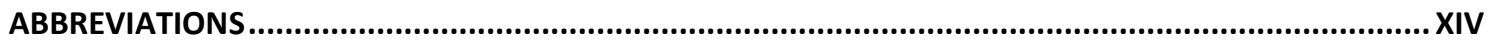

$1 \quad$ INTRODUCTION

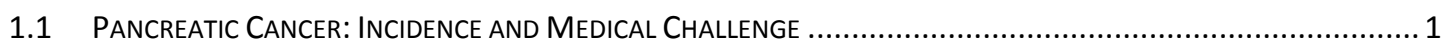

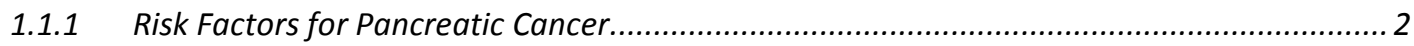

1.1.2 Tumor Genesis of Pancreatic Cancer ............................................................................... 3

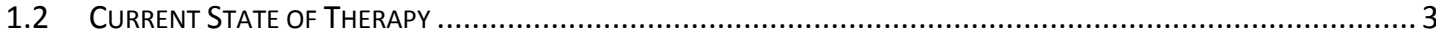

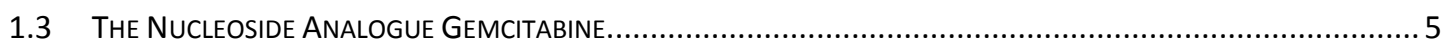

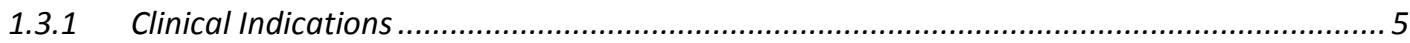

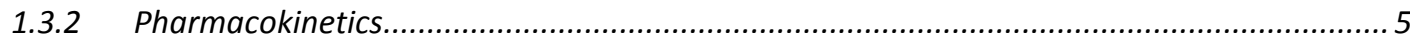

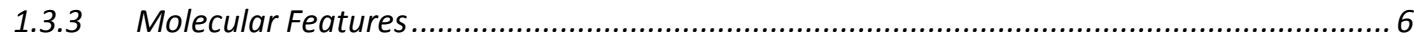

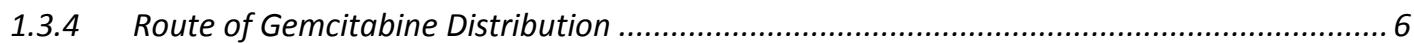

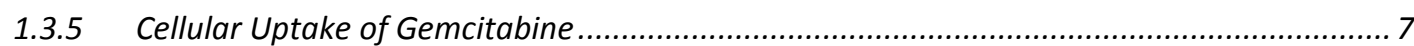

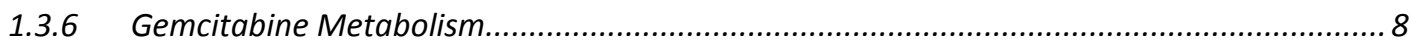

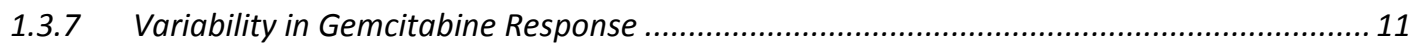

1.3.8 Genetic Polymorphisms Affecting Gemcitabine Response................................................ 12

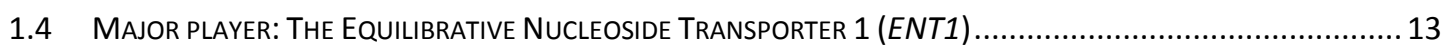

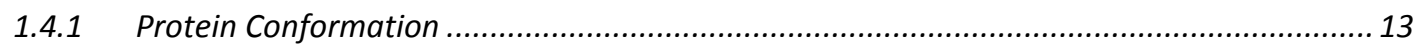

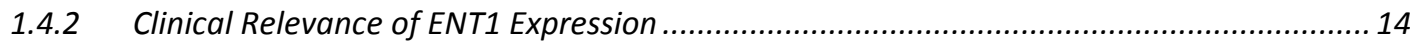

1.4.3 ENT1 Expression Regulation and Transcript Variants....................................................... 15

1.4.4 Genetic Variability in ENT1 ….................................................................................. 15

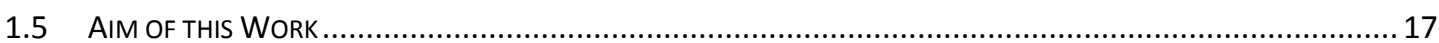

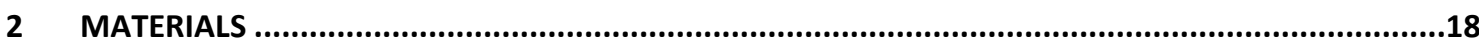

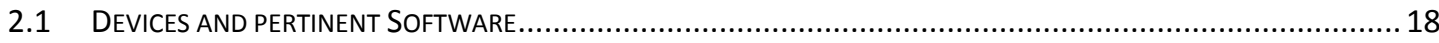

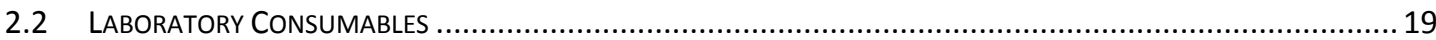

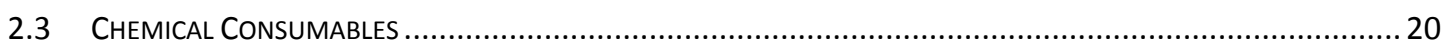

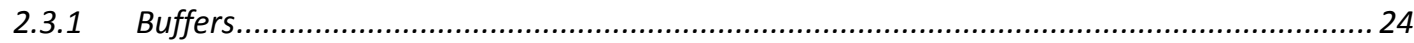




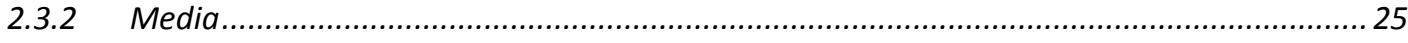

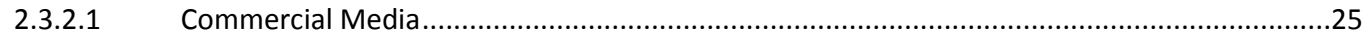

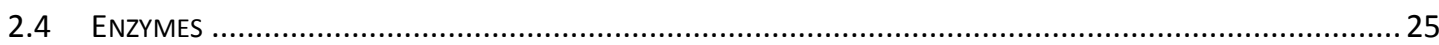

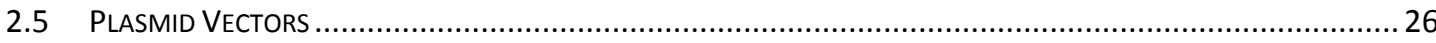

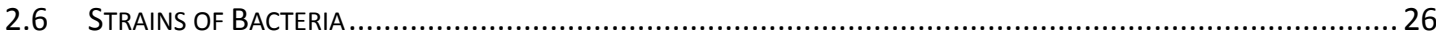

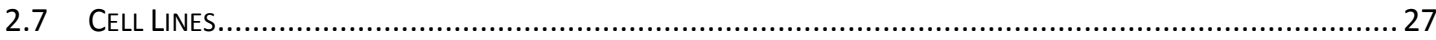

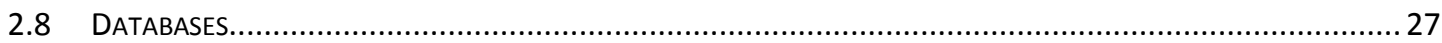

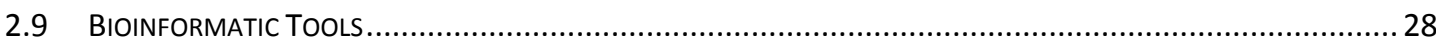

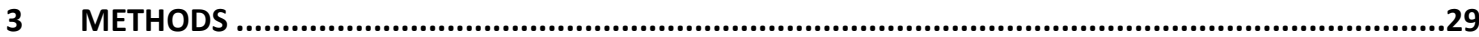

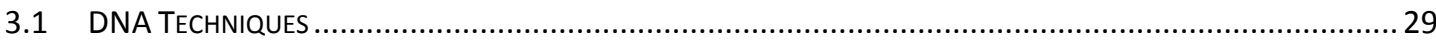

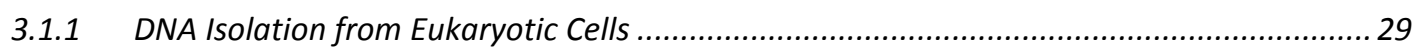

3.1.2 DNA Isolation from Bacteria .................................................................................... 29

3.1.2.1 Isolation of Plasmid DNA by Chloroform Extraction (Plasmid Mini-Prep)............................29

3.1.2.2 Isolation of Plasmid DNA by Solid Extraction (Plasmid Midi Prep)..........................................31

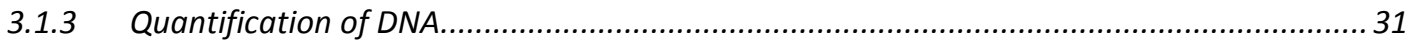

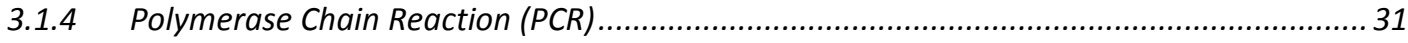

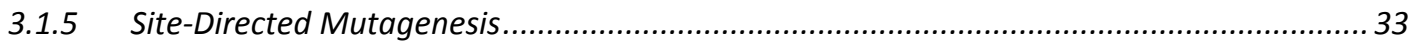

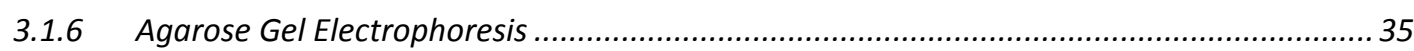

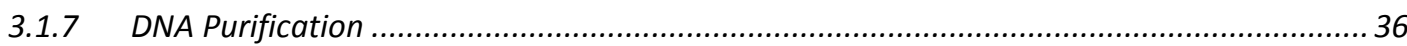

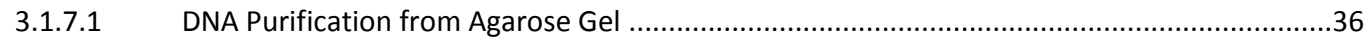

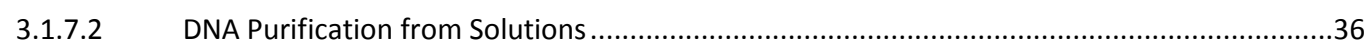

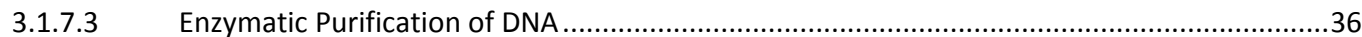

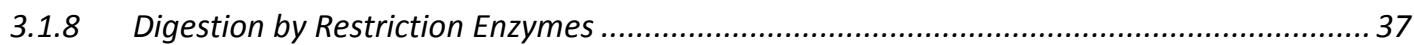

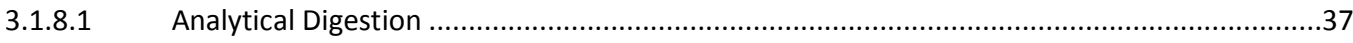

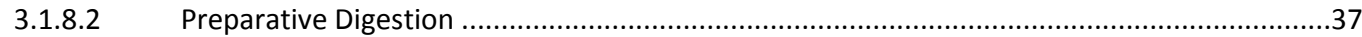

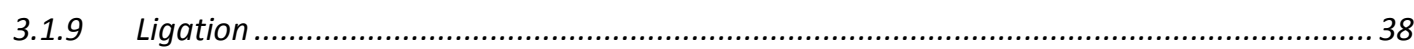

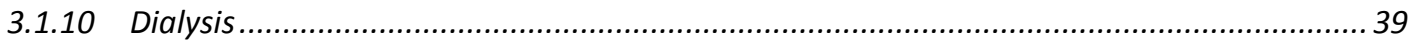

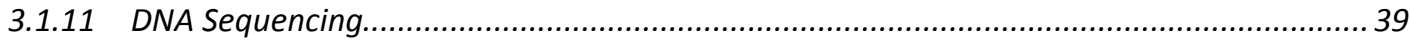

3.1.12 Genotyping by Primer Extension Method (SNaPshot ${ }^{T M}$ ) ............................................ 41

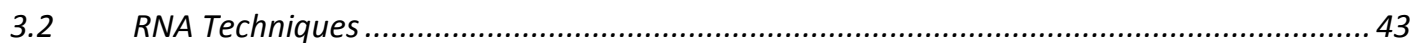

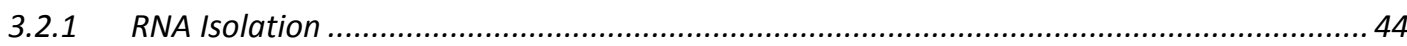

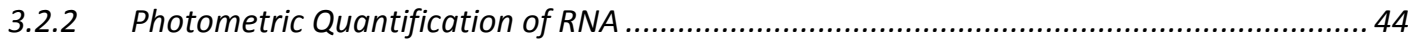

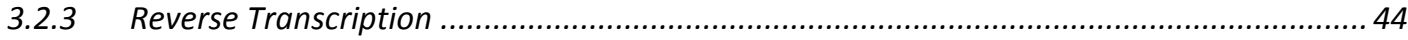

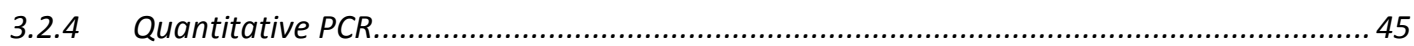

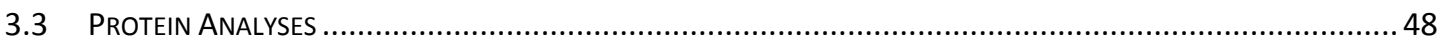

3.3.1 Quantification of Total Protein Using Bicinchoninic Acid (BCA)....................................... 48

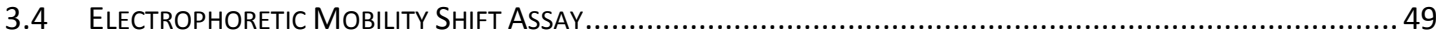

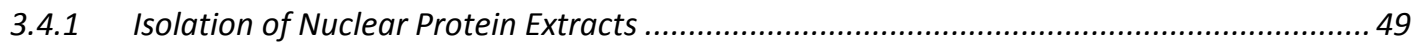

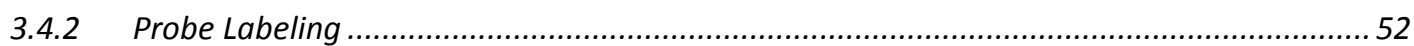




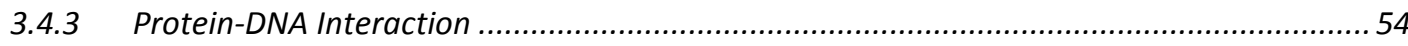

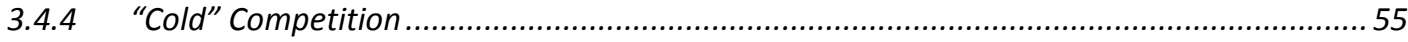

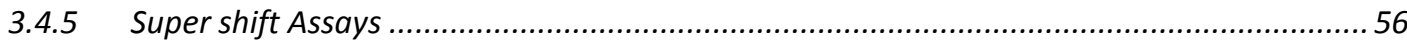

3.4.6 Non-Denaturating Polyacrylamid-Gel Electrophoresis ..................................................... 56

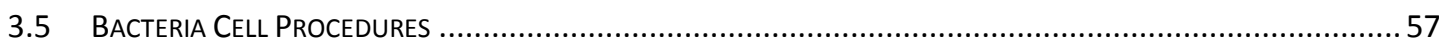

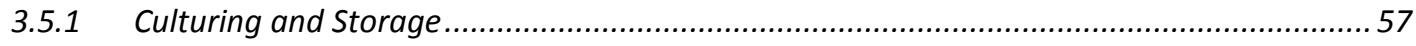

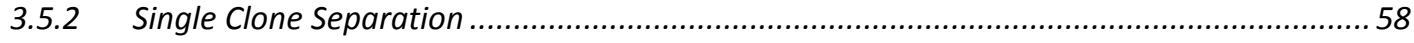

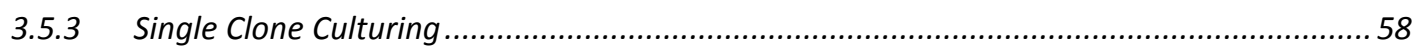

3.5.4 Transformation by Electroporation .......................................................................... 59

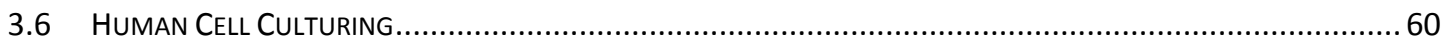

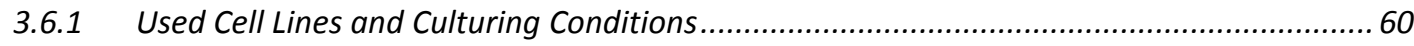

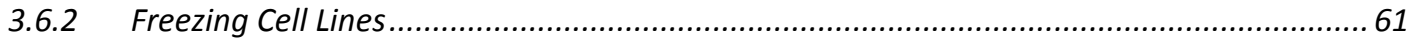

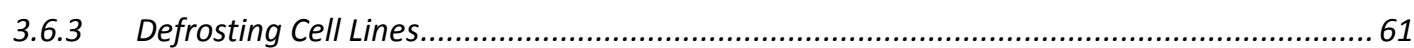

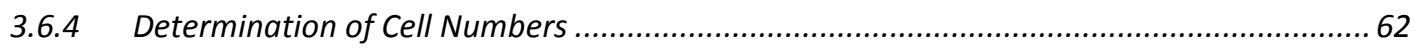

3.6.4.1 Cell Counting with Neubauer-Cell Chamber ......................................................................62

3.6.4.2 Cell Counting with Propidium lodide Staining by Flow Cytometry .........................................62

3.6.4.2.1 Determination of Cell Numbers in a Suspension with Counting Beads ............................63

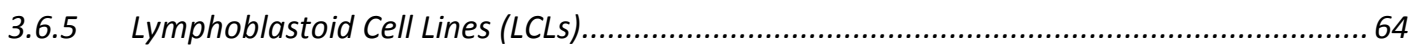

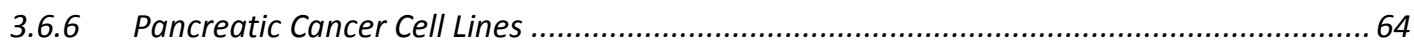

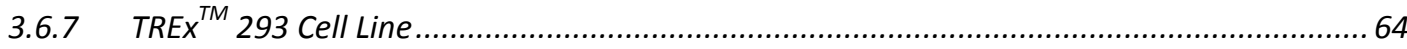

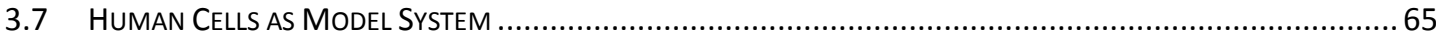

3.7.1 Transient Transfection for Luciferase Reporter Gene Assay .........................................65

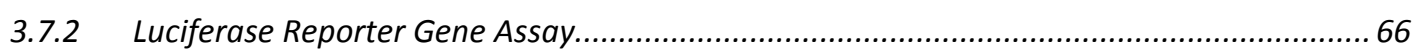

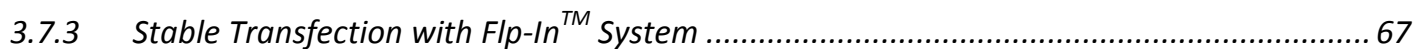

3.7.3.1 Confirmatory PCR to Validate Chromosomal Integration of pcDNA5 Constructs ....................69

3.8 Sequential StePS for Cloning of AlLeLE SPeCific ConstructS...................................................... 71

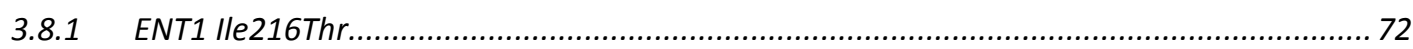

3.8.2 hENT1-v4/-v5 Promoter Polymorphism rs507964 ................................................... 73

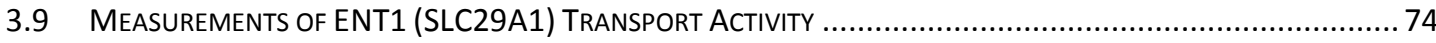

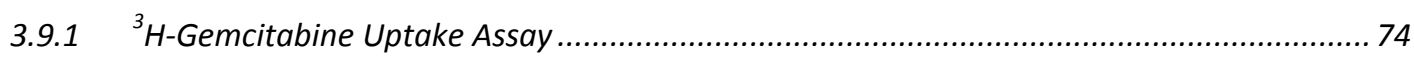

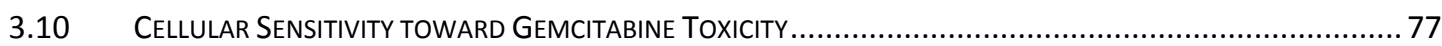

3.10.1 Staining of Lymphoblastoid Cell Lines (LCLS) with CFSE .............................................. 79

3.10.2 Determination of Vitality by Vybrant Ruby and Sytox Blue Staining and Determination of

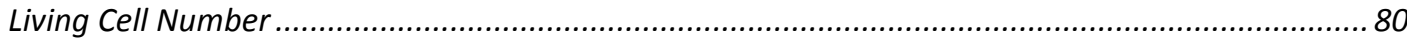

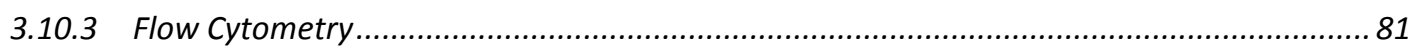

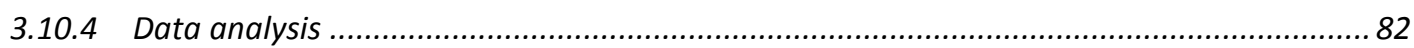

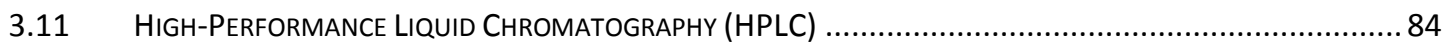

3.11.1 Self-Established HPLC Method for Quantification of Radioactive Labeled Gemcitabine Metabolites. 


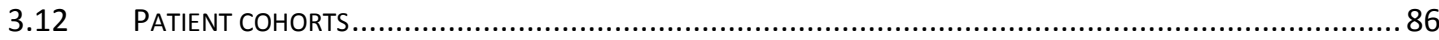

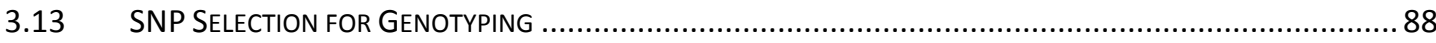

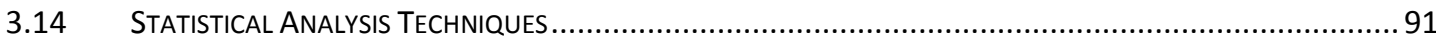

4 RESULTS

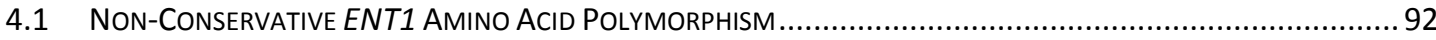

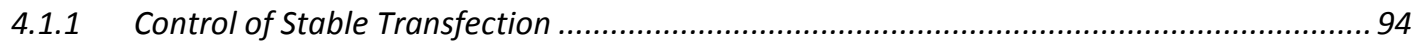

4.1.2 Impact on Gemcitabine Uptake .................................................................................... 94

4.2 Functional Evaluation of ENT1 Promoter Polymorphism ....................................................... 97

4.2.1 ENT1 Transcript Variant Expression ......................................................................... 97

4.2.2 Gemcitabine Effects on ENT1 Expression .............................................................. 101

4.2.3 Impact of ENT1 Promoter SNP on ENT1 transcription ................................................ 103

4.2.4 Exploration of Genetic Linkage Disequilibrium of rs1057985 ........................................ 104

4.2.5 In silico Assessment of Regulatory Genetic Elements ................................................... 105

4.2.6 Nuclear Protein Interaction with ENT1 SNP Region ................................................... 107

4.2.7 Identification of the Nuclear Binding Protein ............................................................. 109

4.2.8 Effect of ENT1 SNP rs507964 on promoter activity..................................................... 113

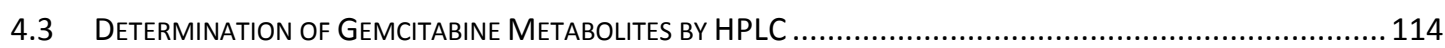

4.4 ReCENTLY SUgGESTEd NeW BIOMARKER: WWOX RS11644322 ................................................. 115

4.3.1 Confirmation of GWAS in Clinical Cohort.............................................................. 115

4.3.2 Modulation of Gene Expression .............................................................................. 117

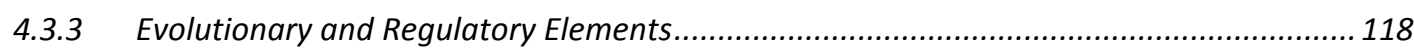

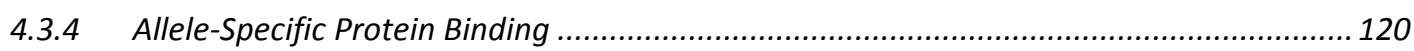

4.4 GenOME-Wide DeterminANTS For GemCITABINE SenSITIVITY ................................................... 123

4.4.1 Variability of Gemcitabine Cytotoxicity .............................................................. 124

4.4.2 Genome-Wide Determinants of Gemcitabine Sensitivity........................................... 125

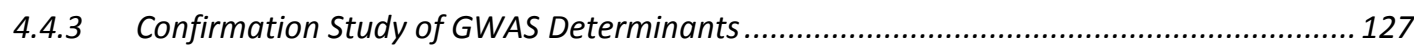

5 DISCUSSION

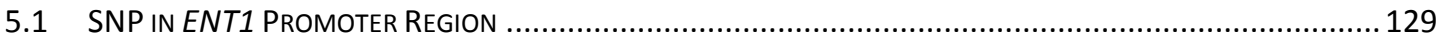

5.1.1 Expression of Different ENT1 Transcript Variants.......................................................... 130

5.1.2 Transcript Variant Expression affected Gemcitabine ..................................................... 130

5.1.3 Gemcitabine Transcript Induction Modulated by Promoter SNP................................... 131

5.1.4 Genetic Linkage Disequilibrium Analysis for rs1057985 ............................................. 131

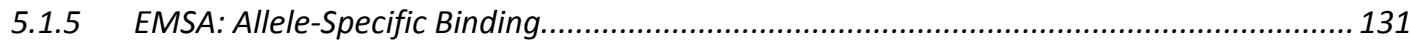

5.1.6 Reporter Gene Analysis: SNP Region with High Promoter Activity ................................. 132

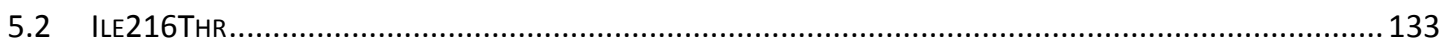

5.2.1 ENT1 as the Major Gemcitabine Uptake Route in HEK Cells......................................... 133

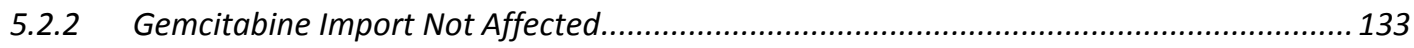


5.3 Fields of Application for Gemcitabine Metabolites Determination by HPLC .................................135

5.4 CONFIRMATION OF A GWAS FINDING: WWOX RS11644322 ...................................................... 135

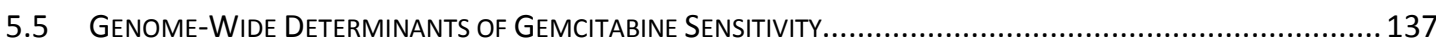

5.5.1 RS6898780 as a New Putative Marker .......................................................................... 137

5.5.2 Considerations about the Phenotypic Robustness....................................................... 137

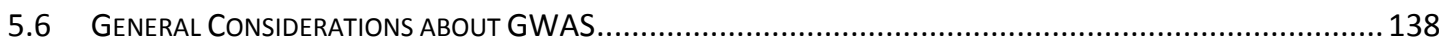

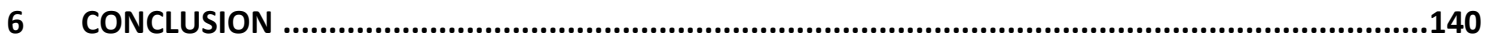

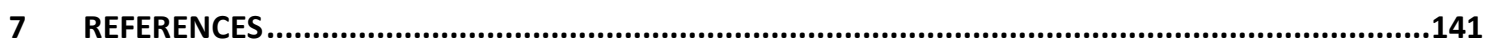

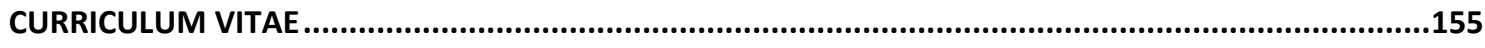

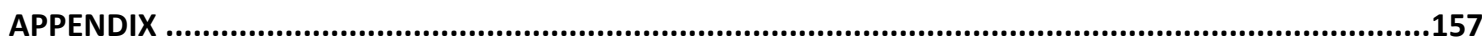




\section{List of Publications}

Florez, L. A., S. F. Roppel, A. G. SChMeISKy, C. R. LAmmers and J. StUlKe, 2009 A community-curated consensual annotation that is continuously updated: the Bacillus subtilis centred wiki SubtiWiki. Database (Oxford) 2009: bap012.

Lammers, C. R., L. A. Florez, A. G. Schmeisky, S. F. Roppel, U. Mader et al., 2010 Connecting parts with processes: SubtiWiki and SubtiPathways integrate gene and pathway annotation for Bacillus subtilis. Microbiology 156: 849-859. 


\section{Acknowledgments}

Most of all, I would like to express my sincere gratitude to my advisor Dr. Markus Schirmer for the continuous support of my PhD study and research, for his patience, motivation, enthusiasm, and immense knowledge. His guidance helped me in all the time of research and writing of this thesis. I could not have imagined having a better advisor and mentor for my PhD study.

Besides my advisor, I would like to thank the rest of my thesis committee: Prof. Dr. med. Jürgen Brockmöller, Prof. Dr. Tim Beißbart, and Prof. Dr. Steven Johnsen, for their encouragement, insightful and constructive comments.

My sincere thanks go again to Prof. Dr. Tim Beißbart, for his essential support in statistical evaluation of a genome wide association study. For bioinformatics assistance in identifying DNA binding proteins I owe my great thanks to Martin Haubrock. I also like to thank PD. Mladen Tzvetkov for his help with molecular issues during the time of my research.

I am indebted to Prof. Dr. med. Jürgen Brockmöller to offer me the great privilege to spend several years in the Department of Clinical Pharmacology at George August University, Göttingen.

I yield my dearest thanks to my parents, especially to my mother for continuous, mental, practical and financial support with my thesis. She always motivated me and had faith in me and my work.

I owe my deepest gratitude to Katrin Engel who had utmost patience with me and my untypical and long working hours and for her assistance in preparing some of the pictures in my thesis. She was always there cheering me up and stood by me through the good times and bad.

I thank my fellow lab mates in Schirmer-Group for the good working atmosphere and for all the fun we have had in the last years.

I acknowledge Deutsche Forschungsgemeinschaft (DFG): Graduiertenkolleg GRK1034 for granting the scholarship to me which gave me the opportunity of conducting my research. 


\section{Abstract}

Pancreatic ductal adenocarcinomas are the fourth leading cause of death among all kinds of cancers. The poor prognosis is due to usually late diagnosis and, in most cases, the available therapeutic options lack sustained efficacy. Thus, there is an urgent need to identify new biomarkers, which might help to tailor therapy for patients. At present, the standard chemotherapeutic agent is gemcitabine, a nucleoside analogue and is contained in almost each chemotherapy regimen in pancreatic cancer. A recent clinical study performed in our institute revealed two SNPs in the genetic region of the equilibrative nucleoside transporter 1 (ENT1) associated with the overall survival of patients treated with gemcitabine for pancreatic cancer. The first SNP (rs1057985) of which the variant allele (minor allele frequency 33\% in Caucasians) resulted in a significantly prolonged overall survival is located in an ENT1 promoter region. The second (rs45573936) of which the variant allele (2\%) was linked to a dramatically reduced overall survival, constitutes an amino acid exchange at codon 216 from isoleucine to threonine. Recently, a genome-wide approach has featured SNPs for the first time in relation to the outcome of gemcitabine-based chemotherapy in pancreatic cancer. The aim of my thesis was to elucidate the molecular mechanisms of the aforementioned ENT1 polymorphisms and to explore new biomarkers for gemcitabine sensitivity in a genomewide fashion.

ENT1 transcript variant expression was determined via quantitative real time PCR in a panel of various human tissues as well as pancreatic cancer and lymphoblastoid cell lines. These analyses included ascertainment upon gemcitabine exposure. Transcription factor binding was analyzed by electrophoretic mobility shift assay (EMSA) with addressing hypothesized allele-specific disparities. Allele-specific constructs were generated both for the ENT1 promoter region and for Ile216Thr. The functional consequences were assessed by reporter gene assay in a transiently transfected pancreatic cancer cell line and transport kinetics of ${ }^{3} \mathrm{H}$-labelled gemcitabine in stably transfected HEK293 cells, respectively. Genome-wide dose-response relationships for gemcitabine sensitivity were determined in a training set of 196 and a test set of 95 lymphoblastoid cell lines. Regarding the training set, comprehensive genotypes were available from resequencing. Twenty top hits were examined in the test with primer extension method used for genotyping.

Quantitative real time experiments demonstrated strong expression of an ENT1 transcript variant with the transcription start in vicinity to the index promoter SNP. The 
variant allele of this SNP was concomitant with higher induction of this transcript variant in 101 LCLs upon gemcitabine exposure. Linkage disequilibrium analysis revealed complete coherence of the so far investigated index SNP (rs1057985) with another SNP (rs507964) located even closer to the start site of the considered ENT1 transcript variant. In silico analysis predicted regulatory elements in the region surrounding rs507964, but not for rs1057985. In EMSA experiments protein binding was detected only in presence of the wild type, but not the variant allele of rs507964. No protein binding was detected when probes for rs1057985 were used regardless of the allele configuration. A bioinformatic screen suggested a member of the SP family to be the observed binding protein on the probe containing rs507964 and was supported by cold competition with respective probes in EMSA. However, reporter gene assays did not reveal any allele-specific impact of rs507964. Regarding Ile216Thr, the two alleles did not alter gemcitabine uptake. One of the findings from a recently published genome wide association study (GWAS) in relation to overall survival of pancreatic cancer patients could be confirmed, i.e. worse outcome of the variant allele of the SNP rs11644322 in the WWOX gene. Since the sequence pattern around this SNP resembled that of rs507964 EMSA experiments were likewise performed. This procedure revealed stronger protein binding for the probe with the wild type than the variant allele of rs11644322 again suggesting a member of the Sp family interacting. The genome-wide screen in LCLs elicited SNP rs6898780 as a potential new candidate for cellular gemcitabine sensitivity.

In conclusion, the ENT1 promoter index SNP appears to act transcript-specifically as corroborated by expression analysis and EMSA. The lack of functionality in reporter gene assay points to so far unknown additional components which may interfere, but not yet understood. With respect to Ile216Thr, because no effect on gemcitabine uptake was noted, the relation to export kinetics should be addressed. In case of rs11644322 in the pro-apoptotic WWOX gene the allele clinically associated with poor survival exhibited reduced protein binding and showed a trend to weaker induction by gemcitabine in vitro. The herein newly identified SNP rs6898780 in relation to gemcitabine sensitivity is currently not attributable to a gene or transcript and should be investigated further. 


\section{List of Figures}

Figure 1: Structure formula of cytidine (left) and gemcitabine (right) .........................6

Figure 2: Route of gemcitabine and metabolism .................................................... 10

Figure 3: Conformation of the protein encoded by ENT1 .........................................14

Figure 4: Chromosomal integration of gene of interest by stable transfection with FlpIn System

Figure 5: Illustrated FACS data of untreated LCL cells 83

Figure 6: Illustrated FACS data of LCL cells teated with 10,8 nM gemcitabine for 72 hours

Figure 7: Illustrated FACS data of LCL cells teated with $76 \mathrm{nM}$ gemcitabine for 72 hours

Figure 8: Chromatograms of gemcitabine and gemcitabine-metabolite separation by HPLC

Figure 9: Plot of linkage disequilibrium in ENT1 $(-10 \mathrm{~kb} /+2.5 \mathrm{~kb})$ genetic region based on 247 fully sequenced individuals

Figure 10: Scheme of ENT1 transporter (SLC29A1) with Ile216Thr (rs45573936) ....93

Figure 11: ${ }^{3} \mathrm{H}$-gemcitabine transport kinetic of ENT1-rs45573936 wild type clones in relation to non transfected pcDNA empty vector clones.

Figure 12: Transport activity of ENT1-rs45573936 clones in relation to non transfected clones

Figure 13: Transport activity in presence of $50 \mu \mathrm{M}$ NBTI inhibitor of ENT1rs45573936 clones in relation to non transfected clones

Figure 14: Transport activity of HEK-ENT1-rs45573936 wild type and variant clones in presence of $0.1 \mu \mathrm{M}$ NBTI

Figure 15: ENT1 transcript variant expression in a panel of various human tissues .....99

Figure 16: ENT1 transcript variant expression in pancreatic cancer cell lines .............100

Figure 17: Quantitative variability of ENT1 transcript variants in 16 LCLs...............101

Figure 18: Gemcitabine effects on transcription of ENT1 variants in 16 LCLs.......... 102

Figure 19: Induction of ENT1 transcripts by $5 \mu \mathrm{M}$ gemcitabine in pancreatic cancer cell lines

Figure 20: Plot of linkage disequilibrium in ENT1 $(-10 \mathrm{~kb} /+2.5 \mathrm{~kb})$ genetic region based on 247 fully sequenced individuals (rs1057985)

Figure 21: Plot of linkage disequilibrium in ENT1 $(-10 \mathrm{~kb} /+2.5 \mathrm{~kb})$ genetic region based on 247 fully sequenced individuals (rs1057985 \& rs507964). 105 
Figure 22: Ilustration of evolutionary conserved regions (ECRs) in the DNA of different species compared to humans 106

Figure 23: Assessment of the ENT1 rs1057985 and rs507964 containing sequences for putative promoter sites by UCSC genome Browser 107

Figure 24: EMSA with allele-specific ${ }^{32} \mathrm{P}$-labelled probes at rs507964 108

Figure 25: Cold competition experiments for ${ }^{32} \mathrm{P}$-labelled rs507964 wild type probe 108 Figure 26: Cold competition experiments for ${ }^{32} \mathrm{P}$-labelled rs507964 wild type probe (bar chart)

Figure 27: Cold competition experiments via electrophoretic mobilityshift assays with consensus sequences for putative binding proteins at ENT1 rs507964 using nuclear extracts from LCLs

Figure 28: Comparison between the binding motif V\$SP1_Q6 and the sequence context at rs507964 111

Figure 29: Analysis of SP1 binding motif mutations 112

Figure 30: Allele specific induction of 2122bp ENT1-V4/-v5 rs507964 promoter fragments in pXP2 vector.

Figure 31: Allele specific induction of rs507964 EMSA primer in pT81 vector 114

Figure 32: Survival rate in dependence on WWOX rs11644322 as ascertained in a set of 392 patients by univariate unadjusted log-rank test $(\mathrm{p}=0.0008)$ 116

Figure 33: Inducing effect of gemcitabine on WWOX expression in LCLs 117

Figure 34: Effect of rs11644322 on gemcitabine-mediated WWOX induction 118

Figure 35: Potentially regulatory regions surrounding WWOX rs34310485 119

Figure 36: Potentially regulatory regions surrounding WWOX rs11644322 119

Figure 37: Representative EMSA plot for assessing transcription factor binding of nuclear protein extracts at WWOX rs11644322

Figure 38: Quantification of allele-specific differential transcription factor binding at WWOX rs11644322 as assessed by EMSA in nuclear protein extracts 122

Figure 39: SP1_Q6 binding motif in relation to WWOX rs11644322.. 122

Figure 40: Relevance of SP1 motif for nuclear protein extract binding ..... 123

Figure 41: Distribution of gemcitabine sensitivity on cell vitality and proliferation of LCLs. 124

Figure 42: Reproducible impact of rs6898780 on proliferation inhibition by gemcitabine 128 
Figure 43: Reproducible impact of rs6898780 on reduction of vitality by gemcitabine 128

\section{List of Tables}

Table 1: Mutagenesis primer for $h E N T 1$ - rs45573936- WT $\rightarrow \operatorname{Var}(\mathrm{t} \rightarrow \mathrm{c}) \ldots \ldots \ldots \ldots \ldots . . . . . . . .34$

Table 2: ENT1-Thr216 sequencing Primer ................................................................ 34

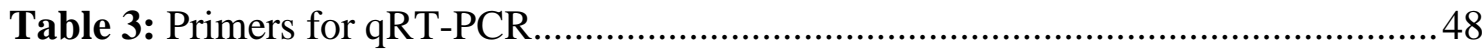

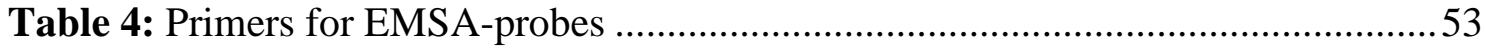

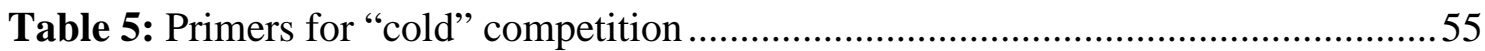

Table 6: List of primers for validation of chromosomal integration of pcDNA5 constructs

Table 7: Primer for hENT1 amplification and insertion of EcoRV and XhoI restriction sites. 72

Table 8: Primer pair for hENT1 promoter amplification 74

Table 9: Sequencing ENT1-Promoter-Primer .74

Table 10: Gemcitabine concentrations applied for cytotoxicity study. 78

Table 11: Volumes of gemcitabine incubated samples for flow cytometry measurements

Table 12: Distribution of the patients' baseline parameters, tumor stages, chemotherapy regimens, as well as time of follow-up and overall survival in the two study cohorts...87

Table 13: Features of the five genotyped SNPs 88

Table 14: Primer sequences for genotyping 90

Table 15: Induction of ENT1-V5 by gemcitabine in LCLs in dependence on the SNP rs1057985

Table 16: Genetic polymorphisms representative for loci strongest associating with proliferation inhibition by gemcitabine in the training set. 126

Table 17: Transcription factor binding prediction on hENT Promotr-SNP rs507964.157 Table 18: Lymphoblastoid cell lines from Coriell Cell Repositories (http://ccr.coriell.org) 157 


\section{Abbreviations}

APS

$\mathrm{ASP}^{+}$

BSA

bp

CDA

ChIP-Seq

cDNA

CMPK1

CNT1

CNT2

d-

Da

DCK

DCTD

dd-

$\mathrm{ddH}_{2} \mathrm{O}$

$\mathrm{dFdC}$

dFdC-MP

dFdC-DP

dFdC-TP

dFdU

dFdU-MP

dFdU-DP

dFdU-TP

DMEM

DMFA

DMSO

DNA

dNTP

DTT

E. coli

EC50
Ammonium persulfate

4-(4-(dimethylamino)styryl)-N- methylpyridinium Bovine Serum Albumin

Base pair

Cytidine deaminase

Chromatin ImmunoPrecipitation DNA-Sequencing copy DNA

Cytidine monophosphate kinase

Concentrative nucleoside transporter 1 (SLC28A1)

Concentrative nucleoside transporter 2 (SLC28A2)

Deoxy-

Dalton

Deoxycytidine kinase

Deoxycytidylate deaminase

Didesoxy-

bi-distilled Water

2', 2'-difluorodeoxycytidine

2', 2'-difluorodeoxycytidine-monophosphate

2', 2'-difluorodeoxycytidine-diphosphate

2', 2'-difluorodeoxycytidine-triphosphate

2', 2'-difluorodeoxcyuridine

2', 2'-difluorodeoxcyuridine-monophosphate

2', 2'-difluorodeoxcyuridine-diphosphate

2', 2'-difluorodeoxcyuridine-triphosphate

Dulbecco's Modifiziertes Eagle Medium

Dimethylformamid

Dimethylsulfoxide

Desoxyribonucleic acid

Deoxynucleosidetriphosphate

Dithiothreitol

Escherichia coli

half maximal effect concentration 


\begin{tabular}{|c|c|}
\hline EDTA & Ethylene di-amine tetra-acetic acid \\
\hline ENT1 & Equilibrative nucleoside transporter (SLC29A1) \\
\hline et al. & Et alii \\
\hline $\mathrm{F}$ & Farad \\
\hline FAM & 6-Carboxyfluorescein \\
\hline g & Gravity acceleration $\left(9.81 \mathrm{~m} / \mathrm{s}^{2}\right)$ \\
\hline GWAS & Genome wide association study \\
\hline h & hour \\
\hline HBSS & Hank’s balanced salt solution Medium \\
\hline HPLC & High performance liquid chromatography \\
\hline IMDM & Iscove’s Modified Dulbecco’s Medium \\
\hline IRES & Internal Ribosomal Entry Site \\
\hline $\mathrm{kb}$ & Kilobase pair \\
\hline $\mathrm{kV}$ & Kilo volt \\
\hline LB & Luria-Bertani Medium \\
\hline M & Molarity \\
\hline MAF & Minor allele frequency \\
\hline $\min$ & Minutes \\
\hline $\mathrm{MPP}^{+}$ & 1-methyl-4-phenylpyridinium \\
\hline mRNA & messenger RNA \\
\hline MTT & 3-(4,5-Dimethylthiazol-2-yl)-2,5- \\
\hline & diphenyltetrazolium bromide \\
\hline n. s. & Not significant \\
\hline NBMPR / NBTI & S-(4-Nitrobenzyl)-6-thioinosine \\
\hline NDP & Nucleoside diphosphate \\
\hline NDPK & Nucleoside diphosphate kinase \\
\hline NTP & Nucleoside triphosphate \\
\hline NT5C3 & Cytosolic 5'-nucleotidase 3 \\
\hline $\mathrm{p}$ & Significant level \\
\hline PAGE & Polyacrylamide gel electrophoresis \\
\hline PBS & Phosphate buffered saline \\
\hline PCR & Polymerase chain reaction \\
\hline $\mathrm{pH}$ & pH-value \\
\hline
\end{tabular}




\begin{tabular}{ll} 
RNA & Ribonucleic acid \\
Rnase & Ribonuclease \\
RRM & Ribonucleotide reductase \\
RT & Room temperature \\
rpm & Rotations per minute \\
SDS & Sodiumdodecylsulfate \\
SEM & Standard error of the mean \\
Taq & Thermus aquaticus \\
TBA & Tetra-N-butylammonium \\
TEA & Tetraethylammonium \\
TBE-Buffer & Tris-Borat-EDTA-buffer \\
TBP & TATA-Box-Bindeprotein \\
TE-Buffer & Tris-hydroxymethyl-aminomethan-EDTA-buffer \\
TEMED & “N,N,N',N'-Tetramethylethylenediamine \\
Tris & Tris-hydroxymethyl-aminomethane \\
U & unit \\
UV & Ultraviolet \\
v/v & Volume per Volume \\
w/v & Weight per Volume \\
\hline
\end{tabular}




\section{Introduction}

\subsection{Pancreatic Cancer: Incidence and Medical Challenge}

In most cases pancreatic cancer is referred to ductal pancreatic carcinoma, which is diagnosed in about $80 \%$ of patients with pancreatic malignancies. Most of the carcinomas stem from exocrine tissues (AHLGREN 1996), which are predominantly localized in the head of the pancreas. In few cases pancreatic tumor genesis originates from acinar cells (BARDEesy and DePinHo 2002; De LA and MurTAUgh 2009). Certain kinds of stem cells could represent the origin from which pancreatic cancer arises (GIDEKEL FRIEDLANDER et al. 2009). Ductal pancreatic adenocarcinomas are the fourth leading cause of death referred to cancer following lung, prostate and colorectal cancer (WARSHAW and FERNANDEZ-DEL CASTILlO 1992). The incidence for ductal adenocarcinomas is about 10 per 100.000 citizens in most parts of Europe, North America and parts of South America according to the International Agency for Research on Cancer (http://www-dep.iarc.fr/). For Germany, about 7600 women and 7800 men were expected to develop pancreatic cancer in 2012 according to a report of the RobertKoch-Institute. The average age of occurrence is 70 years for men and 76 years for women (Robert-Koch-Institut 2012). The appearance of pancreatic cancer in individuals below 40 years is extremely rare (WARSHAW and FERNANDEZ-DEL CASTILLO 1992)

Due to the high mortality in advanced stages and the lack of sufficient early detection screenings the prognosis of adenoductale pancreatic cancer is very poor. The absolute overall survival is five years after detection of the cancer, which makes it to the type with the lowest survival rate between all kinds of cancer (according to Robert-KochInstitut 2012).

Most patients (about 80\%) show advanced stages of pancreatic cancer at time of diagnosis, which cannot be completely resected by surgery (Loos et al. 2008). Even in the subgroup in which surgery could be executed in curative intention the five-year survival rate is not more than 20\%-25\% (VINCENT et al. 2011). When considering all cases diagnosed with pancreatic cancer this rate is only about 5\% (JEMAL et al. 2010). The median overall survival for locally advanced tumors ranges from $8-12$ months. The worst prognosis is observed for patients with distant metastases with a median survival time of 3-6 months (Huguet et al. 2009; SHAIB et al. 2006). This poor prognosis renders pancreatic cancer to those types of cancer with the lowest survival rates (according to Robert-Koch-Institut 2012). 


\subsubsection{Risk Factors for Pancreatic Cancer}

Risk factors for the appearance of adenoductale pancreatic carcinomas are considered to be inheritance, pancreatitis, overweight, smoking, consumption of saturated fat (LYON et al. 1993). The chronic pancreatitis was also assumed to cause about a 20-fold increased risk of pancreatic cancer (LOWENFELs et al. 1993). But newer studies claim that occurrence of pancreatic cancer in individuals who were suffering from chronic pancreatitis for 20 years was just about 5 \% (RAIMONDI et al. 2010). Persons suffering from a primary sclerosing cholangitis show a 14-fold risk of pancreatic cancer incidence (BERGQUist et al. 2002; SCHRUMPF and BoBerg 2003). In several studies smoking is considered to lead to a 2 to 3 times increased risk of pancreatic cancer (HART et al. 2008; MACK et al. 1986; MALFERTHEINER and SCHUTTE 2006). In about $25 \%$ of pancreatic tumors smoking is associated with the occurrence. In people smoking the cancer develops even ten years earlier than in non smokers and the risk increases with the timeframe of smoking cigarettes (AHLGREN 1996; HASSAN et al. 2007). There are several hereditary syndromes promoting pancreatic cancer development such as PeutzJeghers polyposis, Li-Fraumeni syndrome, cystic fibrosis and telangiectatic ataxia (Louis-Bar syndrome), melanoma syndrome, hereditary breast-ovarian cancer syndrome, familial adenomatous polyposis syndrome and familial atypical multiple mole (LYNCH et al. 2001). Persons who have an appearance of pancreatic cancer in their family history have statistically a considerably higher risk of pancreatic cancer emergence. Individuals with a pancreatic cancer case under their first-degree relatives have a 6.8-fold increased risk of pancreatic cancer incidence as well (BRUNE et al. 2010). Members of the population who suffer from diabetes mellitus are considered to be exposed to a higher risk of pancreatic cancer occurrence to a certain extent, since high amounts of insulin are suspected to have a mitogenic effect (DRAZNIN 2010). The consumption of coffee has been refused to be a reason for developing pancreatic carcinomas (TURATI et al. 2012). There was also no evidence that the consumption of cigars, pipe tobacco, alcoholic potables (HART et al. 2008), or tea are promoting the development of pancreatic cancer (MACMAHON et al. 1981). Individuals carrying the blood group 0 show up a reduced risk to develop pancreatic cancer in comparison to those carrying the blood groups A or B. The development of pancreatic cancer out of regular epithelia cells is suggested to evolve out of several mutations. 


\subsubsection{Tumor Genesis of Pancreatic Cancer}

The tumor genesis of pancreatic cancer was investigated in detail in a study by Jones et al 2008 identifying markers in 24 genetically analyzed pancreatic cancers. About 63 genetic alterations were found on the average causing the tumor genesis in pancreatic cancer. Most of them were point mutations and referred to 12 cellular signaling pathways including apoptosis, regulation of cell cycle and cell signaling cascades (e.g. KRAS)(JONES et al. 2008). The deactivation of tumor suppressor genes (e.g. p53, p16 and SAMD4) and the activation of oncogenes (e.g. KRAS) are a frequent reason for the development of pancreatic cancer (BARDEESY and DEPINHO 2002). Thereby KRAS mutation is one of the most common mutations with $75 \%$ to $90 \%$ occurrence discovered in pancreatic cancer (GHANEH et al. 2007; HRUBAN et al. 1993; MOSKALUK et al. 1997)

\subsection{Current State of Therapy}

Despite major efforts in the treatment of pancreatic cancer in the recent years the high lethality rate did not change significantly. Besides surgery, adjuvant treatment is regularly intended including patients with $\mathrm{R} 0$ resection status due to high risk for locoregional recurrence. In addition, chemotherapy is also considered as part of palliative care. New developments in the field consider neoadjuvant regimens prior to surgery. Whereas surgery is still considered as first choice therapy it means substantial time delay for adjuvant therapies or the patients' general condition does not recover well to receive adjuvant treatment. Therefore, neoadjuvant strategies have emerged recently. According to data of the MD Anderson Cancer Center (MDACC), patients who respond to a neoadjuvant chemoradiation therapy had higher rates of R0 resections and lower rates of local reoccurrence which leads to a prolonged overall survival. It is assumed that in "borderline resectable cases", i.e. when it cannot clearly be defined if resectable or not, there might be a particular benefit for neoadjuvant radiotherapy (KATZ et al. 2008).

The first chemotherapeutic agent applied to gastrointestinal including pancreatic cancer was 5-fluorouracil, which dates back to the early 1960s (WEISS and JACKSON 1961). In 1997, based on a landmark phase III study, gemcitabine was introduced for palliative therapy of pancreatic cancer with an overall survival of 5.6 months for gemcitabine compared with 4.4 for 5-fluorouracil (BURRIS et al. 1997). Later, gemcitabine was also 
approved for the adjuvant setting as tumor recurrence after complete resection was delayed (OetTle and Neuhaus 2007). In the adjuvant situation, a translation into significantly improved overall survival was not observed for gemcitabine, however, adverse events were strongly reduced in comparison to 5-fluorouracil (NEOPTOLEMOS et al. 2010).

In the recent decade, a plethora of combinations with other cytostatic drugs based on gemcitabine were investigated. However, no breakthrough in terms of improved overall survival was achieved, regardless which add-on drug was considered, e.g., 5-FU (BERLin et al. 2002), capecitabine (HERRMANn et al. 2007) (CUNNINGHAM et al. 2009), cisplatin (COLUCCI et al. 2010; HEINEMANN et al. 2006), irinotecan (STATHOPOULOS et al. 2006), or oxaliplatin (LOUVET et al. 2005; Poplin et al. 2009). The latest advances in this field represent triple therapy. The most popular one has become the combination of 5-FU, irinoteca and oxaliplatin (FOLFIRINOX). This therapy showed relatively strong efficacy compared to gemcitabine alone in metastatic pancreatic cancer with an overall survival of 11.1 over 6.8 months, however accompanied by aggravated toxicity (CONROY et al. 2011). For the latter reason, FOLFIRINOX is recommended only to patients younger than 76 years with a high performance status and good hepatobiliary functions (Ko 2011). As another triple therapy based on conventional cytostatic drugs the GTX regimen was suggested consisting of gemcitabine, docetaxel, and capectiabine (DE Jesus-Acosta et al. 2012; Fine et al. 2008).

Ongoing approaches evaluate combinations of gemcitabine with specific targeted therapy, i.e. the small molecule inhibitors of tyrosine kinases. The pioneer in this regard was erlotinib which targets the epidermal growth factor receptor (EGFR). A slightly increased overall survival was noticed for the combination with gemcitabine over gemcitabine alone (MOORE et al. 2007). In view of the very minor advantage, this regimen has not yet evolved as a common standard therapy (MIKSAD et al. 2007). Efforts using an antibody directed against EGFR (e.g., cetuximab) did not show any advance in comparison to a gemcitabine monotherapy (PHILIP et al. 2010). Targeting the vascular endothelial growth factor (VEGF) signaling by bevacizumab in combination with gemcitabine did not result in prolonged survival (KINDLER et al. 2010; VAN CUTSEM et al. 2009). Subsequent approaches shifted to inhibition of VEGF receptors by small molecules like axitinib (KINDLER et al. 2011; SPANO et al. 2008) or sorafenib (EL-KHOUEIRY et al. 2012) in combination with gemcitabine, however with so far no significant improvement of therapeutic outcome. Other potential targets might be 
inhibition of KRAS (GYSIN et al. 2011) or the Hedgehog signaling pathway (OLIVE et al. 2009).

In total less than $25 \%$ of pancreatic cancer patients show at least moderate response to the currently used chemotherapy strategies (DHAYAT et al. 2011; JIMENO and HIDALGO 2006). The limited benefit should be balanced against the toxic side effects of the therapy. There is no established second line option in case gemcitabine-based therapy fails. At present, continuous use of gemcitabine combinations is recommended for patients with good performance status by the National Comprehensive Cancer Network Guidelines (available at www.nccn.org).

\subsection{The Nucleoside Analogue Gemcitabine}

\subsubsection{Clinical Indications}

While developed first as an antiviral drug gemcitabine showed striking antitumoral activity targets in vitro and in vivo. At present, the approved indications comprise metastatic pancreatic cancer (BURRIS et al. 1997) or adjuvant therapy of the same (OETTLE and NeuHAus 2007), in combination with cisplatin bladder cancer (VON DER MAASE et al. 2000) and non-small lung cancer (SANDLER et al. 2000), in combination with carboplatin (XIROs et al. 2005) ovarian cancer, and as second-line therapy in breast cancer (JoNES et al. 2009). Furthermore, it is sometimes used in mesothelioma, and head and neck malignancies.

\subsubsection{Pharmacokinetics}

Gemcitabine requires intravenous administration due to a high first-pass effect in the gastrointestinal tract. The usually recommended dose is $1000-1250 \mathrm{mg} / \mathrm{m}^{2}$ (Eli Lilly and Company drug information GEMZAR) given in a time frame from 0.4 to 1.2 hours. In case of patient discomfort or side-effects like haematologic toxicity dose reduction is commonly performed. Maximal plasma concentrations range between 11 and $170 \mu \mathrm{M}$ and are achieved within 5 min upon infusion stop. Plasma half-life is between 42 and 90 minutes depending on the age of the patient, gender and body surface area as well as the duration of infusion (STORNIOLO et al. 1997; Eli Lilly and Company drug information GEMZAR). The plasma half-life is dose-independent (ABBRUZZESE et al. 1991). Only 
$10 \%$ of the parent drug is found in the urine suggesting that the majority of the given dose is degraded before reaching the target cell (ABBRUZZESE et al. 1991). The major enzyme responsible for rapid degradation, the cytidine deaminase (CDA), is described in detail below.

\subsubsection{Molecular Features}

The antineoplastic agent gemcitabine (2',2'-difluoro 2'-deoxycytidine, $\mathrm{dFdC}$ ) is a nucleoside analogue of cytidine with two fluorine substituents at the second position of the furanose ring (Figure 1). Thus, it constitutes an antimetabolite competing with natural nucleosides in RNA and DNA synthesis. It has a molecular weight of $263.2 \mathrm{~g}^{*} \mathrm{~mol}^{-1}$ and is highly hydrophilic (EMERICH et al. 2000), which requires an active transport in the cell. Gemcitabine offers high chemical stability in the absence of degrading enzymes (XU et al. 1999).
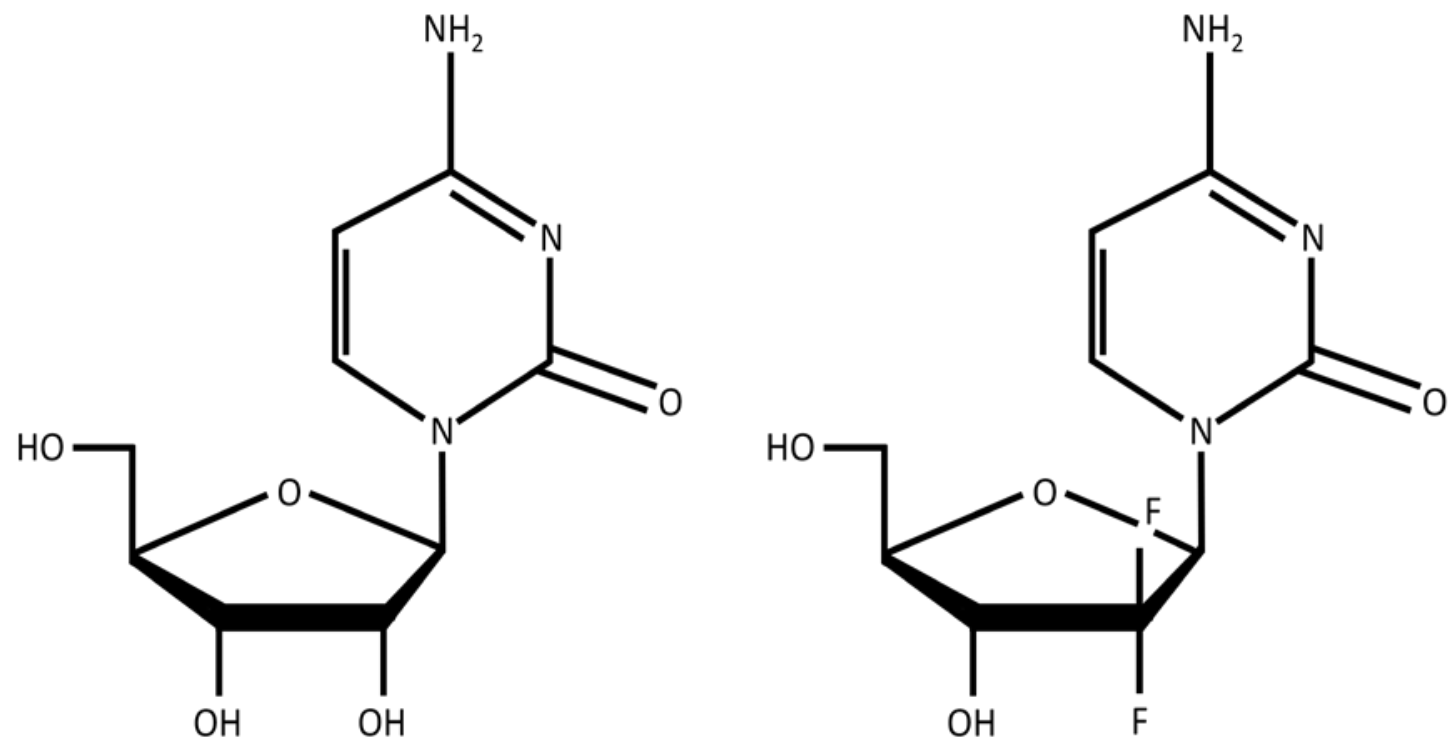

Figure 1: Structure formula of cytidine (left) and gemcitabine (right)

\subsubsection{Route of Gemcitabine Distribution}

As soon as gemcitabine ( $\mathrm{dFdC}$ ) is administered to the patients, it is delivered by the blood stream and degraded by the enzyme cytidine deaminase (CDA) to difluorodeoxyuridine (dFdU, (HEINEMANN et al. 1992)). 


\subsubsection{Cellular Uptake of Gemcitabine}

Gemcitabine has to be transported and activated in the target cell to exert cytostatic effects (Mini et al. 2006). Since gemcitabine diffuses very slowly through plasma membrane, transporter proteins are required. Equilibrative, non-sodium-coupled (ENTs) and sodium-coupled concentrative (CNTs) nucleoside transporters (NTs) are involved in gemcitabine uptake. For five NTs a function in gemcitabine transport was suggested (ERrasti-Murugarren and PASTOR-Anglada 2010). The major players for gemcitabine uptake are ENT1 (BELT et al. 1993; GRIFFITH and JARVIS 1996; MACKEY et al. 1998; MARECHAL et al. 2009) and, to a lesser degree, the CNT1 (GARCIAMANTEIGA et al. 2003; MACKEY et al. 1999) and CNT3 transporters (RITZEL et al. 2001a; RITZEL et al. 2001b). For other ENTs (i.e., ENT2, ENT3, ENT4) or CNTs (i.e., CNT2) there is no compelling evidence for clinical relevance in gemcitabine treatment. ENTs participate in the bidirectional transfer of a broad range of nucleosides and nucleoside analogues, in case of ENT2 also nucleobases, through biological membranes along the diffusion gradient. Affected drugs include cytarabine (CLARKE et al. 2006), fludarabine, cladribine, clofarabine (KING et al. 2006), 5'-deoxy-5'-fluorouridine (MOLINA-ARCAS et al. 2006) and gemcitabine (MACKEY et al. 1999). ENTs are typically found in basolateral and apical membranes, but also in non-polarized cells (ERRASTI-MURUGARREN and PASTOR-ANGLADA 2010).

The CNT1 is expressed on the apical side in polarized cells like intestinal cells, proximal tubule cells of the kidney, as well as hepatocytes and breast cells (GloecKner-Hofmann et al. 2006; MANGRAvite et al. 2001; NGo et al. 2001). High CNT1 expression may render pancreatic cancer cells sensitive toward gemcitabine (BHUTIA et al. 2011). A clinical relation to the outcome in pancreatic cancer has not yet been demonstrated. CNT3 is also found on the apical membrane, but the type of cells in which it is predominantly expressed differs from CNT1 with additional presence, for instance, in the pancreas (DAMARAJU et al. 2007; RITZEL et al. 2001b). The clinical contribution of CNT3 to gemcitabine-treated pancreatic cancer outcome is not clear since only once having been associated with no further replication (MARECHAL et al 2009). In view of its paramount relevance based on literature and own data the ENT1 with pertinent genetic variation is described in detail below (1.4.4). 


\subsubsection{Gemcitabine Metabolism}

The initial phosphorylation of gemcitabine to gemcitabine monophosphate is mediated by deoxycytidine kinase (dCK), which is suggested to be the rate limiting step for the activating biotransformation (MINI et al. 2006). The thymidine kinase 2 (TK2) also performs this phosphorylation step, but has an extremely poor affinity to gemcitabine in comparison to dCK (5-10\%, (WANG et al. 1999)). The next phosphorylation step to gemcitabine diphosphate is catalyzed by cytidine monophosphate kinase (CMPK) (MINI et al. 2006; NAKANO et al. 2007). The gemcitabine diphosphate and triphosphate are the active forms of the cytostatic agent, which have multiple intracellular targets for their cytotoxic impact (HEINEMANN et al. 1988). It was shown that gemcitabine triphosphate competes with the natural deoxycytidine triphosphate (dCTP) and is incorporated in DNA (HUANG et al. 1991) where it is stalling DNA synthesis by inhibition of the DNA polymerase (HEINEMANN et al. 1988) (HERTEL et al. 1990) (GANDHI and PlunKeTt 1990). As soon as gemcitabine triphosphate is incorporated in DNA the synthesized strand is extended with only one further nucleotide, then the elongation process is terminated (Ross and CUDDY 1994). The 3'-->5' exonuclease activity of DNA polymerase is not capable to excise nucleotides from DNA, which contains gemcitabine monophosphate (GANDHI et al. 1996; HUANG et al. 1991; SCHY et al. 1993). There is additional evidence that incorporated gemcitabine triphosphate inhibits the detection and repair by cellular DNA repair mechanisms (PAUwELs et al. 2006). The inhibition of DNA synthesis is one major issue, which causes the induction of apoptosis induced in gemcitabine-treated cells (HuANG and PlunketT 1995). Further it was discovered that gemcitabine triphosphate is also incorporated in RNA, which hampers RNA synthesis (RUIZ VAN HAPEREN et al. 1993b). While there is no conclusive knowledge about the impact of RNA incorporation on the cell function, the degree of RNA incorporation is negatively correlated with internal resistance towards gemcitabine in human tumor cell lines (KROEP et al. 2000). The metabolites gemcitabine di- and triphosphate promote a self-potentiating effect in the inhibition of the ribonucleotide reductase, a key player in the de novo synthesis of deoxy-nucleotides. This aggravates the toxic effects of gemcitabine as the reduced amounts of natural nucleotides in the cell facilitate an increased incorporation of gemcitabine triphosphate in DNA (HEINEMANN et al. 1990) (BAKER et al. 1991). Another site of actions is the inhibition of cytidine triphosphate synthetase (CTP synthetase) (HEINEMANN et al. 1995), thereby reducing the pool of 
CTP for RNA synthesis and instead increasing incorporation of gemcitabine into RNA. It was further shown that gemcitabine modulates the activity of topoisomerase-I, which causes enhanced strand breaks in DNA and may contribute to the cytotoxic effect (Pourquier et al. 2002). Thus, the toxic effects of gemcitabine are not limited to the early S phase during cell cycle, but also affect non-dividing cells (ROCKWELL and GRINDEY 1992).

Gemcitabine activation competes with degradation. Non-phosphorylated gemcitabine is degraded by the ubiquitously expressed CDA to 2',2'-difluoro-deoxyuridine (dFdU), mainly before the parent drug could enter the target cells (as outlined above in, 1.3.4), but also therein. The inactivation of the gemcitabine monophosphate metabolite (dFdCMP) to dFdUMP is executed by deoxycytidine deaminase (DCTD, official full name dCMP deaminase). The latter is inhibited by gemcitabine triphosphate (HEINEMANN et al. 1992) further enhancing gemcitabine effects. The aforementioned transport, bioactivation and degradation processes of gemcitabine are displayed in coherence in Figure 2. 


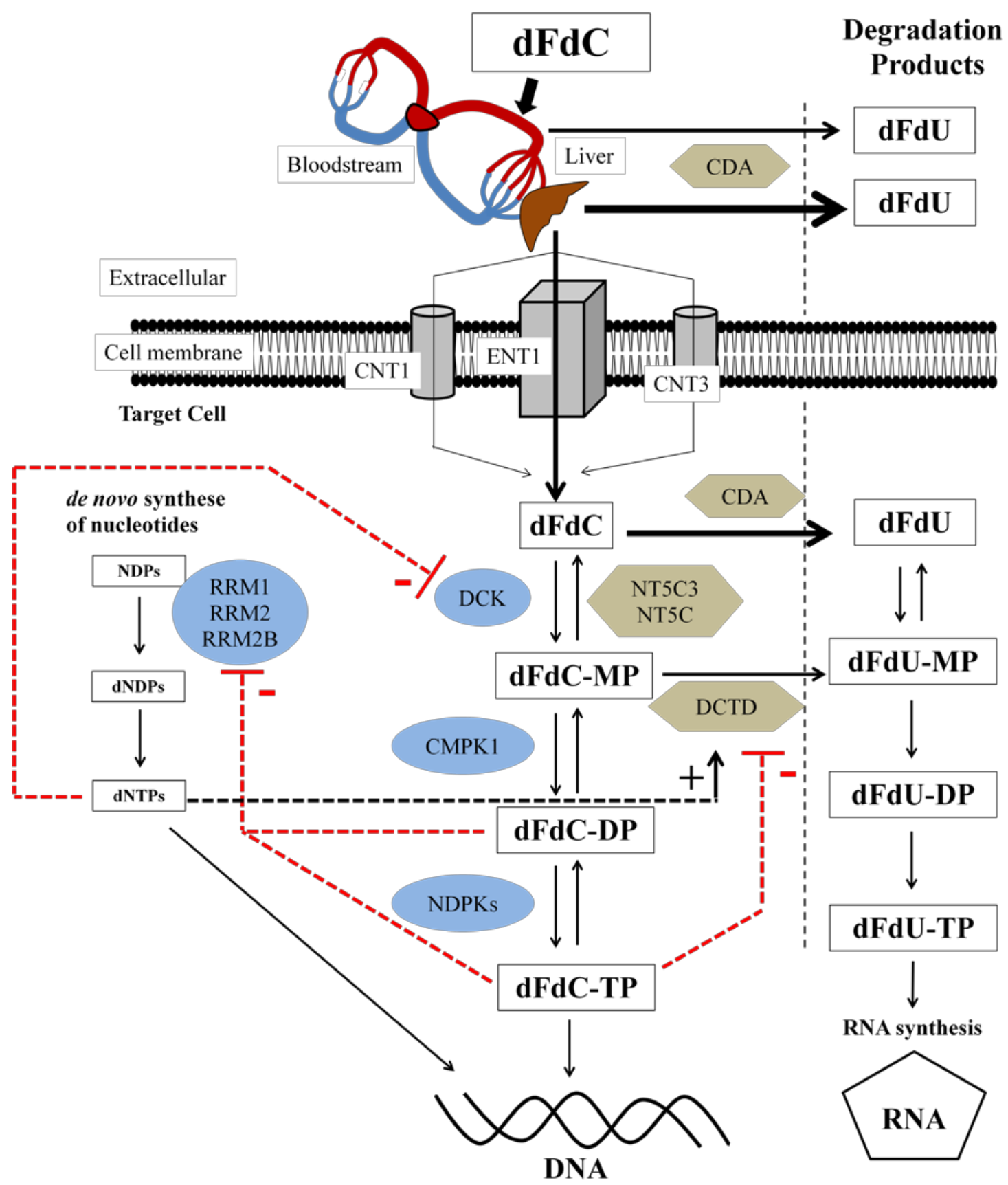

Figure 2: Route of gemcitabine and metabolism. Black dashed lines indicate stimulation, red dashed inhibition. (CDA: cytidine deaminase; ENT1: equilibrative nucleoside transporter1; CNT1: concentrative nucleoside transporter1; CNT3: concentrative nucleoside transporter1; DCK: deoxycytidine kinase; NT5C3: cytosolic 5'-nucleotidase 3; NT5C: 5'(3')-deoxyribonucleotidase; CMPK1: cytidine monophosphate kinase; DCTD: deoxycytidylate deaminase; dFdU: 2',2'-difluoro 2'-deoxyuridine; dFdUMP: 2',2'-difluoro 2'-deoxyuridine monophosphate; NDPs: nucleoside-diphosphate; dNDPs: deoxynucleoside-diphosphate; dNTPs: deoxynucleoside-triphosphate; RRM2,RMM1, RRM2B: subunits of ribonucleotide reductase) 


\subsubsection{Variability in Gemcitabine Response}

In the clinical situation gemcitabine-treated patients show progression of pancreatic cancer in most cases. This unsatisfying response to gemcitabine is due to the high degree of inherited and acquired chemoresistance (CARMICHAEL et al. 1996; Li et al. 2004). The degree of sensitivity towards gemcitabine depends on the intracellular metabolite levels, which are modulated by the activity of transporters as well as enzymes for bioactivation and degradation (BERGMAN et al. 2002).

The enzyme CDA is associated with gemcitabine toxicity (NeFF and BLAU 1996). The actual significance of this enzyme for the gemcitabine response is not decisive, on the one hand it was proven, that cell lines with decreased CDA activity are sensitive towards gemcitabine (BERGMAN et al. 1998), but on the other hand human tumor cells and human tumor xenodrafts do not show evidence that inherited resistance and CDA activity are linked (RUIZ VAN HAPEREN et al. 1993a; VAN HAPEREN et al. 1996). But the increased expression of CDA might affect the acquired resistance towards gemcitabine, which often occurs in patients during gemcitabine-based treatment (BENGALA et al. 2005).

The first phosphorylation step of gemcitabine by deoxycytidine kinase (dCK) is suggested to have a major role in the response to gemcitabine (KROEP et al. 2002). Some cells in vitro and in vivo with inherited and acquired resistance towards gemcitabine exhibit a lack of dCK (BERGMAN et al. 2002). Other contributors to the sensitivity towards gemcitabine are 5'-nucelotidases, which convert nucleotides in nucleosides. In some studies the sensitivity of cells was referred to the presence of 5'nucelotidases (DUMONTET et al. 1999; HUNSUCKER et al. 2001). There is evidence that cells with an enhanced expression of ribonucleotide reductase subunit 1 (RRM1) exhibit gemcitabine resistance (DAVIDSON et al. 2004), since an increased activity of ribonucleotide reductase leads to higher concentration of natural dCTPs, which are competing with gemcitabine triphosphate (GoAN et al. 1999).

Gemcitabine efficacy is highly correlated with the maintenance of gemcitabine triphosphate in the cells. The longer the gemcitabine metabolites persist in the cell the higher the sensitivity towards gemcitabine treatment is, which was shown in vitro and in vivo tumor models (RUIZ VAN HAPEREN et al. 1994; VAN HAPEREN et al. 1996). As demonstrated in many studies one of the most important issues concerning the response 
and toxicity by gemcitabine is the transport into target cells, which is mainly performed by the equilibrative transporter -ENT1 and, to a lesser extent, by CNT3.

\subsubsection{Genetic Polymorphisms Affecting Gemcitabine Response}

The understanding of sensitivity and resistance mechanisms towards gemcitabine can support the choice and adjustment of therapy modalities. In this regard, knowledge of genomic markers might help to predict the clinical outcome of a certain therapy to obtain the best treatment for pancreatic cancer patients. Already several studies tried to elucidate polymorphisms in genes involved in gemcitabine transport, bioactivation and degradation (FUKUNAGA et al. 2004; Li et al. 2012; TANAKA et al. 2010; Xu et al. 2011). Polymorphisms in genes encoding for proteins involved in transport (e.g., ENT1), degradation $(C D A)$ or bioactivation $(d C K)$ of gemcitabine as well as in pathways competing with gemcitabine activity (RRM1) were considered to be predictive markers for gemcitabine efficacy and side effects in patients with locally advanced pancreatic cancer (TANAKA et al. 2010). The quantitative trait of gemcitabine pharmacokinetics was also subjected to an association analysis in gemcitabine pathway genes. In 250 Japanese cancer patients the plasma concentration of gemcitabine and its metabolite dFdU was determined. SNPs in the CDA gene were claimed to be a significant contributor to gemcitabine clearance whereas no significant effect of SNPs in DCK and ENT1 could be demonstrated (SUGIYAMA et al. 2010). Under clinical conditions the need to make the considered cohorts as homogenous as possible results in low sample sizes typically under-powering statistical association studies when multiple markers are tested. Thus, findings are often preliminary until confirmation in replication studies.

Another approach to identify genetic factors putatively contributing to the outcome of gemcitabine-based chemotherapy represents genome-wide association studies (GWAS). When my thesis work was already ongoing a GWAS for advanced stage pancreatic cancer treated with gemcitabine was reported (INNOCENTI et al. 2012). The strongest associating signal exhibited a polymorphism in IL17A, a component linked to angiogenesis.

Furthermore, GWAS have also been applied to functional traits. One single study screened for genome-wide markers affecting gemcitabine drug response in 
lymphoblastoid cell lines (LCLs). This analysis revealed the most significant hits beyond typical candidate genes, whereby not reaching statistical significance for gemcitabine cytotoxicity upon adjustment for multiple testing (Li et al. 2009). Besides genetic polymorphisms, drug-naïve genome-wide transcripts in LCLs were correlated with cytotoxic effects of gemcitabine (Li et al. 2008).

\subsection{Major player: The Equilibrative Nucleoside Transporter 1 (ENT1)}

The ENT1 transporter is almost ubiquitously expressed and facilitates import and export of gemcitabine over the cell membrane as well as between intracellular compartments (LAI et al. 2004; MANI et al. 1998). It is well known that the ENT1 has a key player position in the transport of gemcitabine, which was demonstrated in vitro, ex vivo and in vivo (FARRELl et al. 2009; MACKEY et al. 2005; MACKEY et al. 2002; MARCE et al. 2006; Marechal et al. 2009; SANTini et al. 2008; Spratlin et al. 2004). Pyrimidines as well as purines are substrates for ENT1, which is sensitive towards NBMPR (nitrobenzylthioinosine), a specific inhibitor.

\subsubsection{Protein Conformation}

The ENT1 gene encodes a protein containing 456 residues (CANO-SOLDADO and PASTOR-ANGLADA 2012). It consists of eleven transmembrane domains including a huge intracellular loop between the transmembrane domains six and seven (Figure 3). A PEXN motif consisting of proline 71, glutamate 72, and asparagine 74 was reported to be important for mitochondrial trafficking of this protein (LEE et al. 2006). The residues phenylalanine 334 and asparagine 338 in the transmembrane domain 8 seem to be crucial for protein folding, inhibitor sensitivity, and catalytic activity (VISSER et al. 2007). Nucleoside selectivity may be, at least in part, rendered by residues in the transmembrane domain 1 like tryptophan 29 (PAPROSKI et al. 2008). The exchange to threonine at position 29 results in a selective loss of pyrimidine transport activity (PAPROSKI et al. 2008). In addition, mutations of glycine 24 reduced both substrate transport activity and inhibitor binding (ZIMMERMAN et al. 2009). 


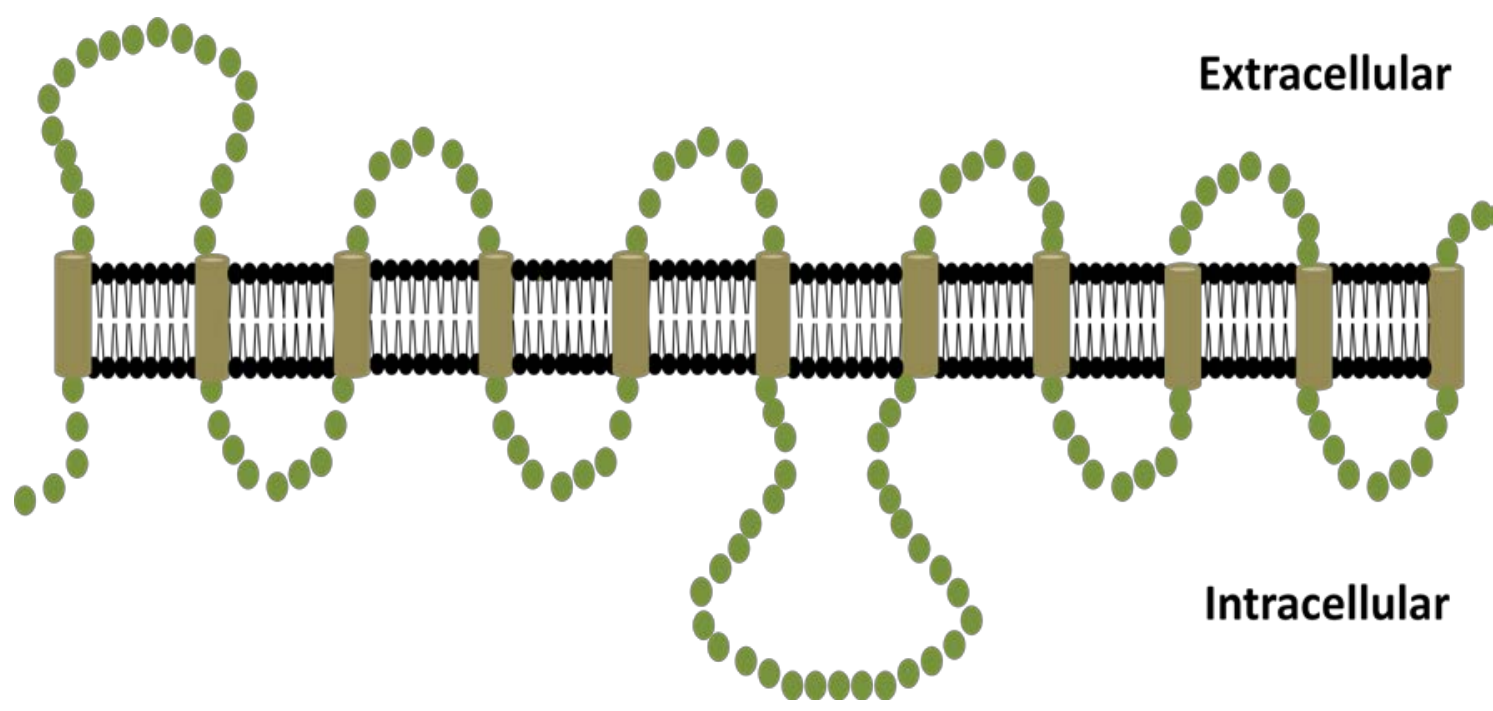

Figure 3: Conformation of the protein encoded by ENT1. It composes eleven transmembrane domains. The N-terminus is located intracellularly, the C-terminus extracellularly. Image modified according to Osato (OSATO et al. 2003).

\subsubsection{Clinical Relevance of ENT1 Expression}

The expression of ENT1 is highly correlated with the sensitivity towards gemcitabine and other nucleoside analogues in vitro (ACHIWA et al. 2004; GALMARINI et al. 2002; GATI et al. 1997). The quantities of immunohistochemically detected ENT1 in pancreatic cancer tissue turned out as a predictor for overall survival. In a first report, it was shown that patients with higher intratumoral expression experienced better outcome (SPRATLin et al. 2004). This finding was later confirmed (FARRELL et al. 2009; MARECHAL et al. 2009). Similar findings were reported for mRNA levels (GiovanNETTi et al. 2006). Apparently, fine-needle biopsies are not suitable to detect reliably an association between ENT1 transcripts and gemcitabine treatment response according to tumor markers (ASHIDA et al. 2009). Ex vivo sensitivity testing in pancreatic cancer cell lines derived from patients corroborated the significance of ENT1 mRNA expression (MiCHALSKI et al. 2008). The latter was also partially attributable to acquired resistance toward gemcitabine (NAKANO et al. 2007). Beyond pancreatic cancer, the relevance of ENT1 was demonstrated also in gemcitabine treatment of urinary bladder cancer (MEY et al. 2006) as well as biliary tract cancer (SANTINI et al. 2011) whereby higher ENT1 prevalence was favorable in both tumor types. Conversely, high ENT1 expression elicited as a poor prognostic factor in gastric cancer 
(SANTINI et al. 2010) and ampullary cancer (SANTINI et al. 2008) without gemcitabine administration.

\subsubsection{ENT1 Expression Regulation and Transcript Variants}

There are temporal, spatial and quantitative differences in ENT1 expression inter- and intra-individually (PENNYCOOKE et al. 2001). Regulation occurs both at the transcriptional and translational level (SOLER et al. 2003). It was also shown that the ENT1 expression in T lymphoblastic cells is much higher than in resting peripheral Tlymphocytes (KICHENIN et al. 2000). However, the mechanisms of ENT1 expression regulation have been barely elucidated yet. Some studies claim that the expression of ENT1 transporters is effected by hypoxia (CHAUDARY et al. 2004; ELTZSCHIG et al. 2005), passage numbers of cultured cells (ARCHER et al. 2004), inflammatory cytokines (PETROVIC et al. 2007) and nitride oxide (SOLER et al. 2000). The ENT1-mediated nucleoside transport is primary associated with cell proliferation (SOLER et al. 2001a; SOLER et al. 2001b). It was demonstrated that MCSF (macrophage-colony-stimulatingfactor) induces macrophage proliferation accompanied by upregulation of ENT1 (SOLER et al. 2001a). Conversely, provoking growth arrest in macrophages by IFN (interferon) or LPS (lipopolysaccharide) causes down regulation of ENT1 (SOLER et al. 2001a; SOLER et al. 2001b). At least, twelve ENT1 mRNA isoforms were suggested, which are regulated by four identified alternative promoter regions (ABDULLA and COE 2007; FUKUCHI et al. 2010). The NCBI data base provides five validated transcript variants of the ENT1 transporter (http://www.ncbi.nlm.nih.gov/gene/2030), which all code for the same protein.

\subsubsection{Genetic Variability in ENT1}

Among humans the coding sequence of ENT1 is highly conserved with a single haplotype accounting for $91 \%$ of the genetic variability (OsATo et al. 2003). Despite limited sequence identities with other species there is high conformational conservation indicating functional preservation during evolution (SANKAR et al. 2002). Thereby, the most conserved regions are identified in the putative transmembrane domains suggesting a crucial role in membrane substrate recognition (GRIFFITHS et al. 1997). Polymorphisms in the ENT1 genetic region have been suggested to be implicated in 
treatment response to substrates of ENT1 like gemcitabine and ribavirin (Li et al. 2012; TSUBOTA et al. 2012).

The most frequent genetic polymorphism affecting an amino acid substitution in ENT1 is Ile216Thr with a minor allele frequency of $2 \%$. This polymorphism is designated as rs45573936, almost exclusively found in Northern Europe (ABECASIS et al. 2012; OsATO et al. 2003). It is claimed that ethanol incubation leads to a significant difference in transport activity in the ENT1 Ile216Thr-transfected mouse embryonic fibroblasts (KIM et al. 2011).

Genetic variation was mainly studied for the proximal promoter region of ENT1. An involvement in expression of this gene and transcription factor binding was suggested (MYers et al. 2006; SuZUKI et al. 2013). In the clinical setting, at present, it is controversial if gemcitabine pharmacokinetics are affected by the genetic variability in the proximal ENT1 promoter region (GuSELLA et al. 2011; SUGIYAMA et al. 2010). An impact of this variability on the risk for hematologic anemia in treatment with ribavirin, a substrate for ENT1, could not be proven (DoEHRING et al. 2011).

In our own institute, the Ile216Thr (rs45573936) and a polymorphism (rs1057985) in a ENT1 promoter region were recently suggested as predictive biomarkers for the outcome of gemcitabine-based chemotherapy in pancreatic cancer patients (SCHAUDINN 2013) (Christian Zimmer, medical thesis in preparation). Thereby, the variant allele of rs1057985 was associated with a prolonged overall survival in three independent patient cohorts from Göttingen $(\mathrm{n}=96 ; \mathrm{p}=0.03)$, Hamburg $(\mathrm{n}=124 ; \mathrm{p}=0.002)$ and Heidelberg $(n=91 ; p=0.05)$. The effect of the rare variant allele of Ile216Thr (minor allele frequency of rs 45573936 only about $2 \%$ in Caucasians) was less consistent. In the Göttingen cohort, presence of Thr216 was accompanied by dramatically reduced overall survival ( $\mathrm{p}<0.001$ ) exhibiting statistical significance even upon adjustment for multiple testing. However, in the cohort form Hamburg this finding could not be verified, whereas in the Heidelberg cohort only one patient carried the variant allele not allowing statistical assessment. 


\subsection{Aim of this Work}

The aim of my thesis was to identify and to functionally assess markers which affect the response towards gemcitabine. For two recently suggested promising candidate markers pertinent to the ENT1 gene the functional mechanisms should be investigated.

The amino acid exchange Ile216Thr was hypothesized to alter transport of gemcitabine. Due to the reduced survival time in the clinical setting, it was hypothesized that the Thr216 allele may result in lower intracellular accumulation of gemcitabine. To pursue this idea, effects on radio-labeled gemcitabine transport should be studied by means of stably transfected allele-specific constructs in a model line.

Regarding the suggested ENT1 promoter polymorphism, enhanced ENT1 transcription in presence of the minor allele was assumed. This assumption should be clarified. First, it was asked for differential effects on ENT1 transcript variants. Next, it should be tested whether there might be allele-specific differences in binding of nuclear proteins and, if so, to identify the putatively involved protein. Finally, a direct impact on gene transcription should be analyzed by reporter gene assays.

As not yet sufficiently addressed nor in literature nor in previous theses in our department, a genome-wide approach was considered to elicit new potential markers for gemcitabine sensitivity. Such markers should be identified by dose-response curves for gemcitabine toxicity with fully sequenced LCLs as model and replicated in an independent second cohort of LCLs. While working on my thesis a report emerged in literature addressing for the first time a GWAS with respect to the outcome of gemcitabine-based chemotherapy in pancreatic cancer. The therein reported top association signals should be tested for reproducibility in our patient cohorts. If reproduced, underlying functional mechanisms should be addressed. 


\section{Materials}

\subsection{Devices and pertinent Software}

\section{Equipment and software}

3100 Data Collection Software

3130xl Genetic Analyser

Adobe Photoshop

Bacteria Incubator-Incudrive

Biofuge fresco

Biofuge pico

BioPhotometer

BioRobot ${ }^{\circledR}$ EZ1

Centrifuge $5810 \mathrm{R}$

Centrifuge JA-20 Rotor

Clone Manager Suite

CO2-Incubator BBD 6220

ComPhor L Mini Gel-chamber

Concentrator 5301

Confocal laser scanning Microscope

CorelDRAW X3

DNA Sequencing Analysis

Electroporator Gene Pulser II

Fine weight machine

Flow cytometer BD LSRII, special order system

Fluor-STM MultiImager

Gel chamber Ruby SE600

GloMax-96-Plate-Luminometer

HPLC Analysing System

Labofuge 400R

Magnetic stirrer

Mastercycler gradient

Membran-Vacuum pumpe

Microscope Axiovert 40 CFL

MS 2 Mini shaker-Vortexer

Nanodrop cuvette

Neubauer-Cell chamber

\section{Manufacturer}

Applied Biosystems , Darmstadt

Applied Biosystems, Darmstadt

Adobe Systems GmbH, München

Schütt, Göttingen

Heraeus, Hanau

Heraeus, Hanau

Eppendorf, Hamburg

Qiagen, Hilden

Eppendorf, Hamburg

Beckman, München

SECentral

Heraeus, Hanau

Biozym, Hessisch Oldendorf

Eppendorf; Hamburg

Carl Zeiss, Jena

Corel Corporation

Applied Biosystems

BioRad, Hercules USA

Sartorius, Göttingen

Becton Dickinson, Franklin Lakes, USA

BioRad, Hercules, USA

Hoefer, San Francisco, USA

Turner BioSystems, Sunnyvale, USA

Merck Hitachi, Darmstadt, Germany

Heraeus, Hanau

IKAMAG

Eppendorf, Hamburg

Vacuubrand, Wertheim

Zeiss, Jena

IKA, Staufen

Implen

Schütt, Göttingen 
PTC-200 Peltier Thermal Gradient Cycler

QiaCube

Scintillation instrument LS1801

Shaker for Bacteria K2 260 basic

Stereomicroscope Stemi 1000

Sterile Bench-Clean Air type DFL/REC4 KL2A

TaqMan 7900HT

Thermomixer 5436

Transilluminator TI 2

Vertical-Autoclave KSG 40/60

Vertical-Autoclave: FV

Water bath GFL 1083
MJ Research/BioRad, Hercules, USA

Qiagen, Hilden

Beckman, München

IKA, Staufen

Zeiss, Jena

Mahl, Trendelburg

Applied Biosystems, Darmstadt

Eppendorf, Hamburg

Biometra

KSG, Olching

Tecnorama, Fernwald

Schütt, Göttingen *

\subsection{Laboratory Consumables}

\section{Used Materials}

$50 \mathrm{ml}$ Centrifuge tube

$5 \mathrm{ml}$ Polysterene Round-Botton Tube

96 Millipore MAHV N45 Plate

96 Millipore MANU 030 PCR-Plate

96 White Plate for luminescence measurement

96er PCR-Plate

24 Well, Zellkultur Multiwellplatte

Absolute QPCR Seal (Optical Folie for Taqman)

Adhesive PCR Foil Seals

Culture flask $25 \mathrm{~cm}^{2}$ and $75 \mathrm{~cm}^{2}$

Cuvette (UVetten) 50-1000 $\mu 1$

Cuvette 10x4x45 mm

Dialyse filter VSWP01300

Electroporation cuvette $2 \mathrm{~mm}$

FBS

Filter paper Nr. 2668

Filter paper Nr. 2CHR

Flat cap strips, 12er

Flat cap strips, 8er

FrameStar ${ }^{\circledR} 384$

\section{Manufacturer}

Beckman, München

BD Falcon, Durham USA

Millipore, Bedford, USA

Millipore, Bedford, USA

Greiner, Frickenhausen

ABgene, Epsom

Greiner, Frickenhausen

Thermo Scientific

ABgene, Epsom

Sarstedt, Nümbrecht

Eppendorf, Hamburg

Sarstedt, Hamburg

Millipore, Bedford, USA

PeqLab, Erlangen

Gibco/Invitrogen

Schleicher und Schuell

Schleicher und Schuell

ABgene, Epsom

ABgene, Epsom

4titude, Wotton 
Freezing container, Nalgene ${ }^{\circledR}$, Mr. Frosty

Glass Pasteur pipette $230 \mathrm{~mm}$

LiChroCART 25-4 RP-18 HPLC Cartriges

LiChroCART 125-4 RP-18 HPLC Cartriges

Minisart $20000.2 \mu \mathrm{m}$

Minisart-plus $0.2 \mu \mathrm{m}$

Nunclon $^{\mathrm{TM}}$ Multidishes 6 und 12 Wells

Parafilm ${ }^{\circledR}$

Petri Dish

Petri Dish for Cell culture, Falcon 353003

Pipette Tip $(10 \mu \mathrm{l}, 100 \mu \mathrm{l}, 1000 \mu \mathrm{l})$

Plate loader for Sephadex

Plate Retainer for Sequencing

Quali-Filterpipett tip sterile

Reactions vessel $0.2 \mathrm{ml}$ (RNase-free)

Reactions vessel $1.5 \mathrm{ml}$ und $2 \mathrm{ml}$

Sterile Pipette ( 5 ml, 10 ml, $25 \mathrm{ml}$ )

Sterile Polypropylen-tube $15 \mathrm{ml}$

Sterile Polypropylen-tube $50 \mathrm{ml}$

Thermo-Fast 384er Plate (PCR-Plates for Taqman)

Thermo-Fast 96er Plate
Sigma-Aldrich, Deisenhofen

WU, Mainz

Merck, Darmstadt

Merck, Darmstadt

Sartorius, Göttingen

Sartorius, Göttingen

Nunc, Wiesbaden

Brand, Wertheim

Sarstedt, Hamburg

Schütt, Göttingen

Sarstedt, Hamburg

Millipore, Schwalbach

Applied Biosystems, Darmstadt

Kisker, Steinfurt

Biozym, Hessisch Oldendorf

Sarstedt, Hamburg

Sarstedt, Hamburg

Greiner, Frickenhausen

Sarstedt, Hamburg

ABgene Epsom

ABgene, Epsom

\subsection{Chemical Consumables}

\section{Chemical consumables}

[ $\alpha$-32P]-dCTP

$1 \mathrm{~kb}$ Standard Ladder for Agarosegel

100 bp Standard Ladder for Agarosegel

2-Mercaptoethanol $\geq 99 \%$

40\% (w/v) Acrylamide:Bisacrylamide/ Mix 37.5:1

4326322E (TBP,VIC-MGB)

40 micron cell strainer

Acetic acid $100 \%$, pro analysis

Acetonitril

Agar (for Bacteriology)

Agarose Ultra Pure

\section{Manufacturer}

Hartmann Analytic, Braunschweig

Rapidozym, Berlin

Rapidozym, Berlin

Sigma-Aldrich, Deisenhofen

Biomol, Hamburg

Applied Biosystem, Darmstadt

BD Falcon (352340)

Merck, Darmstadt

Merck, Germany

AppliChem, Darmstadt

Invitrogen, Karlsruhe 
Ammonium persulfate $\geq 98 \%$

Ammonium sulfate $\geq 99.5 \%$

Ampicillin 99\%

Aquasafe 500 Plus, Safty Scintillator

Bicinchoninic acid

BigDye ${ }^{\circledR}$ Sequencing Kit

Boric Acid 100\%

Bovine serum albumin (BSA)

Bromphenolblue Na-Salt (for Electrophoresis)

CFSE Proliferation Dye

Chloroform $\geq 99.8 \%$

Coomassie Brilliant Blue R 250

Copper sulfate pentahydrate

CountBright $^{\mathrm{TM}}$ absolute counting Beads

P1,P4-Di(adenosine-5') tetraphosphate ammonium salt

2',2'-difluorodeoxyuridin

Dimethyl sulfoxide (DMSO)

Disodium hydrogen phosphate $\geq 99.9 \%$

Dithiothreitol $\geq 99.5 \%$ (for Molecular biology)

DNeasy Blood \& Tissue Kit

dNTP Set

Dual-Luciferase ${ }^{\circledR R e p o r t e r ~ A s s a y ~ S y s t e m ~}$

EDTA $0.5 \mathrm{M}$ in water solution

EDTA pure

Ethanol 96\%

Ethanol denatured 99\% (Desinfection agent)

Ethidiumbromide $1 \%$ in $\mathrm{H} 2 \mathrm{O}$ (for electrophorese)

Exonuclease I E.coli $(20 \mathrm{u} / \mu \mathrm{l})$

Expand Long Template PCR System

FACS Safe Clean

FACS Flow

FACS Rinse
Sigma-Aldrich, Deisenhofen

Sigma-Aldrich, Deisenhofen

AppliChem, Darmstadt

Zinsser Analytic, Berkshire, UK

Sigma-Aldrich, Deisenhofen

Applied Biosystems, Darmstadt

Merck, Darmstadt

Sigma-Aldrich, Deisenhofen

Roth, Karlsruhe

eBioscience, Frankfurt

J.T. Baker, Phillipsburg, USA

BioRad, München

Sigma-Aldrich, Deisenhofen

Invitrogen, Karlsruhe

Sigma-Aldrich, Deisenhofen

Eli Lilly andCompany, Indianapolis,

USA

AppliChem, Darmstadt

Merck, Darmstadt

AppliChem, Darmstadt

Qiagen, Hilden

ABgene, Hamburg

Promega, Mannheim

Sigma-Aldrich, Deisenhofen

Merck, Darmstadt

Merck, Darmstadt

Chemie-Vertrieb Hannover

Merck, Darmstadt

Fermentas, St. Leon-Roth

Roche Diagnostics, Mannheim

Beckton Dickinson, Franklin Lakes

(USA)

Beckton Dickinson, Franklin Lakes

Beckton Dickinson, Franklin Lakes 
(USA)

FuGene 6

Gemcitabine (dFdC)

${ }^{3} \mathrm{H}-$ Gemcitabine (dFdC)

Gemcitabine monophosphate (dFdC-MP)

Gemcitabine diphosphate (dFdC-DP)

Gemcitabine triphosphate (dFdC-TP)

GeneScanLIZ120 standard ladder for SNaPshot ${ }^{T M}$

Glycerol 85 \%

HBSS medium

Helipur ${ }^{\circledR} \mathrm{H}$ plus $\mathrm{N}$ desinfection agent

HotStarTaq Master Mix Kit (250 units)

Human RNA Tissue Panel (20 different Tissues)

Hydrogen chloride

Hygromycin B (50mg/ml)

Isoamylalcohol 98\%

Isopropanol $\geq 99.9 \%$

Kanamycin $\geq 750 \mathrm{U} / \mathrm{mg}$

Klenow-Fragment

KOD HotStart DNA Polymerase

Ligate- $\mathrm{IT}^{\mathrm{TM}}$ Rapid Ligation Kit

Lipofectamine $^{\mathrm{TM}} 2000$

LongRange PCR Kit (100)

Magnesium chloride $\geq 99 \%$

Magnesium sulfate $\geq 99.5 \%$

Methanol for analysis

Mini Quick Spin Oligo Columns

Neodisher ${ }^{\circledR}$ A 8, cleaning powder

Nonidet ${ }^{\circledR}$ P40 Substitute (Nonylphenylethylenglycol) PBS
Roche, Mannheim

Sigma-Aldrich, Deisenhofen

American Radiolabeled Chemicals, Inc,

St. Louis USA

Eli Lilly andCompany, Indianapolis,

\section{USA}

Eli Lilly andCompany, Indianapolis, USA

Eli Lilly andCompany, Indianapolis, USA

Applied Biosystems, Darmstadt

Central Pharmacy, Clinic Hospital

Göttingen

Gibco/Invitrogen

Braun, Melsungen

Qiagen, Hilden

Ambion Huntingdon, United Kingdom

Merck, Darmstadt, Germany

Invitrogen, Karlsruhe

Schuchardt, Hohenbrunn

Merck, Darmstadt

AppliChem, Darmstadt

Fermentas, St. Leon-Roth

Novagen Merck, Darmstadt

usb, Staufen

Invitrogen, Karlsruhe

Qiagen, Hilden

Riedel-De Haën AG, Seelze

Merck, Darmstadt

Merck, Darmstadt

Roche, Mannheim

Chem. Fabrik Dr. Weigert,

Mühlenhagen

Sigma-Aldrich, Deisenhofen

Invitrogen, Karlsruhe 
PBS Powder (Dulbeccos 10-fold)

Penicillin/Streptomycin-Solution

Phenylmethansulfonyl fluoride (PMSF)

Polylysin-D-hydrobromide

Polymer POP6 und POP7 for sequencer

Prime Star HS DNA Polymerase

Propidium Iodide

PureYield ${ }^{\mathrm{TM}}$ Midiprep Kit

Puromycin

QIAquick Gel Extraction Kit

QIAquick PCR Purification Kit

5x HOT FIREPol ${ }^{\circledR}$ EvaGreen ${ }^{\circledR}$ qPCR Mix Plus

Quickszint Flow 302, Liquid Scintillator

Random hexanucleotide primers $d N 6$

RNAse A 70\%

RNeasy Mini Kit

RNeasy Plus Mini Kit

Sephadex ${ }^{\text {TM }}$ G-50 Superfine

Shrimp Alkaline Phosphatase $(1 \mathrm{u} / \mu \mathrm{l})$

SnapShot ${ }^{\mathrm{TM}}$ Multiplex Kit

Sodium acetate

Sodium chloride

Sodium dihydrogen phosphate monohydrate

Sodium dodecyl sulfate

Sodium hydrogen phosphate monohydrate

Sodium hydroxide pellets pure

Super Script II reverse transcriptase

SYTOX ${ }^{\circledR}$ Blue Dead Cell Stain, for flow cytometry

T4 DNA Ligase

Taq DNA polymerase

TEMED $\geq 99 \%$

Tetrabutylammonium hydrogen sulfate

Thiazolyl blue tetrazolium bromide

TOPO® XL PCR Cloning Kit
AppliChem, Darmstadt

Invitrogen, Karlsruhe

Sigma-Aldrich, Deisenhofen

Sigma-Aldrich, Deisenhofen

Applied Biosystems, Darmstadt

Takara Bio Europe/SAS, Saint-

Germain-en-Laye, France

BD Biosciences, California, USA

Promega, Mannheim

Invitrogen, Karlsruhe

Qiagen, Hilden

Qiagen, Hilden

Solis BioDyne, Estonia

Zinsser Analytic, Berkshire, UK

Roche, Mannheim

AppliChem, Darmstadt

Qiagen, Hilden

Qiagen, Hilden

Amersham Bioscience, Freiburg

usb, Staufen

Applied Biosystems, Darmstadt

Merck, Darmstadt

Merck, Darmstadt

Merck, Darmstadt

BioRad, Hercules, USA

Merck, Darmstadt

Merck, Darmstadt

Invitrogen, Karlsruhe

Life Technologies Corporation,

Darmstadt

MBI Fermentas, St. Leon-Roth

Qiagen, Hilden

Sigma-Aldrich, Deisenhofen

Sigma-Aldrich, Deisenhofen

Sigma, Steinheim, Germany

Invitrogen, Karlsruhe 
TopTaq Polymerase

Tramadol

Tris $100 \%$

Triton X-100

Trypan blue -solution (0.4\%)

TrypLETM Express

Tryptone

Tween 20 (Polyoxyethylen-Sorbit-Monolaurat)

Vybrant ${ }^{\circledR}$ DyeCycle ${ }^{\mathrm{TM}}$ Ruby stain

X-ray film developer G150

$\mathrm{X}$-ray film fixer G354

Xylene cyanol FF (for molecular biology)

Zeocin
Qiagen, Hilden

Sigma-Aldrich, Deisenhofen

Roth, Karlsruhe

Roth, Karlsruhe

Sigma-Aldrich, Deisenhofen

Gibco/Invitrogen, Karlsruhe

AppliChem, Darmstadt

BioRad, München

Life Technologies Corporation,

Darmstadt

AGFA, Leverkusen

AGFA, Leverkusen

AppliChem, Darmstadt

Invitrogen, Karlsruhe

\subsubsection{Buffers}

\section{Commercial Buffers}

HBSS

\section{Manufacturer}

Invitrogen, Karlsruhe

\section{PBS-buffer (pH7.4)}

\begin{tabular}{|lc|}
\hline Substance & Final concentration [mM] \\
\hline $\mathrm{NaCl}$ & 128.5 \\
\hline $\mathrm{KCl}$ & 2.8 \\
\hline $\mathrm{NA}_{2} \mathrm{HPO}_{4}$ & 8.1 \\
\hline $\mathrm{KH}_{2} \mathrm{PO}_{4}$ & 1.5 \\
\hline
\end{tabular}

TBE-buffer (pH 8.3)

\begin{tabular}{|lc|}
\hline Substance & Final concentration $[\mathrm{mM}]$ \\
\hline Tris & 100 \\
\hline Boric Acid & 100 \\
\hline EDTA & 3.0 \\
\hline
\end{tabular}




\section{$\underline{\text { TE-buffer (pH 7.5) }}$}

\begin{tabular}{|lc|}
\hline Substance & Final concentration [mM] \\
\hline Tris & 10 \\
\hline EDTA & 1 \\
\hline
\end{tabular}

\subsubsection{Media}

\subsubsection{Commercial Media}

\begin{tabular}{ll} 
Media & Manufacturer \\
\hline DMEM & Invitrogen, Karlsruhe \\
RPMI & Invitrogen, Karlsruhe \\
McCoy & Invitrogen, Karlsruhe \\
IMDM & Invitrogen, Karlsruhe \\
\hline
\end{tabular}

\subsection{Enzymes}

\begin{tabular}{ll}
\hline Restriction Enzyme & Manufacturer \\
\hline BamHI & Fermentas, St. Leon-Roth \\
BgIII & Fermentas, St. Leon-Roth \\
DpnI & New England Biolabs, Beverly, USA \\
EcoRI & Fermentas, St. Leon-Roth \\
EcoRV & Fermentas, St. Leon-Roth \\
HindIII & Fermentas, St. Leon-Roth \\
NotI & New England Biolabs, Beverly, USA \\
PstI & Fermentas, St. Leon-Roth \\
SacI & Fermentas, St. Leon-Roth \\
SalI & Fermentas, St. Leon-Roth \\
$\boldsymbol{X h o I}$ & Fermentas, St. Leon-Roth \\
$\boldsymbol{X m a I}$ & New England Biolabs, Beverly, USA \\
\hline
\end{tabular}




\subsection{Plasmid Vectors}

\begin{tabular}{|c|c|c|c|}
\hline Clone-Nr. & Vector & Resistance & Delivery \\
\hline pOG44 & & Ampicillin & Invitrogen, Karlsruhe \\
\hline pOTB7::SLC29A1 & Expression vector & Chloramphenicol & $\begin{array}{l}\text { SourceBioscience, } \\
\text { Nottingham UK }\end{array}$ \\
\hline pcDNA5:FRT & Expression vector & Ampicillin & Invitrogen, Karlsruhe \\
\hline pT81 & $\begin{array}{l}\text { Luciferasereportergene } \\
\text { vector }\end{array}$ & Ampicillin & $\begin{array}{l}\text { Molecular } \\
\text { Pharmacology } \\
\text { Prof. W. Knepel }\end{array}$ \\
\hline pXP2 & $\begin{array}{l}\text { Luciferasereportergene } \\
\text { vector without internal } \\
\text { promoter activity }\end{array}$ & Ampicillin & $\begin{array}{l}\text { Molecular } \\
\text { Pharmacology } \\
\text { Prof. W. Knepel }\end{array}$ \\
\hline
\end{tabular}

2.6 Strains of Bacteria

\begin{tabular}{cccc}
\hline Strain of Bacteria & Origin & $\begin{array}{l}\text { Application } \\
\text { for Transfection }\end{array}$ & Delivery \\
\hline $\begin{array}{c}\text { Top10 } \\
\text { (One shot TOP10 }\end{array}$ & Escherichia coli & Electro-competent & $\begin{array}{c}\text { Invitrogen, } \\
\text { Kactsruhe }\end{array}$ \\
\hline
\end{tabular}




\subsection{Cell Lines}

\begin{tabular}{lccc} 
Cell line & Origin & Characteristics & Delivery \\
\hline HEK Flp-In ${ }^{\text {TM }}$ TREx & Human & $\begin{array}{c}\text { Embryonic kidney cell line } \\
\text { (contain Flp Recombination } \\
\text { Target (FRT)-manipulate }\end{array}$ & $\begin{array}{c}\text { Invitrogen, } \\
\text { stable in Genome integrate) }\end{array}$ \\
AsPCI & Human & ATCC, Wesel \\
BxPC3 & Human & ATCC, Wesel \\
CFPac & Human & ATCC, Wesel \\
CapanI & Human & ATCC, Wesel \\
CapanII & Human & ATCC, Wesel \\
MiaPaca2 & Human & ATCC, Wesel \\
PancI & Human & ATCC, Wesel \\
Su.86.86 & Human & ATCC, Wesel \\
Lymphoblastoid cell & & Coriell Cell \\
lines (HapMap and & Human & Repositorie, \\
1000Genome Project) & & Camden, New \\
\hline
\end{tabular}

\subsection{Databases}

\section{Database}

ECR Browser

ENSEMBL Genome Browser

HapMap

National Center for

Biotechnology Information

TRAP

TFSEARCH

TRANSFAC-Database

UCSC Genome Browser

\section{URL}

http://ecrbrowser.dcode.org/

http://www.ensembl.org/index.html

http://hapmap.ncbi.nlm.nih.gov/

http://www.ncbi.nlm.nih.gov/

http://trap.molgen.mpg.de/cgi-bin/home.cgi

http://mbs.cbrc.jp/research/db/TFSEARCH.html

$$
\text { BIOBASE, Göttingen }
$$

(http://www.biobase-

international.com/product/explain)

http://genome.ucsc.edu/ 


\subsection{Bioinformatic Tools}

Bioinformatic tool

3100 Data Collection Software

Adobe Photoshop

Advanced Image Data Analyzer (AIDA)

V.4.15 025

BASReader (FujiFilm BAS1800-II)

Clone Manager Suite

DNA Sequenzing Analysis

Endnote X4

GeneMapper, Version 3.7

Haploview

MS Office 2007

Oligo

Quantity One S

SDS 2.1

SPSS

Staden Package

XFluor4 Software

\section{Manufacturer}

Applied Biosystems

Adobe Systems GmbH, München

Raytest Isotopenmeßgeräte $\mathrm{GmbH}$,

Sprockhövel

Raytest Isotopenmeßgeräte $\mathrm{GmbH}$,

Sprockhövel

SECentral

Applied Biosystems

Wintertree Software Inc.

Applied Biosystems

Broad Institute of MIT and Harvard

Microsoft, USA

Molecular Biology Insights

Bio-Rad, München

Applied Biosystems

SPSS Inc., Chicago, USA

SourceForge.net

Tecan, Crailsheim 


\section{Methods}

\subsection{DNA Techniques}

\subsubsection{DNA Isolation from Eukaryotic Cells}

For isolation of the genomic DNA from eukaryotes the DNeasy Blood \& Tissue Kit (Qiagen) was used with the QiaCube robot (Qiagen). About $5 \times 10^{6}$ cells, which are solved in $100 \mu \mathrm{l}$ PBS Buffer, were used for isolation process. The amount of extracted DNA was determined by photometric quantification [3.1.3].

\subsubsection{DNA Isolation from Bacteria}

\subsubsection{Isolation of Plasmid DNA by Chloroform Extraction (Plasmid Mini-Prep)}

The mini-prep method was an easy way to extract plasmid DNA from bacteria. For this purpose $5 \mathrm{ml}$ bacteria solutions, which were grown over night, were centrifuged (Centrifuge 5810R; Eppendorf) with 4000 rpm for 10 minutes at room temperature. Before this about $5 \mu \mathrm{l}$ of this solution was transferred to an agar plate which should serve as inoculum for further experiments. After the cells were centrifuged, the supernatant was completely discarded and the pellet resolved in $250 \mu \mathrm{l}$ of "resuspension buffer” and transferred to a $1.5 \mathrm{ml}$ Eppendorf tube. In the next step the cells were lysed by adding $250 \mu \mathrm{l}$ of "alkaline lyses buffer" and briefly vortexed. Then $350 \mu \mathrm{l}$ of "neutralization buffer" were mixed with the solution and the tube was inverted 5 to 6 times. The precipitation of the proteins indicates the neutralization of the mixture. This solution was centrifuged (Biofuge pico) with 13,000 rpm for 10 minutes at room temperature. Then the supernatant was placed in a new 1.5 Eppendorf tube and supplemented with $500 \mu \mathrm{l}$ of ice cold Chlorophorm/Isoamyl (24:1) mixture, which was also vortexed briefly. Next this mix was centrifuged again for 5 minutes under the same conditions as before. After centrifugation there were two phases from which the upper one containing the plasmid DNA. The upper one was removed carefully without picking up protein remains between the two phases and transferred to a new $1.5 \mathrm{ml}$ Eppendorf tube. In the next step $600 \mu \mathrm{l}$ of cold $\left(-20^{\circ} \mathrm{C}\right)$ iso-propanol was added to the solution and vortexed briefly. After this the mixture was centrifuged (Biofuge fresco) with 13,000 rpm for 15 minutes at $4^{\circ} \mathrm{C}$. The supernatant was removed and the pellet washed with 
$600 \mu \mathrm{l}$ of a $70 \%$-Ethanol solution $\left(-20^{\circ} \mathrm{C}\right)$ for 6 minutes under the same conditions as before. Then the supernatant was removed and the tube, whose lid was open, was placed on a heat block with $37^{\circ} \mathrm{C}$ while shaking. After about $10-20$ minutes the pellet was dry and clear and was resolved in $50 \mu \mathrm{l}$ TE Buffer.

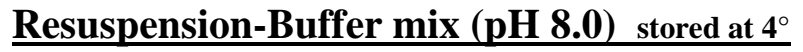

\begin{tabular}{|l|c|}
\hline Reagent & Concentration \\
\hline Tris -HCL & $50 \mathrm{mM}$ \\
\hline EDTA & $10 \mathrm{mM}$ \\
\hline RNAse A (added after autoclaving) & $100 \mu \mathrm{g} / \mathrm{ml}$ \\
\hline
\end{tabular}

Lysis-Buffer mix (pH 8.0) stored at RT

\begin{tabular}{|lc|}
\hline Reagent & Concentration \\
\hline $\mathrm{NaOH}$ & $200 \mathrm{mM}$ \\
\hline SDS & $1 \%(\mathrm{w} / \mathrm{v})$ \\
\hline
\end{tabular}

Neutralization-Buffer mix (pH 5.5) stored at RT

\begin{tabular}{|lc|}
\hline Reagent & Concentration \\
\hline Potassium acetate & $3 \mathrm{M}$ \\
\hline
\end{tabular}

TE-Buffer mix (pH 7.5) stored at RT

\begin{tabular}{|lc|}
\hline Reagent & Concentration \\
\hline Tris & $10 \mathrm{mM}$ \\
\hline EDTA & $1 \mathrm{mM}$ \\
\hline
\end{tabular}




\subsubsection{Isolation of Plasmid DNA by Solid Extraction (Plasmid Midi-Prep)}

This approach was conducted to achieve high and pure amounts of extracted plasmid DNA. Plasmid DNA, which was extracted by this procedure, was used for transfection techniques applied on eukaryotic cells. The ComactPrep Plasmid Kit (Quiagen) was used for this purpose and the extraction was performed according to the manufacturer's recommended protocol.

\subsubsection{Quantification of DNA}

The quantification of DNA samples is accomplished by photometric measurements with an absorbance of $260 \mathrm{~nm}$. An Implen-Nanodropcuvett (Implen) was applied with the BioPhotometer (Eppendorf, Hamburg, Germany). For quantification of DNA $3 \mu$ l of sample was used. Additionally to the extinction of $260 \mathrm{~nm}$ there is an absorbance ratio of 260/280 nm, which expresses the purity of DNA in the samples. In this case the value of about 2 stands for high purity.

The principle of nucleic acid quantification is the Beer-Lambert law:

$$
\mathrm{A}=\alpha \mathrm{cl}
$$

$\mathrm{A}=$ absorbance

$\alpha=$ absorbance coefficient $\left(\mathrm{cm}^{2} / \mu \mathrm{g}\right)$

$\mathrm{c}=$ solute concentration $(\mu \mathrm{g} / \mathrm{ml})$

$\mathrm{I}=$ length of the light path $(\mathrm{cm})$

\subsubsection{Polymerase Chain Reaction (PCR)}

The PCR approach is a technique for DNA amplification in vitro. The KOD Hot Start DNA Polymerase (Novagen Merck, Darmstadt) and the Prime Star HS Polymerase (Takara Bio Europe/SAS, Saint-Germain-en-Laye, France) were used for cloning experiments because of their excellent proofreading activity, which prevents DNA amplification errors. For other purposes than cloning the TopTaq Polymerase (Quiagen, Hilden) was used.

In the PCR reaction the first step is to denaturate the double stranded DNA to single stranded DNA. In the next step the DNA-primers are annealed by temperatures between 
50 and $70^{\circ} \mathrm{C}$. The primers, which represent the start points of amplification, determine the DNA region of interest. After this the temperature heats up again for the elongation process by the polymerase. By repeating these steps for about 35 times the selected DNA region becomes amplified.

The best condition for each new pair of primers in PCR reactions becomes elucidated by a gradient PCR, which tests different annealing temperatures. To reveal the best annealing temperature the fragment size and amount of the PCR product becomes evaluated by an Agarose gel. To improve the amplification in some cases, Q-Solution (from Qiagen Taq-Polymerase-Kit; Quiagen Hilden) was added to the PCR reaction. The PCR reactions were performed according to the manufacturer's recommendations. In the following there is an example for the KOD-PCR reaction.

\section{Standard-KOD-PCR-reaction:}

\begin{tabular}{|c|c|}
\hline Reagent & Volume for 1 Sample [pl] \\
\hline $\mathrm{ddH}_{2} \mathrm{O}$ & 8.8 \\
\hline 10x Buffer & 2.2 \\
\hline dNTPs (2mM) & 2.2 \\
\hline $\mathrm{MgSO}_{4}$ & 0.9 \\
\hline Q-Solution (optional) & 4.4 \\
\hline Primer forward (10 $\mu \mathrm{M})$ & 0.5 \\
\hline Primer reward $(10 \mu \mathrm{M})$ & 0.5 \\
\hline DNA $(300 \mu g / m l)$ & 2 \\
\hline 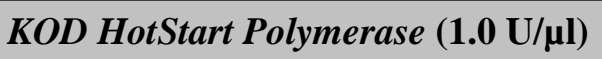 & 0.5 \\
\hline Total & 20 \\
\hline
\end{tabular}

Standard-KOD-PCR-conditions:

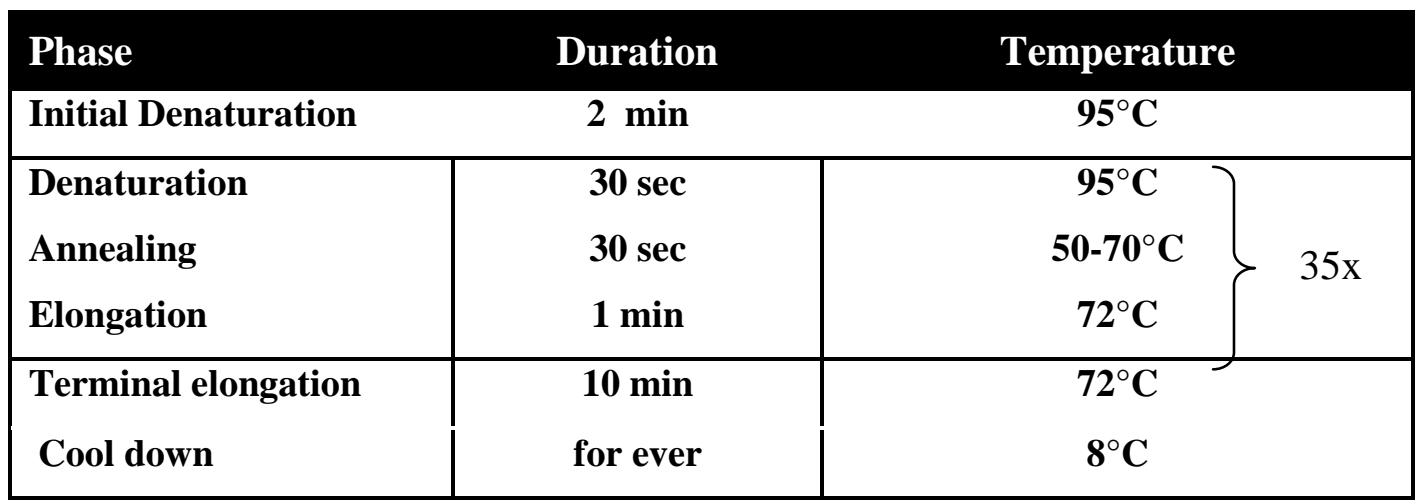




\subsubsection{Site-Directed Mutagenesis}

Site-directed mutagenesis is a method to make specific mutations to one or up to four bases in DNA-sequences by mutagenesis primers. In this case the single nucleotide polymorphism rs45573936 in the cDNA sequence (Clone 3051441 / IRAUp969A097D; SourceBioscience, Nottingham, UK; http://www.lifesciences.sourcebioscience.com/ genomecube? $\mathrm{kw}=3051441$ ) of $h E N T 1$ (SLC29A1) was modified in the SNP rs45573936 position from $\mathrm{T}>\mathrm{C}$ with the mutagenesis primer (Table 1 ) to obtain the variant allele additionally to the wild type allele, which is present in the clone of this polymorphism. When purchased the hENT1 gene had been inserted in the vector pOTB7. With this construct (pOTB7::hENT1) "Site-directed-mutagenesis" was performed.

In order to conduct the side directed mutagenesis it was necessary that the construct, which should be mutated, was harvested from bacteria and had specific methylation patterns. After the amplification in the site-directed mutagenesis PCR the original constructs without the site-directed mutagenesis could be degraded by DpnI endonuclease (methylation specific restriction enzyme). The new generated constructs which derived from the PCR amplification step, did not show methylation patterns and were not degraded by DpnI. The site-directed mutagenesis PCR was performed with the KOD Hot Start DNA Polymerase Kit (Novagen Merck, Darmstadt). To elucidate the right annealing temperatures for PCR conditions a gradient PCR was conducted with the mutagenesis primers first (Table 1) [3.1.4].

\section{Site-directed mutagenesis PCR Mixture}

\begin{tabular}{|c|c|}
\hline Reagent & Volume [pl] \\
\hline $10 \times$ buffer & 5 \\
\hline dNTPs (2 mM) & 5 \\
\hline $\mathrm{MgSO}_{4}(25 \mathrm{mM})$ & 2 \\
\hline Q-Solution & 10 \\
\hline Primer-for (10 nM) & 1.3 \\
\hline Primer-rev (10 nM) & 1.3 \\
\hline Plasmid DNA (50 ng/pl) & 1 \\
\hline KOD HotStart Polymerase (1.0 U/ $\mu \mathrm{l})$ & 1 \\
\hline $\mathrm{ddH}_{2} \mathrm{O}$ & 23.4 \\
\hline Total Volume & 50 \\
\hline
\end{tabular}


$\underline{\text { PCR conditions for Site-directed mutagenesis }}$

$\left.\begin{array}{|l|c|c|}\hline \text { Phase } & \text { Duration } & \multicolumn{1}{c|}{\text { Temperature }} \\ \hline \text { Initial Denaturation } & 3 \mathrm{~min} & \mathbf{9 5}^{\circ} \mathbf{C} \\ \hline \text { Denaturation } & 30 \mathrm{sec} & \mathbf{9 5}^{\circ} \mathbf{C} \\ \text { Annealing } & \mathbf{3 0 ~ s e c} & \mathbf{6 0}^{\circ} \mathbf{C} \\ \text { Elongation } & 3 \mathrm{~min} \mathrm{30} \mathrm{sec} & \mathbf{7 2}^{\circ} \mathbf{C}\end{array}\right\} 19 \mathrm{x}$

For degradation of the not mutated constructs $2 \mu \mathrm{l}$ of DnpI endonuclease was added to the PCR reaction mixture and incubated for 1 hour at $37^{\circ} \mathrm{C}$. Then $1 \mu \mathrm{l}$ of Dpn 1 was supplemented again and incubated again for 1 hour at $37^{\circ} \mathrm{C}$. In the next step the digested PCR mixture was dialyzed [3.1.10].Then the dialyzed solution was transformed in E. coli TOP10 strain by electroporation [3.5.4]. After this the pOTB7::hENT1 constructs were isolated from single bacteria clones by mini prep [3.1.2.1] and the open reading frame of $h E N T 1$ was fully sequenced [3.1.11] with sequencing primers (Table 2) to validate the correct sequence of the $h E N T 1$ gene with the mutated SNP rs45573936 ( $\mathrm{T}>\mathrm{C})$.

Table 1: Mutagenesis primer for $h E N T 1-$ rs45573936- WT $\rightarrow$ Var $(t \rightarrow c)$

\begin{tabular}{|lc|}
\hline Primer & Sequence \\
\hline ENT1-Thr216-for & ${ }^{5}$ ACAGCCTGTGCTGTTACCATTTTGACCATCATC ${ }^{3}$ \\
\hline ENT1-Thr216-rev $^{5}$ 'GATGATGGTCAAAATGGTAACAGCACAGGCTGT \\
\hline
\end{tabular}

Table 2: ENT1-Thr216 sequencing Primer

\begin{tabular}{|lc|}
\hline Primer & Sequence \\
\hline ENT1_Seq-1_rev & ${ }^{5}$ CCAGACCACTCAGGATCAC $^{3{ }^{\prime}}$ \\
\hline ENT1_Seq-2_rev & ${ }^{5}$ ATGCTGGACTTGACCTCAAC $^{3}$ \\
\hline ENT1_Seq-3_rev & ${ }^{5}$ GATGGCACCAAATGAATTAATGAG $^{3}$ \\
\hline
\end{tabular}




\subsubsection{Agarose Gel Electrophoresis}

The agarose gel electrophoresis is a technique for separating DNA fragments by their size on a two dimensional matrix. The principle of this approach is that negative charged DNA fragments move in an electric field to the positive pole. Smaller DNA fragments can move faster in the agarose-gel-matrix than bigger ones. In regard to the used DNA fragment size the agarose concentrations vary from $0.8 \%-3 \%$.

For agarose gel preparation the appropriate amount of agarose (Agarose Ultra Pure; Invitrogen) was weighed, dissolved in TBE-Buffer [2.3.1] and heated up in the microwave until boiling. After cooling down for several minutes $0.5 \mu \mathrm{g} / \mathrm{ml}$ Ethidium bromide (Merck, Darmstadt) were added and mixed with a magnet stirrer. After this the agarose gel liquid was filled in a gel tray, gel combs were used to shape appropriate size and amount for the sample pockets. After 15-30 minutes the agarose gel was hardened. Then the gel tray was placed in the gel chamber and covered with $1 \mathrm{x}$ loading buffer (TBE- Buffer [2.3.1] + Ethidium bromide).

Before placing the DNA samples in the gel pockets, they became mixed with $1 \mathrm{x}$ loading dye. DNA ladders with $100 \mathrm{bp}$ and $1 \mathrm{~kb}$ (ABgene, Fermentas) were used for a visual DNA standard with known DNA-fragment-sizes. The electrophoresis was performed with $120 \mathrm{~V}$ for 30 min using a ComPhor L Mini Gel chamber (Biozym). To analyze electrophoretic results the DNA bands became visualized by Fluor-STM MultiImager (BioRad, Hercules, USA) with the software Quantity One® S Version 4.3.1 (Bio-rad).

\section{5x Loading Dye}

\begin{tabular}{|lc|}
\hline Substance & Final concentration \\
\hline Glycerol & $30 \%(\mathrm{v} / \mathrm{v})$ \\
\hline EDTA & $50 \mathrm{mM}$ \\
\hline Bromphenol blue & $0.25 \%(\mathrm{v} / \mathrm{v})$ \\
\hline Xylene cyanol & $0.25 \%(\mathrm{v} / \mathrm{v})$ \\
\hline
\end{tabular}




\subsubsection{DNA Purification}

\subsubsection{DNA Purification from Agarose Gel}

For DNA extraction from agarose gels first the DNA spots of interest get sliced out of the gel under UV-light using transilluminator TI2 (Biometra). The slices should not exceed $200 \mathrm{mg}$ of $2 \%$ agarose. For purification of the DNA the QIAquick Gel Extraction Kit (Qiagen) was used with the QiaCube robot (Qiagen) according to manufacturers’ protocol.

\subsubsection{DNA Purification from Solutions}

To purify DNA from enzymatic reaction mixtures (e.g. from PCR or restriction digestion [3.1.8]) the QIAquick PCR-Purification Kit (Qiagen) was applied according to manufacturers"' protocol.

\subsubsection{Enzymatic Purification of DNA}

The enzymatic digestion was used to purify PCR-products from remaining primers and nucleotides of the PCR reaction. Shrimp alkaline phosphatase (SAP, Fermentas, Thermo Scientific) was used to dephosphorylate nucleotides (dNTPs) and Exonuclease I from E.coli (Fermentas, Thermo Scientific) was applied to degrade primers. The prepared reaction mixture is displayed next:

\section{Mixture for enzymatic purification of DNA solutions}

\begin{tabular}{|lc|}
\hline Reagent & Volume [ $\mu \mathrm{l}]$ \\
\hline SAP $(1 \mathrm{U} / \mu \mathrm{l})$ & 5 \\
\hline ExoI $(10 \mathrm{U} / \mu \mathrm{l})$ & 0.2 \\
\hline 10 X SAP buffer & 2 \\
\hline PCR product & 13 \\
\hline
\end{tabular}

The reaction mix was incubated for $1 \mathrm{~h}$ at $37^{\circ} \mathrm{C}$. Afterwards the enzymes were inactivated by incubation for $15 \mathrm{~min}$ at $80^{\circ} \mathrm{C}$ in the thermal cycler (BioRad, Hercules, USA). 


\subsubsection{Digestion by Restriction Enzymes}

This basic method of molecular biology is used for the specific cleavage of DNA fragments for analytical or preparative purpose. The cleaving is performed by restriction enzymes which are types of endonucleases. The identification of correct cleavage of DNA fragments and the separation from different sized DNA pieces takes place by agarose gel electrophoresis [3.1.6].

\subsubsection{Analytical Digestion}

This method was used to confirm the awareness of correct DNA fragment by obtaining a specific pattern of individual sized DNA fragments after cleaving with a certain digestion enzyme. To confirm the results DNA constructs became cleaved in independent sets with at least three different digestion enzymes.

\section{Analytical digestion mix}

\begin{tabular}{|c|c|}
\hline Reagent & Volume [pl] \\
\hline $10 \times$ Restriction buffer & 1 \\
\hline BSA (dependent on enzyme) & 0.1 \\
\hline 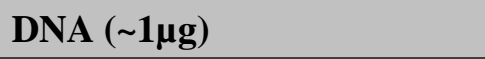 & 1 \\
\hline Digestion enzyme & 1 \\
\hline ddH2O & 7 \\
\hline
\end{tabular}

The analytical digestion mix was incubated for 1 hour at the recommended temperature of the referring digestion enzyme (mostly $37^{\circ} \mathrm{C}$ ). After that the outcome of the digestion was visualized by agarose gel electrophoresis [3.1.6].

\subsubsection{Preparative Digestion}

This approach is used to create matching overhanging DNA tales on inserts and vectors for further ligation steps by which those fragments become connected with each other. Generally, the final aim of this procedure was to transfect the resulting constructs into eukaryotic cells by stable [3.7.3] or transient transfection [3.7.1] or to transform them into bacteria by electroporation [3.5.4] in the end. 


\section{Preparative digestion mix}

\begin{tabular}{|lc|}
\hline Reagent & Volume $[\mu \mathrm{ll}]$ \\
\hline 10 x Restriction buffer & 5 \\
\hline BSA (dependent on enzyme) & 0.5 \\
\hline DNA & (max. $10 \mu \mathrm{g})$ \\
\hline Digestion enzyme (dependent on star activity) & 5 \\
\hline ddH2O & Up to 50 \\
\hline
\end{tabular}

In general the digestion was performed between 2 and 3 hours or even over night dependent on the activity of the applied digestion enzyme. After digesting overnight $1 \mu \mathrm{l}$ of the enzyme was supplemented for 1 further hour the next day. It had also been possible to perform a digestion with two enzymes simultaneously if the enzymes required the same reaction buffer. In case of two independent digestions, the cleaved DNA fragments had to be isolated by a preparative gel electrophoresis [3.1.6] and a gel extraction [3.1.7.1] before the next restriction digestion could be performed.

\subsubsection{Ligation}

This procedure connects double stranded DNA fragments by a ligase enzyme. This method is used for inserting DNA fragments into plasmids. In order to do this the ends of DNA fragments have to match for the linking process. There is the possibility to have sticky ends, which are DNA overhangs in double-stranded DNA fragments or blunt ends, which are plain ends of DNA fragments. The matching DNA termini for a ligation are usually created by restriction enzymes in a preparative digestion reaction [3.1.8.2]. For the ligation procedure the Ligate-ITTM Rapid Ligation Kit (USB, Staufen, Germany) was used. The relation of the used insert and vector was 13:2 (v/v) in a total volume of $15 \mu \mathrm{l}$. The reaction mixture was prepared as depicted in the following chart:

\section{Ligation mixture}

\begin{tabular}{|lc|}
\hline Reagent & Volume $[\boldsymbol{\mu l}]$ per sample \\
\hline $5 x$ Ligase buffer & 5 \\
\hline Vector DNA & 2 \\
\hline Insert (DNA-Fragment) & 13 \\
\hline Ligase & 1 \\
\hline
\end{tabular}


The ligation reaction was performed in 5 to 10 minutes incubation at room temperature. After this the mixture was placed on ice for 10 minutes. To analyze the quality of the previous restriction digestion of the vector, which was used to create sticky ends in the vector DNA, one ligation sample with only vector DNA (negative control) was prepared. After this sample was transformed by electroporation [3.5.4] into bacteria cells in the end, the amount of emerging clones on the agar plate were much fewer then on the other plates. If there were high amounts clones on the negative control agarose plate it would be an indication of a less efficient restriction digestion. This implies high rates of empty vector transfected clones on the sample plates.

\subsubsection{Dialysis}

The dialyses procedure is a required step necessary for the transformation of DNA fragments into bacteria by electroporation [3.5.4]. By this process the salt components in mixture were removed. In order to perform the dialyzation $20 \mu \mathrm{l}$ of the mixture (mostly ligation solutions) was transferred to a semipermeable membrane (Dialyse filter VSWP01300, Millipore, Bedford, USA), which was placed on the surface of $\mathrm{ddH}_{2} \mathrm{O}$ in a petri dish for 30 minutes. After this time the solution was transferred in an Eppendorf tube and was ready for the electroporation process [3.5.4].

\subsubsection{DNA Sequencing}

DNA sequencing is an approach to identify the exact order of nucleotides in DNA strands. The chain-termination method, which was invented by Sanger and Coulson 1975, was applied. The principle of this approach is that there are different fluorescently labeled di-deoxy nucleotide triphosphates (ddNTPs) additionally to ordinary deoxy nucleotide triphosphates (dNTPs), which are lacking a 3'OH-Group and cannot be extended in DNA amplification process. During the sequencing PCR the ddNTPs are randomly incorporated and cause chain termination. In the end the resulting different sized DNA fragments can be aligned by automated sequencing machines. Since the last fluorescently labeled ddNTP of each fragment reveals the identity of the last nucleotide, the sequence of region concerned can be determined by arrange the fragments by their size. 
To sequence genomic regions a pre-PCR had to be performed to quantify the regions of interest for the sequencing PCR step. To sequence DNA products, which were isolated by Mini-Prep [3.1.2.1], there was no need for a pre-PCR. After this the master mix for sequencing was prepared using BigDye ${ }^{\circledR}$ terminator v1.1 Sequencing Kits (Applied Biosystems, Darmstadt). In the sequencing PCR just one of the complementary DNA strands was analyzed, in order to this just one sequencing primer was used for one sample.

\section{Sequencing-PCR-Mix:}

\begin{tabular}{|lc|}
\hline Reagent & Volume $[\boldsymbol{\mu l}]$ per sample \\
\hline DMSO & 0.25 \\
\hline Primer $(10 \mu \mathrm{M})$ & 0.5 \\
\hline BigDye ${ }^{\circledR}$ & 1 \\
\hline ddH $_{2} \mathrm{O}$ & 2.25 \\
\hline DNA $(\sim 300 \mu \mathrm{g} / \mathrm{ml})$ & 1 \\
\hline Total volume & 5 \\
\hline
\end{tabular}

Sequencing-PCR conditions:

\begin{tabular}{|c|c|c|c|}
\hline Phase & Duration & Temperature & \\
\hline Initial Denaturation & $2 \mathrm{~min}$ & $94^{\circ} \mathrm{C}$ & \\
\hline Denaturation & $15 \mathrm{sec}$ & $96^{\circ} \mathrm{C}$ & \\
\hline Annealing & $15 \mathrm{sec}$ & $56.5^{\circ} \mathrm{C}$ & $25 x$ \\
\hline Elongation & $4 \mathrm{~min}$ & $60^{\circ} \mathrm{C}$ & \\
\hline Terminal elongation & $7 \mathrm{~min}$ & $60^{\circ} \mathrm{C}$ & \\
\hline Cool down & for ever & $8^{\circ} \mathrm{C}$ & \\
\hline
\end{tabular}

After the sequencing-PCR the reaction mix had to be purified by a Sephadex purification step to remove the not incorporated ddNTPs. For this purpose $35 \mathrm{mg}$ Sephadex G50 superfine (Amersham, Freiburg) were filled in the wells of a 96-well 
filter plate (MAHV-N45, Millipore) together with $300 \mu l d_{d H_{2}} \mathrm{O}$, then the Sephadex was swelled for 3 hours at room temperature.

Next the plate got centrifuged (Centrifuge 5810 R, Eppendorf) with 650 g for 5 minutes at room temperature to remove the superfluous water. After this another amount of 150 $\mu \mathrm{l} \mathrm{ddH}_{2} \mathrm{O}$ was added to each well and incubated for another 30 minutes at room temperature. To remove the superfluous water the plate got centrifuged again under the same conditions. Meanwhile $35 \mu \mathrm{l}$ of $\mathrm{ddH}_{2} \mathrm{O}$ were added to the $5 \mu \mathrm{l}$ of the sequencingPCR-mix. Then this solution was poured in the Sephadex-wells and centrifuged again by $650 \mathrm{~g}$ for 5 minutes at room temperature. The purified solution was free of unbound dNTPs and ddNTPs and could be used for sequencing analysis with 3130xl Genetic Analyser (Applied Biosystems). The sequencing data was evaluated with Staden Package software Version 4.0 (SourceForge.net) and Clone Manager (SECentral).

\subsubsection{Genotyping by Primer Extension Method (SNaPshot ${ }^{\mathrm{TM}}$ )}

To determine single nucleotide polymorphisms (SNPs) in genomic DNA of human individuals the primer extension method $\mathrm{SNaPshot}{ }^{\mathrm{TM}}$ was applied. By this method it was possible to evaluate over 20 genotypes in one reaction. The principle of this approach is that different sized primers (between 18bp and 40bp) were designed in that manner that their 3'terminus exactly annealed one position upstream of the nucleic acid of the SNP of interest. By means of di-deoxy single-base extension PCR reaction step with fluorescently labeled ddNTPs (SNaPshot Master mix: ABI PRISM SNaPshot ${ }^{\mathrm{TM}}$ Multiplex-Kit) the genotypes were identified. Di-deoxy nucleotides (ddNTPs) don't have an OH-group on the 3'-terminus, which causes a termination of DNA amplification. Because of this an extension of the used primers with only one nucleotide occurs and reveals the polymorphic genotype by the fluorescent stain of the added ddNTP. The identity of each SNP in the reaction set with many primers, which were fluorescently labeled, were coded by the specific length of each primer, which refers to only one polymorphic locus. An internal DNA size standard was used to determine the exact length of the extended primers (Gene Scan ${ }^{T M} 120$ LIZ $^{T M}$ Size Standard, Applied Biosystems). Each ddNTPs has its characteristic fluorescent stain (FS): Adenine = green $(\mathrm{FS}=\mathrm{dR6G})$; Cytosine = black $\left(\mathrm{FS}=\mathrm{dTAMRA}^{\mathrm{TM}}\right)$; Guanine = blue $(\mathrm{FS}=\mathrm{dR} 110)$, Thymine $=$ red $\left(\mathrm{FS}: \mathrm{dROX}^{\mathrm{TM}}\right)$. 
Before performing a SNaPshot ${ }^{\mathrm{TM}}$-PCR on genomic DNA you have to amplify genomic regions with the polymorphic loci (Multiplex PCR Kit, Qiagen, Hilden). After multiplex PCR reaction the "first clearance” with SAP (Shrimp alkali phosphatase, USB, Staufen) and ExoI (Exonuclease I, USB Staufen) was applied to remove the multiplex primers and degrade dNTPs. The reaction mix was incubated for 3 hours at $37^{\circ} \mathrm{C}$. Then the enzymes became deactivated by incubation for 15 minutes at $80{ }^{\circ} \mathrm{C}$.

Reaction mixture for the "first clearance"

\begin{tabular}{|c|c|}
\hline Reagent & Volume $[\mu \mathrm{l}]$ per Sample \\
\hline 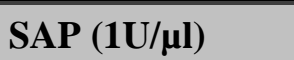 & 1.695 \\
\hline SAP-Puffer (10x) & 0.6 \\
\hline 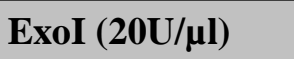 & 0.705 \\
\hline PCR-product & 6 \\
\hline Total volume & $9 \mu \mathrm{l}$ \\
\hline
\end{tabular}

\section{Following an example of SNaPshot ${ }^{\mathrm{TM}}$-PCR}

\begin{tabular}{|lc|}
\hline Reagent & Volume $[\boldsymbol{\mu l}]$ per sample \\
\hline SNaPshot ${ }^{\mathrm{TM}}-$ Master mix & 0.5 \\
\hline Primer mix $(2-12 \mu \mathrm{M})$ & 0.5 \\
\hline ddH2O & 2 \\
\hline Purified PCR-product & 2 \\
\hline Total volume & $5 \mu \mathrm{l}$ \\
\hline
\end{tabular}

\section{PCR cycle for SNaPshot PCR}

\begin{tabular}{|lcc|}
\hline Phase & Duration & Temperature \\
\hline Initial Denaturation & $2 \mathrm{~min}$ & $94^{\circ} \mathrm{C}$ \\
\hline Denaturation & $10 \mathrm{sec}$ & $\mathbf{9 6}^{\circ} \mathrm{C}$ \\
\hline Annealing & $5 \mathrm{sec}$ & $50^{\circ} \mathrm{C}$ \\
\hline Elongation & $30 \mathrm{sec}$ & $\mathbf{6 0}^{\circ} \mathrm{C}$ \\
\hline Total volume & for ever & $8^{\circ} \mathrm{C}$ \\
\hline
\end{tabular}


After SNaPshot ${ }^{\mathrm{TM}}$-PCR reaction the "second clearance” was performed to degrade the superfluous fluorescently labeled dNTPs, which cause background noise during analysis. This reaction was incubated for 30 minutes at $37^{\circ} \mathrm{C}$. Afterwards the enzymes became deactivated by incubation for 15 minutes at $80^{\circ} \mathrm{C}$.

\section{Reaction mixture for the "second clearance"}

\begin{tabular}{|c|c|}
\hline Reagent & Volume $[\mu l]$ per sample \\
\hline SAP (1U/pl) & 0.5 \\
\hline SAP-Puffer (10x) & 0.5 \\
\hline SNaPshot $^{\mathrm{TM}}$-reaction mixture & 5 \\
\hline
\end{tabular}

For determination of the genotypes the cleaned up samples were prepared for evaluation by 3130xl Genetic Analyser using Gene mapper v3.7 software ${ }^{\circledR}$ (Applied Biosystems). For this purpose the following reaction mixture became heated for 10 minutes at $95^{\circ} \mathrm{C}$ and afterwards placed on ice immediately for 10 minutes.

\section{Mixture for evaluating SNaPshot reaction in sequencer:}

\begin{tabular}{|ll|}
\hline Reagent & Volume [ $\boldsymbol{\mu l}]$ \\
\hline Formamid (Hi-Di TM Formamid, Applied Biosystems) & 10 \\
\hline Gene ScanTM 120LIZTM Size & $\mathbf{0 . 0 5}$ \\
\hline cleaned up Sample & 1 \\
\hline
\end{tabular}

\subsection{RNA Techniques}

Since RNA can quickly be degraded by RNases, all the working surfaces and materials had to be free of RNases. For this purpose all preparations were done under a fume hood and all used materials were treated with an anti-RNase-spray (RNaseZap; SigmaAldrich) before working. Additionally RNase-free pipette tips (QualiFilterpipettenspitzen steril; Kisker, Steinfurt) were used to prevent contamination with RNases. 


\subsubsection{RNA Isolation}

For RNA isolation about $1 \times 10^{6}$ cells were taken and washed with about $4 \mathrm{ml}$ PBSbuffer [2.3.1]. Afterwards cells became centrifuged with $250 \mathrm{~g}$ for 5 minutes at room temperature. Then the supernatant became discarded and the very last liquid in the tube became removed with a pipette. In the next step the pellet was lysed in $350 \mu$ l RLT Plus buffer (Qiagen). For this step no 2-Mercaptoethanol was used. Then the solution was transferred to a $2 \mathrm{ml}$ Eppendorf tube. The RNA was isolated with the RNeasy Plus Mini Kit (Qiagen) by the QiaCube (Qiagen) robot according to the recommended protocol. In the end the extracted RNA concentration was determined by the photometric quantification [3.2.2].

\subsubsection{Photometric Quantification of RNA}

The quantification of RNA samples is accomplished by photometric measurements with an absorbance of $260 \mathrm{~nm}$. An Implen-Nanodrop cuvette (Implen) was applied with the BioPhotometer (Eppendorf, Hamburg, Germany). For quantification of RNA $3 \mu \mathrm{l}$ of sample was used. Additionally to the extinction of $260 \mathrm{~nm}$ there is an absorbance ratio of 260/280 nm, which expresses the purity of RNA in the samples. In this case the resulting value of about 2 stands for high purity.

The principle of nucleic acid quantification is the Beer-Lambert law:

$$
\mathrm{A}=\alpha \mathrm{cl}
$$

$\mathrm{A}=$ absorbance

$\alpha=$ absorbance coefficient $\left(\mathrm{cm}^{2} / \mu \mathrm{g}\right)$

$\mathrm{c}=$ solute concentration $(\mu \mathrm{g} / \mathrm{ml})$

$\mathrm{I}=$ length of the light path $(\mathrm{cm})$

\subsubsection{Reverse Transcription}

The reverse transcription method is utilized to analyze the expression of genes by the determination of the amount of produced RNA transcripts in cells.

In order to do this the extracted RNA had to be transcribed in cDNA (copy or complementary DNA) by Super Script II reverse transcriptase (Invitrogen, Karlsruhe) first. Next the amount of specific cDNA transcripts was quantified by qPCR. Since the cDNA became generated directly from mRNA, there were no introns in resulting cDNA 
fragments. For reverse transcription first the random primers got annealed for 5 minutes at $70^{\circ} \mathrm{C}$ in the following reaction with the total amount of $1 \mu \mathrm{g}$ RNA. After this the samples became cooled down on ice for 10 minutes.

\section{Mixture for primer annealing}

\begin{tabular}{|c|c|}
\hline Reagent & Volume $[\mu l]$ per Reaction \\
\hline 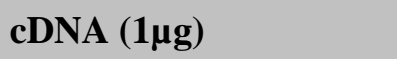 & Volume for $1 \mu \mathrm{g}$ \\
\hline dN6 (random Primers) & 2 \\
\hline $\mathrm{ddH}_{2} \mathrm{O}$ & Add to 18.54 \\
\hline
\end{tabular}

In the meantime the master mix for reverse transcription was prepared. Subsequently the master mix was added to each sample and the reverse transcription was conducted under $42^{\circ} \mathrm{C}$ for 1 hour as described in the following example:

\section{Reverse transcription reaction mixture}

\begin{tabular}{|lc|}
\hline Reagent & Volume $[\mu \mathrm{l}]$ \\
\hline 5 x Superscript RT buffer & 6 \\
\hline DTT $(0.1 \mathrm{M})$ & 3.5 \\
\hline dNTPs $(10 \mathrm{mM})$ & 1 \\
\hline RNase Inhib P/N $(40 \mathrm{un} / \mu \mathrm{l})$ & 0.5 \\
\hline Super Script ${ }^{\mathrm{TM}} \mathrm{II}(200 \mathrm{U} / \mu \mathrm{l})$ & 0.25 \\
\hline Total volume & 11.25 \\
\hline
\end{tabular}

At last the cDNA concentration was adjusted to a concentration between $2 \mathrm{ng} / \mu \mathrm{l}$ and $10 \mathrm{ng} / \mu \mathrm{l}$ by diluting with TE-buffer [2.3.1].

\subsubsection{Quantitative PCR}

The quantitative PCR (also qPCR or real-time PCR) is a method for quantification of cDNA transcripts, which were derived from mRNA reverse transcription [3.2.3], during PCR amplification process. 
The produced DNA products were monitored by eva green $($ Excitation $=500 \mathrm{~nm}$; Emission $=530 \mathrm{~nm}$ ), which is a fluorescent intercalating dye and a component of the qPCR-master mix (Solis BioDyne, Estonia). During several PCR cycles the cDNA became amplified. Between the cycles the total amount of amplified DNA was monitored. The fewer the amount of specific cDNA in the beginning the more cycles of PCR were necessary to reach a threshold (Threshold Cycle (Ct)) of a preset DNA quantity (HIGUCHI et al 1993). The lower the cycle number the higher was the expression of this gene. To be able to compare expression patterns in different cells with deviating total RNA amounts, it was necessary to normalize the quantity of transcripts with the quantity of at least one housekeeping gene (e.g. GAPDH, $U B C$ etc.), which were ubiquitously expressed genes. For determination of amplification efficacy during the cycles a basic grade with a pool of cDNA of cell lines, which were supposed to be analyzed, was compounded. This basic grade was prepared by a serial dilution of cDNA with six concentrations (1:5 dilutions). The amount of amplified DNA became monitored. In the end the amplification efficacy was calculated and referred to the data of the samples.

The $5 x$ HOT FIREPol ${ }^{\circledR}$ EvaGreen ${ }^{\circledR}$ qPCR Mix Plus (Solis BioDyne, Estonia) was used for real-time PCR and was prepared as described in the following example:

\section{qPCR master mix:}

\begin{tabular}{|lc|}
\hline Reagent & Volume $[\boldsymbol{\mu l}]$ per sample \\
\hline qPCR Master mix & 2 \\
\hline Primer $[1: 10]$ & 0.2 \\
\hline ddH $_{2} \mathrm{O}$ & 4.8 \\
\hline cDNA & 3 \\
\hline total & 10 \\
\hline
\end{tabular}

The quantitative PCR was executed by TaqMan 7900HT (Applied Biosystems) in a 384 Well Plate (Thermo Fast Plate 384 PCR, ABgene), which was covered with a special “optical clear” cover slide (Adhäsiv PCR-Folie, ABgene). 


\section{qPCR-Program:}

\begin{tabular}{|llc|}
\hline Phase & Duration & Temperature \\
\hline Initial denaturation & $15 \mathrm{~min}$ & $95^{\circ} \mathrm{C}$ \\
\hline Denaturation & $15 \mathrm{sec}$ & $95^{\circ} \mathrm{C}$ \\
\hline Primer annealing & $20 \mathrm{sec}$ & $60^{\circ} \mathrm{C}$ \\
\hline Elongation & $40 \mathrm{sec}$ & $72^{\circ} \mathrm{C}$ \\
\hline Melting curve & & \\
\hline
\end{tabular}

The results were evaluated with the software SDS 2.1. The specific melting curve in this qPCR process was an indication that the intended PCR product was amplified. Different DNA fragments have various melting temperatures due to their number of nucleotides and to the amount of guanosine and cytosine bonds. Because of this it was possible to recognize wrong amplified fragments, when a second melting curve had appeared. For normalization of the quantity of transcripts with housekeeping genes the $\Delta \Delta \mathrm{C}_{\mathrm{T}}$ method was used.

This method was applied in my thesis for determination of ENT1 transcript variants, which derived from lymphoblastoid cell lines [3.6.5], pancreatic tumor cell lines (AsPC1, MiaPaca2, Su.86.86, CFPac, Panc1, Capan1) [3.6.6] and a human RNA tissue panel from Ambion (Huntingdon, United Kingdom). The samples of the total RNA panel derived from tissues of at least three unrelated healthy humans and were extracted post mortem. The primer used for quantification of ENT1 transcript variant as well as for the determination of reference genes are outlined in Table 3. 
Table 3: Primers for qRT-PCR.

\section{Gene}

Forward Primer (5'->3')

Reverse Primer (5'->3')

AL [bp]

\section{Reference genes}

\begin{tabular}{|c|c|c|c|}
\hline \multirow[b]{2}{*}{ GAPDH $^{1}$} & & & \\
\hline & СССТTCATTGАССТСААСТАСАТ & ACGATACCAAAGTTGTCATGGAT & 407 \\
\hline HPRT1 ${ }^{1}$ & TGACACTGGCAAAACAATGCA & GGTCCTTTTCACCAGCAAGCT & 93 \\
\hline $\mathrm{UBC}^{2}$ & CGGTGAACGCCGATGATTAT & ATCTGCATTGTCAAGTGACGA & 123 \\
\hline $36 b 4^{3}$ & GCAGATCCGCATGTCCCTT & TGTTTTCCAGGTGCCCTCG & 92 \\
\hline \multicolumn{4}{|c|}{ ENT1 transcript variants } \\
\hline all ${ }^{4}$ & TGTTTCCAGCCGTGACT & CAGGCCACATGAATACAG & 147 \\
\hline v1 & TGCGGTCACGTTGACCT & CCTAGGAGGTGCTCCTAGTTCA & 113 \\
\hline v2 & ATCTCAGCGCGGGAGCA & v1-rev & 85 \\
\hline v3 & CGAGAGCGCGCGGATCT & GGGGCCTGCCGCAGAAG & 50 \\
\hline v4 & GAGATGAGGAGGGAGAGAAC & СCTGCTGCTGAGACTTTG & 93 \\
\hline v5 & v4-for & GGCCTGCTGAGACTTTG & 92 \\
\hline v313248 & v4-for & CTGGTCTTCTGGCTTCTCTC & 132 \\
\hline v371708 & AAGACAGGGCCTCACACTG & AAGCCAGACAGCTTTGTATCTGT & 134 \\
\hline v371713 & v1-for & CAGGGGCCAGATCGATG & 67 \\
\hline v371731 & TCTGCGGCAGGCTTCTC & v1-rev & 151 \\
\hline $\begin{array}{l}\text { The ENT1 } \\
\text { http://www.nct } \\
\text { http://www.ens } \\
\text { are covered by } \\
\text { detect a region } \\
\text { gene names } \\
\text { 3 = PID.174 }\end{array}$ & $\begin{array}{l}\text { transcript variants are based } \\
\text { i.nlm.nih.gov/gene/2030) and }\end{array}$ & $\begin{array}{l}\text { on the entries in NCBI } \\
\text { ENSEMBL (the last four } \\
\text { latabases. Of the other seven ENSEM } \\
\text { I, and one does not code for protein } \\
\text { tigated transcript variants. The prime } \\
\text { ource: } 1 \text { = PMID:16978418, } 2=\text { PI } \\
\text { er denotes self-established primers. }\end{array}$ & $\begin{array}{l}-5, \quad \text { see } \\
\text { vs, see } \\
\text { ntries, six } \\
\text { uct. "All" } \\
\text { ers at the } \\
\text { 9036168, }\end{array}$ \\
\hline
\end{tabular}

\subsection{Protein Analyses}

\subsubsection{Quantification of Total Protein Using Bicinchoninic Acid (BCA)}

For quantification of the total amount of proteins in solutions the bicinchoninic acid (BCA) method was used (SMITH et al. 1985). The principle of this approach is that $\mathrm{Cu}^{2+}$ ions become reduced by the proteins to $\mathrm{Cu}^{+}$ions, which causes a color shift of the reaction mixture from green to purple. The exact transition from the color shift can be photometrically determined and used for quantification of the protein content.

For applying this approach at first a basic grade with a defined amount of BSA protein solution (bovine serum albumin) was transferred into wells of a 96-well plate (Sarstedt). The basic grade, which was prepared in duplicates, consisted of the conditions $0,3,5,7$, 9, $11 \mu \mathrm{l}$ of a $1 \mathrm{mg} / \mathrm{ml}$ BSA stock solution. Then $4-10 \mu \mathrm{l}$ of undetermined protein 
samples were transferred in triplicates to the wells of the 96-well plate. In some cases a 1:10 dilution of the undetermined protein samples was prepared before. The BCAcopper-sulfate-reaction-mixture is composed of 50 parts of Bicinchoninic Acid solution and 1 part of a 4\% copper-sulfate-solution. Then $200 \mu \mathrm{l}$ from this mixture was transferred on the 96-well plate for each sample and incubated for 30 minutes at $37^{\circ} \mathrm{C}$. After this time the color shift based on the amount of proteins in the samples was determined by absorbance measurements at $570 \mathrm{~nm}$ with Tecan Ultra Microplate device (Tecan, Crailsheim). In the end the total protein content could be calculated in applying the basic grade according to the collected date with this formula:

\begin{tabular}{|ccc|}
\hline dilution factor & $x$ & measured value \\
\hline used sample volume & $x$ & slope of basic grade \\
\hline
\end{tabular}

\subsection{Electrophoretic Mobility Shift Assay}

The electrophoretic mobility shift assay (EMSA) is an approach to determine if regulatory proteins (e.g. from nuclear extracts (MURRAY and RUBEL 1992; SCHREIBER et al. 1989)) are binding on DNA probes. The DNA probes were labeled with the radioactive nuclide ${ }^{32} \mathrm{P}$ to visualize the protein binding on the probe. The probes consisted of a pair of complementary oligonucleotides, which had a GATC-nucleotide overhang on the 5 'terminus.

\subsubsection{Isolation of Nuclear Protein Extracts}

The isolation of nuclear protein extracts was performed according to the CelLytic ${ }^{T M}$ NuCLEAR ${ }^{T M}$ Extraction Kit from Sigma. The principle of this method is that cells become lysed by osmotic pressure first. Thus, cytosolic components evade the cells and can be separated by centrifugation steps from membranes and nuclei. An inhibitor of nuclear transporters (Na-ortho-vanadate) is intended to prevent nuclear proteins from escaping the nucleus. Next the membranes become chemically degraded. In the means of another centrifugation step the destroyed membrane fragments can be separated from the nuclear proteins by centrifugation. 
All the required solutions were prepared by me. The isolated nuclear protein extracts derived from lymphoblastoid cell lines [3.6.5] and pancreatic cancer cell lines [3.6.6] and were used for electrophoretic mobility shift assays (EMSA) [3.4.3].

All of the following steps were conducted on ice.

\section{Mixture for Nuclear-Extraction-Buffer A}

\begin{tabular}{|lc|}
\hline Reagent (pH7.9at $\left.4^{\circ} \mathrm{C}\right)$ & Concentration (mM) \\
\hline HEPES/KOH & 10 \\
\hline MgCl $_{2}$ & 1.5 \\
\hline KCl & 10 \\
\hline DTT (added directly before usage) & $\mathbf{0 . 5}$ \\
\hline PMSF (added directly before usage) & $\mathbf{1} \mathbf{~ l}$ \\
\hline Na-Vanadat (added directly before usage) & 1 \\
\hline ddH $_{2} \mathbf{O}$ & Up to 600 ml \\
\hline
\end{tabular}

\section{Mixture for Nuclear-Extraction-Buffer B}

\begin{tabular}{|lc|}
\hline Reagent (pH7.9at $4^{\circ} \mathrm{C}$ ) & Concentration (mM) \\
\hline HEPES/KOH & 20 \\
\hline Glycerin 85\% & $25 \%$ \\
\hline NaCl & 420 \\
\hline MgCl $_{2}$ & 1.5 \\
\hline EDTA & $\mathbf{0 . 2}$ \\
\hline NP40 (=modification) & $\mathbf{1} \%$ final conc. \\
\hline Na-Doc (=modification) & $\mathbf{0 . 5 \%}$ final conc. \\
\hline DTT (added directly before usage) & $\mathbf{0 . 5}$ \\
\hline PSMF (added directly before usage) & 1 ml \\
\hline Na-Vanadat (added directly before usage) & (of a saturated solution) \\
\hline ddH $_{2}$ O & Up to 1000 ml \\
\hline
\end{tabular}


For the nuclear protein extraction about $1 \times 10^{7}-1 \times 10^{8}$ cells were used. The cells were harvested from the culture flask and transferred to pre-cooled Falcon tubes. Next they were centrifuged (Heraeus Laborfuge 400R) at $300 \mathrm{~g}$ for 5 minutes at $4^{\circ} \mathrm{C}$. Thereafter the supernatant was discarded and the pellet was resolved in $10 \mathrm{ml}$ of ice cold PBS [2.3.1] (supplemented with $1 \mathrm{mM}$ Na-ortho-vanadate). If many Falcon tubes were used at this point, all the aliquots would be pooled in one $50 \mathrm{ml}$ Falcon tube. After this the cells were centrifuged again (Heraeus Laborfuge 400R) at $600 \mathrm{~g}$ for 5 minutes at $4^{\circ} \mathrm{C}$. In the following procedure the supernatant was completely removed and the cells were resolved in $1 \mathrm{ml}$ of ice cold PBS (supplemented with $1 \mathrm{mM}$ Na-Orthovanadat) and transferred to a $2 \mathrm{ml}$ Eppendorf tube. Then the samples were centrifuged (Biofuge fresco) with $600 \mathrm{~g}$ for 5 minutes at $4^{\circ} \mathrm{C}$. Hereafter the supernatant was removed and cells became resolved in the nuclear extraction mixture buffer A with the approximate fivefold volume of the pellet. Then cells were incubated for 20 minutes on ice. Subsequently the vitality of the cells was checked by Trypan blue staining under the microscope. In most cases just $60 \%-80 \%$ of the cells were lysed. Next $10 \mu \mathrm{l}$ of a $10 \%$ NP-40 solution (1\% final concentration) per $100 \mu$ l of cell mixture was applied and vortexed vigorously for 10 seconds. After that cells became centrifuged (Biofuge fresco) with 11,000 g for 2 minutes at $4^{\circ} \mathrm{C}$. At this point supernatant includes cytosolic proteins and could be wasted. Then the pellet was removed and resuspended in an amount of nuclear extraction mixture buffer $B$, which corresponds to $2 / 3$ of the volume of the pellet. This mixture was stuck to a vortexer and shaken with 1,800 rpm for about $30-60$ minutes at $4^{\circ} \mathrm{C}$ in the cooling room. In the end the solution was centrifuged (Biofuge fresco) with $17,000 \mathrm{~g}$ for 10 minutes at $4^{\circ} \mathrm{C}$. Thereupon the supernatant included the nuclear proteins and was pooled. Then an aliquot was taken for protein quantification measurement [3.3.1] and the remain was transferred to $1.5 \mathrm{ml}$ Eppendorf tubes and was frozen at $-80^{\circ} \mathrm{C}$ for further usage. 


\subsubsection{Probe Labeling}

Probes which were supposed to be radiolabeled with $\alpha-{ }^{32} \mathrm{P}-\mathrm{dCTP}$ had to be annealed first.

\section{Mixture for probe-annealing}

\begin{tabular}{|lc|}
\hline Reagent & Volume $[\mu \mathrm{ll}$ per Sample \\
\hline Oligo_for $(100 \mu \mathrm{M})$ & 1 \\
\hline Oligo_rev $(100 \mu \mathrm{M})$ & 1 \\
\hline $\mathrm{NaCl}(0.5 \mathrm{M})$ & 1 \\
\hline $\mathrm{ddH}_{2} \mathrm{O}$ & 47 \\
\hline
\end{tabular}

The above mentioned probe-annealing-mixture became incubated in one liter of hot water (ca.95 ${ }^{\circ} \mathrm{C}$ ), which was stirred gently (about $100 \mathrm{rpm}$ ) on the magnetic stirrer, until the water was cooled down to room temperature and the oligonucleotides were annealed.

With Klenow-reaction (Klenow-Fragment, St. Leon-Roth) the single stranded GATC overhangs on the 5 -termini became double stranded. During Klenow-reaction the $\alpha{ }^{32} \mathrm{P}$ cytidine nucleotides became incorporated and the probe radioactively labeled. The nucleotides dATP, dGTP and dTTP were not radioactively labeled.

The labeling of the probes was performed in the radioactivity area. In order to do this all safety procedures and rules had to be observed. The labeling mixture was prepared outside the radioactivity laboratory. Thereafter the Klenow-enzyme and the radioactive dCTPs were added to this solution in the radioactive control area and incubated for 1 hour at $37^{\circ} \mathrm{C}$. 


\section{$\underline{\text { Mixture for } \alpha-\underline{32}} \underline{\text { P-dCTP-probe-labeling }}$}

\begin{tabular}{|lc|}
\hline Reagent & Volume $[\mu \mathrm{ll}$ per Sample \\
\hline Annealed oligonucleotides $(2 \mathrm{pmol} / \mu \mathrm{l})$ & 1 \\
\hline 10x Klenow Buffer & 1 \\
\hline dNTPs $(\mathrm{A}, \mathrm{G}, \mathrm{T}$ each $1 \mathrm{mM})$ & 1 \\
\hline $\mathrm{ddH}_{2} \mathrm{O}$ & 12 \\
\hline$\alpha-{ }^{32} \mathrm{P}-\mathrm{dCTP}(10 \mu \mathrm{Ci} / \mu \mathrm{l})$ & 2 \\
\hline Klenow-Fragment $(1 \mathrm{U} / \mu \mathrm{l})$ & 2 \\
\hline
\end{tabular}

To purify the labeled probes from unbound $\alpha-{ }^{32} \mathrm{P}$-dCTP the mixture was filtered by a mini Quick Spin Oligo Columns (Roche). At first the sephadex matrix had to be homogenized by vortexing. After this the lid of the column and the outlet was opened. Then the column was placed in an empty tube for centrifugation $(3,200 \mathrm{x} \mathrm{g}=900 \mathrm{rpm}$, 2 min, RT; Biofuge 15 R, Heraeus) to remove surplus liquid. The dry column was placed in a new $1.5 \mathrm{ml}$ Eppendorf tube and the mixture for $\alpha-{ }^{32} \mathrm{P}$-dCTP-Probe-labeling, which was centrifuged before to avoid contamination by opening the tube, was pipetted in the middle of the columns matrix. Then the column became centrifuged $(3,200 \times \mathrm{g}=$ $900 \mathrm{rpm}, 4 \mathrm{~min}, \mathrm{RT}$; Biofuge 15 R, Heraeus). The eluate consisted of the purified radioactively labeled probes. To determine the exact amount of radioactivity in the eluate $1 \mu \mathrm{l}$ of latter was used, mixed with $4 \mathrm{ml}$ of safety scintillator (Aquasafe 500 Plus, Zinsser Analytic) and applied to the scintillation counter LS1801. For the EMSA binding reaction the amount for 30,000 cpm of the probe was used. Primers which were labeled in order to use them for EMSA experiments are depicted in Table 4.

Table 4: Primers for EMSA-probes

\begin{tabular}{|c|c|}
\hline Primer name & Sequence \\
\hline EMSA-Primer- rs1057985-C & ${ }^{5}$ GATCTAATATCTGAGTTGCCTATGGAGGCAGACCT ${ }^{3}$ \\
\hline EMSA-Primer- rs1057985-G & ${ }^{5}$ GATCAGGTCTGCCTCCATAGGCAACTCAGATATTA ${ }^{3 \prime}$ \\
\hline EMSA-Primer- rs1057985-T & ${ }^{5}$ GATCTAATATCTGAGTTGCTTATGGAGGCAGACCT ${ }^{3 '}$ \\
\hline EMSA-Primer- rs1057985-A & 5'GATCAGGTCTGCСTCCATAAGCAACTCAGATATTA ${ }^{3^{\prime}}$ \\
\hline EMSA-Primer- rs507964-C & 5'GATCAAGGCAACTCACССАССССТАGTСТСТТСТА \\
\hline EMSA-Primer- rs507964-G & ${ }^{5}$ GATCTAGAAGAGACTAGGGGTGGGTGAGTTGCCTT ${ }^{3}$ \\
\hline EMSA-Primer- rs507964-A & 5'GATCAAGGCAACTCACCCAАCССТАGTCTСТTСТА ${ }^{3^{\prime}}$ \\
\hline EMSA-Primer- rs507964-T & ${ }^{5}$ GATCTAGAAGAGACTAGGGTTGGGTGAGTTGCCTT ${ }^{3}$ \\
\hline
\end{tabular}




\subsubsection{Protein-DNA Interaction}

The binding reaction was prepared according to the following protocol. Since proteins are very sensitive all the steps were performed on ice.

\section{Protein-DNA binding-reaction-mixture}

\begin{tabular}{|c|c|}
\hline Reagent & Volume [pl] per sample \\
\hline $4 x$ binding buffer & 5 \\
\hline Nuclear cell extracts [3.4.1] & $\sim 20-40 \mu g$ \\
\hline Poly dI-dC (1 $\mu \mathrm{g} / \mu \mathrm{l})$ & 2 \\
\hline$\alpha-{ }^{32} P$-dCTP-labeled probes & $30,000 \mathrm{cpm}$ \\
\hline $\mathrm{ddH}_{2} \mathrm{O}$ & Up to $20 \mu \mathrm{l}$ \\
\hline
\end{tabular}

\section{$4 \mathrm{x}$ binding buffer mix $(\mathrm{pH} 7.9)$ stored at $4^{\circ} \mathrm{C}$}

\begin{tabular}{|lc|}
\hline Reagent & Concentration [mM] \\
\hline Hepes (pH 7.8) & 80 \\
\hline EDTA (pH 8) & 4 \\
\hline DTT & 2 \\
\hline Glycerin & $40 \%$ \\
\hline KCl & 560 \\
\hline
\end{tabular}

\section{$6 x$ loading dye}

\begin{tabular}{|lc|}
\hline Reagent stored at $-20^{\circ} \mathrm{C}$ & Concentration [\%] \\
\hline Glycerin $87 \%$ & $30(\mathrm{v} / \mathrm{v})$ \\
\hline Bromphenol blue & $0.25(\mathrm{w} / \mathrm{v})$ \\
\hline Xylen Cyanol FF & $0.25(\mathrm{w} / \mathrm{v})$ \\
\hline
\end{tabular}

After the binding reaction mix was prepared without $\alpha-{ }^{32} \mathrm{P}$-dCTP-labeled probes, the solutions were incubated on ice for 10 minutes. After the pre-incubation of 10 minutes the $\alpha-{ }^{32} \mathrm{P}-\mathrm{dCTP}$-labeled probes $(30,000 \mathrm{cpm})$ were added in the radioactive area and incubated for 30 minutes on ice. After that time $4 \mu \mathrm{l}$ of the $6 \mathrm{x}$ loading dye were added to each sample and then transferred to the pockets of a native polyacrylamid gel [3.4.6]. 


\subsection{4 “Cold" Competition}

In cases of "cold" competition experiments a non-radiolabeled probe was also added to the binding mixture. In those experiments the specificity of protein binding on probes should be elucidated. By a competition with a non-radiolabeled probe in different concentrations (5 times till 300 times surplus), it was possible to visualize the competing effect of a protein binding on the radiolabeled probe. Thus it was feasible to identify the DNA bases of the probe, which were relevant for the protein binding. By means of the "cold" competition it was possible to predict the interacting protein due to the specific binding pattern.

The "cold" competition procedure was applied to investigate binding affinities between polymorphic regions in relation to their allelic constitution for an ENT1 promoter SNP rs507964 and a WWOX SNP rs11644322. In these cases the primer for the opposite allele (Table 4) was used to compete with the actual protein interaction to determine if one allelic region showed higher affinity to the binding protein than the other. For determination of the binding protein on EMSA probes, consensus sequences of binding motives referring to putative interacting proteins were used. The primers for determination of binding proteins are outlined in Table 5.

Table 5: Primers for “cold” competition

\begin{tabular}{|c|c|}
\hline Primer declaration & Sequence \\
\hline EMSA-P300-1 & ${ }^{51}$ GAGAGGGAGAAAGTGAAGCTGGGAGTTGCC ${ }^{3 \prime}$ \\
\hline EMSA-P300-2 & ${ }^{51}$ GAGACCGAGAAAGTGAAGCTCCGAGTTGCC ${ }^{31}$ \\
\hline EMSA-CDP-1 & ${ }^{{ }^{5} \text { ACCCAATGATTATTAGCCAATTTCTGA }}{ }^{3_{1}}$ \\
\hline EMSA-CDP-1 & 5'TCAGAAATTGGCTAATAATCATTGGGT' \\
\hline EMSA-AP2-Alpha-1 & ${ }^{{ }^{5} \text { 'GATCGAACTGACCGCCCGCGGCCC } \text { GT }^{3 !}}$ \\
\hline EMSA-AP2-Alpha-2 & ${ }^{54}$ ACGGGCCGCGGGCGGTCAGTTCGATC ${ }^{31}$ \\
\hline EMSA-SP1-1 & ${ }^{{ }^{5} \text { ATTCGATCGGGGCGGGGCGAGC }{ }^{3 !}}$ \\
\hline EMSA-SP1-2 & ${ }^{51}$ 'GCTCGCCCCGCCCCGATCGAAT ${ }^{3 !}$ \\
\hline EMSA-EGR-family-1 & ${ }^{{ }^{5} \text { 'GGATCCAGCGGGGGCGAGCGGGGGCGA }}{ }^{31}$ \\
\hline EMSA-EGR-family-2 & ${ }^{5 \text { TCGCCCCCGCTCGCCCCCGCTGGATCC }{ }^{3 !}}$ \\
\hline
\end{tabular}




\subsubsection{Super shift Assays}

This method is used to prove the identity of a binding protein in an EMSA experiment. By applying a specific antibody against the protein of interest to the binding reaction, there should additionally occur a protein-protein interaction besides the DNA-protein binding. The additional mass of the second protein causes a retarded migration of the complex in the gel matrix during the gel electrophoresis in comparison to the probeprotein binding without the antibody. If retarded migration can be observed, which is a very specific reaction, the identity of the binding protein is proven.

The SP1 antibodies (PEP2 and IC6) were obtained from Santa Cruz Biotechnology, Inc. (Heidelberg) and the super shift assays were performed according to their recommendation. The antibodies were applied to the binding reaction mix on ice 1 hour before the radiolabeled probes were added.

\subsubsection{Non-Denaturating Polyacrylamid-Gel Electrophoresis}

The non-denaturating polyacrylamid gel electrophoresis was prepared according to the following protocol. The property of this polyacrylamid-gel was that it did not contain any SDS and therefore the proteins kept their native structure and stayed functional.

\section{5 \% Polyacrylamid-Gel}

\begin{tabular}{|c|c|}
\hline Reagent & Volume [ml] per sample \\
\hline $\begin{array}{l}\text { 40\% (w/v) Acrylamid/Mix } \\
\text { 37:5:1 }\end{array}$ & 4.4 \\
\hline $5 \times \mathrm{TBE}$ & 3.5 \\
\hline ddH2O & 27 \\
\hline APS $10 \%(w / v)$ & 0.35 \\
\hline TEMED & 0.035 \\
\hline
\end{tabular}

\section{$5 \times$ TBE buffer (pH8)}

\begin{tabular}{|lc|}
\hline Reagent & Concentration $[\mathrm{mM}]$ \\
\hline Tris & 450 \\
\hline Bor acid & 450 \\
\hline EDTA & 10 \\
\hline
\end{tabular}


Before the samples were applied to the gel pockets the polyacrylamid gel had to be equilibrated in $0.5 \%$ TBE-buffer [2.3.1] at $180 \mathrm{~V}$ (maximal power of $\mathrm{mA}$ ) for about 1 hour. After that the binding reaction samples could be transferred to the gel. Thereafter the gel was run under the same conditions for 1.5 hours. The gel was placed on two Whatman papers (Nr. 2668, Schleicher und Schuell) and covered with cling film. Then the gel was placed with the Whatman papers on a vacuum-gel-drying system. By this the gel was dried for about 2 hours at $80^{\circ} \mathrm{C}$. After the gel was dry, it was positioned in a cassette with a Fujifilm BAS1500 plate over night. The next day the radioactive signals could be visualized with PhosphorImager device (Raytest, Sprockhövel, Germany) by the software BASreader and AIDA (Version 4.15.025, Raytest, Sprockhövel, Germany). After positive results the gel was additionally placed in a cassette with an x-rayfilm (Hyperfilm MP $(18 \times 24 \mathrm{~cm})$; GE Healthcare) for $10-14$ days at $-80^{\circ} \mathrm{C}$. Thus it was possible to get a better resolution of the radioactive signals. The $\mathrm{x}$-rayfilms were developed with $\mathrm{x}$ ray-developer G150 und fixer G354 (AGFA, Leverkusen) in the darkroom. Analogous signal counting was performed using the Fluor-STM MultiImager (BioRad, Hercules, CA, USA).

\subsection{Bacteria Cell Procedures}

The electro competent bacteria strain One Shot ${ }^{\circledR}$ TOP10 Electrocomp ${ }^{\mathrm{TM}}$ E. coli (Invitrogen, Karlsruhe) was used to amplify vectors with inserted genes of interest intracellularly.

\subsubsection{Culturing and Storage}

The Luria-Bertani (LB) complex media was used in solid and liquid condition to breed E.coli top 10 strains (Invitrogen) for experimental purpose. The following mixture was used for LB preparation: 


\section{LB-media}

\begin{tabular}{|lc|}
\hline Reagent & Amount [g] \\
\hline Trypton & 10 \\
\hline Yeast extract & 5 \\
\hline $\mathrm{NaCl}$ & 5 \\
\hline ddH2O & Up to $1000 \mathrm{ml}$ \\
\hline
\end{tabular}

For preparation of solid LB-plates the amount of $14 \mathrm{~g}$ Agar (APPliChem, Darmstadt) was added before autoclaving. Then the liquid LB-media (temperature $\sim 50^{\circ} \mathrm{C}$ ) was supplemented with antibiotics (e.g. Ampicillin $100 \mu \mathrm{g} / \mathrm{ml}$; Kanamycin 20 $\mu \mathrm{g} / \mathrm{ml}$; Chloramphenicol $170 \mu \mathrm{g} / \mathrm{ml})$. Then the media was transferred to $92 \mathrm{~mm}$ petri dishes underneath the sterile bench where pertri dishes were cooled down and dried. LB media on petri dishes were stored at $4^{\circ} \mathrm{C}$ as well as in liquid form. For storing bacteria cultures for a long time, bacteria-LB-Media solution was mixed 1:1 with a 50\% glycerol solution in a $1.5 \mathrm{ml}$ Eppendorf tube and frozen at $-80^{\circ} \mathrm{C}$.

\subsubsection{Single Clone Separation}

Separation of single clones from a liquid bacteria solution is performed by dispensing cells with a bended Pasteur pipette, which was flame-treated, on the agar-plate. Then the agar-plate was incubated upside down in the incubator Incudrive (Schütt, Göttingen) overnight. Plates could be stored at $4^{\circ} \mathrm{C}$ for about one month if they had been sealed with parafilm (Brand; Wertheim).

\subsubsection{Single Clone Culturing}

This procedure was used to enlarge the amount of a single bacteria clone in a short time. For this purpose $5 \mathrm{ml}$ LB-media in a sterile $15 \mathrm{ml}$ tube (Greiner, Frickenhausen) for mini-prep [3.1.2.1] and $30 \mathrm{ml}$ LB-media in a sterile $500 \mathrm{ml}$ bottle for midi-prep [3.1.2.2] were supplemented with the referring antibiotic as selection marker. Then the media was supplemented with the inoculum and incubated while shaking on K2 260 basic-shaker for bacteria (IKA, Staufen) with $250 \mathrm{rpm}$ at $37^{\circ} \mathrm{C}$ over night. For shaking the samples were placed in sloping position to enlarge the surface of the media for better supply with oxygen and the lid was never closed. 


\subsubsection{Transformation by Electroporation}

Electroporation is an approach to import plasmid DNA into bacteria. The electric shock ( 2,500 volts/cm) applied to the bacteria causes small cracks in their membrane, through which the plasmid DNA is able to enter the cells. The bacteria multiply the amount of plasmids, which can be extracted for further experiments for example by Mini-Prep [3.1.2.1] or Midi-Prep [3.1.2.2]. To ensure that just bacteria, which contain the inserted plasmid, can propagate an antibiotic resistance was also included in the plasmid DNA as selection marker.

Mostly the plasmids for electroporation derived from a previous restriction digestion [3.1.8] and a ligation step [3.1.9]. In this case the salt concentration of these reaction mixtures had to be lowered by dilution [3.1.10]. In order to do this a $92 \mathrm{~mm}$ petri dish was filled with $\mathrm{ddH}_{2} \mathrm{O}$ and the mixture containing the plasmid of interest was transferred to a $0.025 \mu \mathrm{m}$ dialysation filter VSWP01300 (Millipore, Bedford, USA), which was placed on the surface of the water. After 30 minutes of dialysation the solution was carefully removed from the filter and translocated in a $1.5 \mathrm{ml}$ tube.

The bacteria cell line One Shot ${ }^{\circledR}$ TOP10 Electrocomp ${ }^{\mathrm{TM}}$ E. coli (Invitrogen, Karlsruhe), was used for electroporation and was kept on ice for this procedure. For the electroporation process the following reaction mixture was prepared.

\section{Electroporation mix}

\begin{tabular}{|lc|} 
Reagent & Volume [ $\mu \mathrm{l}]$ \\
\hline electrocompetent $E . c o l i$ & 10 \\
\hline Plasmid DNA & $1-3$ \\
\hline ddH2O & 40 \\
\hline
\end{tabular}

Then the sample was transferred to a $2 \mathrm{~mm}$ electroporation cuvette (PeqLab, Erlangen), which was cooled down on ice before. The electroporation was performed with Gene Pulser II (Biorad, Hercules USA) with the settings $2.5 \mathrm{kV}, 25 \mu \mathrm{F}$ and $200 \Omega$ for about 5 milliseconds. After this the electroporated cells were immediately diluted with $800 \mu \mathrm{l}$ warm LB media and incubated for one hour to recuperate. Subsequently different amounts (between 50 - $300 \mu \mathrm{l}$ ) of this suspension were dispensed on agar-plates [3.5.2] 
containing the specific antibiotic to obtain single colonies of bacteria including the plasmids of interest.

\subsection{Human Cell Culturing}

\subsubsection{Used Cell Lines and Culturing Conditions}

All operations with mammalian cells were conducted under the sterile bench. Cells were cultured with Penicillin and Streptomycin to prevent bacterial contamination. Cells were visually examined with a microscope (Axiovert 40 CFL, Zeiss, Jena) to elucidate the health status of the cells and to check for microbiological contamination. Cells were cultured in an incubator ( $\mathrm{CO}_{2}$-Inkubator $\mathrm{BBD} 6220$; Heraeus) at $37^{\circ} \mathrm{C}$ with $95 \%$ humidity and $5 \% \mathrm{CO}_{2}$. The culture media was warmed up at $37^{\circ} \mathrm{C}$ in a water bath (GFL 1083; Schütt, Göttingen) before applied to the cells. The splitting interval was dependent on the proliferation rate of the specific cell lines and on the specific requirement of the planned experiments. In general the cell number of suspension cells was kept between $3 \times 10^{5}$ and $8 \times 10^{5}$ cells per milliliter media and adherent cell lines were splitted not later than $80 \%$ of confluency. For splitting adherent cells they had to be washed with PBS buffer [2.3.1] and then detached from the surface of the culturing flask. For detaching the cells $5 \mathrm{ml}$ of trypsin (TrypLE ${ }^{\mathrm{TM}}$ Express, Gibco/Invitrogen) were applied on $75 \mathrm{~cm}^{2}$ flasks and $3 \mathrm{ml}$ on $25 \mathrm{~cm}^{2}$ flasks for about $3 \mathrm{~min}$ at $37^{\circ} \mathrm{C}$. Depending on the cell type the incubation time under trypsin could be increased. After cells were released from the surface, the trypsin was inactivated by diluting it with at least the same amount of media, which was supplemented with FCS (fetal calf serum). After this the required volume of cells was determined (e.g. by counting) and transferred to a $50 \mathrm{ml}$ Falcon tube. Then the cell suspension was centrifuged (Centrifuge 5810R; Eppendorf) for 3 minutes with $300 \mathrm{~g}$ at room temperature. After this the supernatant was discarded and the cells were resolved in the decided volume of media and transferred to a new culturing flask.

If media turned into yellow before $80 \%$ of confluency was reached, indicating that the $\mathrm{pH}$ value was declining, the old media was removed and cells were supplied with new media. Suspension cells were splitted by taking the intended amount of cells from the culturing flask, after cells had been mixed by pipetting to resolve cell clumps. Then the 
cell suspension was centrifuged (Centrifuge 5810R; Eppendorf) for 3 minutes with $300 \mathrm{~g}$ at room temperature and transferred to a new culturing flask. If media turned yellow, cells were transferred into a $50 \mathrm{ml}$ Falcon tube and centrifuged (Centrifuge 5810R; Eppendorf) for 3 minutes with $300 \mathrm{~g}$ at room temperature. The old media was removed and cells were resuspended with new media and transferred back into a culturing flask.

\subsubsection{Freezing Cell Lines}

Freezing cell lines in liquid nitrogen has the purpose to preserve them for later usage. Thus it was possible to keep cell lines in low passage numbers to prevent them from enriching mutation, which occurs when cells were cultured over a long period of time.

For freezing cell lines a special freezing solution was necessary, which consists of $90 \%$ pure FCS (fetal calf serum) with $10 \%$ of sterile DMSO (Dimethylsulfoxide, AppliChem, Darmstadt).

To freeze cell lines they had first to be cultured in big culture flasks $\left(75 \mathrm{~cm}^{2}\right)$ to an approximate confluency of $80 \%$. Then cells were harvested and transferred to a $50 \mathrm{ml}$ Falcon tube. Then they were centrifuged with $300 \mathrm{~g}$ for 5 minutes at room temperature (Heraeus Laborfuge 400R). Afterwards the supernatant was discarded and the pellet was resolved in $4 \mathrm{ml}$ of cool freezing solution. It was necessary to prepare all following steps on ice. Then the cells were transferred to $1.5 \mathrm{ml}$ Cryo tubes (Nunc, Thermo Scientific, Denmark) and placed in Mr. Frosty freezing box (Sigma-Aldrich, Deisenhofen), which allows the cells to be cooled down at speed of $1^{\circ} \mathrm{C} / \mathrm{min}$ in a $-80^{\circ} \mathrm{C}$-freezer and was pre-cooled in the refrigerator for this purpose. After 24 hours the cells were replaced in liquid nitrogen (about $-170^{\circ} \mathrm{C}$ ) for further storage.

\subsubsection{Defrosting Cell Lines}

Cell lines, which were stored in liquid nitrogen, had to be defrosted and relieved from the DMSO (Dimethylsulfoxid) in the freezing media to get them back in culture. In order to do this the aliquot-tube with frozen cells had to be warmed up by hand until the outer surface of the ice block started to melt. Then the tube was opened and the ice block was dumped in a falcon tube with $10 \mathrm{ml}$ DMEM media (1\% Penicillin/Streptomycin). The Falcon tube was shaken until the ice was melted. Then 
the tube was centrifuged (Heraeus Laborfuge 400R) with $300 \mathrm{~g}$ for $3 \mathrm{~min}$ at room temperature. After this the supernatant was discarded and the pellet resolved in $5 \mathrm{ml}$ of fresh culture media according to the culture recommendations of the specific cell line. In the end cells became transferred to a $25 \mathrm{~cm}^{2}$ culture flask and placed in the incubator ( $\mathrm{CO}_{2}$-Incubator BBD 6220 Heraeus, Hanau).

\subsubsection{Determination of Cell Numbers}

\subsubsection{Cell Counting with Neubauer-Cell Chamber}

In order to determine the number of cells in a suspension one possibility was to use the Neubauer-cell chamber. For this procedure a pre-defined amount of cell suspension was

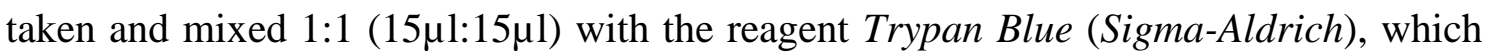
enters cells via cracks in cell membrane. By means of this staining procedure dead cells could be distinguished from living cells. Thereupon the suspension mix was transferred to the Neubauer-cell chamber, which was covered with a cover slip. Then living cells for each of the four squares were counted and the concentration of cells was calculated for the total amount of cells in the suspension.

Cell concentration $/ \mathrm{ml}=\frac{\text { Cell number (in all } 4 \text { squares) } * 2 * 1000}{4 * 0.1 \mu \mathrm{l} / \text { square }}$
$\frac{\text { Cell number (in all } 4 \text { squares) } * 5000}{1}$

First the mean of the cell number per square is determined. Each square has an area of $1 \mathrm{~mm}^{2}$ and a chamber height of $0.1 \mathrm{~mm}$, which results in a volume of $0.1 \mu \mathrm{l} / \mathrm{square}$. The dilution of this mixture was $1: 2$. To get the concentration per milliliter the factor 1000 has to be considered.

\subsubsection{Cell Counting with Propidium Iodide Staining by Flow Cytometry}

One possibility to count cell numbers and to determine the living cell concentration in a suspension is to perform a Propidium Iodide staining (BD Biosciences) and to select and count living cells by flow cytometry (Flow cytometer BD LSRII, Becton Dickinson, Franklin Lakes, USA). Propidium Iodide is a DNA intercalating substance, 
which only enters cells with demolished cell membranes. With this procedure it is feasible to mark dead and apoptotic cells. To determine the concentration of the living cell fraction in the suspension, counting beads (Invitrogen, Karlsruhe) are added in the Propidium Iodide staining solution additionally. The counting beads are homogeneous particles in a known concentration, which are fluorescent in a broad spectrum of wavelength. A pre-defined concentration of the counting beads is added. By flow cytometry the living cell population can be selected and counted as well as the added counting beads. Since it is known which amount of beads is included in the mixture, the counted living cell fraction can be related to the counted bead number. Thus the concentration of living cells in the original cell suspension can be calculated [3.6.4.2.1].

\section{Propidium Iodide staining solution mixture}

\begin{tabular}{|lc|}
\hline Reagent & Volume $[\mu \mathrm{l}]$ per sample \\
\hline RPMI-Media & 200 \\
\hline Propidium Iodide & 0.24 \\
\hline Counting Bead solution & 10 \\
\hline Total & 210 \\
\hline
\end{tabular}

\subsection{Determination of Cell Numbers in a Suspension with Counting Beads}

The determination of cell numbers by counting beads (CountBrightTM absolute counting Beads, Invitrogen, Karlsruhe) was performed according to manufacturers' recommendation.

The cell concentration was determined with the formula displayed next:

Counted cells $x$ total number of beads in solution $x$ dilution

Counted beads $x$ total volume of sample (cell supension+ bead volume)

This technique was used for determination of cell concentration exclusively for flow cytometry. For this purpose cells had been stained with Propidium Iodide (BD 
Bioscience) [3.6.4.2] or with Sytox Blue (Life Technologies Corporation) and Vybrant Ruby (Invitrogen) [3.10.2] before.

\subsubsection{Lymphoblastoid Cell Lines (LCLs)}

Lymphoblastoid Cell lines were once B-lymphocytes, which were immortalized with the Ebstein-Barr-Virus (EBV). Most of them (196) were commercially bought from the Coriell Cell Repositories (Table 18; http://ccr.coriell.org) and others (95) were self established (with ethic committee approval and patient informed consent) by the Department of Radiotherapy as well as by the Department of Immunology and Experimental Oncology, Göttingen University. These cell lines were cultured in RPMI Media (15\% FCS and 1\% Penicillin/Streptomycin). The LCLs were incubated in $75 \mathrm{~cm}^{2}$ culturing flasks, which were kept in the upright position and filled with $50 \mathrm{ml}$ of media at maximum. The cell concentration was kept between $3 \times 10^{5}-8 \times 10^{5}$ cells per ml. All LCLs from the Coriell Cell Repositories used for experiments are listed in Table 18.

\subsubsection{Pancreatic Cancer Cell Lines}

There had been eight pancreatic cancer cell lines (MiaPacaII, AsPcI, Su86.86, BxPC3, CapanI, CapanII, CFPac, PancI) for experiments, which were officially bought from ATCC, Wesel (www.atcc.org). These cell lines were cultured according to the recommendation of ATCC (http://www.lgcstandards-atcc.org)

\subsubsection{TREx ${ }^{\text {TM }}$ 293 Cell Line}

The TREx ${ }^{\mathrm{TM}} 293$ cells were cultured in DMEM media (10\% FCS and 1\% Penicillin/Streptomycin and $0.1 \%$ Zeocin). Cells were cultured and split as described in [3.6.1]. 


\subsection{Human Cells as Model System}

\subsubsection{Transient Transfection for Luciferase Reporter Gene Assay}

The transient transfection is an approach for transferring plasmid DNA in cells, which is not supposed to be inserted in the chromosomal DNA. Therefore the transfected DNA is only intracellularly stable for just a certain period of time. Because of this the method is suitable for short time overexpression analysis and was used for luciferase reporter gene assays in this context.

The cell line AsPC1, which was supposed to be transfected with a hENT1 promoter fragment, was adjusted to $3 \times 10^{4}$ cells/well in a 6 well plate $\left(=9,6 \mathrm{~cm}^{2}\right)$ and incubated for 24 hours at $37^{\circ} \mathrm{C}$ and $5 \% \mathrm{CO}_{2}$. The next day AsPC1 (about $70 \%$ confluency) was transiently transfected with FuGene 6 (Roche, Mannheim) according to the protocol below. After the Media and the FuGene 6 transfection reagent was mixed, it was incubated for 5 minutes at room temperature. Thereafter the pCMV-Renilla-luciferase plasmid $\left(1.7 \mathrm{ng} / \mathrm{cm}^{2}\right)$, which was used as an internal standard for transfection efficacy, was added. Then the mixture was aliquoted and the referring reporter gene with the promoter construct was supplemented in each sample and incubated for 15 minutes at room temperature. During the incubation time the media in the wells was removed and replaced by $2 \mathrm{ml}$ media with FCS (fetal calf serum) without antibiotics. Subsequently $100 \mu \mathrm{l}$ from the transfection mixture was added to the wells and incubated for 46 hours. After this the transfection media from the wells was discarded and replaced by Media with FCS (fetal calf serum) and antibiotics. To investigate the condition under gemcitabine, $5 \mu \mathrm{M}$ of the cytostatic was supplemented.

The cells used to be lysed after 48 hours of incubation for determination of luciferase activity [3.7.2]

\section{Transient Transfection mixture in 6 well plate $\left(=9.6 \mathrm{~cm}^{2}\right)$}

\begin{tabular}{|lc|}
\hline Reagent & Volume for one transfection \\
\hline Cell confluency & $\sim 70 \%-80 \%$ \\
\hline DMEM-Media & $100 \mu \mathrm{l}$ \\
\hline Fugene* & $3 \mu \mathrm{l}$ \\
\hline Plasmid-DNA & $1 \mathrm{\mu g}$ \\
\hline Renilla-Vector & $15 \mathrm{ng}$ \\
\hline Transfection volume/well & $2 \mathrm{ml}$ \\
\hline
\end{tabular}

* Transfection reagent:DNA $(\mu \mathrm{l}: \mu \mathrm{g})=3: 1$ 


\subsubsection{Luciferase Reporter Gene Assay}

The Dual-Luciferase ${ }^{\circledR R e p o r t e r}$ Assay System (Promega, Mannheim) was used to investigate expression regulating effects of DNA sequences and applied according to the recommendation of manufactures protocol.

With this approach a potential ENT1-v4 and -v5 promoter fragment, which expands from the transcription start site of the ENT-v4 and $-v 5$ to 2122 bp upstream, was cloned ahead of the Firefly-Luciferase gene, which was contained in the luciferase vector pXP2 [3.8.2]. This construct was transiently transfected [3.7.1] in the pancreatic tumor cell line AsPCI [3.6.6].

After transient transfection the cells were incubated for 48 hours. Then media was removed and cells were washed once with about $1 \mathrm{ml}$ PBS. In the following step the cells were lysed with $300 \mu \mathrm{l}$ of $1 \mathrm{x}$ passive lysis buffer in the 6-well plate for 10 minutes. After this the passive lysis buffer with the lysed cells were transferred to a $1.5 \mathrm{ml}$ Eppendorf tube, which was frozen in liquid nitrogen and defrosted with a thermomixer at $37^{\circ} \mathrm{C}$ for three times. After this procedure the cell debris was removed by centrifugation (Biofuge fresco) for 5 minutes with $13,000 \mathrm{rpm}$ at $4^{\circ} \mathrm{C}$. Then the supernatant, which contained the cellular proteins, was transferred into a new $1.5 \mathrm{ml}$ Eppendorf tube and kept on ice. For later analysis of the samples they were stored at $-80^{\circ} \mathrm{C}$. For fluorescent measurement $16 \mu \mathrm{l}$ of this solution were transferred into a well of a white 96-well plate (Greiner, Frickenhausen). The determination of luciferase activity was conducted with the GloMax-96-Plate-Luminometer (Turner BioSystems, Sunnyvale, USA). During measurement procedure the amount of fluorescence, which correlates with the amount of the expressed Firefly-Luciferase proteins and the reference Renilla-Luciferase proteins, was detected in the sample. The fluorescent substrates were LAR II (Luciferase Assay Reagent II) for Firefly-luciferase proteins and Stop \& Glo for Renilla-luciferase proteins. LAR II -Luciferase Assay Reagent II was not included in the luciferase kit and had to be prepared separately by diluting LAR IILuciferase Assay Substrate with LAR II-Luciferase Assay Buffer II. For evaluation of luciferase data the relation of Firefly-Luciferase signal to Renilla-Luciferase signal was determined. 


\subsubsection{Stable Transfection with Flp-In ${ }^{T M}$ System}

The stable transfection is an approach to integrate target DNA in the chromosomal DNA of the host cell. In order to do this the Flp-In ${ }^{T M}$ System (Invitrogen) was used. The difference between stable and transient transfection is basically that the DNA in a stable transfection stays everlasting in the host cells, which gives the possibility of performing experiments over a long period of time.

The host cells which were used in the Flp-In ${ }^{T M}$ System (Invitrogen) were TREx 293 which derived from a HEK cell strain. In this cell line a Flp-Recombination Target (FRT) was integrated already by the plasmid pFRT/lacZeo. This side was the location for further integration steps by the Flp recombinase. The simultaneously inserted Zeocin resistance functioned as a selection marker for recombinant cell lines with FRTsites included. The gene which was supposed to be integrated had to be inserted in the vector pcDNA5 first, which also contained a FRT site and was isolated by Midi Prep extraction method [3.1.2.2] out of bacteria before. Additionally the plasmid had a Hygromicine B resistance to select positive integrated cells after transfection process. A second plasmid pOG44 was necessary to perform the transfection. This plasmid was cotransfected and expressed the Flp recombinase. During the transfection process the Flp recombinase translocated the gene of interest (GOI) and the Hygromicine B resistance into the FRT side of the host cell. The details of the explained procedure are depicted in Figure 4.

For the stable transfection $9 \times 10^{5}-1 \times 10^{6}$ cells were placed in each well of a 6 -well plate and incubated over night. The next day cells were supposed to be confluent for $\sim 80 \%$. For transfection process a master mix had to be prepared. For each transfection process $12 \mu$ l Fugene 6 transfection reagent (Roche, Mannheim) were supplemented to $100 \mu$ of DMEM Media in a master mix and incubated for 5 minutes at room temperature. After this $112 \mu \mathrm{l}$ of this mix were aliquoted to $1.5 \mathrm{ml}$ tubes and $3.6 \mu \mathrm{g}$ of pOG44 plasmid and 0.4 $\mu$ g of pcDNA5 plasmid with the gene of interest (relation of pOG44 and pcDNA5 9:1) were added and incubated for further 15 minutes at room temperature. During the incubation the cells in the 6-well plate were washed twice with DMEM (10\% FCS) without antibiotics. Then $1.9 \mu$ of the same media composition was supplemented to each well. After the 15 minutes of incubation had passed, the transfection-master mix for each sample was added to the corresponding well and placed in the incubator for 48 hours. 
After this time the media from the 6-well plates were discarded and the cells were transferred to $92 \mathrm{~mm}$ petri dishes (Falcon, Schütt, Göttingen) in $9 \mathrm{ml}$ of DMEM (10\%FCS and 1\% Penicillin/Streptomycin). After 24 hours the media was supplemented with Hygromicine B as screening antibiotic for a final concentration of $300 \mu \mathrm{g} / \mathrm{ml}$. During the next ten days most of the cells which were not transfected died, but the transfected cells were generating colonies. These colonies got picked and transferred to wells in a 12-well plate at first. During the cultivating process cells got translocated in 6-well Plates first, then into small culture flasks $\left(25 \mathrm{~cm}^{2}\right)$ and after this into big culture flasks $\left(75 \mathrm{~cm}^{2}\right)$. To increase the cell growth of selected cell clones the Hygromycin B concentration was reduced to $100 \mu \mathrm{g} / \mathrm{ml}$ in further cultivation steps. During passaging of the cells DNA and RNA were isolated to confirm the positive integration [3.7.3.1] and the correct expression of the gene of interest (ENT1) [3.2.4]. In the case mentioned above, the qPCR primers for detection of all ENT1 transcript variants were used (Table 3).

\section{Master-mix for stable transfection:}

\begin{tabular}{|c|c|c|c|}
\hline Reagents & Volume per sample & \multirow{5}{*}{$\begin{array}{l}5 \text { minutes } \\
\text { incubation first }\end{array}$} & \\
\hline DMEM Media & $100 \mu \mathrm{l}$ & & \multirow{4}{*}{$\begin{array}{l}\text { Then } 15 \text { minutes } \\
\text { incubation all } \\
\text { together }\end{array}$} \\
\hline Fugene 6 transfection reagent & $12 \mu \mathrm{l}$ & & \\
\hline pOG44 & $3.6 \mu g$ & & \\
\hline pcDNA5 with GOI & $0.4 \mu g$ & & \\
\hline
\end{tabular}




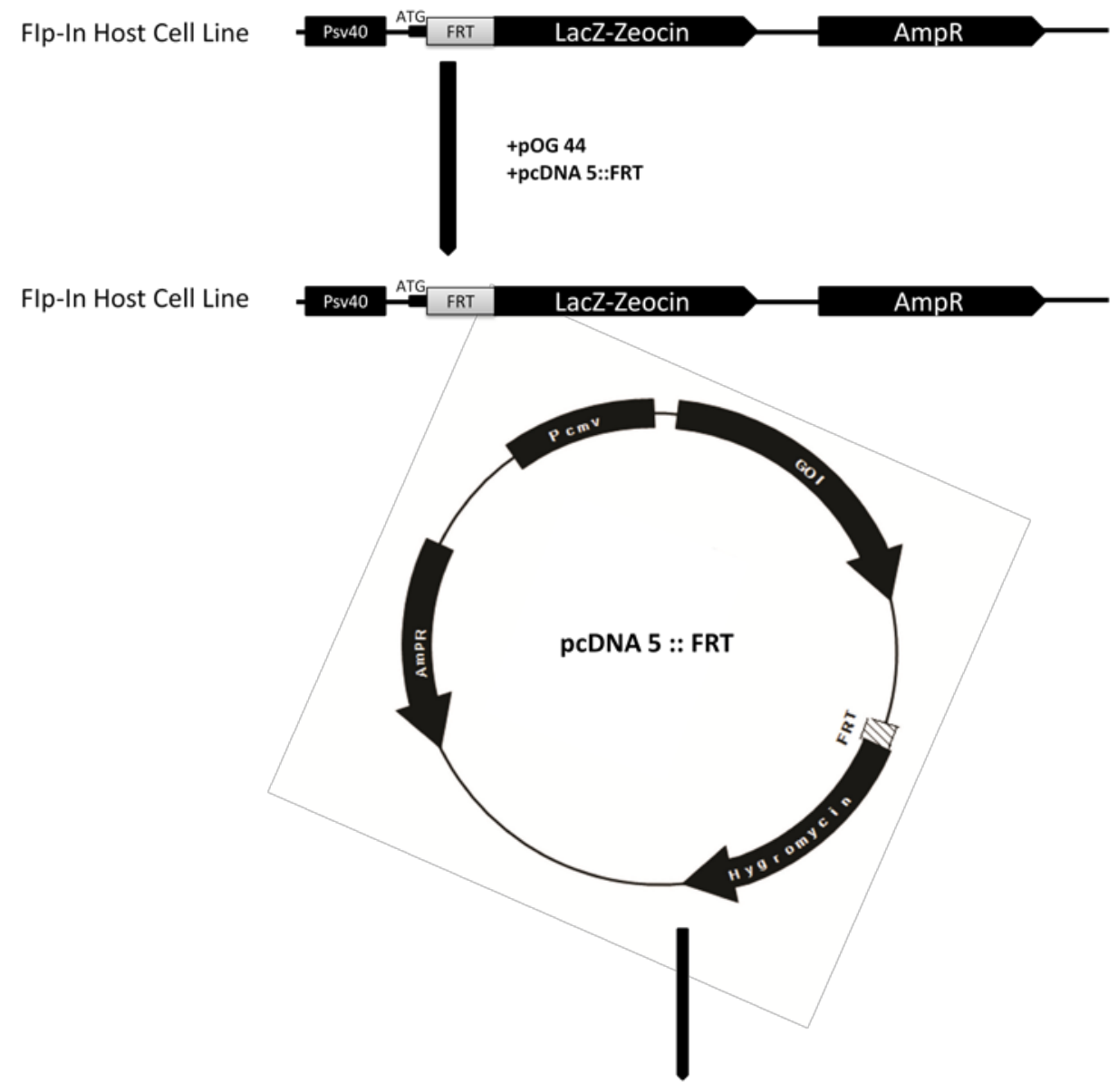

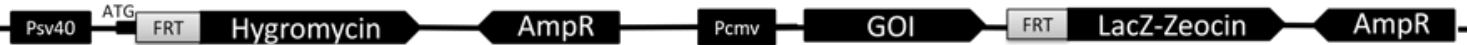

Figure 4: Chromosomal integration of the gene of interest by stable transfection with Flp-In System

\subsubsection{Confirmatory PCR to Validate Chromosomal Integration of pcDNA5 Constructs}

After a stable transfection with the Flp-In ${ }^{T M}$ System (Invitrogen), the chromosomal integration of the gene of interest as well as the Hygromycin B resistance, which acts as a selection marker for integration, has to be further verified. This verification is conducted by two PCR reactions.

In order to make the confirmatory PCR to check the chromosomal integration of hENT1 with the two alleles of rs45573936, chromosomal DNA had to be extracted first [3.1.1]. The first PCR tested the integration of the Hygromycin B in the chromosomal DNA of the stable transfected TREx HEK293. The forward primer "PSV40" (Table 6) annealed 
in the SV40 promoter of the pFRT/lacZeo site, which was the target of chromosomal integration and a component of the Flp-In ${ }^{T M}$ System (Invitrogen) in the TREx HEK293. The reverse primer "Hyg” (Table 6) anneals in the Hygromycin B resistance gene, which was originally located in the pcDNA5 vector. Only if the Hygromycin B gene was really integrated in the genome, this PCR should generate a PCR-product.

Mixture for confirmatory PCR of Hygromycin B integration

\begin{tabular}{|c|c|}
\hline Reagent & Volume per sample \\
\hline $10 \mathrm{x}$ buffer & $2.2 \mu \mathrm{l}$ \\
\hline dNTPs (2 mM) & $2.2 \mu \mathrm{l}$ \\
\hline $\mathrm{MgSO}_{4}(25 \mathrm{mM})$ & $0.9 \mu \mathrm{l}$ \\
\hline 5x Q-Solution & $4.4 \mu \mathrm{I}$ \\
\hline Forward-Primer $P_{\mathrm{SV} 40}(10 \mathrm{nM})$ & $0.5 \mu \mathrm{l}$ \\
\hline Reverse-Primer Hyg (10 nM) & $0.5 \mu \mathrm{l}$ \\
\hline Template DNA (300 ng/pl) & $2 \mu \mathrm{l}$ \\
\hline 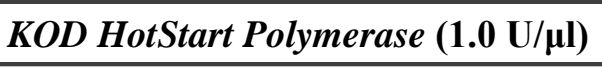 & $0.5 \mu \mathrm{l}$ \\
\hline $\mathrm{ddH}_{2} \mathrm{O}$ & $8.8 \mu \mathrm{l}$ \\
\hline Total volume & $22 \mu \mathrm{l}$ \\
\hline
\end{tabular}

\section{PCR-Conditions for confirmatory PCR of Hygromycin B integration}

\begin{tabular}{|lcc|}
\hline PCR-Condition & Duration & Temperature \\
\hline Initial Denaturation & $2 \mathrm{~min}$ & $95^{\circ} \mathrm{C}$ \\
\hline Denaturation & $30 \mathrm{sec}$ & $95^{\circ} \mathrm{C}$ \\
\hline Annealing & $30 \mathrm{sec}$ & $64^{\circ} \mathrm{C}$ \\
\hline Elongation & $1 \mathrm{~min}$ & $72^{\circ} \mathrm{C}$ \\
\hline Terminal elongation & $10 \mathrm{~min}$ & $72^{\circ} \mathrm{C}$ \\
\hline & for ever & $\mathbf{8}^{\circ} \mathrm{C}$ \\
\hline
\end{tabular}

With the second confirmatory PCR the gene of interest, which was inserted in the genome, was amplified with the primers PCMV and LacZ (Table 6) and was performed with the ExpandLong Polymerase Mix. These primers annealed to the flanking region of the gene of interest. 
Mixture for confirmatory PCR of gene of interest

\begin{tabular}{|lc|}
\hline Reagent & Volume per sample \\
\hline $10 \times$ ExpandLong Buffer-1 & $2.8 \mu \mathrm{l}$ \\
\hline dNTPs $(2 \mathrm{mM})$ & $4.5 \mu \mathrm{l}$ \\
\hline MgSO $_{4}(25 \mathrm{mM})$ & $1 \mu \mathrm{l}$ \\
\hline $5 x Q$-Solution & $5.6 \mu \mathrm{l}$ \\
\hline Forward-Primer LacZ $(10 \mathrm{nM})$ & $0.5 \mu \mathrm{l}$ \\
\hline Reverse-Primer PMV $_{\mathrm{CM}}(10 \mathrm{nM})$ & $0.5 \mu \mathrm{l}$ \\
\hline Template DNA & $3 \mu \mathrm{l}$ \\
\hline ExpandLong Polymerase Mix & $0.3 \mu \mathrm{l}$ \\
\hline ddH & $9.8 \mu \mathrm{l}$ \\
\hline Total volume & $28 \mu \mathrm{l}$ \\
\hline
\end{tabular}

\section{PCR conditions for confirmatory PCR of gene of interest}

\begin{tabular}{|lcc|}
\hline PCR-Condition & Duration & Temperature \\
\hline Initial Denaturation & 2 min & $94^{\circ} \mathrm{C}$ \\
\hline Denaturation & $30 \mathrm{sec}$ & $96^{\circ} \mathrm{C}$ \\
\hline Annealing / Elongation & $4 \mathrm{~min}$ & $\mathbf{6 8}^{\circ} \mathrm{C}$ \\
\hline Final elongation & $10 \mathrm{~min}$ & $\mathbf{6 8}^{\circ} \mathrm{C}$ \\
\hline & for ever & $8^{\circ} \mathrm{C}$ \\
\hline
\end{tabular}

Table 6: List of primers for validation of chromosomal integration of pcDNA5 constructs

\begin{tabular}{|c|c|}
\hline Primer & Sequence \\
\hline $\mathbf{P}_{\mathrm{SV} 40}-\mathbf{f}$ & 5'AGCTGTGGAATGTGTGTCAGTTAGG ${ }^{3 '}$ \\
\hline Hyg-r & 5'ACGCCСТCСТАCATCGAAGCTGAAA ${ }^{3^{\prime}}$ \\
\hline $\mathbf{P}_{\text {CMV }}$ & ${ }^{5^{\prime} \text { CCATGGTGATGCGGTTTTGGCAGTA }}{ }^{3^{\prime}}$ \\
\hline LacZ & 5'CCTTCCTGTAGCCAGCTTTCATCAA ${ }^{3^{\prime}}$ \\
\hline
\end{tabular}

\subsection{Sequential Steps for Cloning of Allele Specific Constructs}

Here, the order of the single procedures to achieve the final constructs is described. The procedures themselves are each referred to the detailed description above. 


\subsubsection{ENT1 Ile216Thr}

For the creation of allele specific $h E N T 1$ rs45573936 constructs the $h E N T 1$ gene (DNA sequence in Appendix) was purchased from SourceBioscience (Nottingham UK ; Clone 3051441, IRAUp969A097D; http://www.lifesciences.sourcebioscience.com /genomecube?kw=3051441) When purchased, the $h E N T 1$ gene had been inserted in pOTB7 vector with the wild type T-allele for rs45573936. In this vector the sitedirected-mutagenesis [3.1.5] with mutagenesis primers in Table 1 was conducted to get hENT1 fragments with rs45573936 variant C allele. The correct sequences were checked by sequencing method [3.1.11] with the ENT1 sequencing primers in Table 2. Then the hENT1 gene was amplified by a PCR reaction with the primers in Table 7. Restrictions sites for the enzymes EcoRV and XhoI were included in the PCR primers for further cloning steps. Next the vector $p C D N A 5$, which is used as vector for stable transfection, was digested with the enzymes EcoRV and XhoI [3.1.8.2] as well as the amplified ENT1 fragments. After this the hENT1 types with rs45573936 wild type T allele and variant $\mathrm{C}$ allele were ligated [3.1.9] with pCDNA5 and then electroporated [3.5.4] in e.coli bacteria. Subsequently clones from e.coli were picked and the pCDNA5::hENT1-rs45573936-WT /-Var constructs were isolated by midi prep [3.1.2.2]. In the end the constructs were stably transfected in HEK293 cell lines [3.7.3]. To proof the correct integration of the constructs in the genome, test PCRs for the integrated Hygromycin resistance gene as well as for the ENT1 target gene were conducted [3.7.3.1]. In addition enhanced expression in transfected cells in comparison to empty vector transfected cells were checked by qPCR [3.2.4] with qPCR primers detecting all transcript variants of ENT1 (Table 3). Thereafter the cells with the integrated hENT1-rs45573936-WT /-Var constructs could be used for further allele specific investigations (e.g. measurements of ENT1 transport activity [3.9]).

Table 7: Primer for $h E N T 1$ amplification and insertion of $E c o R V$ and $X h o I$ restriction sites

\begin{tabular}{|lc|}
\hline Primer & Sequence \\
\hline ENT1-EcoRV-for & ${ }^{5}$ CGAGAACGATATCACCATGACAACCAGTCACC ${ }^{3 \prime}$ \\
\hline ENT1-XhoI-rev & ${ }^{5}$ GCAGTCCTCGAGTCCATCCTTTGTCACACAA ${ }^{3 '}$ \\
\hline
\end{tabular}




\subsection{2 hENT1-v4/-v5 Promoter Polymorphism rs507964}

For investigation of promoter modulating effects by the hENT1 rs507964 polymorphism a promoter fragment with the range of $-1945 /+141$ ahead of the transcription start site of the hENT1 (according to (FUKUCHI et al. 2010)) was amplified by PCR from genomic DNA with the primers provided in Table 8. These primers contain restriction sites for the enzymes XmaI and HindIII. The amplified hENT1 promoter fragment (DNA sequence in Appendix) derived from the LCL GM06984, which is heterogeneous for the SNP rs507964. In the aforementioned promoter fragment the SNP rs1057985, which is in perfect linkage disequilibrium with rs507964, was included in the sequence as well. After the PCR reaction the amplified ENT1 promoter fragment was sequenced [3.1.11] to check for mutations. In order to use the PCR product for sequencing the PCR mixture had to be enzymatically purified [3.1.7.3] to remove the old PCR primers. Next the amplified hENT1-promoter constructs as well as the luciferase vector pXP2 were digested [3.1.8.2] with the restriction enzymes XmaI and HindIII. Then the insert and the vector were ligated [3.1.9], dialyzed [3.1.10] and electroporated [3.5.4] into e.coli bacteria. Thereupon clones of e.coli were picked and pXP2::hENT1-rs507964-promoter constructs were isolated by mini-prep method [3.1.2.1]. The correct sequence of the promoter fragment was assessed by analytical digestions [3.1.8.1] and sequencing [3.1.11] with the sequencing primers depicted in Table 9. Subsequently the validated sequences were isolated from bacteria by midi-prep method [3.1.2.2] for transient transfection [3.7.1] in the pancreatic tumor cell line AsPCI for further luciferase reporter gene assay [3.7.2].

For further analysis of promoter modulating effects by the ENT1 SNP rs507964 the annealed EMSA-primers (Table 4) with the wild type allele as well as with the variant allele of rs507964 were cloned in the luciferase vector pT81 in the same manner. This time the vector was digested with the enzyme BamHI. The annealed EMSA primers already had the correct sticky ends, which were produced by BamHI digestion, after annealing. The correct integration of the inserts was confirmed by sequencing [3.1.11], with the sequencing primer ENT1-Prom-Seq1 (Table 9), which starts the sequencing process already in the vector region. 
Table 8: Primer pair for hENT1 promoter amplification

\begin{tabular}{|lc|}
\hline Primer & Sequence \\
\hline ENT1_Prom_forward & ${ }^{5}$ AGAGTGGAAGCTTGCCTGGAGAGGAGGGAGAGGTTA ${ }^{3}$ \\
\hline ENT1_Prom_reverse & ${ }^{5}$ CCCCGCCCCGGGCACCTGCTGAGACTTTGGAGTGAGCATC ${ }^{3}$ \\
\hline
\end{tabular}

Table 9: Sequencing ENT1-Promoter-Primer

\begin{tabular}{|lc|}
\hline Primer & \multicolumn{1}{c|}{ Sequence } \\
\hline ENT1-Prom-Seq1 & ${ }^{5}$ GAACGGACATTTCGAAGTAT $^{3^{\prime}}$ \\
\hline ENT1-Prom-Seq2_rev & ${ }^{5}$ GCCGGGCGGAAGAGAG $^{3^{\prime}}$ \\
\hline ENT1-Prom-Seq3_rev & ${ }^{5}$ GGGGTGGGGCGGATAG $^{{ }^{\prime}}$ \\
\hline ENT1-Prom-Seq4_rev & ${ }^{5}$ CACCACGCCCGGCTAATT $^{3^{\prime}}$ \\
\hline ENT1_Prom-Seq5 & ${ }^{5}$ CGCCCTGCCCAGACTG $^{3^{\prime}}$ \\
\hline ENT1_Prom-Seq6_rev & ${ }^{5}$ CCCACCCCCACCAACTG $^{3^{\prime}}$ \\
\hline ENT1_Prom-Seq7_rev & ${ }^{5}$ GGGGTGGGTGGGTGTTAG $^{3^{\prime}}$ \\
\hline
\end{tabular}

\subsection{Measurements of ENT1 (SLC29A1) Transport Activity}

\subsection{1 ${ }^{3} \mathrm{H}$-Gemcitabine Uptake Assay}

By this approach the uptake of the radioactive labeled cytostatic agent gemcitabine (American Radiolabeled Chemicals, Inc, St. Louis USA) was measured in ENT1 rs45573936 stable transfected HEK TREx cell lines with the scintillator counter (Scintillation instrument LS1801, Beckman) to investigate functional effects of this SNP on the transport activity. The ENT1 rs45573936 cell line constructs, which were generated by stable transfection [3.7.3; 3.8.1], contains additionally to their endogenous ENT1 transporter a copy of ENT1 integrated in the genome for either the wild type allele of this SNP or the variant allele.

The transport measurements were performed in 12-well plates, which had to be covered with Poly-D-Lysine first (Sigma-Aldrich, Deisenhofen). In order to do this the plates 
were filled with $0.5 \mathrm{ml}$ of poly-D-lysine and incubated for 15 minutes at $37^{\circ} \mathrm{C}$. After the incubation the poly-D-Lysine became removed and plates got dried for 20 minutes at room temperature. For this assay clones with the pcDNA5::ENT1-Thr216 (variant allele) and pcDNA5::ENT1-Ile216 (wild type) were used as well as a transfected clone with the pcDNA empty vector. Before the transport measurements could be performed the transfected HEK TREx cells in a big culture flask $\left(75 \mathrm{~cm}^{2}\right)$ had to be trypsinized with $3.5 \mathrm{ml}$ trypsine (TrypLETM Express, Gibco/Invitrogen) for 3-5 minutes to get a single cell suspension. After trypsinization the cells became diluted with $10 \mathrm{ml}$ of warm DMEM (10\%FCS, 1\% Penicillin/Streptomycin) to inhibit the enzymatic reaction of the digestion enzyme. The cell concentration in this suspension was determined by Neubauer cell chamber (Schütt, Göttingen) [3.6.4.1]. The measurement was performed in triplicates of each condition. In every well of interest a total amount of $0.8 \times 10^{6}$ cells should be placed. The required cell number for this assay was calculated and the volume with the amount of cells were taken from the trypsinized cells and centrifuged with $300 \mathrm{~g}$ for 3 minutes at room temperature. The supernatant was removed and substituted with new DMEM (10\%FCS, 1\% Penicillin/Streptomycin) for a final concentration of $0.4 \times 10^{6}$ cells per $\mathrm{ml}$. Then $2 \mathrm{ml}$ of this suspension was distributed to the wells respectively and incubated at $37^{\circ} \mathrm{C}$ and $5 \% \mathrm{CO}_{2}$ for 48 hours.

The transport measurements were performed with $10 \mu \mathrm{M}$ gemcitabine, which were composed of $50 \mathrm{nM}{ }^{3} \mathrm{H}$-gemcitabine (American Radiolabeled Chemicals, Inc, St. Louis USA) and $9.95 \mu \mathrm{M}$ of non-radioactive gemcitabine (Sigma), for several incubation times (10 seconds to 10 minutes) of. Each sample was prepared in double and each experiment was repeated to a separate time to minimize measurement errors. Additionally transport measurements were conducted in presence of $50 \mu \mathrm{M}$ NBMPR (also termed NBTI) (S-(4-Nitrobenzyl)-6-thioinosine), which is a specific inhibitor of equilibrative nucleoside transporter1 (ENT1), as a negative control means to demonstrate that transport is actually mediated by ENT1 transporter. One hour before measurement the media for all conditions was removed and replaced by $2 \mathrm{ml}$ of fresh media DMEM (10\% FCS, 1\% Penicillin/Streptomycin). Additionally NBMPR was added to the referring transport conditions serving as negative control with the final of concentration of $50 \mu \mathrm{M}$.

For transport measurement the media was removed and replaced by the HBSS buffer (Gibco/Invitrogen) and incubated for 30 seconds. Then the fluid was removed and $400 \mu \mathrm{l}$ of transport solution, which was already supplemented with gemcitabine, was 
added for intended time frames. After the incubation for transport the reaction was stopped immediately by diluting the wells with ice cold stop solution (HBSS buffer including $50 \mu \mathrm{M}$ of NBMPR (S-(4-Nitrobenzyl)-6-thioinosine)). This dilution was incubated for 1 minute and was then removed quickly. Next cells were washed twice with $2 \mathrm{ml}$ of ice cold HBSS buffer containing $50 \mu \mathrm{M}$ NBMPR (S-(4-Nitrobenzyl)-6thioinosine) each time for 30 seconds. Subsequently the cells were lysed with $0.5 \mathrm{ml}$ $0.1 \mathrm{M} \mathrm{NaOH}$. The amount of $100 \mu \mathrm{l}$ was retained for protein quantification [3.3.1] afterwards, which was used to normalize the data from transport experiment with the number of used cells. Finally $400 \mu \mathrm{l}$ of lysed cells were mixed with $9 \mathrm{ml}$ of scintillator (Aquasafe 500 Plus, Zinsser Analytic) and the amount of radioactivity was measured in the scintillator counter (Scintillation instrument LS1801, Beckman).

Because transport of the ENT1 was so fast that even high amounts of radioactivity were transported within 10 to 15 seconds in following transport experiments NBMPR (S-(4Nitrobenzyl)-6-thioinosine) was added to the cells in a concentration of $0.1 \mu \mathrm{M}$ in all steps before stopping the transport including the pre-incubation, to slow down the transport. By delaying transport it was intended to observe differences in the transport uptake of HEK 293 cells with genomic integrated ENT1-rs45573936 wild type and ENT1 rs45573936 variant clones.

\section{Transport Solution}

Reagent

HBSS

NBMPR/NBTI (optional)

Gemcitabine (Sigma)

${ }^{3} \mathbf{H}$-Gemcitabine (American Radiolabeled

Chemicals Inc, St. Louis USA) per 1 Well (in 12 Well Plate)

$0.4 \mu \mathrm{l}$

$0.1 \mu \mathrm{M}$

$9.5 \mu \mathrm{M}$

$0.5 \mu \mathrm{M}$

\section{Stop Solution}

\section{Reagent}

HBSS

NBMPR

\section{per 1 Well}

$6 \mathrm{ml}$

$50 \mu M$ 


\subsection{Cellular Sensitivity toward Gemcitabine Toxicity}

A genome-wide screen using lymphoblastoid cell lines (LCLs) as model system should reveal new loci for gemcitabine sensitivity. When I started my thesis 107 fully resequenced LCLs obtained from the Coriell Institute [3.6.5] and 95 in-house-generated LCLs (with ethic committee approval and patient informed consent) were available and functionally assessed by me. Later, 89 additional fully sequenced LCLs were purchased (Coriell Institute), which were measured by another student in our lab, Mrs. Claudia Lüske. The 196 fully sequenced LCLs served as the training set, and the 95 in-house lines as the test set. For all these LCLs, dose-response curves for eight gemcitabine concentrations varying between 0 and $76 \mathrm{nM}$ (Table 10) in relation to effects on vitality and proliferation were ascertained. These concentration intervals were defined based on literature data (Li et al. 2009) and upon own method development. In addition, RNA and DNA were harvested during the experimental procedure for assessment of gene expression and genetic polymorphisms, respectively. A detailed protocol was elaborated during my thesis which is described in the subsequent chapters.

About 10 to 15 LCL cell lines were analyzed per week. At first the LCLs had to be cultured in big culture flasks $\left(75 \mathrm{~cm}^{2}\right)$ to have enough cells for further preparation steps. Since LCLs were suspension cells, the flasks in which they were cultured stood upright and were filled with media up to $50 \mathrm{ml}$ of RPMI (15\% FCS and 1\% Penicillin/Streptomycin). LCLs were preferably cultured in a concentration between $3 \times 10^{6}$ and $6 \times 10^{6}$ cells/ml to keep them in the logarithmic growth phase.

The incubation time under gemcitabine was 72 hours for determination of vitality and proliferation and 24 hours for RNA and DNA isolation. An untreated LCL control sample for vitality and proliferation measurement was incubated for 48 hours to determine the proliferation index by comparing the collected data with the control sample of the 72 hour incubation.

On the first day of the procedure the cells had to be counted by flow cytometry [3.6.4.2.1] and stained with the appropriate cell number by CFSE (eBioscience, Frankfurt) [3.10.1] for further proliferation analysis. After staining the cells were incubated for 24 hours in normal culture media (RPMI with 15\% FCS and 1\% Penicillin/Streptomycin). CFSE molecules, which were not internally activated and bound could diffuse out of the cells. After 24 hours cells were counted [3.6.4.2.1] again to adjust them to the right cell concentration for the gemcitabine incubation. Each cell 
line was plated at the concentration of $1 \times 10^{6}$ cells/well on a 24-well plate (Greiner) with $1 \mathrm{ml}$ of culture media per well. Seven different gemcitabine concentrations additional to the untreated control condition of the cells on each of the 24-well plates were assessed (Table 10). All the conditions were set up twice to minimize measuring errors.

Table 10: Gemcitabine concentrations applied for cytotoxicity study

\begin{tabular}{|cc|}
\hline Concentration number & Gemcitabine concentration [nM] \\
\hline Control & 0 \\
\hline 1 & 1.9 \\
\hline 2 & 3.8 \\
\hline 3 & 6.4 \\
\hline 4 & 10.8 \\
\hline 5 & 18.1 \\
\hline 6 & 30.4 \\
\hline 7 & 76 \\
\hline
\end{tabular}

Cells for DNA and RNA extraction [3.1.1; 3.2.1] were cultured on 6-well plates. For this purpose the gemcitabine concentration number 2 and 6 were chosen for incubation conditions additionally to an untreated control condition. For each of the incubation conditions respectively three wells of the 6-well plate were taken, which were combined for further extraction steps in the end. By plating the cells on the referring 24- and 6well plates a time schedule was applied by which each cell line was supplemented in successive time intervals with the referring concentration of gemcitabine. Thus it was possible to keep the conditions and incubation time (24 hours for DNA and RNA; 72 hours for gemcitabine incubation) under consideration of the preparation and measuring steps for each cell line similar in the end.

After 24 hours the three wells of each condition were pooled and then transferred in two $5 \mathrm{ml}$ FACS tubes (BD Falcon) to the same amount. One of the samples was prepared for RNA extraction [3.2.1], the other one for DNA extraction [3.1.1].

After exact 72 hours each cell line was harvested for further measuring and evaluation steps. Therefore each well of the 24-well plate was mixed by pipetting to separate cell aggregations and then different amounts of each condition (Table 11) was transferred to 
$5 \mathrm{ml}$ FACS tubes (BD Falcon). The reason for taking different volumes of each condition was to level approximately the number of cells in each sample, since cells had different growth under the particular cytostatic concentration. It was crucial to have similar amounts of cells for uniform staining steps in later procedures.

Table 11: Volumes of gemcitabine incubated samples for flow cytometry measurements

\begin{tabular}{|cc|}
\hline $\begin{array}{c}\text { Concentration Number } \\
\text { Control }\end{array}$ & Used Suspension Volume [ $\boldsymbol{\mu l}]$ \\
\hline 1 & 200 \\
\hline 2 & 200 \\
\hline 3 & 300 \\
\hline 4 & 300 \\
\hline 5 & 400 \\
\hline 6 & 600 \\
\hline 7 & 800 \\
\hline
\end{tabular}

The cells in the $5 \mathrm{ml}$ FACS tubes were washed with PBS and centrifuged with $250 \mathrm{~g}$ for 5 minutes at room temperature. Afterwards the entire supernatant was removed and the staining solution for vitality determination [3.10.2] was added then the pellet was resolved by vortexing. The mixture was incubated for 15 minutes in the incubator. Afterwards the samples were measured by the flow cytometer BD LSRII (Becton Dickinson) [3.10.3] and evaluated by the Software Cyflogic 1.2.1 (http://www.cyflogic.com/), which is a freeware version for scientific research.

\subsubsection{Staining of Lymphoblastoid Cell Lines (LCLs) with CFSE}

The CFSE stain (eBioscience, Frankfurt), which stands for carboxyfluorescein diacetate succinimidyl ester, is an internal marker for monitoring cell division (LYONS and PARISH 1994). After CFSE has entered the cell via passive diffusion it becomes activated by endogenous esterases which cleave the acetate groups. After this process the resulting fluorescent carboxyfluorescein succinimidyl esters are fluorescent (excitation: $492 \mathrm{~nm}$; emission: $517 \mathrm{~nm}$ ) and form conjugates with intracellular amines 
and up to this point is irreversibly bound inside the cell. CFSE, which is not activated or intracellularly bound, escapes the cell by passive diffusion during incubation. During cell division the intracellular amount of the stain becomes divided between the mother and the resulting daughter cell. By this the intensity of the stain in both cells after division is half of the intensity to the non-divided cell. In that way it was possible in my experiments to trace back the numbers of cell division over a time of 72 hours and to elucidate the effect of different concentrations of the cytostatic gemcitabine on proliferation.

Before the staining process could be conducted, the cell concentration had to be determined [3.10.2] [3.6.4.2.1]. Then the volume for the total amount of $15 \times 10^{6}$ cells had to be taken and centrifuged with $250 \mathrm{~g}$ for 7 minutes at room temperature. In the meantime the staining solution was prepared. There were $550 \mu \mathrm{l}$ PBS buffer with $2.2 \mu \mathrm{l}$ CFSE mixed for one cell line to stain. The supernatant had to be totally removed and cells had to be resolved in $500 \mu \mathrm{l}$ PBS buffer and mixed with the $1 \mathrm{ml}$ pipette to get a homogeneous cell suspension for staining. After this $500 \mu \mathrm{l}$ of the staining solution was added and vortexed gently at $1400 \mathrm{rpm}$. Then immediately the cell suspension was placed in the incubator for exact 2 minutes and 30 seconds. After this time rapidly $10 \mathrm{ml}$ of ice cold RPMI media (15\%FCS, 1\% Penicillin/Streptomycin) was added and gently mixed to stop the staining process. After this the solution was placed for 5 minutes on ice in complete darkness. In the next step the mixture was centrifuged for 7 minutes at $250 \mathrm{~g}$ at room temperature and all of the supernatant was removed. Then the pellet was resolved in $25 \mathrm{ml}$ of warm RPMI media (15\%FCS, 1\% Penicillin/Streptomycin) and was incubated for 24 hours. Then the cells were ready for further preparation steps.

\subsubsection{Determination of Vitality by Vybrant Ruby and Sytox Blue Staining and Determination of Living Cell Number}

In order to determine the quantity of living cells in a suspension a staining was used which stains living and dead cells to distinguish between these two groups and to quantify their amounts. For this purpose the two dyes Sytox Blue (Life Technologies Corporation) and Vybrant Ruby (Vybrant ${ }^{\circledR}$ DyeCycle ${ }^{\mathrm{TM}}$ Ruby stain, Invitrogen) were used. Both of the dyes are intercalating dyes which incorporate in the DNA of the stained cells and can be detected by fluorescence measurements. The Sytox Blue stain enters only dead cells, Vybrant Ruby enters dead as well as living cells. By this staining 
it is possible to distinguish living cells from the cell debris and from the dead cells. The staining mixture was prepared in a master mix with $200 \mu$ l RPMI media (15\% FCS, 1\% Pen/Strep) per sample and a dilution of 1:1000 for Sytox Blue and 1:2000 for Vybrant Ruby. In some steps it was necessary to determine the exact number of cells in the suspension, in order to do this $10 \mu \mathrm{l}$ of the counting bead stock solution (Invitrogen, Karlsruhe) was added per sample [3.6.4.2.1].

For the staining procedure cells were mixed with the accu-jet first to separate cell aggregations. Then a pre-defined volume of cell suspension was taken and transferred to a $5 \mathrm{ml}$ Falcon tube. Then the tube was filled up with PBS buffer [2.3.1] for washing. After this the solution was centrifuged with $250 \mathrm{~g}$ for 5 minutes at room temperature. Thereafter the supernatant was completely discarded and the pellet was resolved in $200 \mu \mathrm{l}$ (210 $\mu \mathrm{l}$ for cell counting procedure) of the staining solution. Subsequently the staining mixture was incubated for 15 minutes at $37^{\circ} \mathrm{C}$. After this the cells were ready for measurement.

\section{Vitality staining mixture}

\begin{tabular}{|l|c|}
\hline \multicolumn{1}{|c|}{ Reagent } & Volume per Sample [pl] \\
\hline RPMI (15\%FCS,1\% Pen/Strep) & 200 \\
\hline Sytox Blue & $\mathbf{0 . 2}(1: 1000)$ \\
\hline Vybrant Ruby & $\mathbf{0 . 1}(1: 2000)$ \\
\hline Counting Beads (optional) & $\mathbf{1 0}$ \\
\hline
\end{tabular}

\subsubsection{Flow Cytometry}

The flow cytometry is a technique to analyze single cells in a suspension, which cross a focused laser. The cells can get characterized by several parameters like size, morphology and fluorescent markers. The collected data can be evaluated by specific software.

Flow cytometry was used to analyze the effect of gemcitabine on proliferation and vitality in lymphoblastoid cell lines (LCLs) [3.6.5]. Cells were first characterized by their size (forward scattern channel / FSC) and morphology (sideward scattern / SSC) to determine the particle size. Thus the small particles, which were regarded as cell debris, 
could be excluded from the data (bigger cell debris particles were still included) to simplify the evaluation. The fluorescent dyes Vybrant Ruby (Vybrant ${ }^{\circledR}$ DyeCycle ${ }^{\mathrm{TM}}$ Ruby stain, Invitrogen) and Sytox Blue (Life Technologies Corporation) were used to determine vitality [3.10.2]. The Vybrant Ruby stain (excitation $638 \mathrm{~nm}$ and emission $686 \mathrm{~nm}$ ) was evaluated in the APC channel and the Sytox Blue (excitation $440 \mathrm{~nm}$ and emission $480 \mathrm{~nm}$ ) stain in the PacificBlue channel on the flow cytometer BD LSRII (Becton Dickinson). Since the amount of fluorescence of these two intercalating stains were equivalent to the amount of DNA in cells, it could be possible to examine the cell cycle state with this staining, too. This issue was not pursued in my thesis. The proliferation rate of cells in presence of gemcitabine was evaluated by the CFSE stain (eBioscience, Frankfurt) (excitation: $492 \mathrm{~nm}$; emission: $517 \mathrm{~nm}$ ) [3.10.1] in the FITC channel. The adjusted voltages were 170 volt for FSC-Channel, 210 volt for SSCChannel, 685 volt for APC-Channel, 215 volt for FITC-Channel and 220 volt for PacificBlue-Channel.

\subsubsection{Data analysis}

The collected data from the flow cytometric measurements were evaluated by the Software Cyflogic 1.2.1 (http://www.cyflogic.com/), which is a freeware version for scientific research. In Dot-Plot view on the x-scale was set the APC-channel, on the yscale the Pacific-Blue Channel (Figure 5, Figure 6, Figure 7). In this display, it was possible to gate the living cells and to determine the percentage of living cells compared to dead cells. In addition, the geometric mean of the FITC channel signal representing the CFSE dye indicative for cell proliferation was determined for the fraction of living cells. These data were used for further statistical evaluation of the sensitivity towards gemcitabine and the calculation of the EC50 (EC50 Vit, EC50 Prolif). The EC50 was calculated for the gemcitabine effects on the proliferation inhibition (EC50 Prolif $)$ and on the fraction of living cells (EC50 $\left.{ }_{\mathrm{Vit}}\right)$ using the three-parameter Gompertz (EC50 ${ }_{\text {Prolif }}$ ) and the four-parameter MMF model (Multiple Multiplicative Factor Model) (EC50 Vit), respectively. These models were selected out of a panel comprising 80 models implemented in the software Curve Expert Professional (http://www.curveexpert.net/products/curveexpert-professional/) according to the set model fit criteria of $\mathrm{r}^{2} \geq 0.95$ for the individual cell lines. The EC50 values for the latter were then determined by the Solver algorithm in EXCEL. 


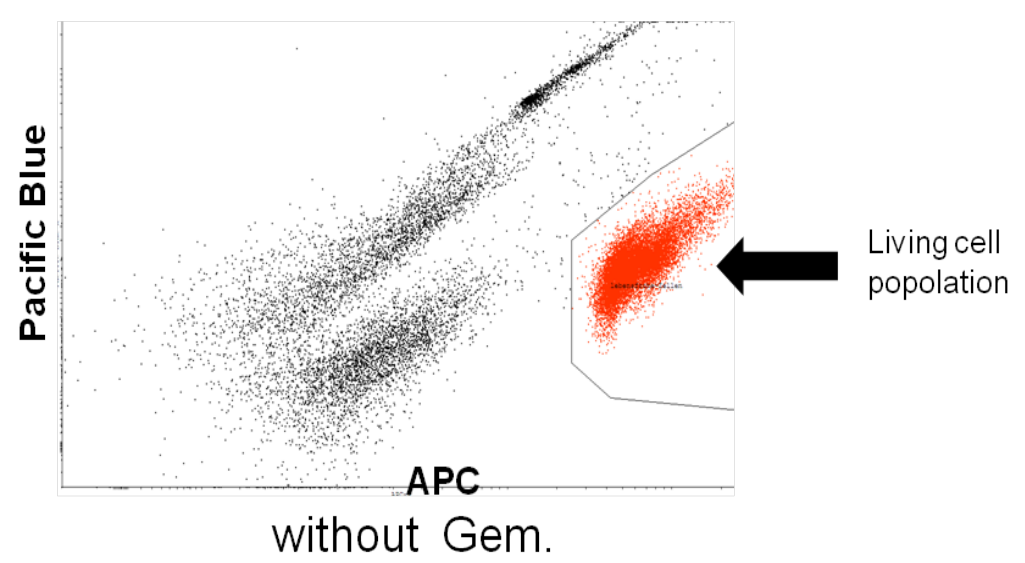

Figure 5: Illustrated FACS data of untreated LCL cells. Cells were stained with VybrantRuby and Sytox Blue for determination of living cell populations (red)

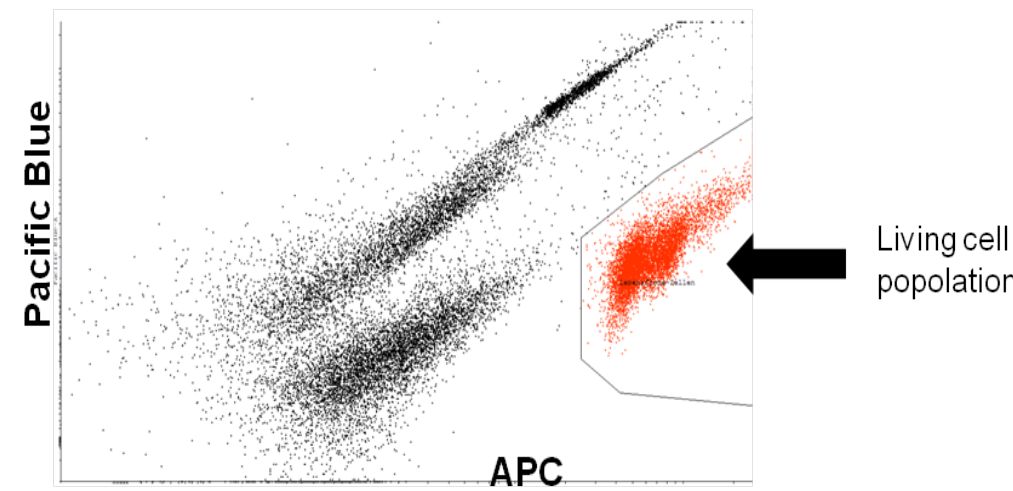

\section{Gem. 4 concentration}

Figure 6: Illustrated FACS data of LCL cells treated with $10.8 \mathrm{nM}$ gemcitabine for $\mathbf{7 2}$ hours. Cells were stained with Vybrant Ruby and Sytox Blue for determination of living cell populations (red)

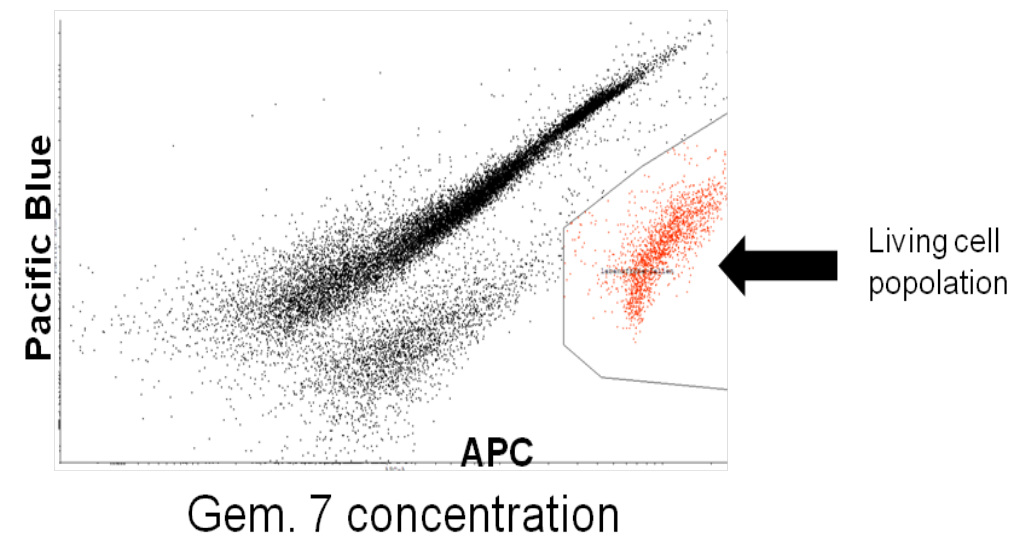

Figure 7: Illustrated FACS data of LCL cells treated with $76 \mathrm{nM}$ gemcitabine for $\mathbf{7 2}$ hours. Cells were stained with Vybrant Ruby and Sytox Blue for determination of living cell populations (red) 


\subsection{High-Performance Liquid Chromatography (HPLC)}

High-performance liquid chromatography (HPLC) is a very sensitive method which isolates specific molecules in a solution from others by using their differences in affinity to the liquid mobile phase and the solid stationary phase. The solution is mixed with the liquid phase and then led through a column which consists of a solid matrix (stationary phase). The differences in affinity of the single molecules in the solutions cause that some of them are retained on the column longer than others and become eluted to certain points of time. Thus the molecules can be separated, purified, identified and even quantified. The most common form of HPLC is the reverse phase HPLC where the column consists of a hydrophobic matrix. The mobile phase is hydrophilic and a composition e.g. of water, acetonitril or methanol. Hydrophobic compounds are retained longer on the stationary phase than hydrophilic. If a single solution is used as mobile phase, it will be termed isocratic elution. If a second or third solution is used to change the polarity of the mobile phase during the chromatography, it will be termed gradient elution. The advantage of a gradient elution is that the elution time (also retention time) of different substances can be adjusted during a chromatography. For example substances, which have similar polarities and are eluted at the same time, can be separated or on the other hand the elution intervals of substance, which have high differences in polarity, can be shortened. The eluted substances can be detected by several systems like UV absorbance, fluorescence or radioactivity counter. Via computer software the collected data becomes evaluated for quantification.

\subsubsection{Self-Established HPLC Method for Quantification of Radioactive Labeled Gemcitabine Metabolites}

The method for quantification of radiolabeled gemcitabine $\left(2^{\prime}, 2^{\prime}\right.$ - difluorodeoxyuridine, $d F d U$ ) and its metabolites was self-established for analysis of gemcitabine metabolism in self-established pancreatic tumor cell lines and in LCL cell lines [3.6.5]. Helpful hints for establishment were used from literature:(DECOSTERD et al. 1999) (VELTKAMP et al. 2008). The gemcitabine metabolites (dFdC-monophosphate, dFdC--diphosphate, $d F d C$--triphosphate and $d F d U$ (2',2'-difluorodeoxycytidine) for reference substances were kindly provided by Eli Lilly and Company (Indianapolis, CA). The pure gemcitabine drug $(d F d C)$ was obtained from Sigma Aldrich (Germany). The ${ }^{3} \mathrm{H}$-Gemcitabine was purchased from American Radiolabeled Chemicals, Inc 
(ACR). At first the detection of gemcitabine and its metabolites was established with the cold reference substances. After the separation of the pure substances was established, lymphoblastoid cell lines (LCLs) were incubated with radiolabeled ${ }^{3} \mathrm{H}$-gemcitabine for different points of time. Thereupon the nucleotides were extracted and detected via HPLC. Methodologically the extraction process for gemcitabine metabolites was not yet well-engineered and did not show replicable results. Because the method for extraction of gemcitabine and its metabolites from LCLs was not brought to a satisfactory conclusion, it is not outlined in this thesis. The internal standard for the HPLC procedure, which was used for normalization of the extraction efficacy, was P1,P4-Di(adenosine-5') tetraphosphate ammonium salt (Sigma). The HPLC system used for the detection was Berthold LB 506-C1 radioactive detector with the HPLC pump Kontron instruments 325 System and the Kontron instruments HPLC 332 UV-Detector. The applied measuring cell was Z1000. The used columns were a

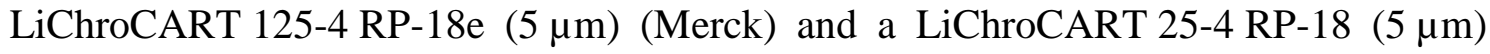
pre-column (Merck) and the evaluation program was Berthold LB06 Version 1.65. The injected volume of substrate was $20 \mu$ l. Additionally to the radioactive detection the elution was also detected by a UV-Detector at the wavelength of $280 \mathrm{~nm}$. The dwelltime was set on $10 \mathrm{sec}$. The liquid scintillator (Quickszint Flow 302, Zinsser Analytic, Berkshire, UK) was mixed in a relation $1: 4$ with the flowrate of $2 \mathrm{ml} / \mathrm{min}$ with the mobile phase after leaving the UV-Detector. A gradient elution with a flowrate of $0.5 \mathrm{ml}$ per min for the mobile phase was selected with buffer A (47.1 $\mathrm{mM} \mathrm{KH}_{2} \mathrm{PO}_{4}$, $2.9 \mathrm{mM} \mathrm{K}_{2} \mathrm{HPO}_{4}, 4 \mathrm{mM}$ Tetrabutylammonium hydrogen sulfate (Sigma) $4 \mathrm{ml} \mathrm{NaOH}$ (1M) per liter)) and eluent B (100\% MeOH).The applied HPLC method was: 0-15 min $100 \%$ buffer $\mathrm{A} \rightarrow$ 85\% buffer $\mathrm{A}+15 \% \mathrm{MeOH}$; $15-50$ min $85 \%$ buffer $\mathrm{A}+15 \%$ $\mathrm{MeOH} \rightarrow 48 \%$ buffer A +52\% MeOH; 50- 55 min 48\% buffer A + 52\% MeOH. The retention times for the single eluents were $11 \mathrm{~min} \mathrm{dFdC}, 14 \mathrm{~min} d F d U, 19.5 \mathrm{~min} d F d C$ MP, $27 \mathrm{~min} \quad d F d C-D P, 32 \mathrm{~min} \quad d F d C-T P$ and $35 \mathrm{~min}$ P1,P4-Di(adenosine-5') tetraphosphate. A cold reference substance for $d F d U-M P$ was not supplied, but according to the chromatograms a peak with a retention time of 24 minutes was considered to be $d F d U-M P$. (Figure 8) 


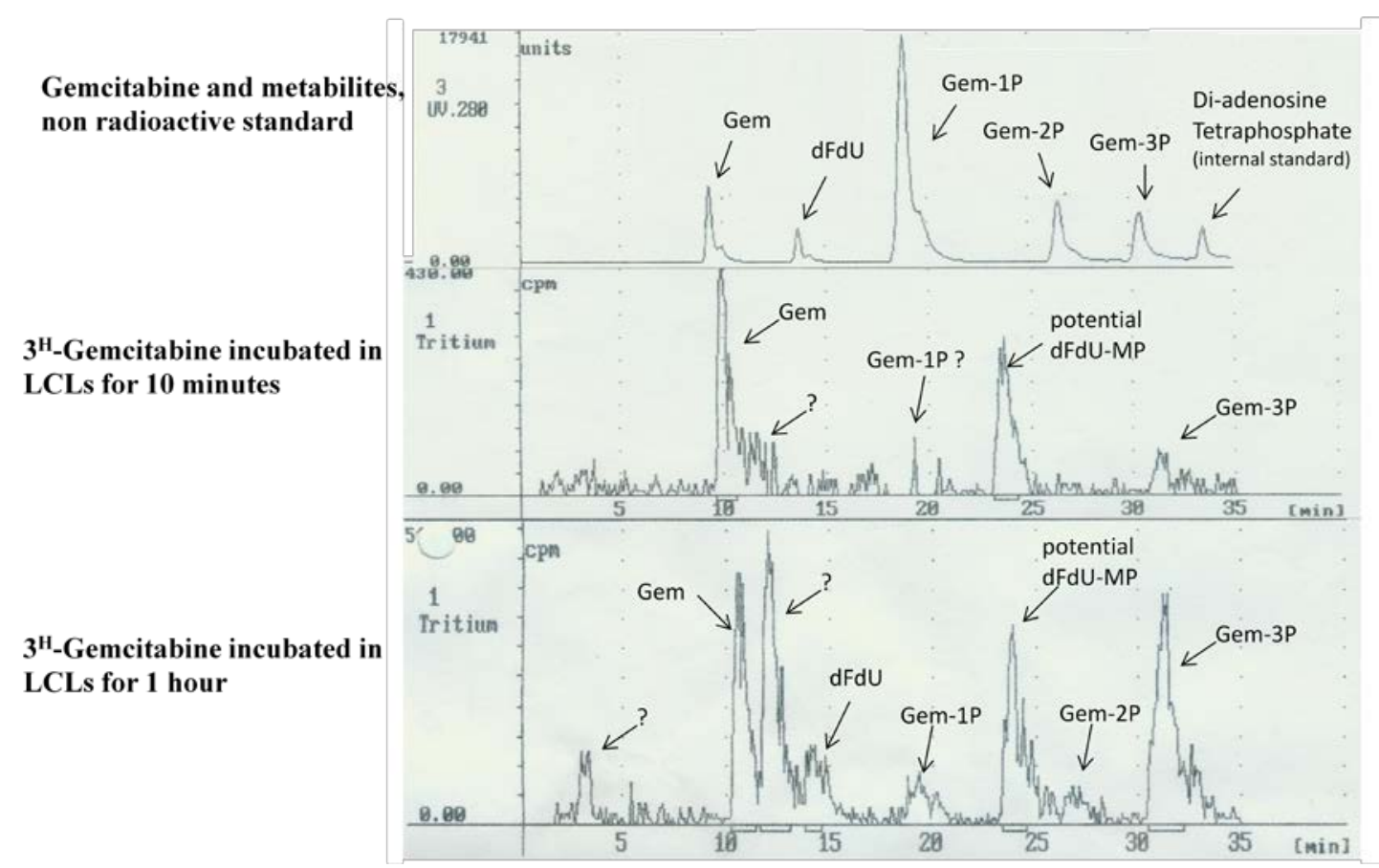

Figure 8: Chromatograms of gemcitabine and gemcitabine-metabolite separation by HPLC. In the upper chromatogram separation of gemcitabine and its' metabolites is displayed. In the middle chromatogram separation of intracellular converted $3^{\mathrm{H}}$-gemcitabine is depicted, which was incubated for 10 minutes in LCLs. In the lower chromatogram intracellular conversion of the ${ }^{3} \mathrm{H}$-gemcitabine is shown, which was incubated for 1 hour in LCLs. The x-axis displays the time and the $\mathrm{y}$-axis features the UVsignal in the upper chromatogram and the radioactive signal in the other ones.

\subsection{Patient cohorts}

The clinical cohort encompassed 397 patients of Caucasian origin. Patients have been recruited at three sites in Germany, Göttingen $(n=142)$, Heidelberg $(n=96)$, and Hamburg $(n=159)$ between 2003 and 2010. They exhibited all histopathologically proven pancreatic adenocarcinoma (without ampullary) and received adjuvant or palliative gemcitabine-based chemotherapy. The study was approved of for each study site by an ethic committee and the patients included in the study had admitted to a written informed consent. The patients from Göttingen and Hamburg were retrospectively collected $(n=301)$ whereas the set from Heidelberg $(n=96)$ was part of a prospective clinical trial (NeOPtolemos et al. 2010). Patient baseline data are summarized in Table 12. 
Table 12: Distribution of the patients' baseline parameters, tumor stages, chemotherapy regimens, as well as time of follow-up and overall survival in the two study cohorts.

\begin{tabular}{|c|c|c|c|}
\hline Variable & $\begin{array}{c}\text { Cohort } 1 \\
\text { Göttingen, } n=142\end{array}$ & $\begin{array}{c}\text { Cohort } 2 \\
\text { Heidelberg, } \mathrm{n}=96\end{array}$ & $\begin{array}{c}\text { Cohort } 3 \\
\text { Hamburg, } n=159\end{array}$ \\
\hline $\begin{array}{l}\text { Age [years], median } \\
\left(\text { (IQD }^{1}, \text { range) }\right.\end{array}$ & $68(61-73,44-88)$ & $62(55-68,34-81)$ & $65(58-72,28-88)$ \\
\hline \multicolumn{4}{|l|}{ Sex, No. (\%) } \\
\hline Female & $68(48)$ & $47(49)$ & $64(40)$ \\
\hline Male & $74(52)$ & $49(51)$ & $95(60)$ \\
\hline \multicolumn{4}{|l|}{ T-stage, No. (\%) } \\
\hline Classified & 138 & 96 & 159 \\
\hline$\leq 2$ & $9(7)$ & $1(1)$ & $29(18)$ \\
\hline 3 or 4 & $129(93)$ & $95(99)$ & $130(82)$ \\
\hline \multicolumn{4}{|l|}{ N-stage, No. (\%) } \\
\hline Classified & 128 & 95 & 159 \\
\hline 0 & $21(16)$ & $7(7)$ & $50(31)$ \\
\hline 1 & $107(84)$ & $88(93)$ & $109(69)$ \\
\hline \multicolumn{4}{|l|}{ M stage, No. (\%) } \\
\hline Classified & 73 & 95 & 159 \\
\hline 0 & $27(37)$ & $84(88)$ & $105(66)$ \\
\hline 1 & $46(63)$ & $11(12)$ & 54 (34) \\
\hline \multicolumn{4}{|l|}{$\begin{array}{l}\text { Resection status, No. } \\
(\%)\end{array}$} \\
\hline Classified & 142 & 96 & 159 \\
\hline 0 & $45(32)$ & $42(44)$ & $98(62)$ \\
\hline 1 & 52 (37) & $50(52)$ & $42(26)$ \\
\hline 2 & $2(1)$ & $4(4)$ & $19(12)$ \\
\hline Not resected & $43(30)$ & $0(0)$ & $0(0)$ \\
\hline \multicolumn{4}{|l|}{ Grading, No. (\%) } \\
\hline Classified & 141 & 96 & 159 \\
\hline G1 & $7(5)$ & $2(2)$ & $21(13)$ \\
\hline $\mathrm{G} 2$ & $94(67)$ & $66(69)$ & $92(58)$ \\
\hline G3 & $40(28)$ & $28(29)$ & 46 (29) \\
\hline \multicolumn{4}{|l|}{$\begin{array}{l}\text { Chemotherapy } \\
\text { regimen, No. (\%) }\end{array}$} \\
\hline Gemcitabine mono & $90(63)$ & $96(100)$ & $90(57)$ \\
\hline $\begin{array}{l}\text { Gemcitabine } \\
\text { combination }\end{array}$ & $52(37)$ & $0(0)$ & $69(43)$ \\
\hline $\begin{array}{l}\text { Follow-up [months], } \\
\text { median (range) }\end{array}$ & $11.0(1-124)$ & $17.5(1-88)$ & $11.5(2-69)$ \\
\hline $\begin{array}{l}\text { OS [months], median } \\
\text { (range) }\end{array}$ & $10.9(1-114)$ & $15.6(3-56)$ & $11.5(2-69)^{2}$ \\
\hline
\end{tabular}




\subsection{SNP Selection for Genotyping}

Genotyping by primer extension method as described before [3.1.12] was carried out in two different issues. First, the top hits of a reported clinical genome-wide association study (GWAS) should be verified. Second, in the self-conducted genome-wide assessment of gemcitabine sensitivity the top hits of the training set should be examined in the test set.

Regarding the clinical GWAS replication, five reported top associations of genetic polymorphisms with overall survival (INNOCENTI et al. 2012) were genotyped in a cohort of 397 patients [3.12]. The basal characteristics of these five SNPs are listed in Table 13 and the used primers in Table 14. Genotypes for the 397 samples at the five considered loci could successfully be determined at 1,972 positions (99.3\%). Repetition analysis of 82 samples (21\%) yielded identical results. Hardy-Weinberg equilibrium was fulfilled for all five SNPs which were analyzed (all $\mathrm{p}>0.5$, assessed by $\chi^{2}$-test comparing observed versus expected genotype distribution according to measured allele frequencies).

Table 13: Features of the five genotyped SNPs

\begin{tabular}{ccclcc}
\hline Gene & SNP & $\begin{array}{c}\text { Genomic localization } \\
\text { (chromosome: position }\end{array}$ & $\begin{array}{c}\text { Genetic } \\
\text { element }\end{array}$ & $\begin{array}{c}\text { Base } \\
\text { exchange }\end{array}$ & MAF $^{2}$ \\
\hline IL17F & rs763780 & $6: 52101739$ & coding & A $>\mathrm{G}$ & 0.049 \\
PRB2 & rs2900174 & $12: 11547532$ & Intron 1 & A $>\mathrm{G}$ & 0.024 \\
$D C P 1 B$ & rs11062040 & $12: 2091257$ & Intron 3 & A $>\mathrm{G}$ & 0.486 \\
WWOX & rs11644322 & $16: 79039600$ & Intron 8 & G $>$ A & 0.259 \\
BTRC & rs10883617 & $10: 103113035$ & Promoter & A $>\mathrm{G}$ & 0.375 \\
\hline
\end{tabular}

According to NCBI genome assembly GRCh37.p5. ${ }^{2}$ Genotype distribution and minor allele frequency (MAF) as observed in our cohorts comprising 397 patients. Genotyping failed for four samples of PRB2 rs2900174 and DCP1B rs11062040 and for five regarding WWOX rs11644322. The minor allele refers to that right to the ">" symbol as indicated in the column "base exchange". 
Regarding the functional GWAS, all SNPs with a frequency of at least $10 \%$ for the combined genotypes of heterozygous and homozygous variant allele status were included. SNP data were derived from HapMap and 1000 human genome databases. For each considered SNP, association with two functional traits of gemcitabine cytotoxicity (proliferation inhibition, vital cell fraction reduction) was assessed by JonckheereTerpstra trend test allowing for allele dosage effects. These analyses were performed by Prof. Beißbarth (group Bioinformatics, Institute of Medical Statistics, Göttingen University Medicine). The thereby elicited top twenty genetic regions were then subjected to fine mapping including all polymorphic sites (i.e. also SNPs with rare frequency) in the considered regions. By that, pairwise genetic linkage disequilibrium was taken into account to determine SNPs which tag the associated loci with a stringency of at least $\mathrm{r}^{2}=0.5$. These procedures were carried out with HaploView software (www.broadinstitute.org/haploview). The tagging approach also allowed selection of alternative SNPs if a certain SNP appeared difficult to assay. The final set of selected polymorphisms is listed in Table 13 with pertinent primers. 
Table 14: Primer sequences for genotyping

\section{Functional replication study}

rs9458655 GCTGTGCTAGCAACCAGCGAGACT

rs4646903

rs7321622

rs6898780

rs1410824

rs55748428

rs62369808

rs35829783

rs74767865

rs62429896

rs7734440

rs2026946

rs10038824

rs12592456

rs1931915

rs67502721

rs113018380

rs2958405

rs10454987

rs9375292

$15: 74748055 b$

rs28362873

\section{Clinical re}

rs763780

rs10883617

rs2900174

rs11062040

rs11644322
TGTAGCCGCTGCACTTAAGCAGTCTG

ATATTTGTGCCCCTGCAGCAAGTCAC GCCACCTGCATTTGTTGCTGTGAC GCTCCAGAGGGCATAAAAGTAAAGACTGTG GCTGGGCCTTGAGAAAAGTAAAGTAGAAC CACATGGGGAAAATGGTAAATGGGAAC CAATGTTTGTGCAGCTAGCTAACCAACAC CCCTGTTCTGTGAACGGATCAAATG GCCTATTGTGGGACCTTGTGATTG TTACAGTTATTGAGGTGGAGAAGTCCAAAG TGCCACCTTCCACCTTAGGGAGATAC GGGGCTCCTTTAGGGTCCACCTCTATAC GGGTAAGGGTGGGAGGGAAGTGAGT CAGGAGAAAGTGTTTTCCCATTAAGAGAAC CAAACACTCAAGTGCCTCATATGTTAACCTC CTGCTGTGGTTGTCAAATAGTTTCCATGTAG GGTCCTCCAGGAAACACTGCTATTTCAG TAGCCCAGCACCAGAGAGCTGATG CAAACTGGGTGTAAAAGCCTGTAAACCTTAC CTGTCCCATTAGGAAACAGTGGATGAC GCCCTTAACCTGTCCTGCCTTCAG

GCACTGGGTAAGGAGTGGCATTTCTAC GGGGCATTTGGGTGTGTGTCAG CAGCTTCACAGATGGTGGCTGATGAG AAGGAAAGCAAATTAATTAGGCTTGTGCTA CTAGGTGGCTTCAGTCAGCAGAACTG
GGAGTTCCCCTTCGGAGTCAGAGAG GCTGAGGTGGGAGAATCGTGTGAG GTTCCCTTCTACCCAGTTCTGGAAAAGATG CACAGCGAAGTGGAATGGATTCACTTG GAAACCTTTTGTCCACCCAGAGATGAG CCCAACATACAGTAAAAAGCAGATGTGAG CCCACTTAGGCAAACATTTTGACCTAAGAG AGGCCAAGGGTTGTTTATTGGATCTG CCCTTTGTAAACTTTCCTAGTGCCTACTGTC CAGAAAGATAGCTGGAAAGTCCCTGTATTAG CCCACCTCCTAGAGGGAACATTTTCTAAC CGAGCCAGAGGATGTTCAAGCTTCTC GCACATGGCCCTACTCTCAAGAAGCTTAG GAGATGGGGGCTGCAATTATGTTTG GCCCACTCCTTCCATTCAGATACAC CAGGGGCAAGAAGCCTAACTCCATC GCCAGCACAGTCAACATGGTCTTCTAGTAC TGACTGCCTGGAGCTGGTGTTTTTC CCCTCCAAACCAGCACTGTTCAATAAAC ATCTTAGCGTCAATGCTAGAAACAGAGATG CCACCTCAGCCTCCCAAAGTACAG GCTGGGCACAGATCTGGAGAGATG

TTGGAGAAGGTGCTGGTGACTGTTG GCCCTGCACTAAGGGTCAAACAGGTAC CCTGCTCATGATGCCCAGAATCAAG GAATGGAGAGTGGGGAGTTATCTTCTAATG TGCCTTCTGTTCTCATGCAACTTCAC
176 TCAGGACCCTCCGAGCCA

151 ACTGTAACCTCCACCTCC

536 ACTGACTAACCGGTGCCCTCACAA GTGGAGAAGTCCAAAGTCAAG CCCAAAGTGCTGAGATTACAG

CACCTCTTACTGCACA

CTTTGGCCTGAAAAGGTACA
CTGTTTGAAATTTGTCAACTTTTCTGAGAA GCTCCAGAGGGCATAAAAGTAAAGACTGTG (ACTG) $)_{3}$ TAAAGTAGAACTTCAGCAAGATCA (ACTG) ${ }_{3}$ TTTTGTAATTTTGCAGTTTAGCTC (ACTG) ${ }_{3}$ ACTCTTCCATCTATTATATTACTAAGGCAG (ACTG ) ${ }_{4}$ ACTTGAATTACTAAGTAACAAGTGCTTAGA $\mathrm{GA}(\mathrm{TA}){ }_{4} \mathrm{TG}(\mathrm{AT})_{5} \mathrm{GCTATATCATACATATATGA}(\mathrm{TA}){ }_{4} \mathrm{~T}$ CTCAAGAAGCTTAGTAGAAGAGATAGA T(GACT ) 2 TCACTCAGGCTGGAATGC GACTTTGAATTTATAATCATTGGACTGGTATTA GACTACTGAATATTTGCTTGGATAGTATATTCT CT (GACT) ${ }_{4}$ GGAGACTATCCTGGCTAACAC ACT (GACT) ${ }_{4}$ AATTTTGTACCACCAGCTGC (GACT) ${ }_{5}$ CTCCTAGCATATGTTGCTATTTCA CTTGAAATAATCTTAATGATTTATTCTTGTAAATATTTACTTAT T( GACT $)_{7}$ CACCATTCCTGGCTTGTTT $\mathrm{CT}(\mathrm{GACT}){ }_{7}$ GACTGGGAGAATAAAGGGCTTGGA

(CTGA) 2 CTCCTTACAAGACTCACAAGTGTTCT

(TGAC) ${ }_{4}$ AATTAATTAGGCTTGTGCTA

GATGTGATTACAGTGAATTAGGGTGG 


\subsection{Statistical Analysis Techniques}

The overall survival of patients was illustrated by Kaplan-Meier curve with the impact of genetic polymorphisms singularly assessed by log-rank test. Dependence of overall survival on multiple factors was ascertained by Cox regression model. Cox models were used in two fashions: to identify the hierarchy of significantly contributing factors by a stepwise model as well as to adjust the effect of a certain variable for potential confounders by an integrated model.

Correlation of continuous functional parameters was analyzed by Pearson and Spearman coefficients for data with parametric and non-parametric distribution, respectively. Distribution was considered as parametric when Kolmogorov-Smirnov and ShapiroWilk test did not indicate deviation from Gaussian for samples sizes $\geq 50$ and $<50$, respectively. Treatment effects on continuous parameters were tested for statistical significance by paired t-test (in case of Gaussian distribution) and paired Wilcoxon's signed rank test (non-Gaussian). Impact of a single discrete, ordinally scaled variable on a dependent variable was investigated with the Jonckheere-Terpstra test. That was typically applied for genetic polymorphisms in relation to functional traits since this test allows for allele dosage effects according to the order of the genotypic configurations. If the independent variable was binary, the effects of the two groups on the considered functional trait were compared by t-test (Gaussian distribution); the non-Gaussian pendant, i.e. the Mann-Whitney $U$ test, was not used in my thesis. All these statistical procedures were carried out using SPSS version 12.0 (IBM, Chicago, IL). 


\section{Results}

Following the aim to identify biomarkers for the efficacy of gemcitabine-based chemotherapy in pancreatic cancer the Department of Clinical Pharmacology at the University of Göttingen launched a genotyping project applying a candidate gene approach. We hypothesized that the observed clinical variability in therapeutic outcome is partially impacted by genetic variability in genes encoding proteins for transport and metabolism of gemcitabine. In eleven referring genes 109 genetic polymorphisms selected by functional and bioinformatic criteria were genotyped and analyzed with respect to the overall survival of gemcitabine-treated patients suffering from pancreatic cancer. This initial study was conducted by a medical thesis student in our department (Alexander Schaudinn, medical dissertation, University of Göttingen 2013). As a major result two genetic polymorphisms pertinent to the equilibrative nucleoside transporter 1 (ENT1), which is officially denoted SLC29A1 according to HGNC (Human Gene Nomenclature), were associated with overall survival. One of these polymorphisms presents an amino acid exchange (Ile216Thr), however, the allelic frequency of the Thr216 is rare (about 2.5\% in Caucasians). The second variant (rs1057985) resides in a putative promoter region of ENT1 and exhibits a frequency of 33\% for the minor allele in the European population.

\subsection{Non-Conservative ENT1 Amino Acid Polymorphism}

The coding region of ENT1 is highly conserved among humans with less genetic variability (OsATO et al. 2003). The isoleucine (Ile) 216 to threonine (Thr) exchange (rs45573936) represents the most frequent one which is primarily found with a MAF (minor allele frequency) of 2.5\% in Northwestern Europeans (Figure 9, Figure 10).

In a clinical association study the variant allele of this SNP was related to a dramatically shortened overall survival rate of pancreatic cancer patients having received gemcitabine-based chemotherapy (SCHAUDINN 2013). In addition, this allele exhibited high resistance in vitro toward gemcitabine-induced toxicity in human T-lymphocytes (KUSCHEL 2012). These data raised the question whether this SNP is functionally and medically relevant. Allele-specific constructs containing either the Ile216 or the Thr216 variant were generated [3.8.1] and subjected for impacting direct gemcitabine transport and cytotoxicity of gemcitabine. 


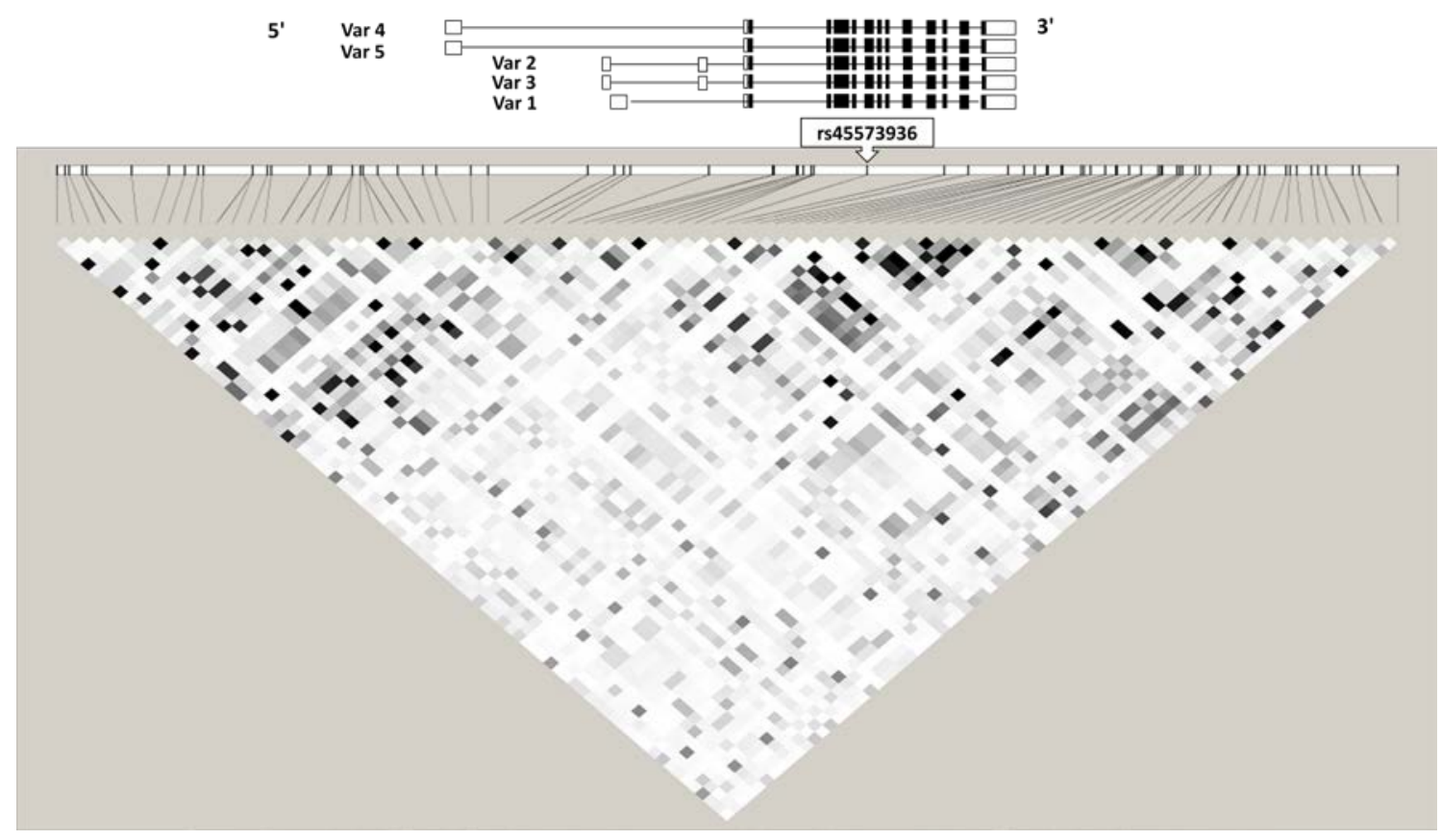

Figure 9: Plot of linkage disequilibrium in ENT1 $(-10 \mathrm{~kb} /+2.5 \mathrm{~kb})$ genetic region based on 247 fully sequenced individuals. The position of the SNP rs45573936 is highlighted. Above the plot, the location of the five ENT1 transcript variants is displayed.

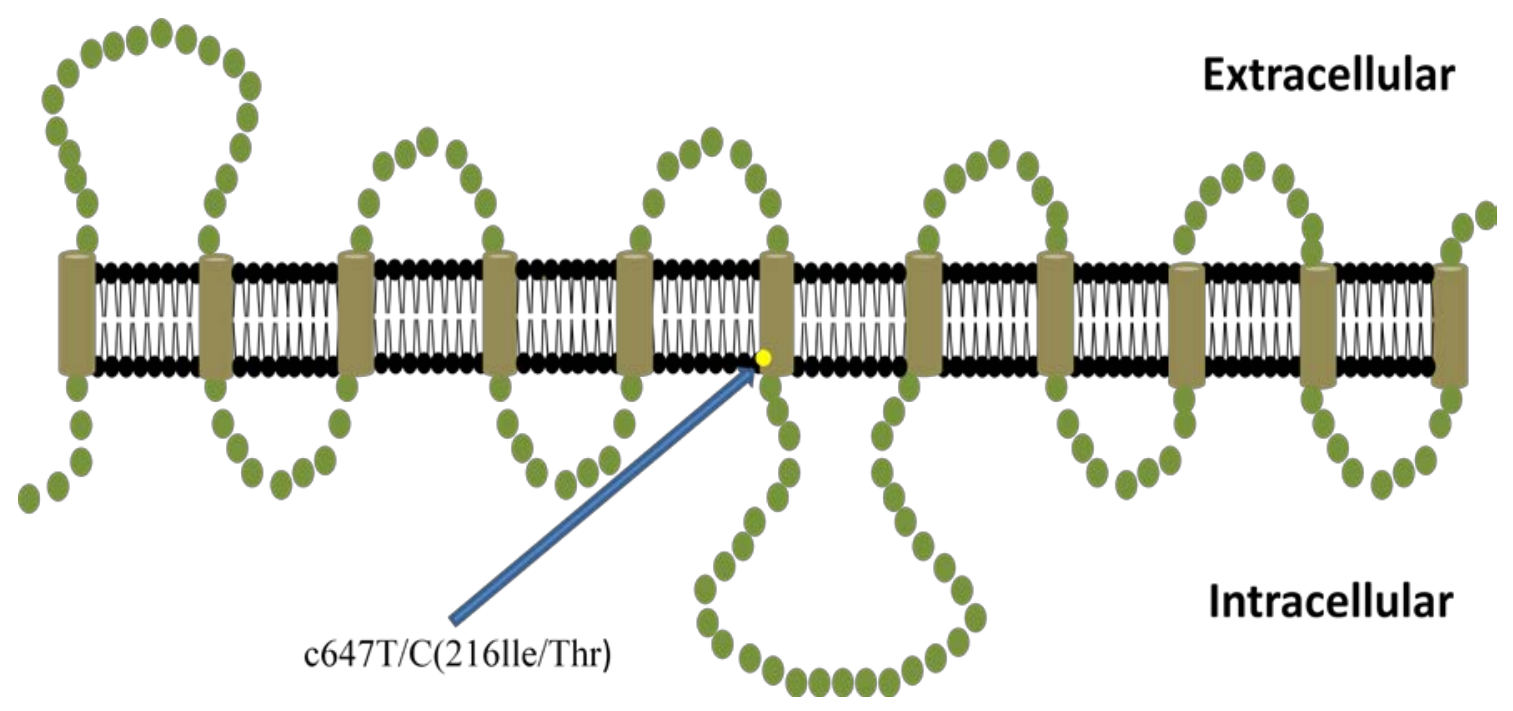

Figure 10: Scheme of ENT1 transporter (SLC29A1) with Ile216Thr (rs45573936) 


\subsubsection{Control of Stable Transfection}

To ensure successful genomic integration of the two entire coding sequences allelespecific for Ile216 or Thr216 several procedures were executed. Hygromycin resistance was proven by cell culturing in presence of Hygromycin. Specificity to the expression of the transfected Hygromycin gene was detected by PCR [3.7.3.1]. Correct genomic integration of ENT1 coding region as the gene of interest was confirmed by PCR spanning the insertion boundaries [3.7.3.1]. Exclusion of undesired mutations in the ENT1 coding region was carried out by complete Sanger sequencing [3.1.11]. Proper transcription of the transfected ENT1 was measured in comparison to empty vectortransfected HEK293 clones indicating the extent of endogenous ENT1 expression [3.2.4]. Upon proof of correct integration these constructs could be used for functional assays [3.9] the results of which are described in the following chapters.

\subsubsection{Impact on Gemcitabine Uptake}

First, the kinetics of cellular gemcitabine uptake were explored by using ${ }^{3} \mathrm{H}$-gemcitabine as tracing molecule. The high affinitive inhibitor NBTI was employed to determine the specific contribution of ENT1. Uptake of ${ }^{3} \mathrm{H}$-gemcitabine was very fast. As early as 15 seconds upon treatment start about $70 \%$ of concentration equilibration was achieved for Ile216 overexpression in comparison to only $14 \%$ for the empty control vector. It took about 10 minutes until the latter reached the same amounts of substrate transport than the Ile216 ENT1 transfectant (Figure 11). Pre-incubation with $50 \mu \mathrm{M}$ NBTI dramatically reduced the transport rate indicating the observed kinetics being largely ENT1-dependent (Figure 11). 


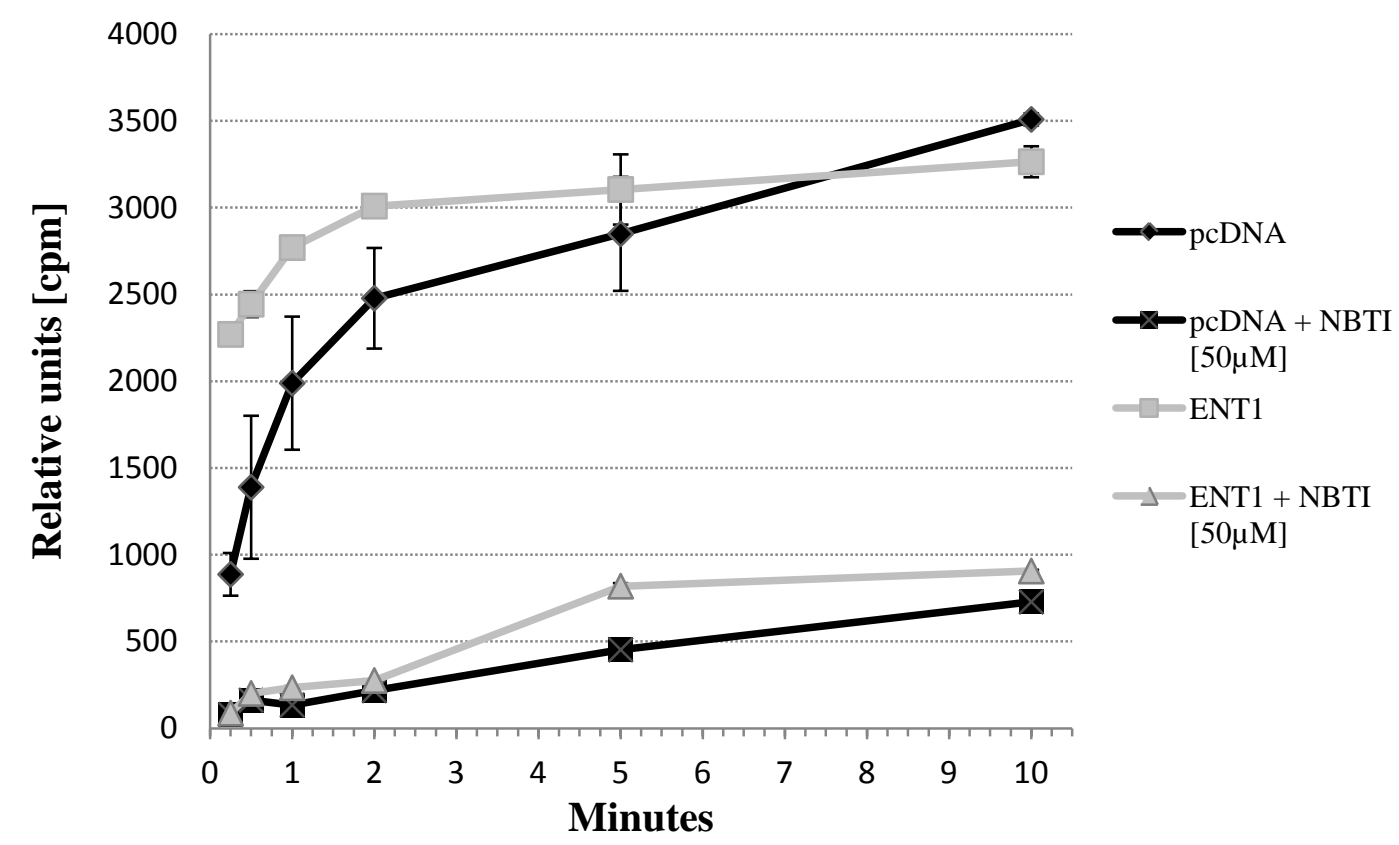

Figure 11: ${ }^{3} \mathrm{H}$-gemcitabine transport kinetic of ENT1-rs45573936 wild type clones in relation to non transfected pcDNA empty vector clones. Transport was conducted for 15 seconds to 10 minutes with ${ }^{3} \mathrm{H}$-gemcitabine. Transport kinetic in presence of $50 \mu \mathrm{M}$ NBTI inhibitor conducted with cells, which were pre-incubated with $50 \mu \mathrm{M}$ NBTI for one hour, demonstrated that NBTI is a specific inhibitor of $3^{\mathrm{H}}$-gemcitabine transport in this issue since only little amounts of radioactivity were absorbed by the cells.

Next, suggested modulation of the ${ }^{3} \mathrm{H}$-gemcitabine transport kinetics by Thr216 was assessed. No differences in transport activity of Ile216 (wild type) clones and Thr216 (variant) clones by transport measurements for 10 and 15 seconds could be observed (Figure 12)

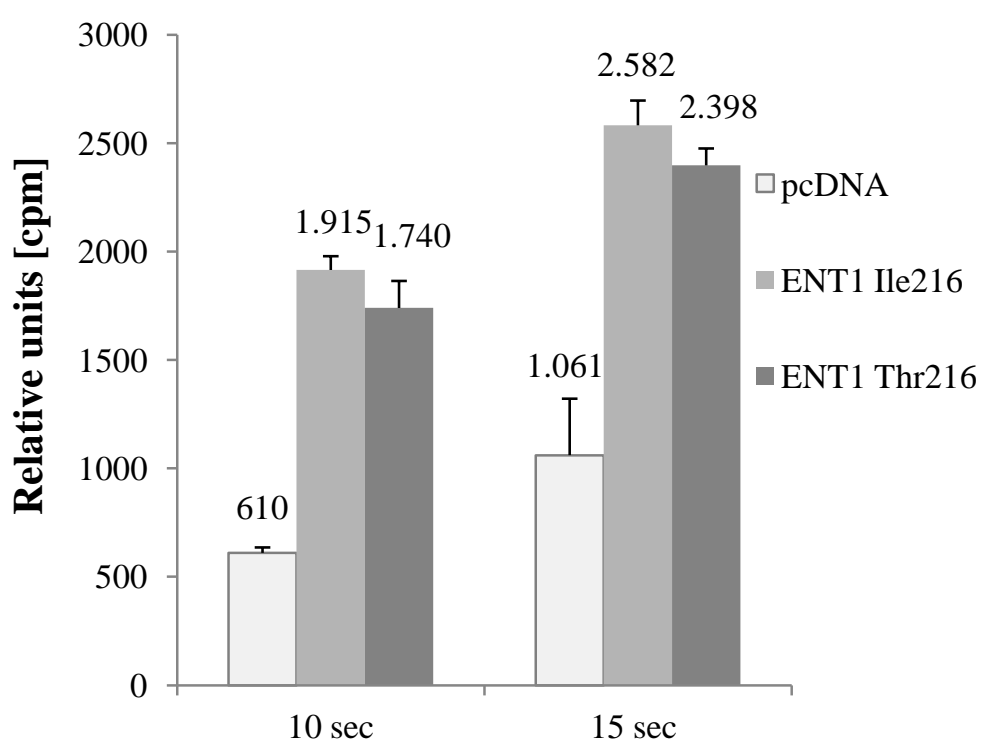

Figure 12: Transport activity of ENT1rs45573936 clones in relation to non transfected clones. Transport was conducted for 10 and 15 seconds with ${ }^{3} \mathrm{H}$-gemcitabine. 
Transport in presence of $50 \mu \mathrm{M}$ NBTI inhibitor conducted with cells, which were preincubated with $50 \mu \mathrm{M}$ NBTI for one hour, demonstrated that the transport measurements were specific since only little amounts of radioactivity were absorbed by the cells (Figure 13).

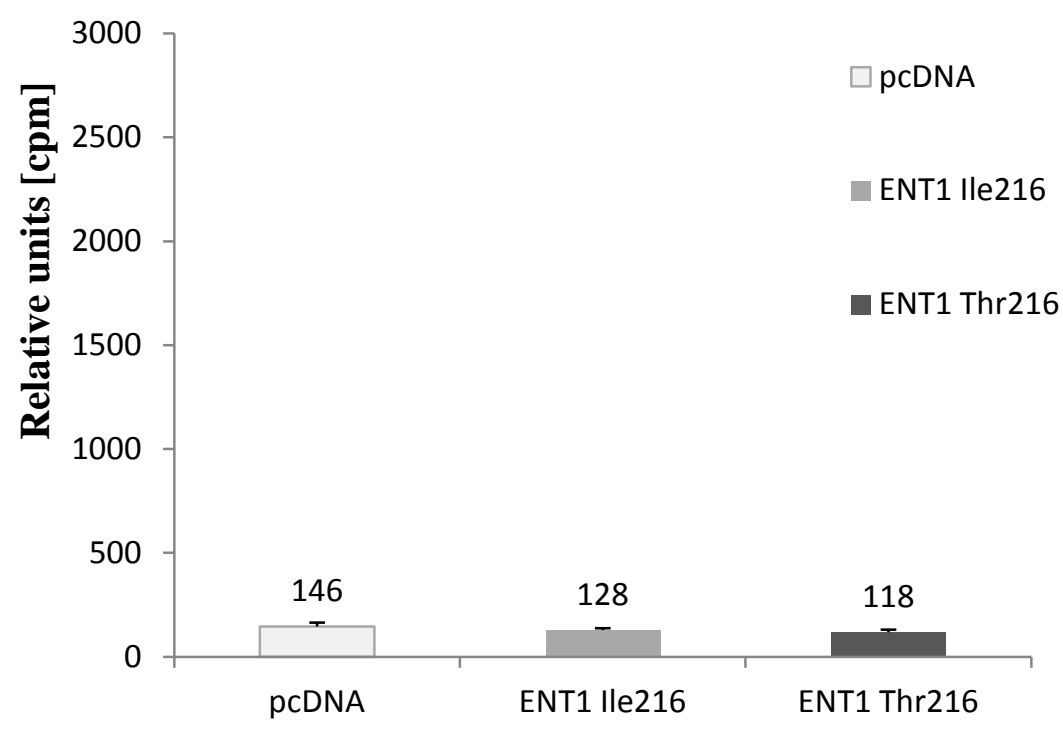

Figure 13: Transport activity in presence of $50 \mu \mathrm{M}$ NBTI inhibitor of ENT1rs45573936 clones in relation to non transfected clones. Transport was conducted for 15 seconds with $3 \mathrm{H}$-gemcitabine. Cells were pre-incubated with $50 \mu \mathrm{M}$ NBTI for one hour, demonstrated that in all clones the ${ }^{3} \mathrm{H}$-gemcitabine transport is mainly dependent on ENT1 transporter.

The transport activity of ENT1 was very fast. The following transport experiments were conducted in presence of NBTI inhibitor $0.1 \mu \mathrm{M}$ with cells, which were pre-incubated with $0.1 \mu \mathrm{M}$ NBTI for one hour, to slow down the transport activities. Even by slowing down the transport activities no significant difference in transport could be observed in the HEK-ENT1- rs45573936 wild type and variant clones (Figure 14). 


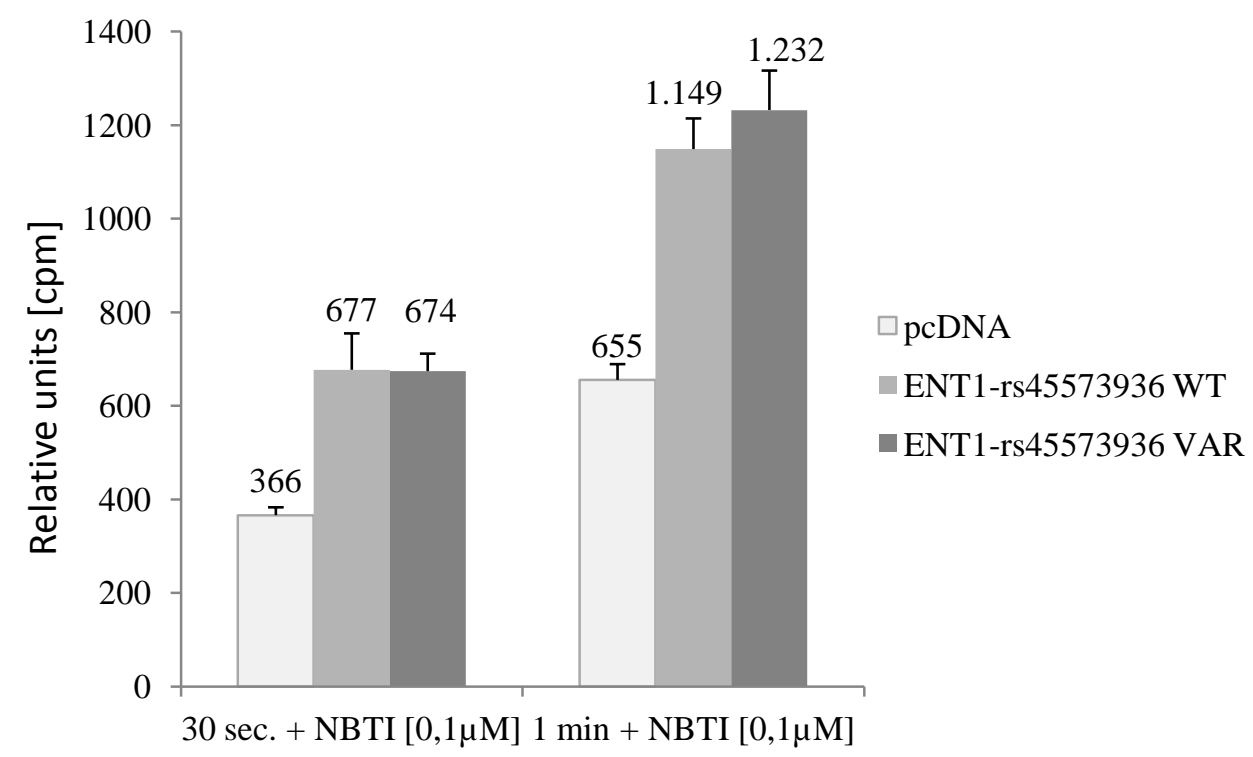

Figure 14: Transport activity of HEK-ENT1-rs45573936 wild type and variant clones in presence of $0.1 \mu \mathrm{M}$ NBTI

\subsection{Functional Evaluation of ENT1 Promoter Polymorphism}

In three independent clinical cohorts a genetic polymorphism upstream of the ENT1 gene was reproducibly related to the overall survival of pancreatic cancer patients having undergone gemcitabine-based chemotherapy (SCHAUDINN 2013) (Christian Zimmer, medical thesis in preparation). Due to the localization of this polymorphism, i.e. rs1057985, upstream of the ENT1 gene functional hypotheses were drawn. Several ENT1 transcript variants have been identified, which differ in the 5' UTR sequence, but all code for the same protein.

\subsubsection{ENT1 Transcript Variant Expression}

A thorough ENT1 promoter region analysis was undertaken suggesting twelve different transcript variants (FUKUCHI et al. 2010). Eleven of them are listed in the ENSEMBL database, of which ten are protein-coding. Of the latter, six are covered by the five transcript variants listed in NCBI gene bank and four are unique in ENSEMBL. For these nine variants, specific primers (Table 3) were designed and expression was tested in lymphoblastoid cell lines and in a pool of pancreatic cancer cell lines by qRT-PCR. Expression beyond marginal was verified only for four variants which correspond to 
variants 2, 3, 4, and 5 in NCBI. These four variants were then determined in different human tissues, six pancreatic cancer cell lines, and a set of lymphoblastoid cell lines. In a panel of 20 human tissues the two most abundant transcript variants were ENT1-v3 and ENT1-v5. Highest expression of ENT1-v5 was observed in adipose tissue whereas it was low in brain, kidney and lung (Figure 15). Unfortunately, no sample of pancreatic tissue was contained in the panel. Instead, the quantities of ENT1 transcript variants were determined in six pancreatic tumor cell lines (obtained from ATCC cell repository). In all pancreatic cancer cell lines tested, ENT1-v5 is expressed most (Figure 16). The second highest expression was observed for ENT1-v4 except for PancI where it was slightly lower than ENT1-v3. ENT1-v4 differs from ENT1-v5 only by a 3 bp insertion inside the 5'-UTR. 


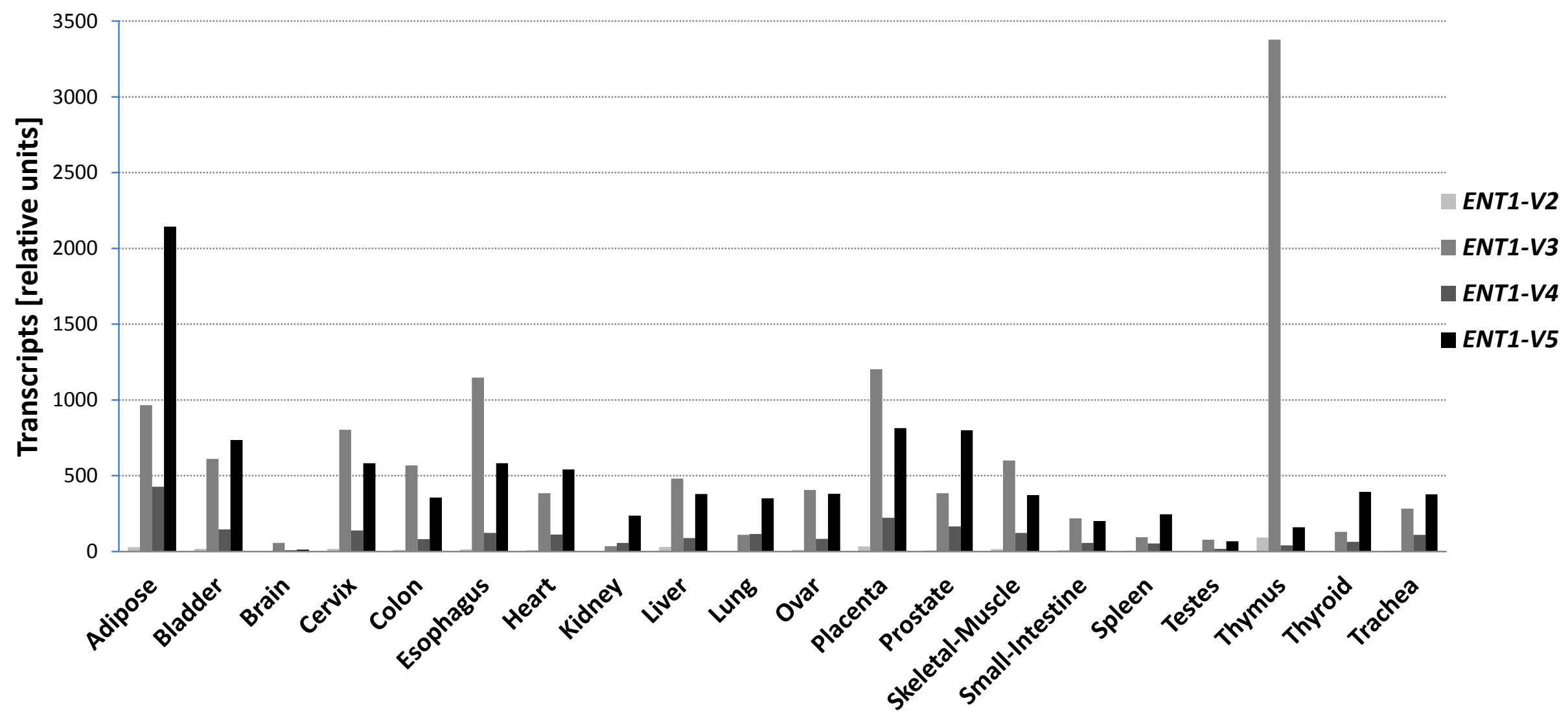

Figure 15: ENT1 transcript variant expression in a panel of various human tissues. Expression data normalized to HPRT1 were referred to the lowest transcript number over all tissues, i.e. ENT1-v2 in kidney. 


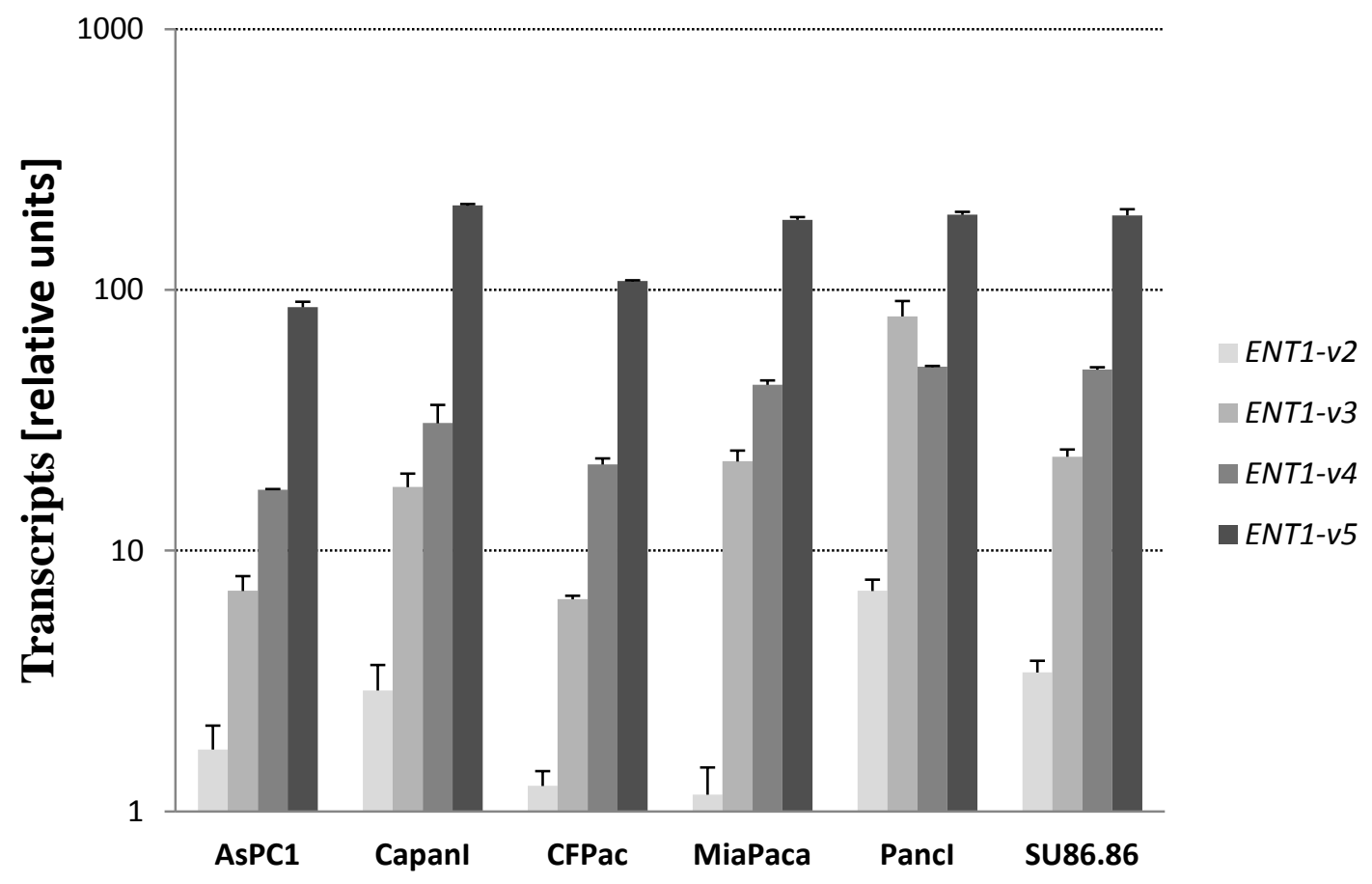

Figure 16: ENT1 transcript variant expression in pancreatic cancer cell lines. Data, which were normalized to the mean expression of the reference genes HPRT1 and 36b4, were all referred to the lowest observed expression value, i.e. ENT1-v2 in MiaPaca. For better visual depiction, the y-axis is scaled logarithmically.

Likewise, ENT1 transcript expression was quantified in 16 lymphoblastoid cell lines [3.6.5] (GM11840, GM12005, GM12154, GM12750, GM12814, GM10854, GM12812, GM07022, GM07357, GM11831, GM11832, GM11882, GM12248, GM12813, GM12749, GM12749). ENT1-v3 exhibited the strongest expression followed by ENT1-v5. These two isoforms presented with much broader expression variability in comparison to the low expressed ENT1-v2 and ENT1-v4 (Figure 17). Expression of ENT1-v1 was neglectable. 


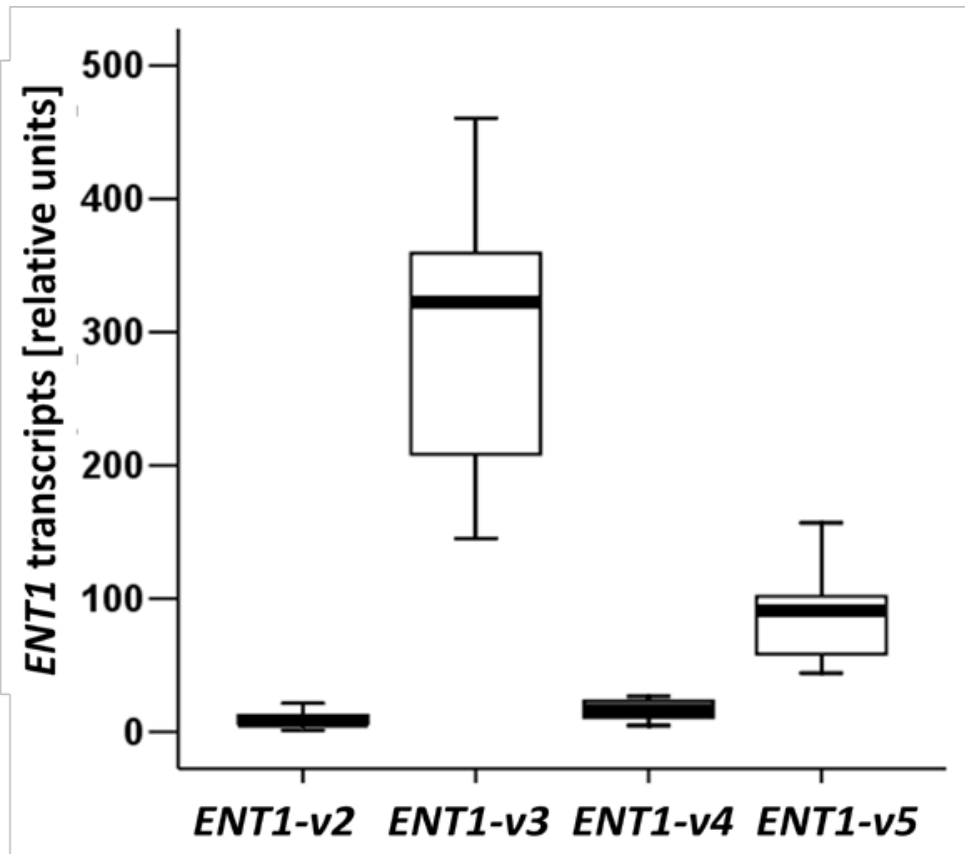

Figure 17: Quantitative variability of ENT1 transcript variants in 16 LCLs. Normalization was carried out by a weighted mean of the reference genes $G A P D H, H P R T 1$, and $U B C$, i.e. the mean of the $\mathrm{Ct}$ (cycle threshold) values of these three genes was subtracted from the Ct values of each ENT1 transcript variant.

\subsubsection{Gemcitabine Effects on ENT1 Expression}

As gemcitabine is the standard treatment in pancreatic cancer and as gemcitabine effects have been attributed to ENT1 the effects of this cytostatic drug on ENT1 transcript variants were investigated. Therefore, the six aforementioned pancreatic cancer cell lines and a panel of 16 LCLs were exposed to a moderate dose (based on literature and pilot experiments) of gemcitabine for $24 \mathrm{~h}$. In LCLs, quantitative measurements by qRT-PCR revealed induction of the long transcript variants ENT1-v4 and ENT1-v5. In contrast, the shorter isoforms ENT1-v2 and ENT1-v3 were not altered (Figure 18).

In the pancreatic cancer cell lines AsPC1, SU.86.86 and CFPac, the expression of ENT1-v4 and ENT1-v5 were substantially upregulated in relation to the reference genes. In contrast, the short transcripts ENT1-v2 and ENT1-v3 were induced to a much lesser extent. In Capan1 and MiaPaca2, ENT1 transcript increase upon gemcitabine was generally less pronounced; a 2-fold induction was noted in Capanl for ENT1-v4 and in MiaPaca2 for ENT1-v4 and v5. In PancI, no notable alteration in ENT1 gene expression by gemcitabine could be observed (Figure 19). 


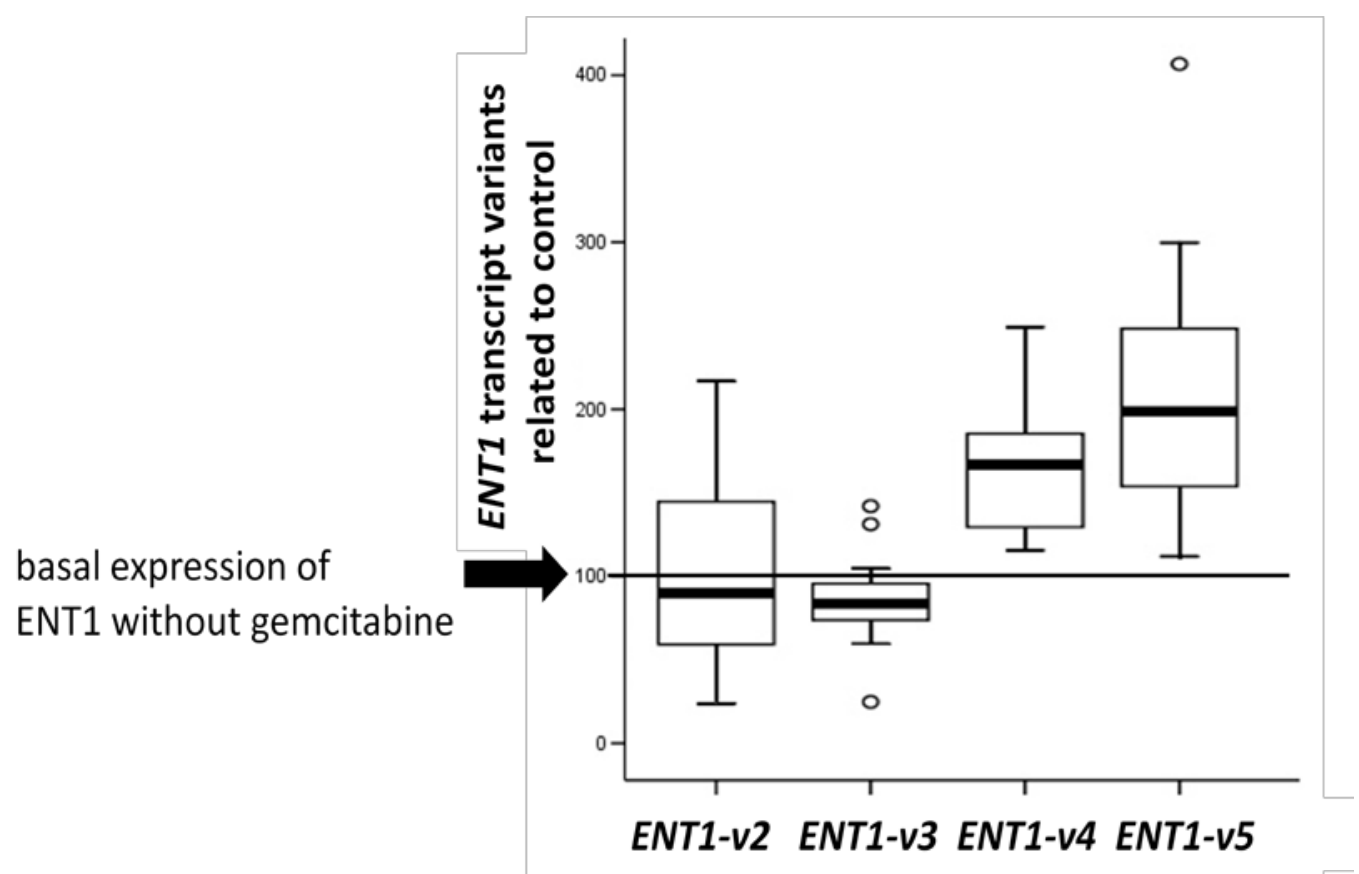

Figure 18: Gemcitabine effects on transcription of ENT1 variants in 16 LCLs. Upon incubation with $18 \mathrm{nM}$ gemcitabine for $24 \mathrm{~h}$ RNA was harvested and transcribed to cDNA. Expression of the indicated ENT1 target transcripts was normalized to a weighted mean of GAPDH, HPRT1, and UBC serving as reference genes.
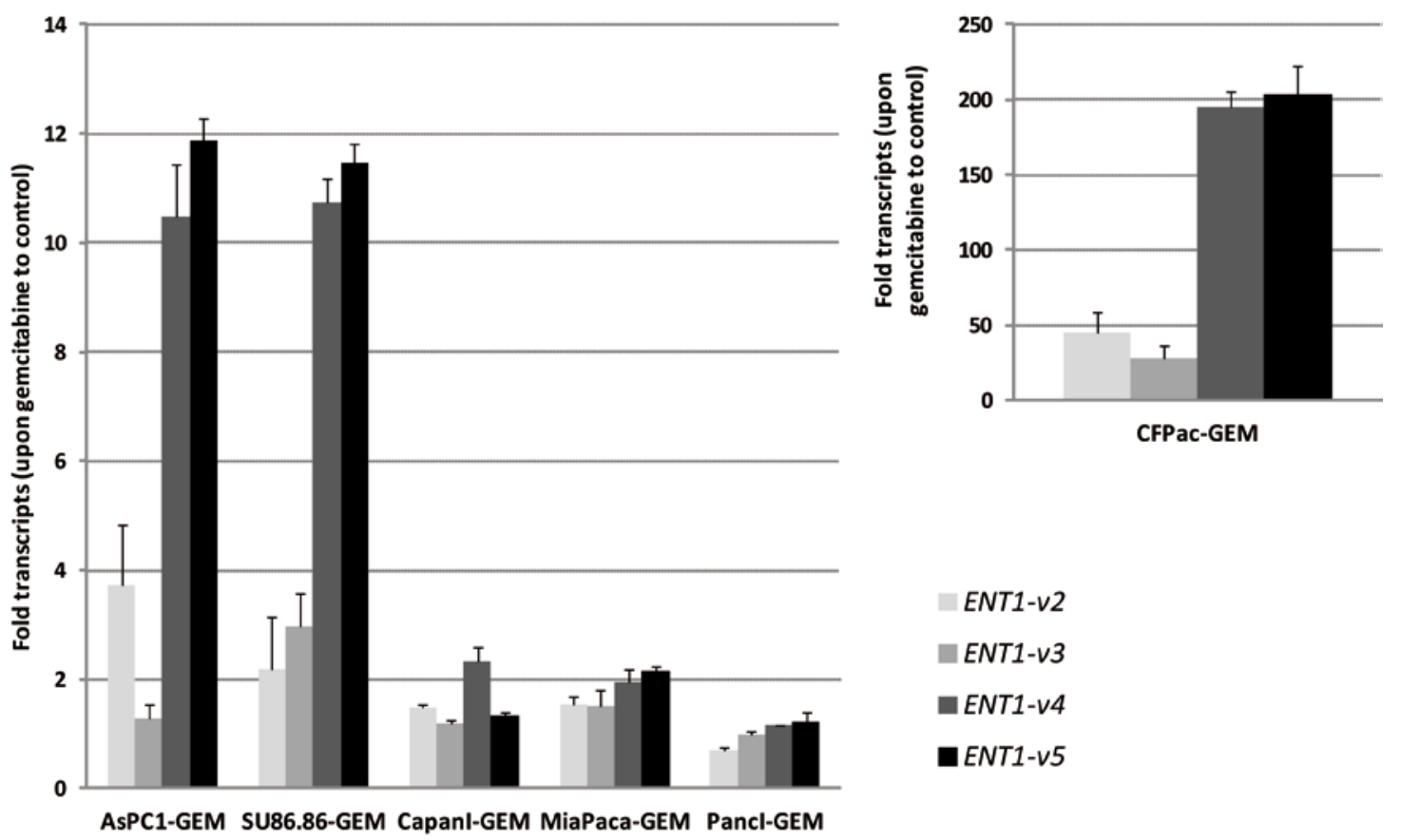

Figure 19: Induction of ENT1 transcripts by $5 \mu \mathrm{M}$ gemcitabine in pancreatic cancer cell lines. The induction of each transcript upon gemcitabine is referred to the untreated control (see Figure 16), which is set to a value of 1 . 


\subsubsection{Impact of ENT1 Promoter SNP on ENT1 transcription}

The location of the recently associated ENT1 polymorphism rs1057985 (SCHAUDINN 2013) was analyzed in relation to the ENT1 genetic region. Rs1057985 is located 1,341 bp upstream of the transcription start site of the two longest ENT1 transcripts, i.e. ENT1-v4 and ENT1-v5 (Figure 20). Thus, the hypothesis that the expression of the latter might be modulated by this polymorphism should be investigated in detail.

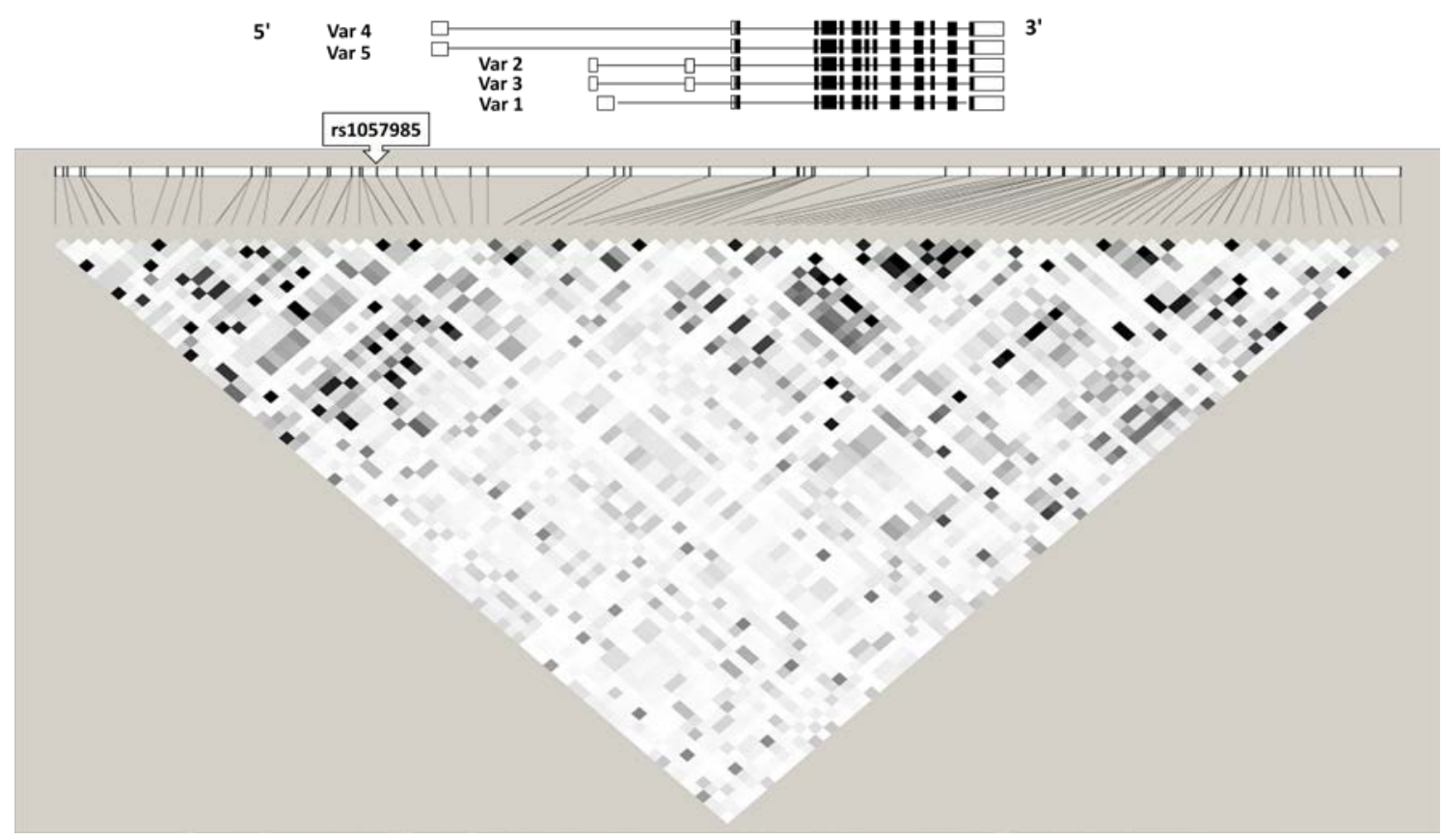

Figure 20: Plot of linkage disequilibrium in ENT1 $(-10 \mathrm{~kb} /+2.5 \mathrm{~kb})$ genetic region based on $247 \mathrm{fully}$ sequenced individuals. The position of the SNP rs1057985 is highlighted. Above the plot, the location of the five ENT1 transcript variants is displayed.

Therefore, effects of rs1057985 on basal and gemcitabine-modulated gene transcription of ENT1-v5 were evaluated in a set of 101 genetically diverse LCLs also used for cytotoxicity assessment. Since ENT1-v4 is only barely expressed in LCLs (Figure 17) this transcript was not assayed here. Under basal conditions without gemcitabine the expression of ENT1-v5 was not related to rs1057985 ( $\mathrm{p}=0.3$, data not shown). Conversely, upon gemcitabine treatment the extent of ENT1-v5 induction was dependent on rs1057985 (Table 15). Homozygous variant allele carriers exhibited the strongest induction, that for heterozygous state was intermediate, and that for 
homozygous wild-type allele was lowest ( $\mathrm{p}_{\text {trend }}=0.03$ in linear regression). This finding points to a putative promoter modulating effect resulting in enhanced expression of ENT1-v5.

Table 15: Induction of ENT1-V5 by gemcitabine in LCLs in dependence on the SNP rs1057985

\begin{tabular}{|l|l|l|}
\hline Genotype & Number & $\begin{array}{l}\text { transcripts } \\
\% \text { to control }\end{array}$ \\
\hline Wildtype & 43 & $\mathbf{1 4 5}$ \\
\hline Heterozygous & 45 & $\mathbf{1 7 7}$ \\
\hline Variant & 13 & $\mathbf{1 9 7}$ \\
\hline & & \\
\hline
\end{tabular}

\subsubsection{Exploration of Genetic Linkage Disequilibrium of rs1057985}

Since genetic markers in high linkage disequilibrium (LD) indicative for common inheritance result in similar associations with phenotypic traits it should be investigated if there are other genetic polymorphisms in high LD with rs1057985. Therefore, genetic data of fully sequenced 247 Caucasian individuals were downloaded from the 1000 human genomes database (http://www.1000genomes.org/) in relation to the ENT1 genetic locus including $10 \mathrm{~kb}$ upstream and $2.5 \mathrm{~kb}$ downstream of the transcription margins and visualized in HaploView (version 4.2, available at http://www.broadinstitute.org). This analysis revealed one SNP, rs507986, in perfect LD (i.e., $\mathrm{r}^{2}=1.0$ ) with rs1057985. No other genetic marker was in high LD with rs1057985 (i.e. $\mathrm{r}^{2}=0.8$ ). The polymorphism rs507964 is positioned $852 \mathrm{bp}$ upstream the transcription start of ENT1-v4 and ENT1-v5. 


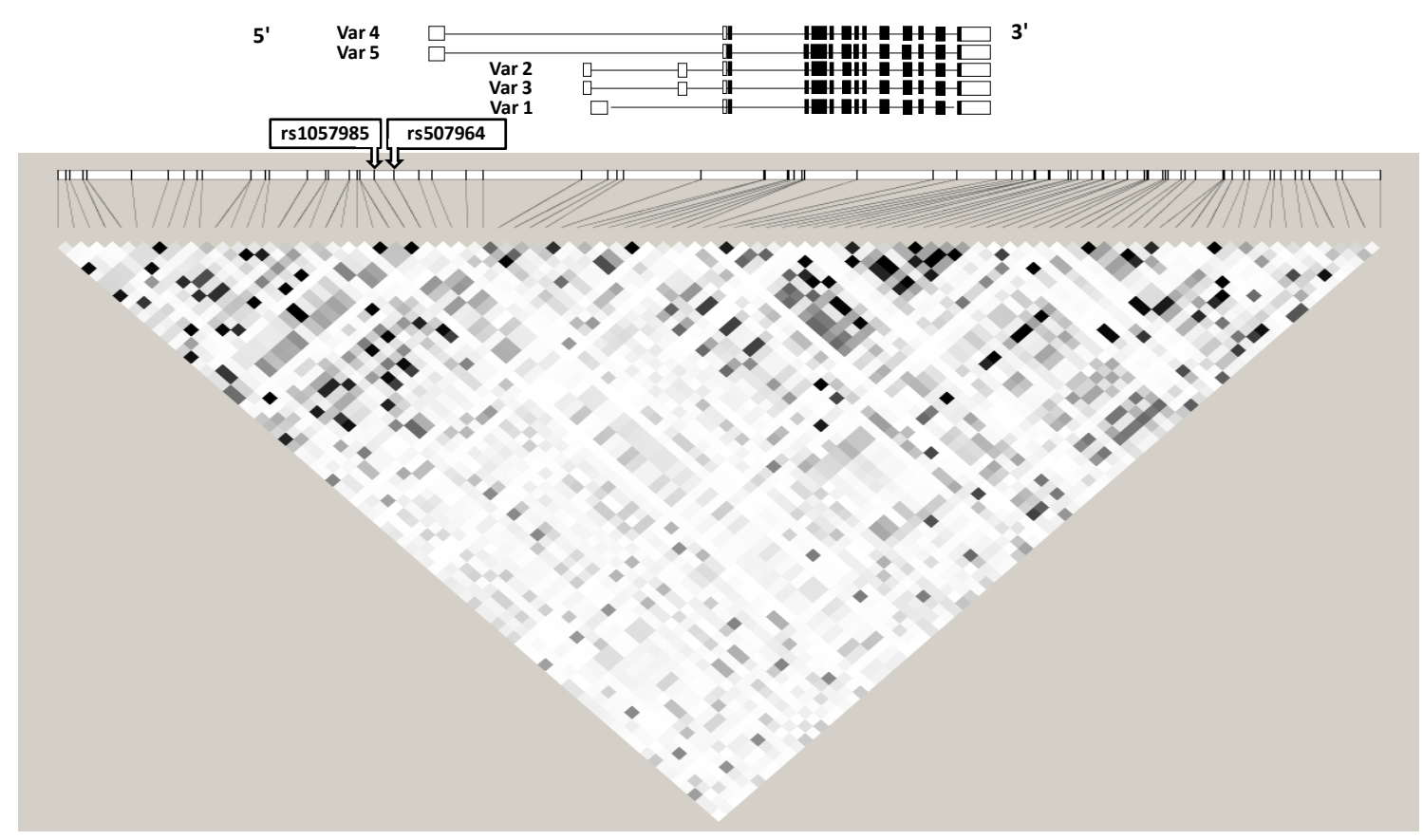

Figure 21: Plot of linkage disequilibrium in ENT1 $(-10 \mathrm{~kb} /+2.5 \mathrm{~kb})$ genetic region based on 247 fully sequenced individuals. SNPs with a minor allele frequency of $1 \%$ are displayed with the positions of the SNPs rs1057985 and rs507964 specifically marked. Above the plot, the location of the five ENT1 transcript variants is depicted.

\subsubsection{In silico Assessment of Regulatory Genetic Elements}

First, the genomic sequence context adjacent to the ENT1 promoter region was evaluated for evolutionary conserved regions suggesting functionality. According to the ECR-Browser (http://ecrbrowser.dcode.org) both SNPs are located in a region evolutionary highly conserved only between man, Chimpanzee and Rhesus macaques (Figure 22). 


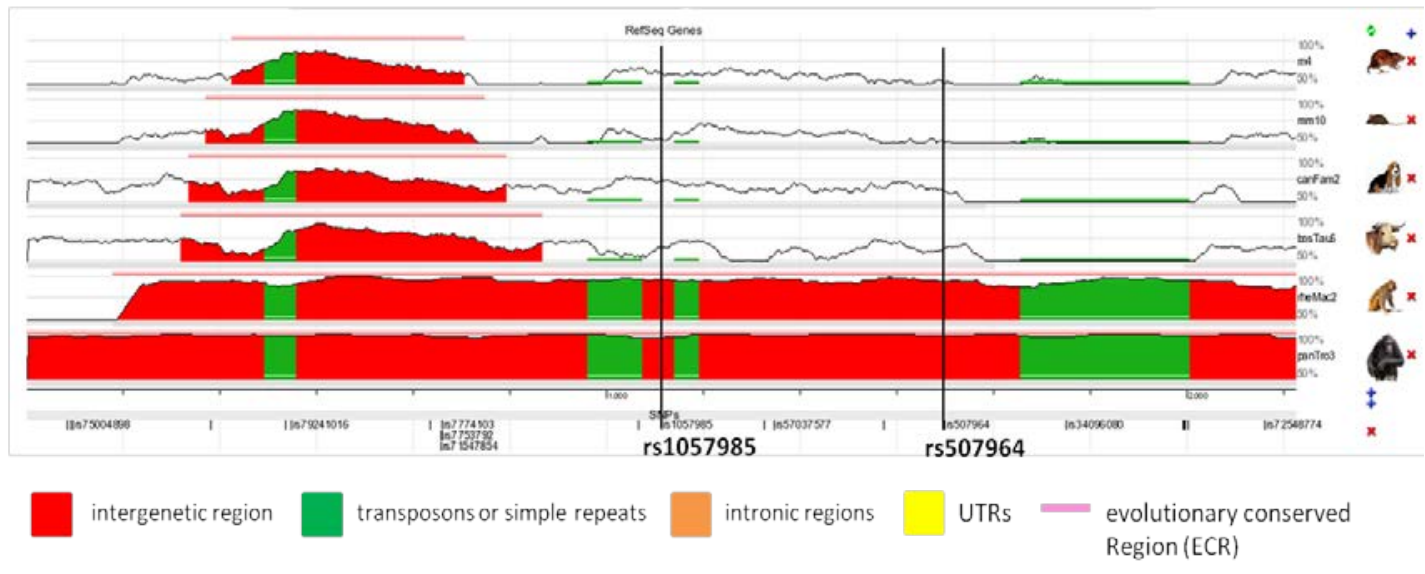

Figure 22: Illustration of evolutionary conserved regions (ECRs) in the DNA of different species compared to humans (according to ECR Genome Browser). The diagram shows the level of evolutionary conservation in the DNA region flanking the two ENT1-SNPs (rs1057985 and rs507964). The kind of species is shown on the right by an icon (rat, mouse, dog, cow, Rhesus macaques and Chimpanzees, in the order from top to down). Types of sequence stretches in regard to genes are shown in different colors. The more a region is evolutionary conserved the higher the peak of the curve is.

According to the UCSC Genome Browser database (http://genome.ucsc.edu) the ENT1 SNP rs507964, but not rs1057985 is located in a putative regulatory element due to the acetylation status at histone H3 lysine 27 (H3K27Ac) (Figure 23), which is often found near active regulatory elements (BOGDANOVIC et al. 2012). In addition, this regions offers a DNase hypersensitivity cluster, again indicative for a regulative role in gene expression. In a DNase hypersensitive cluster the nucleosomal structure is not organized in the normal manner, which makes it sensitive towards DNAse cleavage. In most cases hypersensitive sites are found ahead of active promoter regions. Moreover, the data from the UCSC Genome Browser suggests a transcription factor binding site in the sequence context of rs507964, but not of rs1057985 (Figure 23). Together, these findings indicate that rs507964 is part of a functional region and might play a role in regulation of ENT1 expression. 


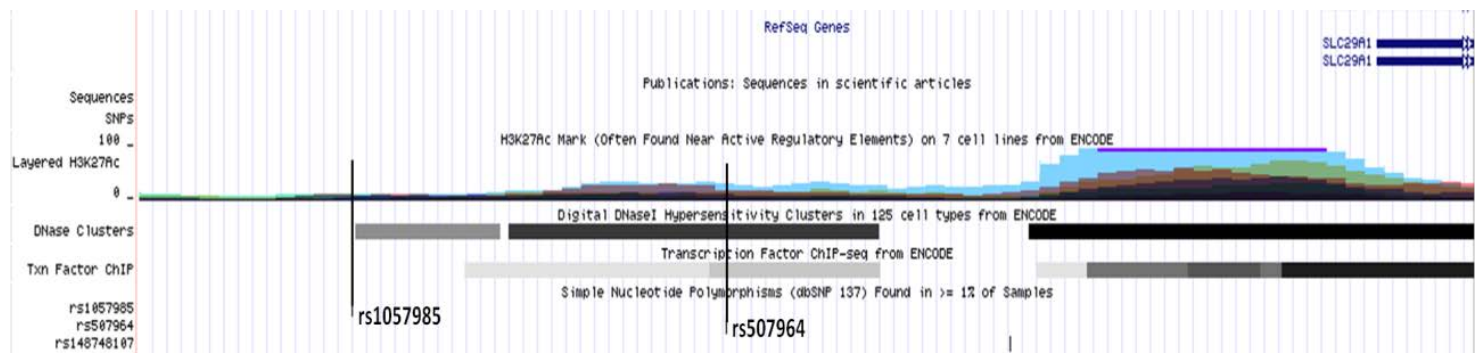

Figure 23: Assessment of the ENT1 rs1057985 and rs507964 containing sequences for putative promoter sites by UCSC genome Browser. The image displays, from top to down, the degree of acetylation by H3K27Ac, DNase hypersensitive clusters, and prediction of transcription factor binding sites based on ChIP-Seq data. Transcription start of ENT1-v4 and ENT1-v5 is indicated by the bars in the right-upside corner termed as "SLC29A1" with the region directly upstream of which suggesting particularly strong regulatory elements.

\subsubsection{Nuclear Protein Interaction with ENT1 SNP Region}

An important mechanism of gene expression regulation is binding of transcription factors on DNA which was suggested to occur in the sequence context of rs507964 according to the abovementioned clinical, gene expression, and bioinformatic data. This hypothesis was tested by electrophoretic mobility shift assays (EMSA). The EMSA reveals nuclear protein binding at rs507964 as demonstrated in different cell lines comprising LCLs, HEK and the pancreatic cancer cell lines MiaPaca and AsPCI (Figure 24) Interestingly, this binding appeared allele-specific only affecting the wildtype at this position. Cold competition experiments with nuclear extracts from LCLs confirmed this allele specificity as the interaction between the radio-labelled wildtype probe and the nuclear protein could be competed more efficiently by the nonlabelled wildtype than the variant allele probe (Figure 26). Non-labelled probe for CRE (cAMP response element) as a reference did not interfere with protein binding suggesting specificity of the aforementioned competition (data not shown). There was no protein binding detectable for the probes of rs1057985 with nuclear extracts from LCLs (data not shown). 


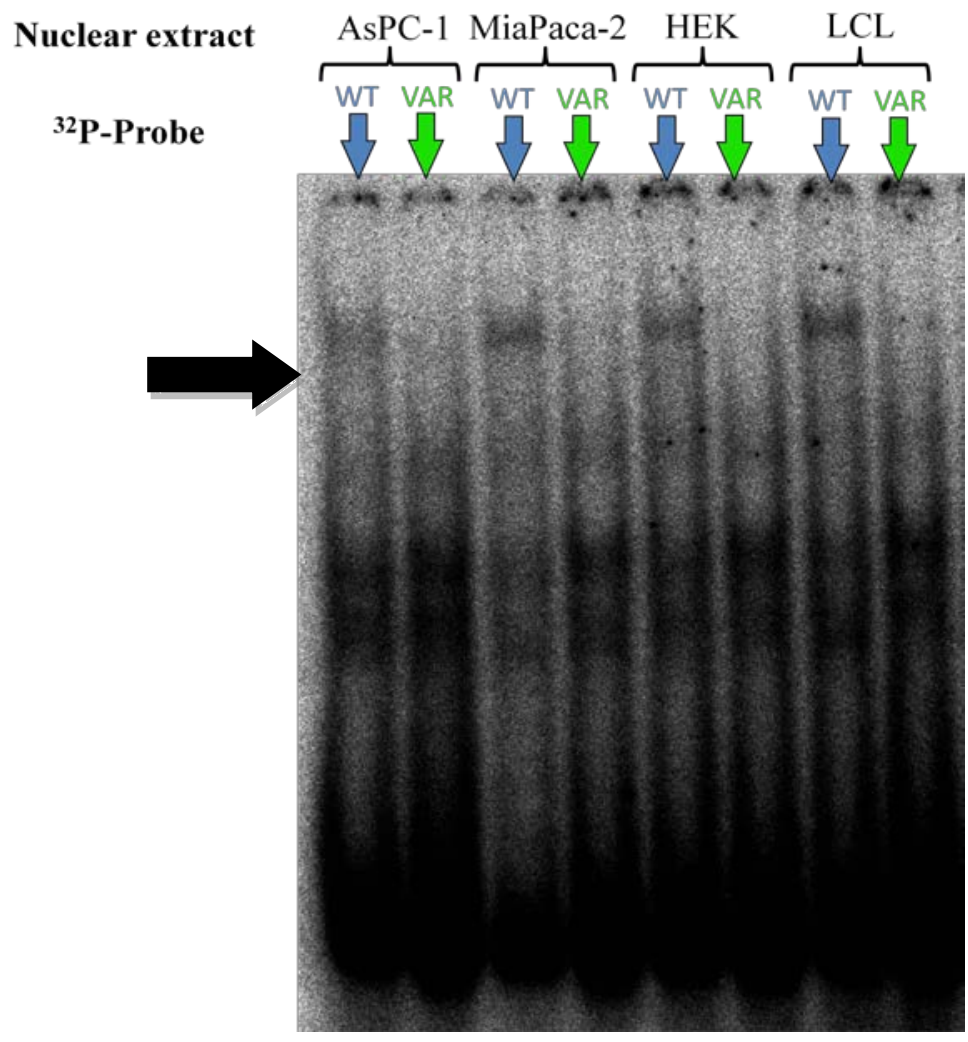

Figure 24: EMSA with allele-specific ${ }^{32}$ P-labelled probes at rs507964. The arrow indicates the band of interest, i.e. binding of nuclear cell extract protein at the labeled probe. The lanes from left to right represent pairwise wild type and variant allele probes incubated with nuclear extracts of AsPC-1, MiaPaca2, HEK and LCL.

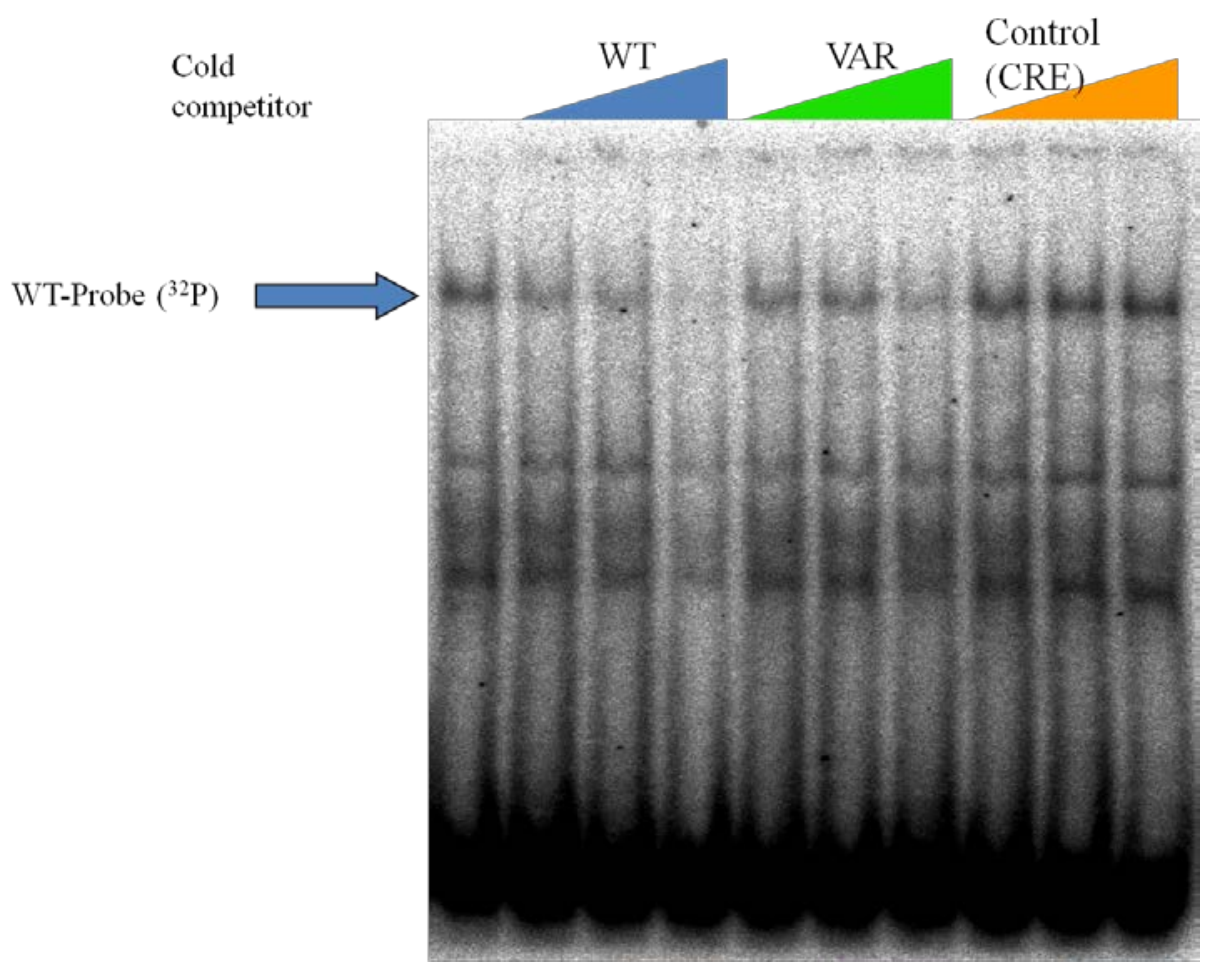

Figure 25: Cold competition experiments for ${ }^{32} \mathrm{P}$-labelled rs507964 wild type probe. The protein binding in lane 1 is interfered with increasing amounts (3-fold, 5-fold and 20fold) of non labeled wild type probes (lane 2-4), variant probes (lane 5-7), and unspecific probe (CRE) (lane 8-10). 


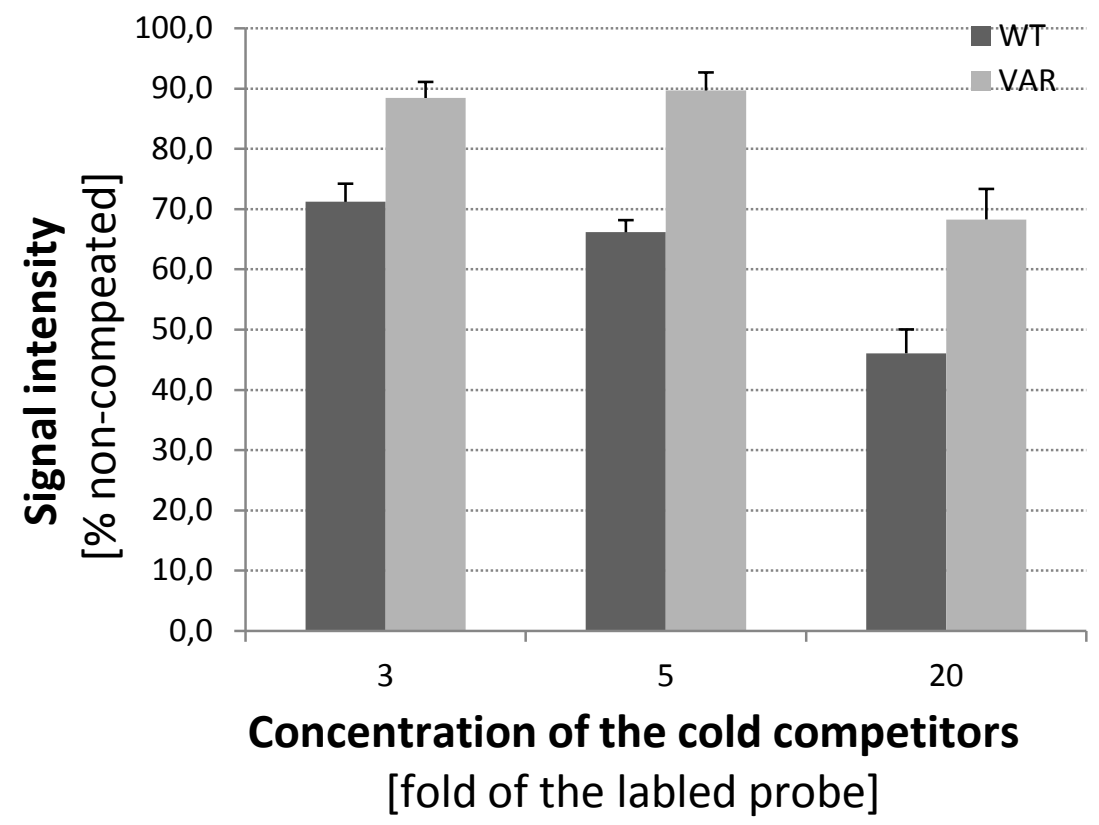

Figure 26: Cold competition experiments for ${ }^{32} \mathrm{P}$-labelled rs507964 wild type probe. To test for specificity, non-radio-labeled probes for the rs507964 wild type and variant allele with identical sequence context were evaluated for interference with nuclear extract binding. The graph illustrates the signal intensity means \pm SEM derived from four independent experiments.

\subsubsection{Identification of the Nuclear Binding Protein}

The protein exhibiting binding at the wild type allele at rs507964 was attempted to be identified. Bioinformatic tools use different patterns of DNA binding (so-called consensus sequences) to calculate the binding probability of a certain protein. Calculations were performed based on the TRANSFAC database (Release 2012.2, (MATYs et al. 2003)) in cooperation with Martin Haubrock (Wingender Group, University Göttingen). The settings were chosen for optimal discrimination at the polymorphic site of interest. The results were sorted according to a score value for the binding probability (Table 17). Five top hits of this analysis (i.e., P300, CDP, AP2Alpha, SP1, EGR-family) were selected for synthesis of probes tested for cold competition in EMSA experiments. Respective primer pairs for validated consensus sequences were taken from Santa Cruz Homepage (http://www.scbt.com/support-tabletranscruz_gel_shift_oligonucleotides.html) except for P300 which was not listed there and instead was adopted from literature (CHEN and HuNG 1997). These sequences were 
compared with the binding motifs elicited by the bioinformatic screen using the Transcription Element Search System (http://www.cbil.upenn.edu/tess). Prominent competition of nuclear extract binding at rs507964 wild type was achieved by even moderate concentrations of the SP1 consensus sequence referred to the binding motif V\$SP1_Q6. The latter interaction was even stronger than that of the corresponding nonlabeled probe of the rs507964 sequence context. At higher concentrations, the consensus sequence of the transcription factor AP2-Alpha also shows competition (Figure 27). Thus, SP1 was considered as a major candidate for the binding protein of the nuclear extracts.

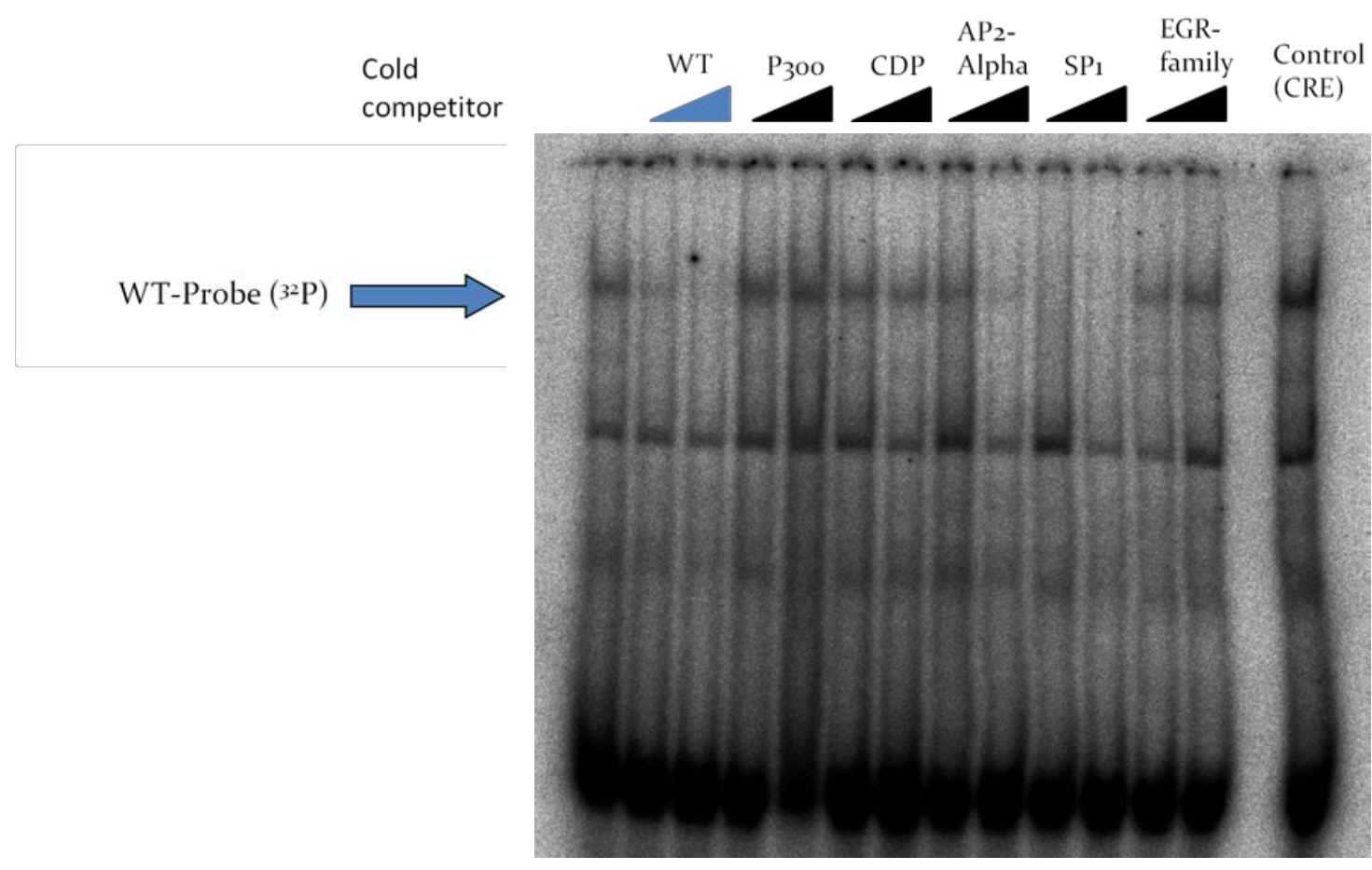

Figure 27: Cold competition experiments via electrophoretic mobility shift assays with consensus sequences for putative binding proteins at ENT1 rs507964 using nuclear extracts from LCLs. All conditions are based on the ${ }^{32} \mathrm{P}$-labelled wild type probe except CRE which served as positive control for the nuclear extract. The lane on the left represents the non-competed probe. Competitions were carried out pairwise (5-fold and 20-fold) with the sequence context of the wild type allele at rs507964 (WT), and with the consensus sequences for the indicated proteins.

To get further evidence whether SP1 is the actual binding partner its binding motif was analyzed in detail. It reveals a mutation in one of the four crucial bases of the SP1 motif in presence of the variant allele at rs507964 making weaker binding plausible in comparison to the wild type allele (Figure 28). 


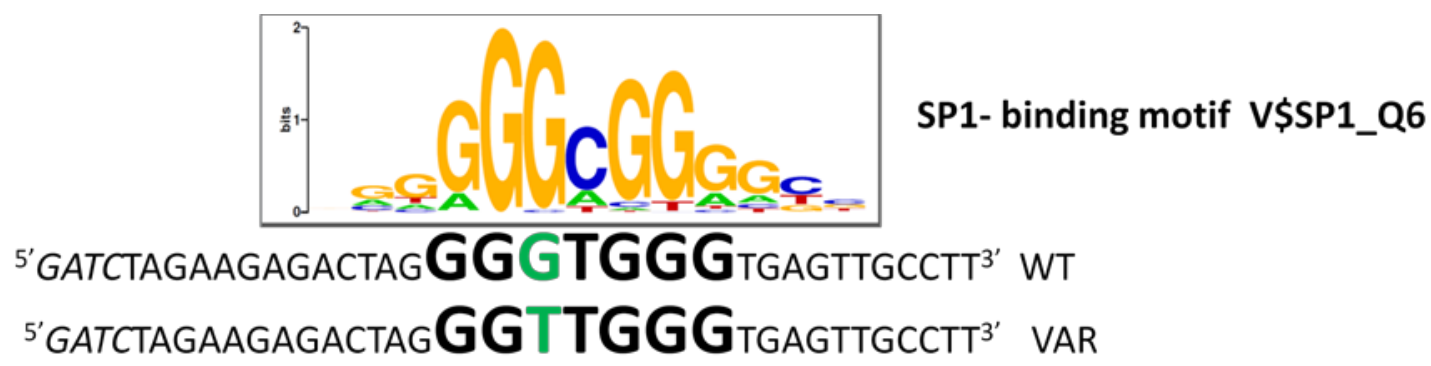

Figure 28: Comparison between the binding motif VSSP1_Q6 and the sequence context at rs507964. This motif was provided by the Transcription Element Search System (http://www.cbil.upenn.edu/tess). The systematic name of this motif is M9525. The higher a letter in this motif is, the more important this specific base for the binding pattern is. The y-axis expresses the respective bits ranging from 0 (no base preferred) to 2 (only one base preferred). Beneath this plot, the sequences flanking the wildtype and variant allele at rs507964 (highlighted in green) are depicted with the bases most relevant for the V\$SP1_Q6 motif displayed in bold.

In the next step, bases promoting binding according to the binding motive provided by TESS (Transcription Element Search System, http://www.cbil.upenn.edu/tess) were mutated with respect to the sequence stretch with wildtype allele at rs507964. The allele at rs507964 itself was not changed here since reduced competition has been demonstrated before for the variant allele of this polymorphism (Figure 26). If SP1 is the real binding protein the competition of the mutated probes should be reduced in comparison to the wildtype sequence. The respective EMSA results are shown in Figure 29. Protein binding at the radio-labelled probe was completely abolished by the consensus sequence for the SP1 motif V\$SP1_Q6. Mutation of four crucial bases in close vicinity of rs570964 did not interfere anymore. Only slight interference was detected for the probes mutated at single positions one base upstream and two bases downstream of rs507964, respectively. 

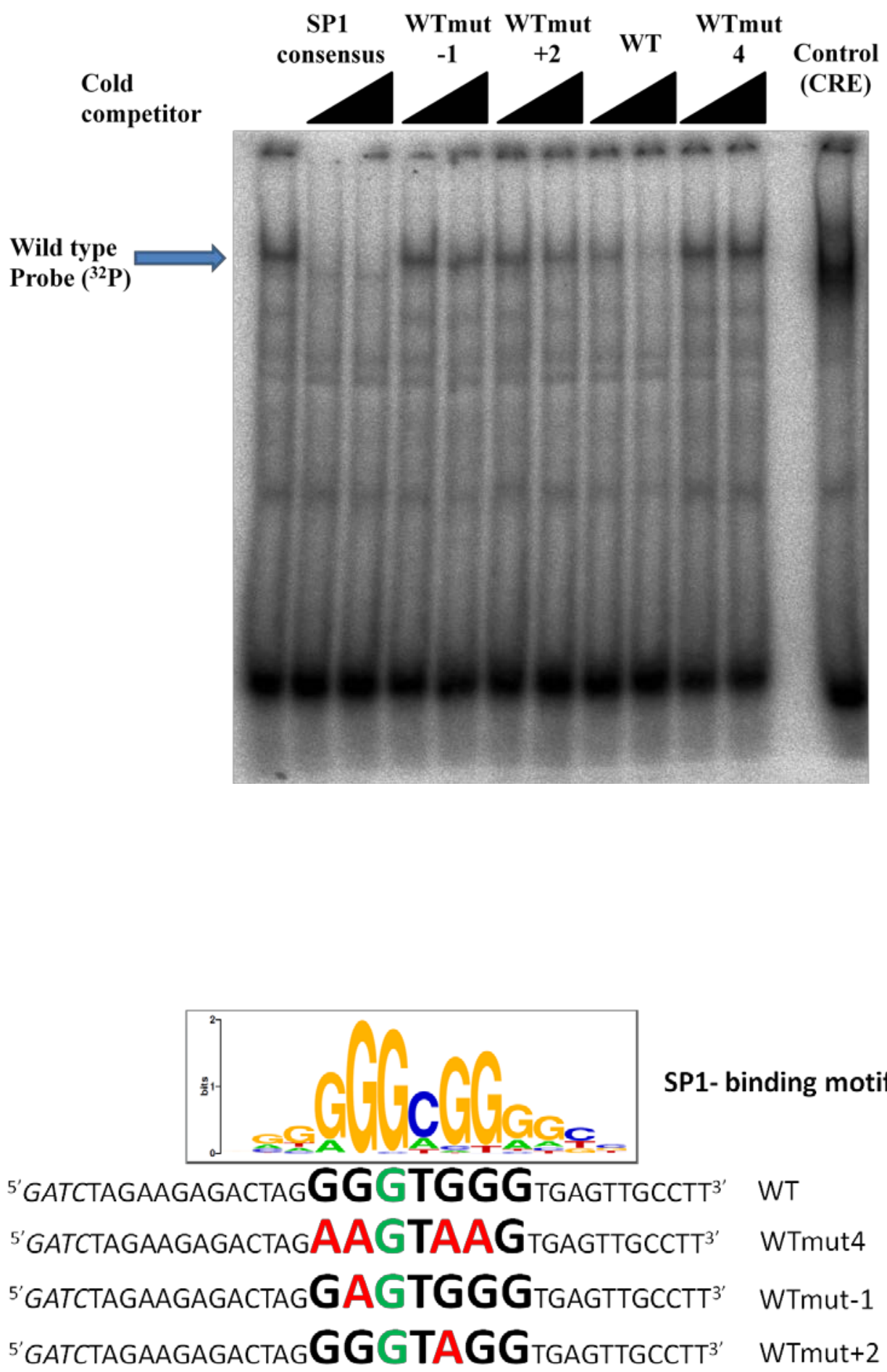

Figure 29: Analysis of SP1 binding motif mutations. Three types of mutations (WTmut4, WTmut-1, WTmut+2) were tested for cold competition with respect to the non-mutated probe (WT) and the consensus sequence for the V\$SP1_Q6 binding pattern (SP1 consensus). The EMSA results are depicted in the upper panel with the non-competed radio-labeled wild type probe on the left, followed by competitions with the indicated sequences (5-fold and 20-fold each). The lower panel depicts the sequences of the mutated probes in relation to the wild type sequence context at rs507964. The mode of illustration is analogous to that described in Figure 28. 


\subsubsection{Effect of ENT1 SNP rs507964 on promoter activity}

The hypothesis of expression regulating elements in the sequence stretch comprising rs507964 should be investigated both whether this region modulates promoter activity in general and whether there is any allele-specific dependency on rs507964.

To address these issues two types of inserts, each for the two alleles of rs507964, were cloned into vectors for reporter gene assays. The first type corresponds to the $35 \mathrm{bp}$ sequences of the abovementioned EMSA primers. The second comprises a $2122 \mathrm{bp}$ DNA fragment upstream of the start codon of the long transcripts ENT1-v4/ENT1v-5 containing rs507964 and rs1057965. As host for reporter gene analysis the pancreatic cancer cell line AsPcI was chosen, since this cell line provides high basal expression rate of the long ENT1 transcript variants according to qPCR results (Figure 16). It was demonstrated that the construct with the long insert exhibited strong promoter activity whereas the short 35 bp insert did not. However, no allele-specific effect of rs507964 was observed. In addition, exposure to gemcitabine did not obviously alter the reporter gene activity of the transfected ENT1 sequence fragments.

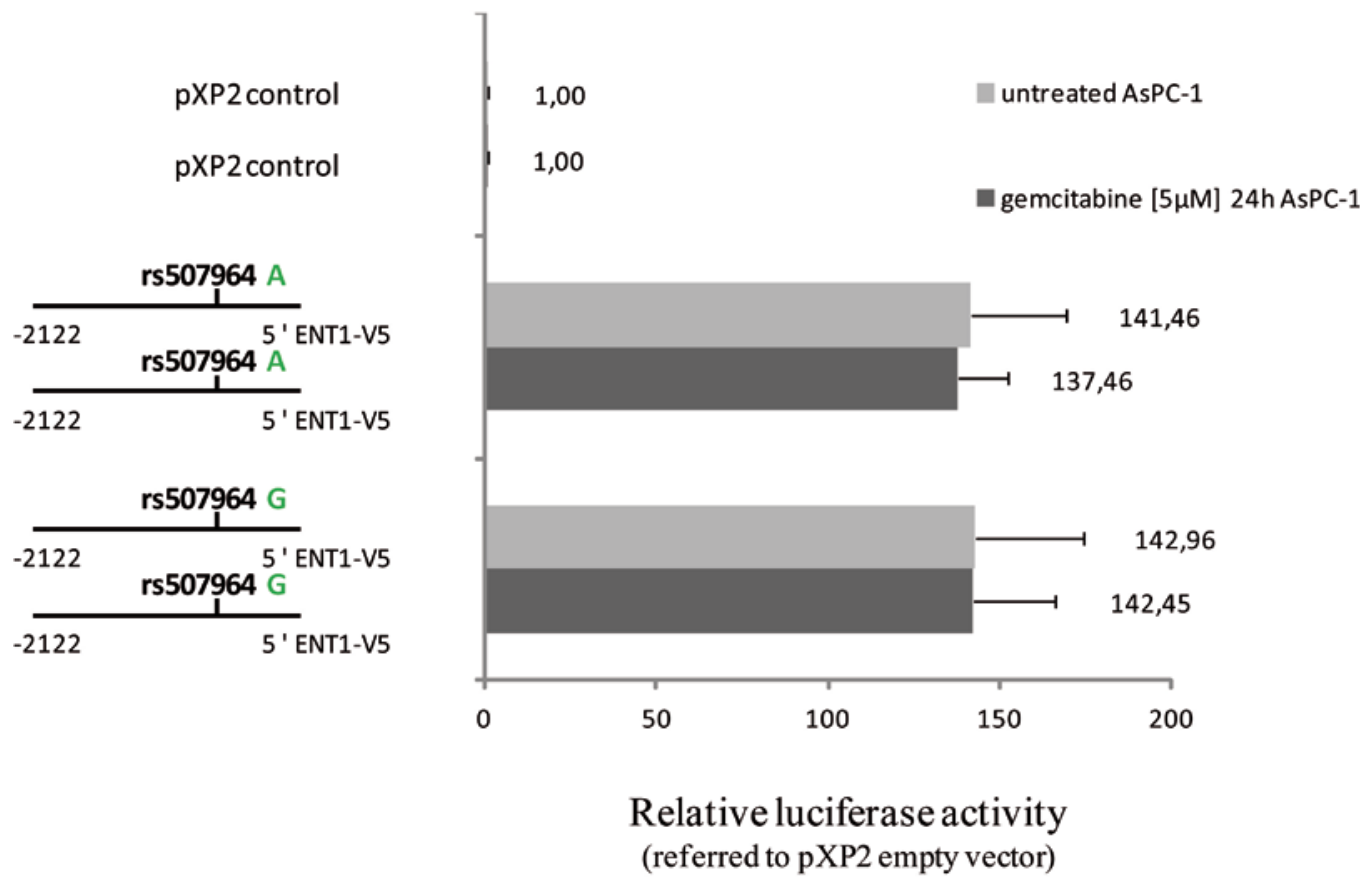

Figure 30: Allele specific induction of 2122bp ENT1-V4/-v5 rs507964 promoter fragments in pXP2 vector. Promoter fragments were transfected in AsPC-1 pancreatic cancer cell line and allele specific induction was measured under normal conditions and in presence of gemcitabine. 


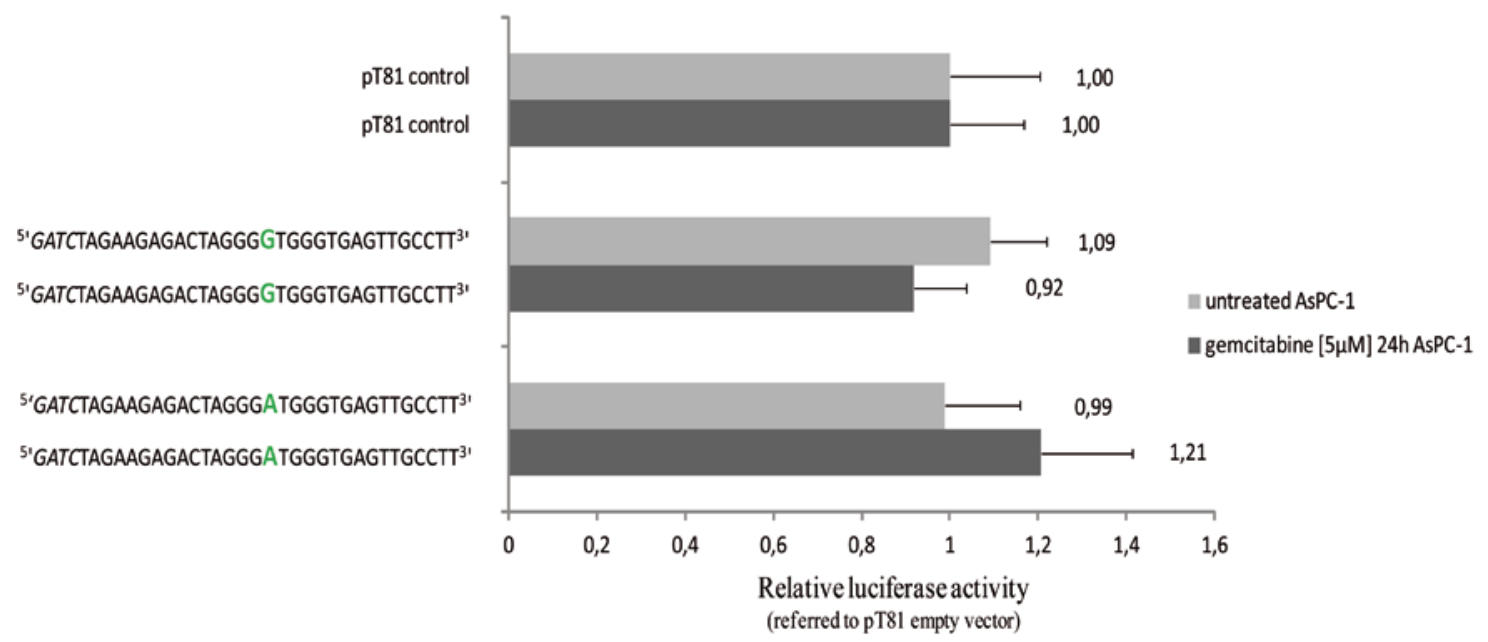

Figure 31: Allele specific induction of rs507964 EMSA primer in pT81 vector. EMSA primer were transfected in AsPC-1 pancreatic cancer cell line and allele specific induction was measured under normal conditions and in presence of gemcitabine.

\subsection{Determination of Gemcitabine Metabolites by HPLC}

During my thesis a method for determination and quantification of tritium labeled gemcitabine and its metabolites was established by myself [3.11.1]. This method turned out to generate very robust and reproducable results. Originally this method was established to determine intracellular amounts of gemcitabine and its metabolites in LCLs. Thus the effect of identified specific biomarkers associated with modulation of sensitivity towards gemcitabine should be examined in relation to gemcitabine metabolism. The method was never applied since the approach for extraction of gemcitabine and its metabolites was insufficient and did not show reproducable results. In addition no biomarkers correlated to gemcitabine metabolism could be identified in our institute. For that reason the perfection of the extraction method was not further pursued. Although the method was not employed in my projects, it proved to be a valuable and reliable procedure for investigating gemcitabine metabolism and can be sensibly applied in further examinations. 


\subsection{Recently Suggested New Biomarker: WWOX rs11644322}

While performing my thesis a paper emerged reporting a genome-wide association study (GWAS) with overall survival of gemcitabine-treated pancreatic cancer (INNOCENTI et al. 2012). Five top findings were set up for replication in three patient cohorts. The hit with the strongest association in the cited study could not be confirmed. However, the association for another of the five investigated polymorphisms, rs11644322 pertinent to the WWOX gene, was reproduced. Stimulated by this finding, a series of mechanistic investigations were performed all demonstrating accordance with the clinical finding. These data are described in the subsequent chapters and are part of a manuscript entitled "WWOX polymorphism in a putative SP1 binding site reproducibly predicts outcome in gemcitabine-treated pancreatic cancer”

\subsubsection{Confirmation of GWAS in Clinical Cohort}

The variant allele of the SNP WWOX rs11644322 was associated with worse overall survival (OS) in gemcitabine-treated pancreatic cancer, however, not having passed statistical significance upon adjustment for multiple genome-wide testing (INNOCENTI et al. 2012). In a cohort comprising 397 patients, I could now confirm this finding (Figure 32). Assuming a gene dosage effect elicited statistical significance at $p=8 * 10^{-4}$ (log-rank test) which passed the threshold criterion for multiplicity testing with five markers. According to the three genotypes of WWOX rs11644322, the mean OS was 22 (95\% confidence interval 19-25) months for GG, 18 (14-21) for GA, and 13 (10-16) for AA, and the median OS was 14 (11-16), 13 (11-15), 10 (7-12) months, respectively. Administration of other chemotherapeutic agents in addition to gemcitabine did not affect OS ( $>0.5)$. Cox multivariate regression analysis including the non-genetic parameters as described above in the Methods Section elicited study site (due to heterogeneity in patient enrolment, i.e., a priori better prognosis for the less advanced stages recruited in Heidelberg), age at therapy start, resection status, WWOX rs11644322, histopathologic grading, and M status as predictors for OS. When adjusting for the effects of the non-genetic contributors, a hazard ratio (HR) of 1.39 (95\% confidence interval [CI] 1.26-1.53, $\mathrm{p}=7.1 * 10^{-4}$ ) for $W W O X$ rs11644322 was noticed. Noteworthy, the impact of this genetic polymorphism was prevalent in both prospective and retrospective study conditions. In the Heidelberg cohort which was collected for a prospective clinical trial with a median OS of 23 months versus 12 for both the 
Göttingen and Hamburg cohort) the effect of rs11644322 was particularly pronounced with a HR of 1.92 (95\% CI 1.55-2.38, p=0.002) upon adjustment for the aforementioned non-genetic parameters. In the study sample from Heidelberg, rs11644322 evolved as a stronger predictor for OS than all considered non-genetic variables whereby outreaching established prognostic parameters like resection status, grading or presence of distant metastasis. However, when restricting the analysis to the two retrospective cohorts (Göttingen and Hamburg), the impact of rs11644322 on OS was less pronounced but still detectable with a HR of 1.27 (95\% CI 1.14-1.42, $\mathrm{p}=0.03)$. The characteristics of patient cohort are described in the methods section (Table 12).

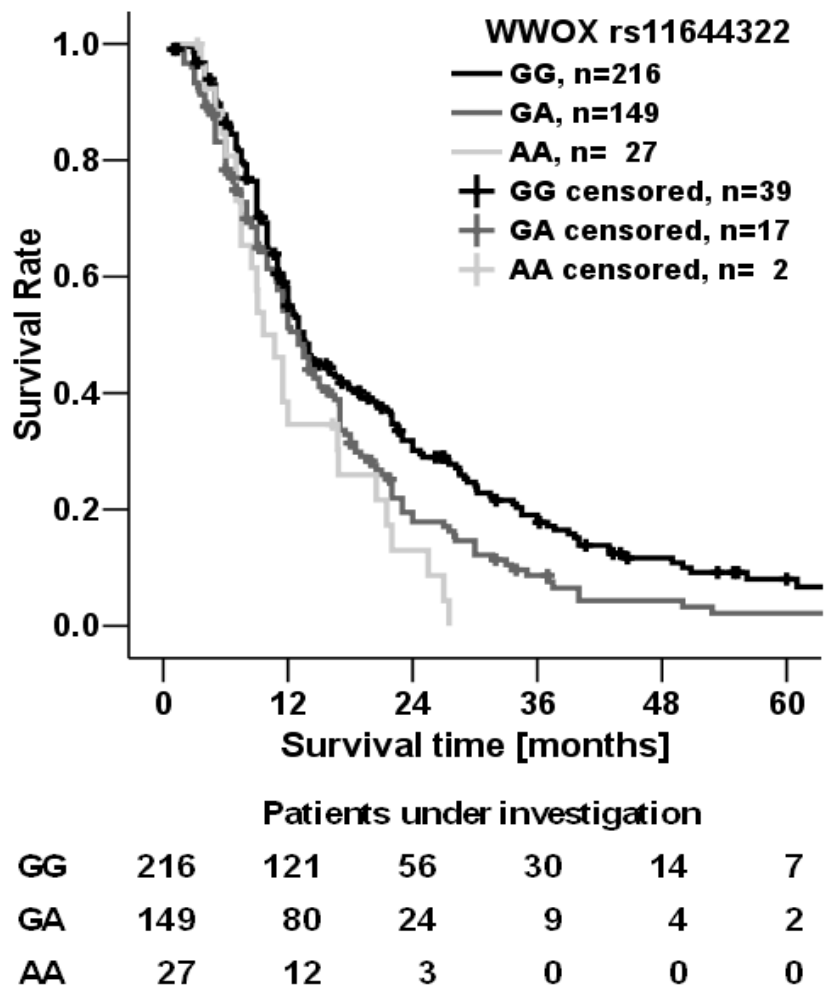

Figure 32: Survival rate in dependence on WWOX rs11644322 as ascertained in a set of 392 patients by univariate unadjusted log-rank test $(p=0.0008)$. Patient numbers under investigation are specified in 12-month-intervals. For five of the entire 397 patients genotyping failed. 


\subsubsection{Modulation of Gene Expression}

Though located in intron 8, an effect of rs11644322 on WWOX gene transcription was suggested due to looping to promoter region (DESHANE et al. 2010). We tested the hypothesis that rs11644322 might be related to transcription of the last exon 9, which is separated from exon 8 by 778856 bp. Ratios of WWOX transcripts derived from exon 8/9 in relation to exon 4/6 were not altered by rs11644322 neither at baseline nor upon exposure to gemcitabine leading us to reject the aforementioned hypothesis. However, an induction of entire WWOX transcripts could be observed in presence of gemcitabine in LCLs $\left(\mathrm{p}=2.4 * 10^{-5}\right)$ (Figure 33). Thereby, a slightly increased inducing effect of the rs11644322 wild type allele on $W W O X$ expression was elicited $(p=0.06$, Figure 34). Upon adjusting data for the two cohorts of LCLs the impact of this SNP became more distinct $(\mathrm{p}=0.03)$.

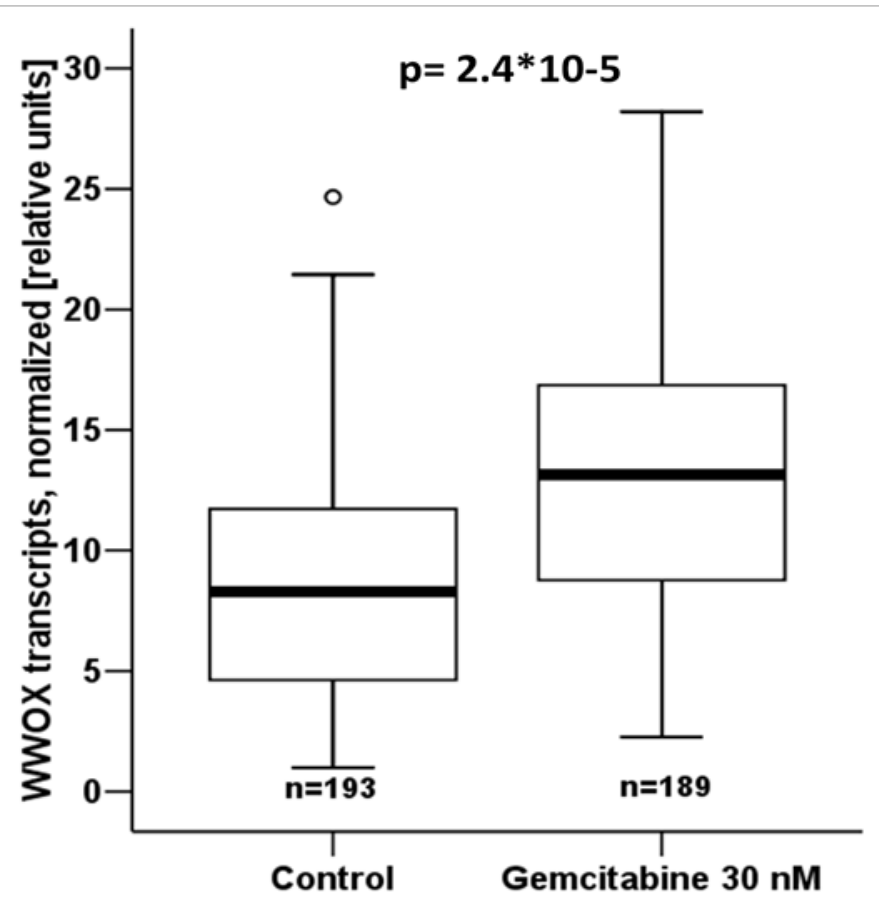

Figure 33: Inducing effect of gemcitabine on $W W O X$ expression in LCLs. LCLs were pre-incubated with $30.4 \mathrm{nM}$ gemcitabine for 24 hours at $37^{\circ} \mathrm{C}$ before cells were harvested for later RNA extraction. Expression data were ascertained by qRT-PCR whereby raw $W W O X$ data were normalized to a weighted mean of HPRT1, $U B C$, and $36 b 4$. The statistical difference between gemcitabine treatment and control with cell culture medium only was rated by paired Wilcoxon's signed rank test. 


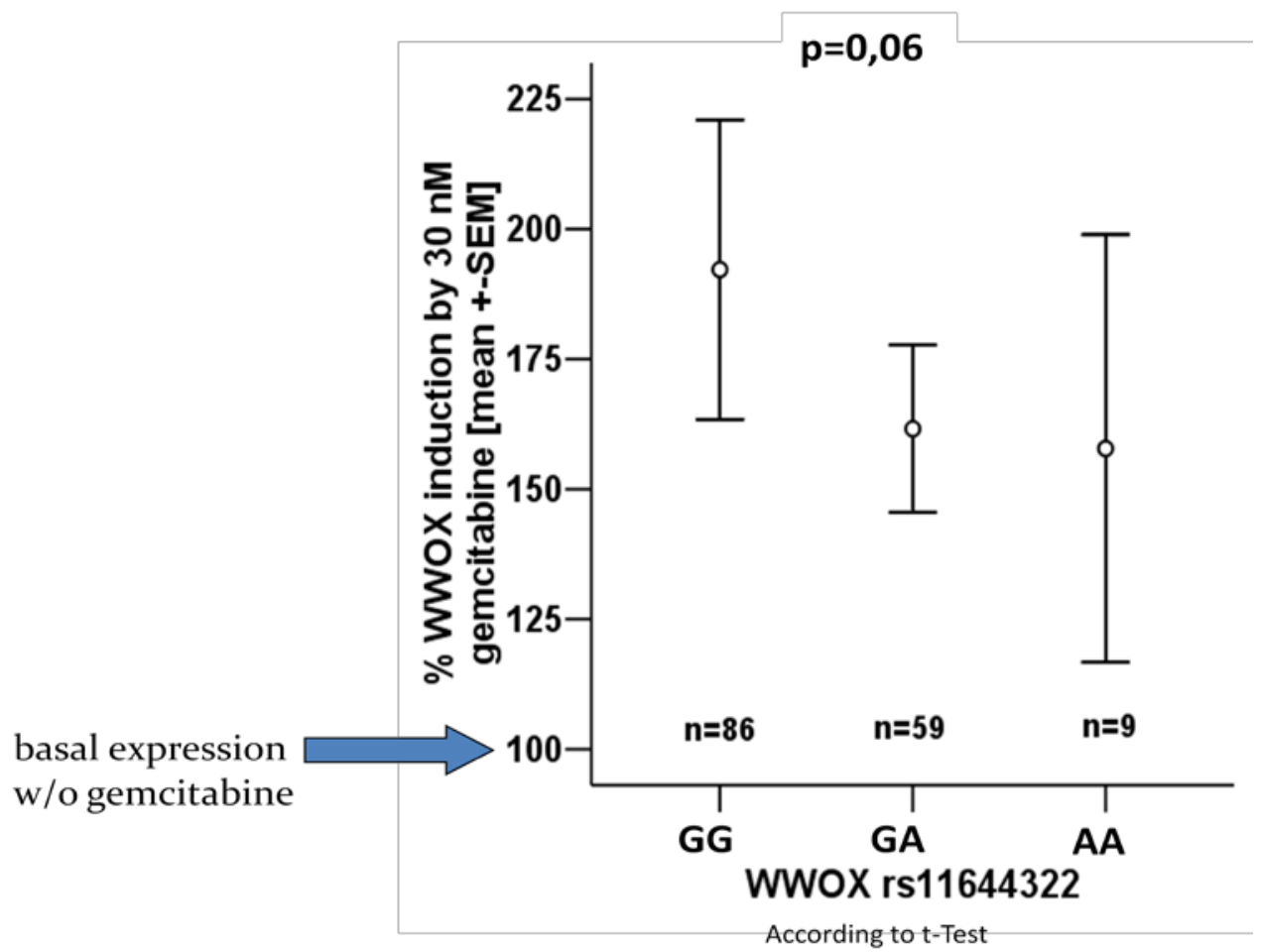

Figure 34: Effect of rs11644322 on gemcitabine-mediated WWOX induction. The y-axis refers to the data from Figure 33 and is here stratified according to the WWOX rs11644322 genotypes. For statistical evaluation with t-test, the heterozygous and homozygous variant allele statuses were combined.

\subsubsection{Evolutionary and Regulatory Elements}

Following the effects of rs11644322 on the clinical outcome of gemcitabine-treated pancreatic cancer the genomic vicinity of rs11644322 was explored for polymorphisms in high LD. Three polymorphisms were discovered by Haploview at $r^{2}>0.8$, rs2062903, rs34310485, and rs12598700. These three SNPs together with rs11644322 were subjected to an analysis screening for evolutionary regions using the ECR Browser (http://ecrbrowser.dcode.org/). None of these four SNPs showed any evolutionary conservation (data not shown).

Next, these four SNPs were checked for surrounding regulatory sites employing the UCSC Genome Browser (http://genome.ucsc.edu/). A DNase hypersensitive site was detected in the sequence stretch comprising rs34310485. In addition, a transcription 
factor binding and a H3K27 acetylation site were elicited each 100 bp upstream of this polymorphism (Figure 35). In contrast, no features indicative for regulatory elements were identified for the clinically associated SNP rs11644322 (Figure 36). Thus, in addition to rs11644322 the SNP in tight LD, rs34310485, was investigated by electrophoretic mobility shift assay (EMSA).

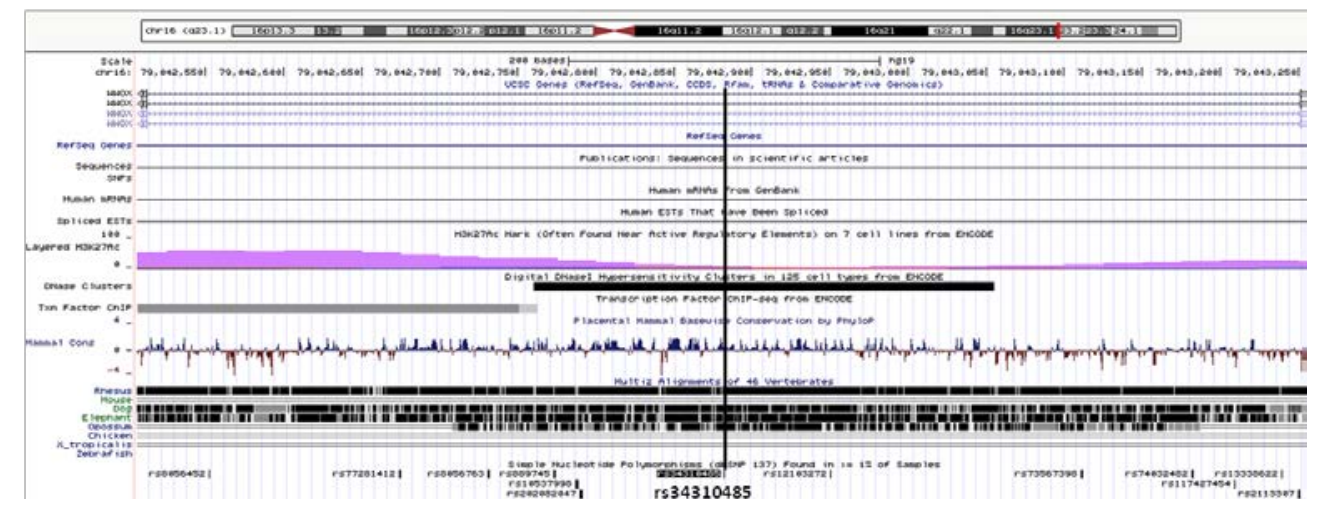

Figure 35: Potentially regulatory regions surrounding WWOX rs34310485. The graph shows the features according to the UCSC genome Browser. rs34310485 is highlighted by a black vertical line.

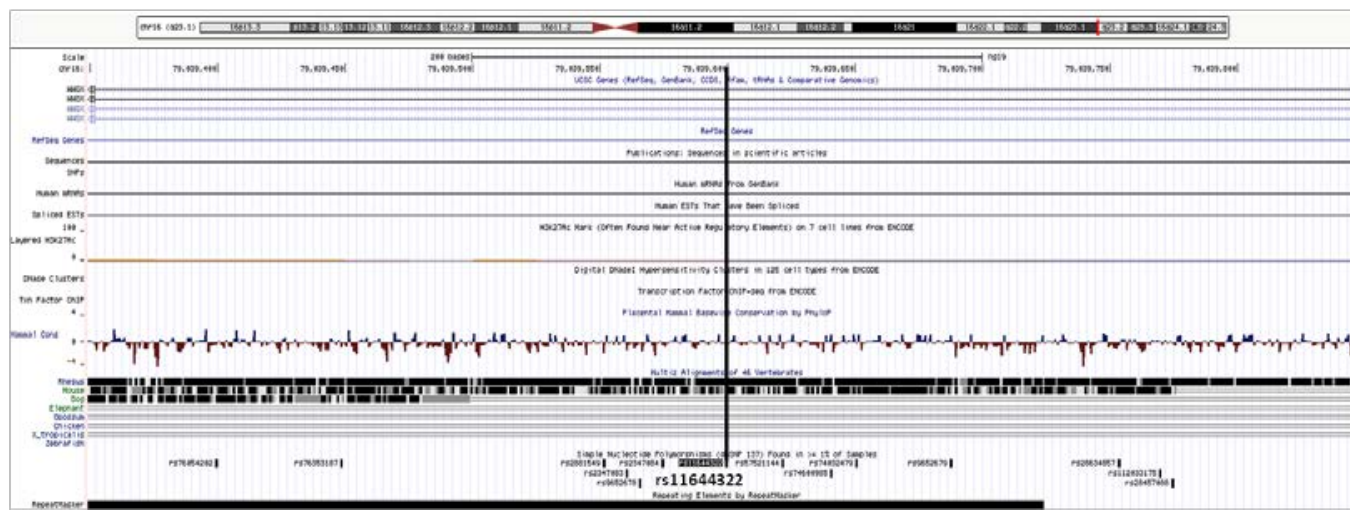

Figure 36: Potentially regulatory regions surrounding $W W O X$ rs11644322. The mode of illustration is analogous to Figure 35. 


\subsubsection{Allele-Specific Protein Binding}

It was asked whether protein binding occurs at the sequence stretch around the clinically associated SNP rs11644322 as well as the bioinformatically suggested rs34310485. Interestingly, not the putatively conserved rs34310485 but rs11644322 indicated transcription factor binding. Moreover, a slight but reproducibly allele-specific binding was noticed: A stronger binding for the $G$ wild-type in comparison to the A variant allele was noticed (Figure 37). Cold competition experiments on the ${ }^{32} \mathrm{P}$-labelled G allele containing probe revealed this difference being statistically significant between the $\mathrm{G}$ and the A allele both with 5-fold and 20-fold excess of the non-radioactive probe (Figure 38). A bioinformatic analysis was conducted to identify candidate proteins binding to rs11644322 in an allele-specific manner. Double-stranded probes representing the consensus sequences of the top hits elicited by the in silico screen were tested for cold competition in EMSA experiments. The probe containing the consensus sequence for the SP1_Q6 binding pattern (Figure 39) abolished the interaction between the nuclear protein extract and the probe with the G allele at rs11644322 (Figure 40) suggesting that the binding protein might be SP1 (or a protein with high structural homology like other SP-family members). Moreover, when mutating four bases at the most crucial positions of the consensus motif no competition was observed anymore (Figure 40) strengthening the hypothesis that a SP-family member binds allelespecifically at rs11644322. 


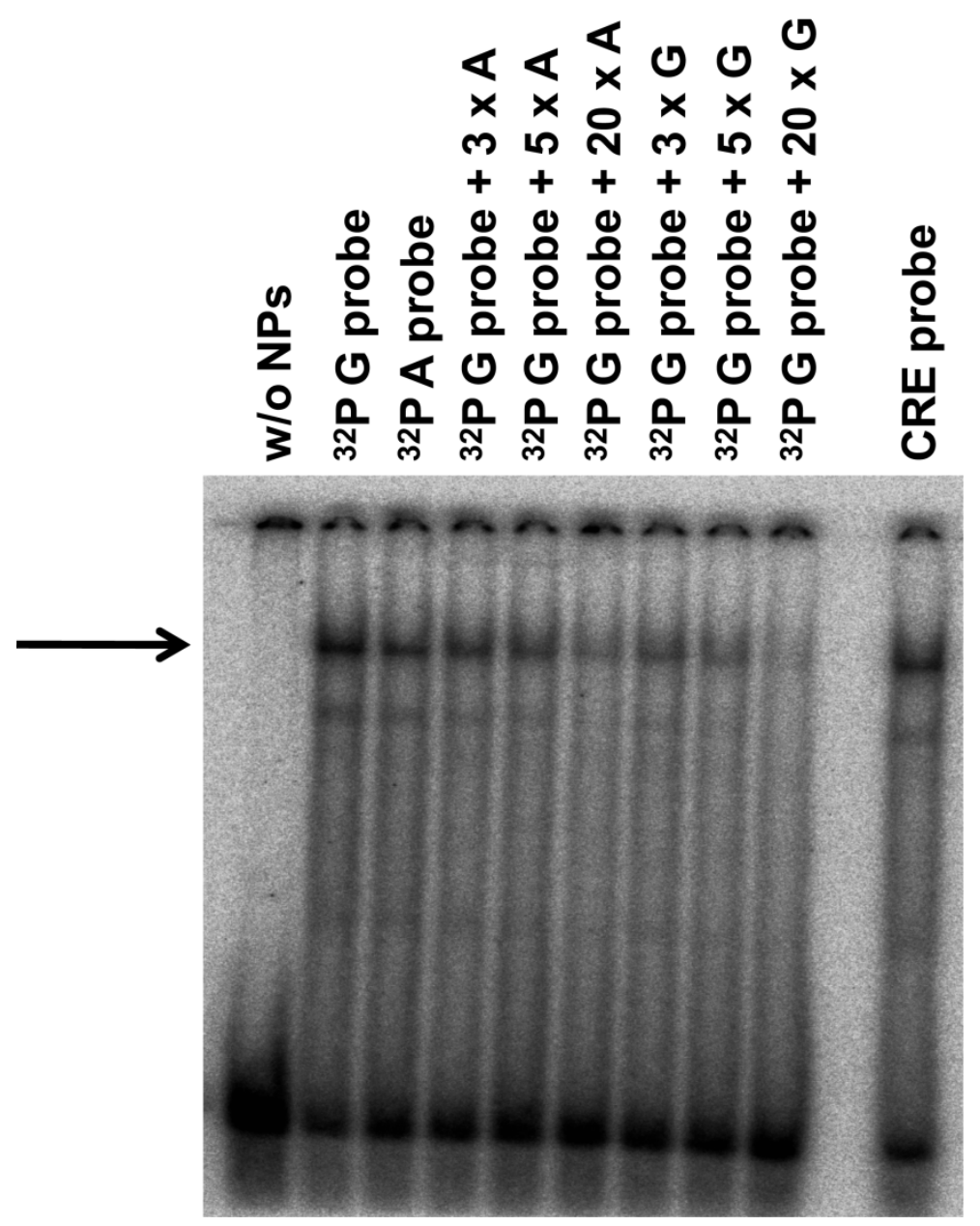

Figure 37: Representative EMSA plot for assessing transcription factor binding of nuclear protein extracts at WWOX rs11644322. Lane 1 indicates negative control without nuclear proteins. Lanes 2 and 3 illustrate 32P-labelled probes containing the wild-type $\mathrm{G}$ and the variant A allele, respectively. In lanes 4-9 the interaction between nuclear proteins and the $G$ allele-containing probe was competed with increasing concentrations of non-radioactive probes (indicated as $x$-fold in comparison to the radio-labeled) for both the $G$ and the A allele to delineate allele-specific interaction affinities. Lane 11 shows positive control for transcription factor binding (CRE probe). The arrow at the left points to the bands of interaction between nuclear proteins and the radiolabeled probes. 


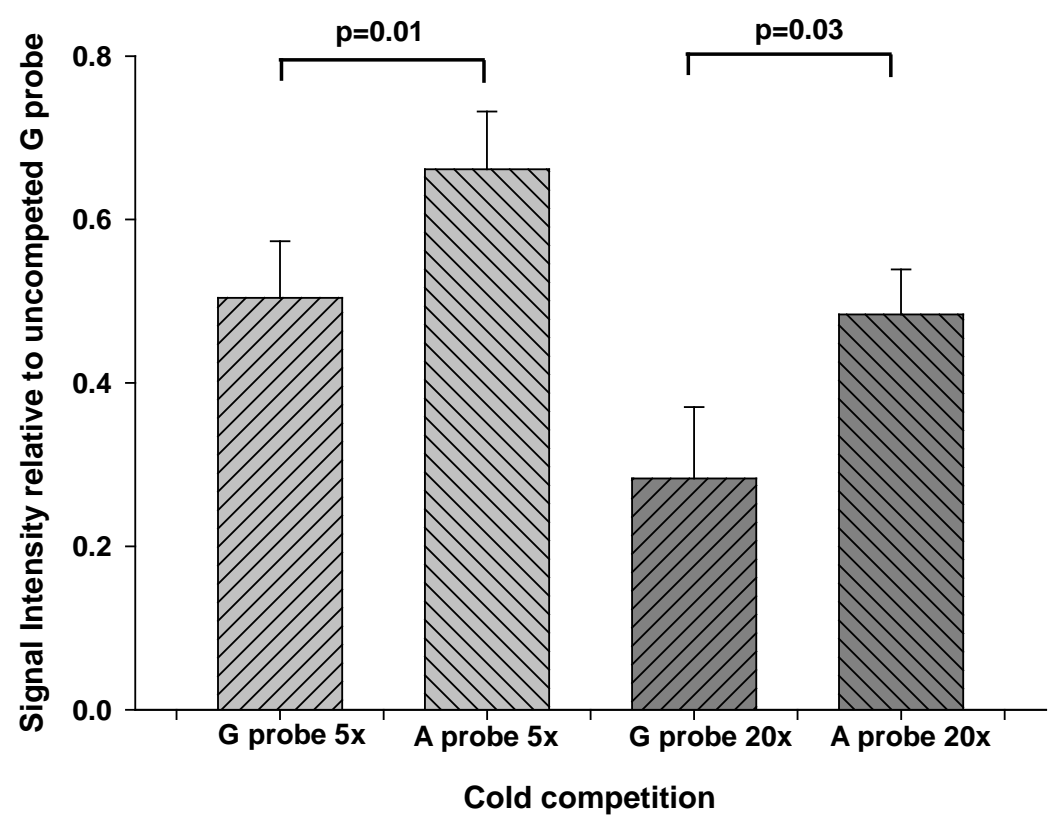

Figure 38: Quantification of allele-specific differential transcription factor binding at WWOX rs11644322 as assessed by EMSA in nuclear protein extracts. The signal intensities of cold competition experiments (5-fold and 20fold surplus of $G$ and $A$ allele-containing probes) were referred to the 32Plabelled wild-type $G$ allele probe without cold competition of which the intensity was set at 1.0. Data represent the results from three independent experiments with the standard error of the mean depicted. Statistical significance was tested by paired student's t-test with the respective p-values denoted.

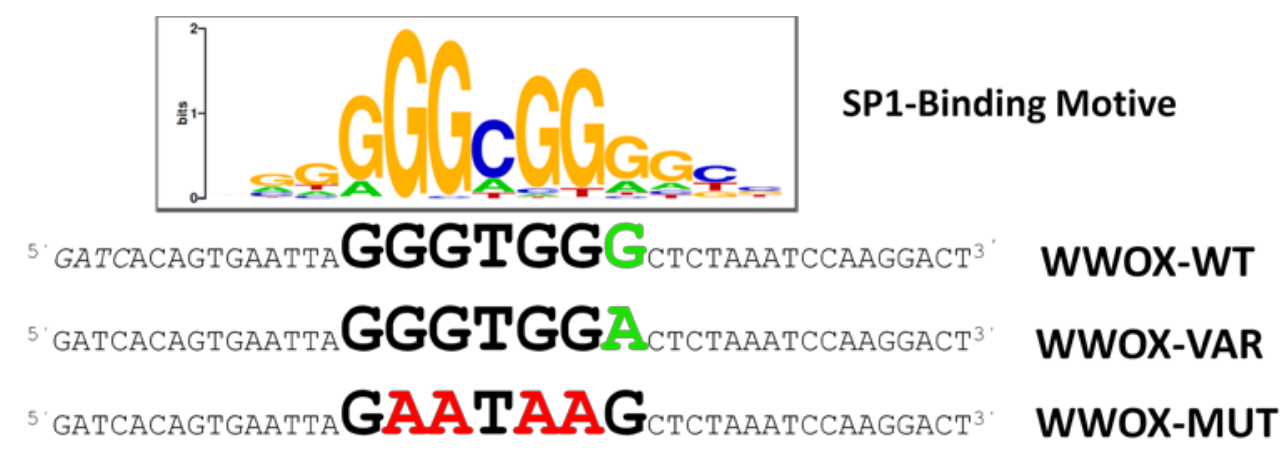

Figure 39: SP1_Q6 binding motif in relation to $W W O X$ rs11644322. The mode of depiction is analogous to that described in Figure 28 and Figure 29. Beneath the motif, the sequences of the used probes are displayed. The first row refers to the wild type G-allele, the second to the Avariant allele at rs11644322 (green), and the third to a sequence artificially mutated at four positions (red) particularly crucial for this motif. 


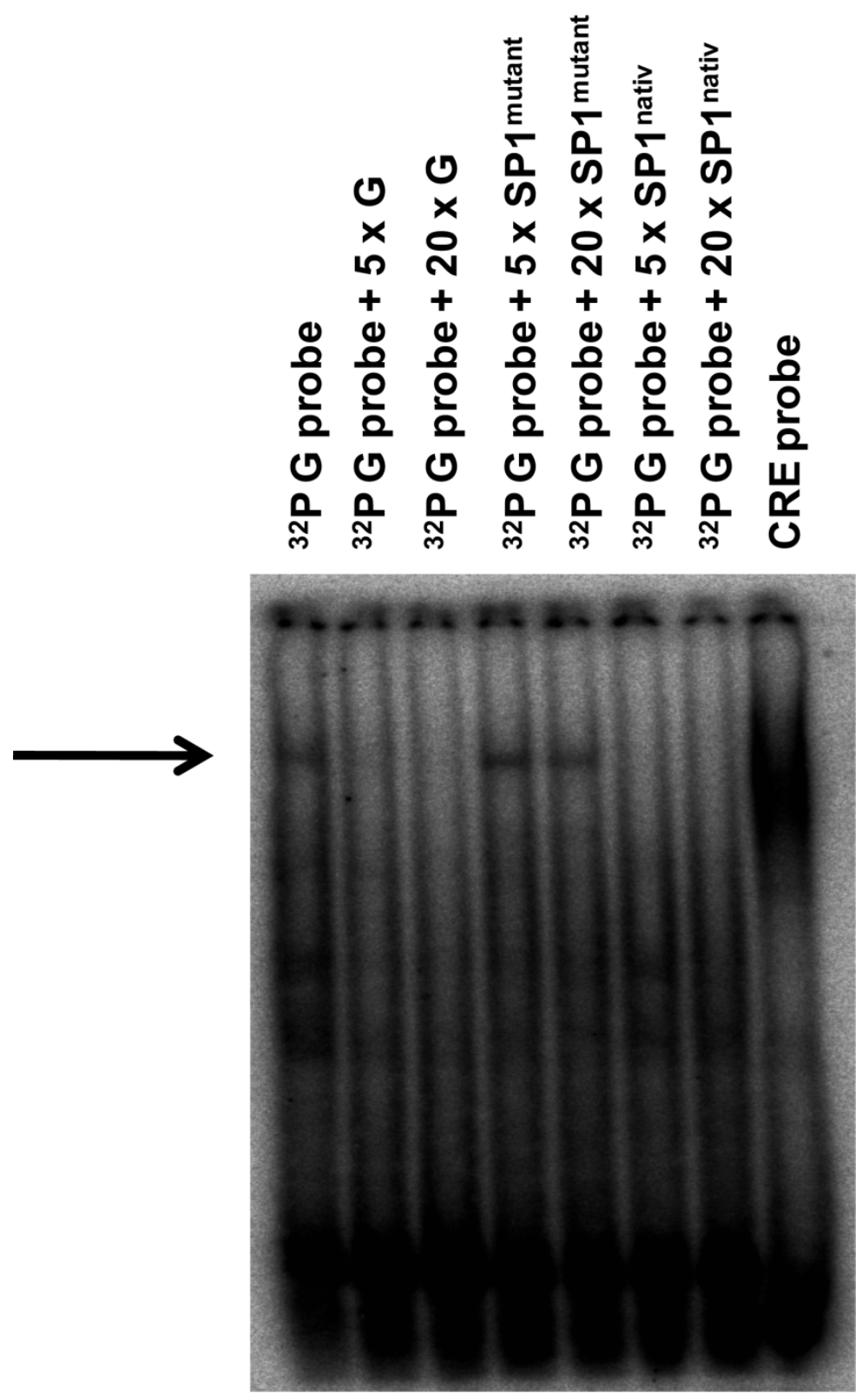

Figure 40: Relevance of SP1 motif for nuclear protein binding. Radio-labeled hybridized double-stranded probes with the $G$ wild-type allele at rs11644322 were subjected to nuclear protein extracts from LCLs. Noncompeted probe (lane 1) was compared with cold competition by excess of the probe itself (lanes 2 and 3, second sequence row in Figure 39), of the probe mutated at the four positions most pivotal for SP1 binding (lanes 4 and 5, third row in Figure 39), and of the SP1_Q6 consensus sequence (lanes 6 and 7, first row in Figure 39. Lane 8 represents a positive technical control displaying strong binding of CRE at a respective radiolabeled probe. The arrow indicates the bands of interest.

\subsection{Genome-Wide Determinants for Gemcitabine Sensitivity}

In 196 fully sequenced lymphoblastoid Cell lines (Coriell Cell Repositories) and 95 self-established LCLs [3.6.5], dose-response curves for gemcitabine sensitivity were generated as described in the Methods section [3.10]. Thereof, gemcitabine concentrations reducing cell vitality by $50 \%\left(\mathrm{EC} 0_{\mathrm{Vit}}\right)$ and lowering cell proliferation

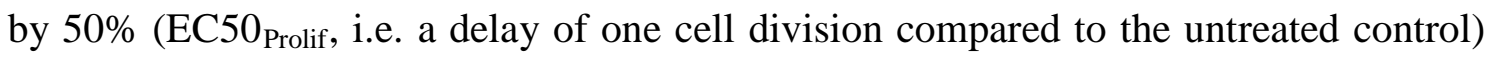
were 
calculated by MMF and Gompertz model, respectively, as outlined above [3.10]. The variability of these data was depicted and assessed for impact of genetic polymorphisms in a training and a test set fashion.

\subsubsection{Variability of Gemcitabine Cytotoxicity}

The overall distribution of the EC50Vit and EC50Prolif values in the training set comprising 196 LCLs is illustrated in Figure 41. For both parameters, the displayed distribution did not significantly deviate from normal $(p>0.2$ according to Kolmogorov-Smirnov test). The parameters representing sensitivity and proliferation effects were highly correlated (Pearson correlation coefficient $r=0.89$ ).
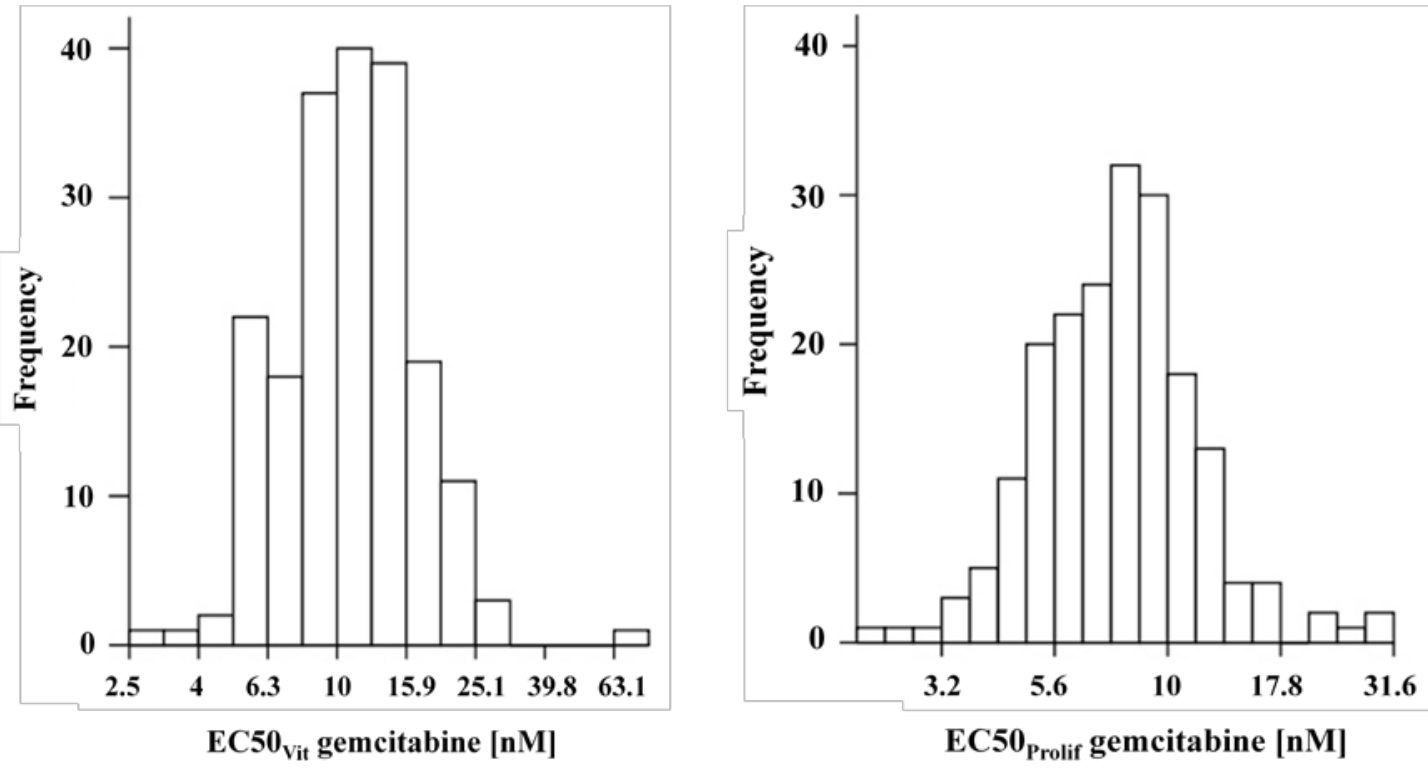

Figure 41: Distribution of gemcitabine sensitivity on cell vitality and proliferation of LCLs. The EC50 ${ }_{\text {Vit }}$ value represents the gemcitabine concentration at which the percentage of vital cells was reduced by $50 \%$ (left panel). Likewise, the EC50Prolif value indicates the concentration of gemcitabine which inhibits cell proliferation by 50\% (right panel). 


\subsubsection{Genome-Wide Determinants of Gemcitabine Sensitivity}

For the training set of LCLs, the two phenotypic parameters for gemcitabine sensitivity were tested for association with genetic variants by a genome-wide screen. This analysis was conducted by Prof Beißbarth (Institute for Medical Statistics, group Bioinformatics, University Medicine Göttingen). Test statistics for each genetic marker was carried out using the non-parametric Jonckheere-Terpstra trend test considering allele dosage effects. For each single association, in addition to the raw p-value multiple testing adjustment was performed per chromosome using FDR (false discovery rate). The most significant 20 top hits over the entire genome according to their FDR were picked for further confirmatory analyses (Table 16). In case of clusters comprising multiple markers in high linkage disequilibrium (LD) a tagging SNP covering the respective cluster was selected. Thereby, for markers with identical FDR the raw p-values were also taken into account. 
Table 16: Genetic polymorphisms representative for loci strongest associating with proliferation inhibition by gemcitabine in the training set.

\begin{tabular}{|c|c|c|c|c|c|c|c|c|}
\hline Ranking & Gen & CHROM & POS & ID & REF & ALT & P value & fdr \\
\hline 1 & CYP1A1 & 15 & 75011641 & rs4646903 & $\mathrm{A}$ & $\mathrm{G}$ & $1.39 \mathrm{E}+07$ & 0.0777 \\
\hline 2 & PACRG & 6 & 163265311 & rs9458655 & $\mathrm{G}$ & $\mathrm{A}$ & $1.57 \mathrm{E}+09$ & 0.1160 \\
\hline 3 & KIAA1024 & 15 & 79731140 & rs190148744 & $\bar{A}$ & $\bar{G}$ & $2.10 \mathrm{E}+09$ & 0.1674 \\
\hline 4 & Inter genetic region & 5 & 159019195 & rs557484428 & $\mathrm{A}$ & $\mathrm{G}$ & $6.27 \mathrm{E}+08$ & 0.1706 \\
\hline 5 & Inter genetic region & 5 & 114987179 & rs55740412 & $\mathrm{C}$ & $\mathrm{T}$ & $1.34 \mathrm{E}+09$ & 0.1715 \\
\hline 6 & Inter genetic region & 6 & 98632010 & rs9385308 & $G$ & $\mathrm{~T}$ & $4.18 \mathrm{E}+09$ & 0.1770 \\
\hline 7 & Inter genetic region & 13 & 75037871 & rs1931915 & $\mathrm{T}$ & $G$ & $2.21 \mathrm{E}+09$ & 0.2071 \\
\hline 8 & Inter genetic region & 6 & 77257094 & rs62429896 & G & $\mathrm{C}$ & $5.09 \mathrm{E}+09$ & 0.2131 \\
\hline 9 & Inter genetic region & 5 & 100987070 & rs113018380 & $\mathrm{C}$ & $\mathrm{T}$ & $2.28 \mathrm{E}+09$ & 0.23888 \\
\hline 10 & ITPKA & 15 & 41789704 & rs2026946 & $\bar{G}$ & $\mathrm{~A}$ & $5.19 \mathrm{E}+09$ & 0.2415 \\
\hline 11 & MEGF11 & 15 & 66502218 & rs12592456 & $\mathrm{A}$ & $\mathrm{G}$ & $5.42 \mathrm{E}+09$ & 0.2455 \\
\hline 12 & GPR116 & 6 & 46824165 & rs9395217 & $\mathrm{T}$ & A & $6.24 \mathrm{E}+09$ & 0.2459 \\
\hline 13 & LOC100506207 & 6 & 8776410 & rs4383861 & $\mathrm{C}$ & $\mathrm{T}$ & $6.05 E+09$ & 0.2459 \\
\hline 14 & Inter genetic region & 6 & 133452425 & rs3904628 & $\mathrm{A}$ & $G$ & $6.12 \mathrm{E}+09$ & 0.2459 \\
\hline 15 & Inter genetic region & 5 & 27500724 & rs12517916 & G & $\mathrm{A}$ & $5.17 \mathrm{E}+09$ & 0.2468 \\
\hline 16 & Inter genetic region & 5 & 33156656 & rs62368013 & $\mathrm{T}$ & $\mathrm{C}$ & $5.28 \mathrm{E}+09$ & 0.2468 \\
\hline 17 & SLC26A2 & 5 & 153362970 & rs78177740 & $\mathrm{C}$ & $\mathrm{T}$ & $7.33 \mathrm{E}+09$ & 0.2468 \\
\hline 18 & CHSY1 & 15 & 101747869 & rs67502721 & $\mathrm{C}$ & $\mathrm{A}$ & $8.79 \mathrm{E}+09$ & 0.3396 \\
\hline 19 & SEMA7A & 15 & 74713300 & rs11857558 & $\mathrm{T}$ & $\mathrm{C}$ & $9.48 \mathrm{E}+09$ & 0.3455 \\
\hline 20 & FAM155A & 13 & 108065075 & rs7321605 & G & $\mathrm{C}$ & $4.88 \mathrm{E}+09$ & 0.3477 \\
\hline
\end{tabular}

The SNPs were ranked in the first instance according to their false discovery rate (fdr) and in the second instance according to their probability value (P-value) and represent the most significant SNPs elicited. If possible, genes are assigned. The third row indicates the respective chromosome number, followed by the chromosomal position. The column "ID" lists theSNP identification number as annotated in dbSNP. "REF" and "ALT" stand for the two allelic configurations of a SNP. 


\subsubsection{Confirmation Study of GWAS Determinants}

The top associations with gemcitabine sensitivity identified in the training set (Table 16), were set up for confirmation in an independent test set of 95 LCLs. For the latter, genotyping was performed in-house by primer extension method.

Four of the 20 SNPs listed in Table 16 failed for genotyping in the test set. They could not be replaced by another SNP in high LD. For SNP rs190148744 (rank \#3 in the training set) highly repetitive sequence stretches made unique primer design for this region impossible. The region of rs62429896 (\#8) was difficult to amplify (GC-content 18\%). Despite it worked with a single PCR the subsequent primer extension method failed (only homozygous wildtype allele status detected possible due to highly repetitive AT-elements). The SNPs rs4383861 (\#13) and rs3904628 (\#14) were skipped for reasons of fine mapping of the respective genetic regions.

Upon fine mapping, the eight SNPs rs55740412 (\#5), rs9385308 (\#6), rs9395217 (\#12), rs12517916 (\#15), rs62368013 (\#16), rs7817740 (\#17), rs11857558 (\#19) and rs7321605 (\#19) were each substituted due to high LD by rs2098630, rs9375292, rs1410824, rs6898780, rs62369808, rs74767865, and rs35829783, rs7321622.

In addition, fine mapping of the 20 regions covered by the SNPs denoted Table 16 elicited four SNPs with a minor allele frequency below the threshold of $10 \%$ as used for the training set. Since these four SNPs are not sufficiently tagged by the other selected SNPs they were included into the analysis. Finally, 20 SNPs were successfully genotyped in the test set. With respect to multiplicity of testing, these 20 SNPs were tested in a hierarchical order according to the regions as ranked in Table 16. Thereby, the threshold for the SNP representing the region ranked highest $(\# 1)$ was set to 0.05 . The other SNPs were sequentially analyzed according to their rank in the training set whereby the statistical threshold was each time divided by the cumulative number of the SNPs already tested.

Just one of the considered 20 SNPs (rs6898780) revealed an association with gemcitabine sensitivity also in the test set. Figure 42 compares the impact of rs6898780 on the gemcitabine-caused inhibition of LCL proliferation. When applying the same phenotype and statistical test, statistical significance was not reached in the test set $(p=0.059$ according to Jonckheere-Terpstra trend test). However, when normalizing the raw EC50 Prolif values to the basal proliferation rate the Jonckheere-Terpstra trend test revealed a p-value of 0.01 . Nonetheless, statistical significance was failed since the threshold for rs6898780 was 0.004 since this SNP was tested as the $11^{\text {th }}$. Likewise, the fraction of vital cells was impacted by this SNP ( $=0.040$, Figure 43). 

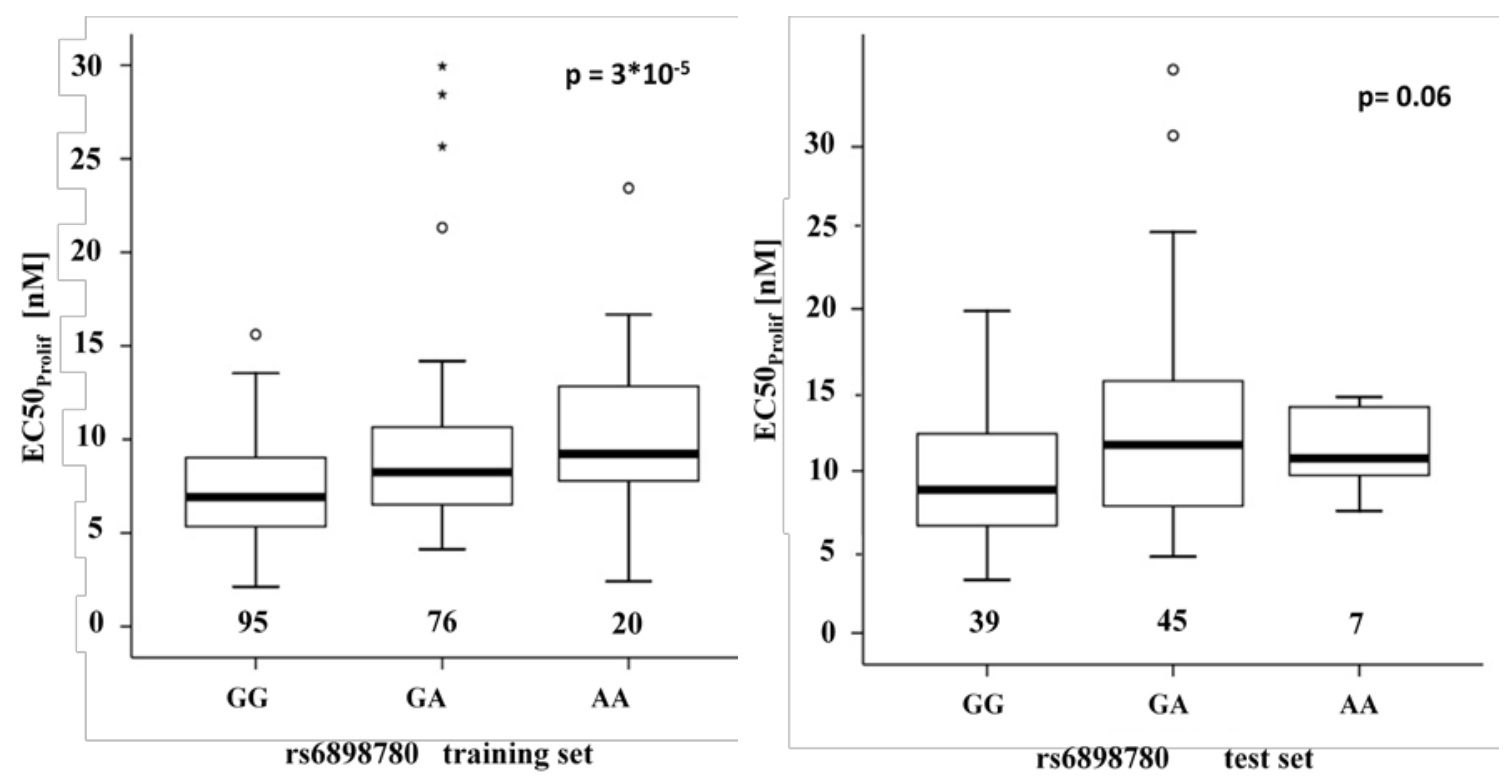

Figure 42: Reproducible impact of rs6898780 on proliferation inhibition by gemcitabine. The left panel shows the training set comprising 191 LCLs (four cell lines with missing genotype). The right image displays the test set with 95 LCLs (for two EC50 was not determinable, for another two genotyping failed). The respective p-values were $3 * 10^{-5}$ and 0.06 according to Jonckheere-Terpstra trend test. The distribution of the data by boxplots is as follows: The thick horizontal line represents the median. The horizontal line below displays the $1^{\text {st }}(\mathrm{Q} 1)$ and that above the $3^{\text {rd }}$ quartil $(\mathrm{Q} 3)$, i.e. $50 \%$ of the values are enclosed by these two lines. The distance between Q1 and Q3 is termed as "interquartil distance (IQD)". Values not more than 1.5-fold the IQD below Q1or above Q3 are covered by the whiskers, i.e. the vertical line bounded by the short horizontal. Values between 1.5 and 3.0-fold the IQD with respect to either Q1 or Q3 are displayed as circles ("outliers"), and those more than 3.0-fold the IQD apart Q1 or Q3 are illustrated as asterisks (“extreme values”).
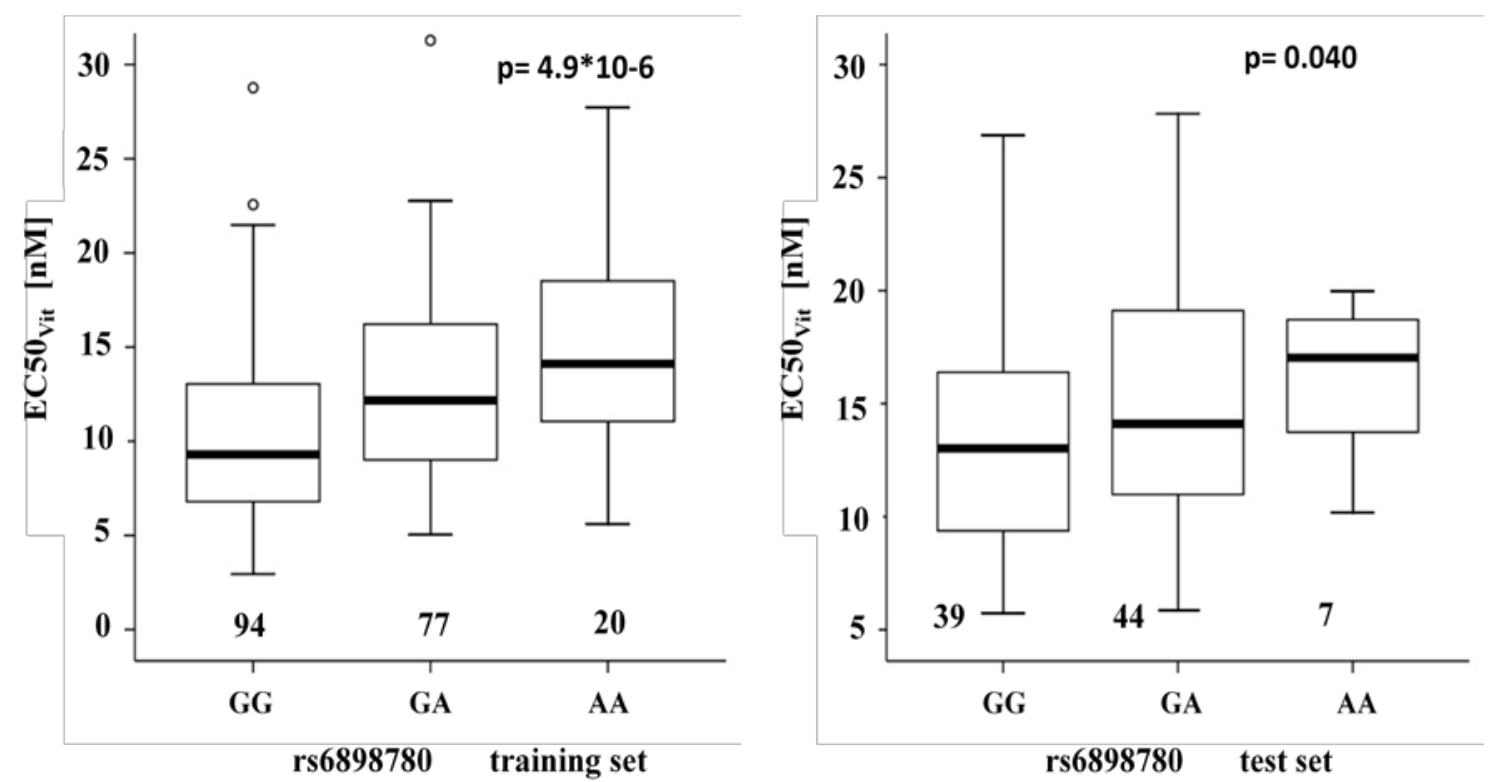

Figure 43: Reproducible impact of rs6898780 on reduction of vitality by gemcitabine. The left panel shows the training set comprising 191 LCLs (four cell lines with missing genotype). The right image displays the test set with 95 LCLs (for two EC50 was not determinable, for another two genotyping failed). The respective p-values were $4.9 * 10^{-6}$ and 0.040 according to Jonckheere-Terpstra trend test. The detailed explanation of the box plots is depicted in Figure 42. 


\section{Discussion}

The major focus of this thesis was to decipher molecular effects of polymorphisms in the ENT1 genetic region recently linked to the outcome of patients treated with gemcitabine for pancreatic cancer. The ENT1-mediated transport of nucleoside analogues can be the rate-limiting step in sensitivity towards gemcitabine (ACHIWA et al. 2004). The absence of ENT1 mRNA results in resistance towards gemcitabine (NAKANO et al. 2007; SPRATLIN et al. 2004). Despite the relevance of ENT1 for the transport of gemcitabine under therapeutic conditions the transcriptional regulation is barely understood. In my PhD thesis, I investigated the molecular effects of the ENT1 promoter SNP rs507964 and the ENT1 Ile216Thr amino acid exchange SNP (rs45573936) in relation to gemcitabine sensitivity in cell culture experiments. In addition, when doing my thesis a published genome-wide screen suggested further loci for outcome of gemcitabine-based chemotherapy in pancreatic cancer (INNOCENTI et al. 2012). Since one of the top hits of this publication could be reproduced in available clinical cohorts functional mechanisms of this SNP were also investigated with the same techniques as established for the ENT1 promoter SNP. The last part refers to our own genome-wide in vitro screen to determine new loci for gemcitabine sensitivity.

\subsection{SNP in ENT1 Promoter Region}

Two recent medical theses conducted in our department revealed a reproducible impact of the SNP rs1057985 located in the promoter region of the ENT1 gene. The variant allele was linked to a prolonged overall survival of pancreatic cancer patients treated with gemcitabine (ScHAUDINN 2013), (Christian Zimmer, medical thesis in preparation). Thus motivated, I set up for detailed functional analyses to clarify the molecular mechanisms driving the observed clinical association. Due to its location an impact on the differential expression of ENT1 transcript variants was hypothesized. Since the variant allele displays a significant prolonged overall survival, it was hypothesized that the polymorphic locus somehow affects the transcript quantities or stabilities of ENT1. The SNP rs1057985 might lead to enlarged amount of ENT1-transporters in cell membranes, which results in higher uptake ability of gemcitabine and in increased sensitivity in cells. 


\subsubsection{Expression of Different ENT1 Transcript Variants}

The analysis of ENT1 transcript variant expression in different tissues and cell types revealed ENT1-v5, -v4, and -v3 as the most abundant variants. The transcription start site of ENT1-v4 and ENT1-v5 is close to the promoter polymorphism associated in the previous clinical-epidemiological study. Beyond these three variants, a substantial expression was also confirmed for ENT1-v2 (nomenclature according to NCBI gene bank entry, release GRCh37.p10). Other suggested variants, ENT1-v1 and those of ENSEMBL database (http://www.ensembl.org/index.html) or as reported in literature (FUKUCHI et al. 2010) not covered by ENT1-v2, -v3, v4, or -v5 were barely expressed. Obviously, expression of ENT1 seems to be almost completely represented by four transcript variants. It remains to be clarified to which extent these four mRNA variants are translated into protein. Since ENT1 protein levels vary considerably between individuals ((ABDULLA and COE 2007; FARRE et al. 2004; MACKEY et al. 2002), it might be interesting to determine the contribution of each mRNA variant. Another issue to be resolved refers to the question about the existence of different transcript variants all coding for an identical protein. It is conceivable that mRNA stability and thus the extent of translation into protein are different between these variants. A major hypothesis is that these transcript variants reflect different regulation events possibly responsible for the high variability of ENT1 mRNA levels among human tissues (PENNYCOOKE et al. 2001).

\subsubsection{Transcript Variant Expression affected Gemcitabine}

ENT1 transcripts, in particular the extended ENT1-v5 and -v4, were induced in all investigated pancreatic cancer cell lines except for PancI (Figure 19). In LCLs, an induction of ENT1-v5 was also observed. These findings suggest a selective regulation of ENT1 variant expression by gemcitabine.

When normalizing the raw expression data to that of the reference genes it was noticed that the latter were massively down-regulated upon gemcitabine. That was particular true for those cell lines in which the normalized ENT1 transcripts showed the highest induction. That raised the question about an unspecific effect. However, that is unlikely for two reasons. First, the less-extended transcript variants ENT1-v2 and ENT1-v3 were not induced to the same extent. Second, we checked the expression of RRM1, the induction of which was linked to gemcitabine resistance (BERGMAN et al. 2005). In contrast to ENT1-v4 and -v5, RRM1 raw data expression indicated down-regulation by gemcitabine. Two 
housekeeping genes reflecting different cellular functions were chosen to minimize systematic bias of gemcitabine effects on normalization.

\subsubsection{Gemcitabine Transcript Induction Modulated by Promoter SNP}

The SNP rs1057985 was assessed for modulation of gemcitabine-driven ENT1 induction. This hypothesis was tested in 101 LCLs for ENT1-v5 since rs1057985 was supposed to be located in a promoter regulatory element for ENT1-v5. The latter was preferred to ENT1v4 which has the same transcription start site but is lower expressed (Figure 17) and weaker induced by gemcitabine in LCLs than ENT1-v5 (Figure 18). The induction of ENT1-v5 by gemcitabine was about 2-fold and 1.5-fold when LCLs were homozygous for the variant and the wild type allele of rs1057985, respectively (Table 15). These findings raised the question whether this SNP is involved in a regulatory element, e.g. a transcription factor binding site. Since the so-far results concerning rs10579865 represent associations without proof of functionality it is also conceivable that another SNP genetically coupled is the causative one.

\subsubsection{Genetic Linkage Disequilibrium Analysis for rs1057985}

Screening for SNPs in high linkage disequilibrium (LD) with the polymorphism rs1057985 revealed rs507964 highly correlated $\left(\mathrm{r}^{2}=1.0\right)$. Rs507964 is closer to the ENT1-v5 and -v4 transcription start site by 489 bp and is located in a region with potentially regulatory elements (according to UCSC-Browser). For none of these two variants any functionality has been reported in literature yet. To elucidate the regulatory impact of rs1057985 and rs507964 on the expression of ENT1-v5 and -v4 protein binding was investigated by EMSA.

\subsubsection{EMSA: Allele-Specific Binding}

EMSA experiments elicited a protein binding on a probe with the wild type but not with the variant allele of rs507964. The region of the SNP rs1057985 did not exhibit any protein binding. These findings supported the hypothesis of an expression-regulating effect of this polymorphism. Cold competition experiments suggested a member of the SP1 family to be the binding protein. However, the final proof would be an EMSA with a super shift by an antibody specific for the supposed binding protein. I tested two different antibodies against 
SP1 which both failed to cause a super shift. Then, I checked super shift with a probe containing the consensus sequence for SP1. Since that also failed it was assumed that the antibodies do not work properly under the specified experimental conditions. A possibility to control that might be the use of standard nuclear protein extracts. Regarding literature, SP1 binding sites in the promoter region of ENT1 have been described long time before ENT1 transcript variants with far upstream-coded 5'-UTRs were discovered (CHOI et al. 2000). How could the discrepancy between the variant allele associated with better clinical outcome and exhibiting no binding of putative SP1 be explained assuming that higher ENT1 expression is beneficial for gemcitabine-based chemotherapy in pancreatic cancer as several times reported (FARRELl et al. 2009; GIOVANNETTI et al. 2006; MARECHAL et al. 2009; SPRATLIN et al. 2004)? Interestingly, overexpression of SP1 or high SP1 protein abundance as provoked by high glucose was linked to down-regulation of ENT1 expression (PueBLA et al. 2008). If so, the observed allele-specific binding of SP1 only in presence of the wild type allele of rs507964 may suggest lower ENT1 levels accompanied by worse clinical response. In this context, it is very unlikely that the binding protein has an expression promoting function, but rather an inhibitory role.

\subsubsection{Reporter Gene Analysis: SNP Region with High Promoter Activity}

Luciferase reporter gene assays did not show any impact of the SNP rs507964 in the pancreatic cancer cell line AsPCI. Even under gemcitabine treatment the two alleles did not cause any differences in expression. Thus, the suggested inhibitory effect of the wild type allele at rs507964 could not be verified under the chosen experimental settings. However, a simultaneous overexpression of SP1 in a reporter gene assay might elucidate an expression-regulating effect of rs507964. Another possibility might be that the effects of rs507964 are masked by other regulatory elements not investigated in this study. The reporter gene assay in AsPCI demonstrated a high promoter activity for the suggested promoter region. Thus, the described promoter in the publication of Fukuchi (FUKUCHI et al. 2010) could be confirmed in a pancreatic cancer cell line. 


\subsection{Ile216Thr}

With respect to the amino acid exchange Ile216Thr in ENT1 (rs45573936), the rare threonine allele (about 2\% in Caucasians) displayed a dramatically reduced overall survival in one clinical cohort (SCHAUDINN 2013). However, this association could not be reproduced in a second cohort (Christian Zimmer, medical thesis in preparation). Nonetheless, the latter negative result does not exclude a medically relevant functionality of this SNP, in particular when considering the low allelic frequency of Thr216 which renders a particular susceptibility to confounding factors in limited sample sizes. Another motivation for further functional investigation was a finding in leucocytes of healthy volunteers. Gemcitabine and cytarabine (another nucleoside analogue) cytotoxicity was strikingly reduced in presence of Thr216 (KUSCHEL 2012). The substitution of isoleucine by threonine constitutes a heavy alteration replacing an aliphatic residue by a side chain which is a potential target for post-translational modification. The hypothesis was that the amino acid exchange Ile216Thr reduces the transport ability of ENT1 towards gemcitabine. This could result in lower intracellular levels of gemcitabine along with increased resistance towards this drug.

\subsubsection{ENT1 as the Major Gemcitabine Uptake Route in HEK Cells}

In transport experiments it could be demonstrated that ${ }^{3} \mathrm{H}$-gemcitabine uptake is dramatically reduced by NBTI $(50 \mu \mathrm{M})$ in stably transfected HEK293 cells (Figure 11). NBTI seems to lower both velocity and maximal capacity of ${ }^{3} \mathrm{H}$-gemcitabine transport. These data indicate that ENT1 is the major uptake route for gemcitabine also in HEK cells, which was already stated for other cell types in literature (FARRELL et al 2009) (SPRATLIN et al. 2004) (SANTINI et al 2008). The extent by which NBTI reduced gemcitabine import demonstrates that other transporters have an inferior role in gemcitabine uptake.

\subsubsection{Gemcitabine Import Not Affected}

Repeated measurements for ${ }^{3} \mathrm{H}$-gemcitabine uptake did not reveal a dependency on Ile216Thr as addressed in allele-specific stably transfected HEK293 cells. One challenge was to control for the endogenous level of ENT1 transporter in HEK293 cells, which contributes to the ${ }^{3} \mathrm{H}$-gemcitabine uptake and causing thereby background noise. Another difficulty was the humongous velocity of uptake mediated by overexpressed ENT1 
transporter. Within $10 \mathrm{~s}$ high amounts of substrate were transported, which impedes the ability to detect small differences due to experimental handling. Therefore, an artificial delay of transport was provoked by application of low NBTI concentrations $(0.1 \mu \mathrm{M})$. However, again no differences in uptake activity between the two allelic constructs were noted. Although ENT1 expression between the two allelic constructs was controlled on the mRNA level differences in ENT1 protein expression could not be excluded and may have masked allelic effects on gemcitabine uptake kinetics.

These findings are in agreement with former literature data. Indirect gemcitabine import kinetics as measured by inhibition of ${ }^{3} \mathrm{H}$-inosine uptake was not affected by Ile216Thr (OSATO et al 2003). However, the conclusions of that study with respect to gemcitabine transport in humans are limited for several reasons: First, the experiments including cytotoxicity assays were preformed in yeast cells. Second, only gemcitabine uptake was addressed and the equilibrative actions of the ENT1 were not considered. Third and most important, no direct interactions between gemcitabine and the two alleles of this polymorphism were analyzed (gemcitabine was used only as transport inhibitor and not as substrate). This is of particular importance as the binding pockets for substrates and inhibitors may differ.

In a second study, a significant difference in transport was observed for Ile216Thr, when cells were pre-incubated with ethanol for 24 hours (KIM et al 2011). It was suggested that Thr216 has an increased uptake activity for adenosine and inosine under these conditions. Additionally, it is claimed that Thr216 results in a decrease of NBTI (specific inhibitor of ENT1) affinity. One reason for altered uptake activity and NBTI affinity is considered to be an increased hydrophilicity introduced by Thr216 in the transmembrane domain 6 which is accompanied with altered domain conformation.

In patients peak plasma concentrations upon infusion reach values of about $40 \mu \mathrm{M}$ lasting for about 15 minutes. Then, the concentrations decrease due to enzymatic degradation. The gemcitabine concentration used in transport experiments (i.e. $10 \mu \mathrm{M}$ ) were chosen according to the peak values in patients' sera adjusted to that estimated to reach the target cells shortly after infusion stop. Using this concentration, gemcitabine appeared intracellularly equilibrated within 5 min in HEK cells (Figure 11). Thus, with respect to the equilibrated intracellular gemcitabine amounts due to import kinetics any potential difference between Ile and Thr216 might probably compensated by the longer drug exposure time in the clinical setting. Since the equilibrative ENT1 acts in both directions it 
is also conceivable that efflux rather than influx kinetics are affected by Ile216Thr, possibly by altered substrate affinities, what was not featured in this thesis. Regarding the clinical situation, upon end of infusion the gemcitabine serum concentrations decrease step-by-step going along with a discretely, but permanently positive gemcitabine gradient from intra- to extra-cellular. Under these conditions, a relevant effect of Thr216 is not unlikely. The hypothesis is that Thr216 facilitates outward-directed transport more efficiently than Ile216 thereby reducing intracellular exposure time toward gemcitabine. This idea would be in agreement with the worse survival observed for patients with Thr216 (SCHAUDinn 2013). The relationship between Ile216Thr and export kinetics has to be investigated in further experiments.

\subsection{Fields of Application for Gemcitabine Metabolites Determination by HPLC}

The self established HPLC method is suitable for precise separation, determination and quantification of gemcitabine and its metabolites (Figure 8). Possible fields of applications are investigations of molecular markers associated with impact on the transformation of gemcitabine metabolites. It might also be an option to compare intracellular amounts of gemcitabine metabolites in resistant and sensitive cell lines to identify possible sensitivity mechanisms by tracing back metabolic phenotypes to their genetic make-up. In order to apply this method the metabolites have to be extracted before. To achieve accurate results, the extracts have to be of a constant quality to identify small differences in metabolite variations.

\subsection{Confirmation of a GWAS Finding: WWOX rs11644322}

The positive confirmation of a GWAS finding (INNOCENTI et al. 2012) renders a potentially clinical implication. In other words, the referenced GWAS result becomes promising not before independently confirmed as now done. In general, GWAS require huge sample sizes so that an association can be regarded as statistically significant upon multiple testing correction. That was not the case for the WWOX rs11644322 polymorphism in the referenced study with about only 300 patients. But even if these 
statistical requirements are more or less met that does typically not guarantee reproducibility. A nice example for that is the association of the polymorphism IL17F rs763780 which was the reported study's top hit and claimed as significant due to statistical considerations (INNOCENTI et al. 2012). However, in the cohorts available for my thesis we could not detect any relationship of rs763780 with outcome of pancreatic cancer. One reason for failure of reproducibility in this case might be due to sample stratifications possibly causing spurious associations. Indeed, the authors admitted loss of significance level if they correct for treatment arm and ethnic ancestry (INNOCENTI et al. 2012). The inherent problems with GWAS highlight the value of independent replication by other GWAS or by analyses restricted to the top hits of the initial GWAS.

The clinical confirmation of WWOX rs11644322 in our available cohorts appeared particularly convincing as the effect of this polymorphism was not only evident in the relatively homogenous subgroup from Heidelberg (part of well-controlled clinical trial), but also, albeit to a weaker extent, in the combined retrospective set from Göttingen and Hamburg. Until now, there are no functional investigations for this SNP in literature. Due to its intronic location and the known function of $W W O X$ as a tumor suppressor gene it was hypothesized that the variant allele of rs11644322 may reduce WWOX expression and thereby reducing its tumor-suppressive effects resulting in worse clinical outcome (INNOCENTI et al. 2012). I have now functionally addressed these ideas.

The first assumption that rs11644322 due to its localization in the last, humongous intron with $>1$ million bp might result in expression loss of the last exon did not prove. However, EMSA experiments indicated weakened binding of putatively SP1 in presence of the variant allele at rs11644322 suggesting expression-related effects for this polymorphism. Interestingly, the induction of WWOX as observed in most LCLs was mitigated by the variant allele of rs11644322, albeit having scarcely failed statistical significance. One should consider that in the experimental setting the LCLs were exposed to gemcitabine only for $24 \mathrm{~h}$ until RNA was harvested. In the more protracted clinical situation, it seems conceivable that the effect of rs11644322 becomes more prominent. The latter issue could be addressed by a clinical study. However, when analyzing cytotoxic effects of gemcitabine in LCLs, no consistent impact of rs11644322 was seen. Nevertheless, the reproducible clinical association in conjunction with the new suggested relation to gemcitabine (at least on the transcriptional level) renders this polymorphism a promising candidate. That appears as much more plausible as this SNP is pertinent to a gene with 
important anti-apoptotic functions in oncological issues including pancreatic cancer (AqEILAN et al. 2007; BEDNAREK et al. 2001; KUROKI et al. 2004; NAKAYAMA et al. 2008; PAIGE et al. 2001)

\subsection{Genome-Wide Determinants of Gemcitabine Sensitivity}

\subsubsection{RS6898780 as a New Putative Marker}

In LCLs a reproducible impact of a SNP, i.e. rs6898780, on cellular gemcitabine sensitivity was observed. The variant allele of rs6898780 conferred resistance toward gemcitabine both in terms of proliferation inhibition and reduction of the vital cell fraction. However, it has to be admitted that the level for statistical significance in the test set failed scarcely when adjusted for multiple testing. This formally necessitates another replication study. Nonetheless, at present this polymorphism is regarded as a promising candidate for gemcitabine sensitivity. This constitutes a new finding as there are so far no literature reports for this issue. Rs6898780 is located on chromosome 5 apart from a known gene or expressed transcript. When analyzing the surrounding sequence context a humongously extended genetic linkage disequilibrium (LD) comprising this SNP was detected. Precisely, rs6898780 is in high LD at $\mathrm{r}^{2}>0.5$ with 144 genetic markers spanning about $110 \mathrm{kbp}$ upstream and $100 \mathrm{kbp}$ downstream of the index SNP. Interestingly, the region of the upstream LD comprises a locus encoding the validated long intergenic non-protein coding RNA 1021 (according to NCBI gene bank). Moreover, the 5'-ends of this RNA and that of the high LD block are identical suggesting potential selection events occurred in this region. No functional relevance of this RNA has been established yet. In view of this large number of genetic markers in high LD it is much conceivable that the causative variant with respect to gemcitabine sensitivity might not be rs6898780, but rather any of the other variants.

\subsubsection{Considerations about the Phenotypic Robustness}

In literature (Li et al. 2008), the effects on cellular vitality and on proliferation are common parameters for sensitivity measurements towards nucleoside analogues. The major challenge to obtain reasonable results is to control for the intra-cell biological variability, 
e.g. changes in the basal proliferation rate very probably affect sensitivity toward an antimetabolite like gemcitabine. Besides that, technical issues like the accuracy of the measurements have to be considered.

To control for the biological variability, a subset of 16 LCLs was subjected to the entire experimental procedure twice. That revealed substantial inter-cell reproducibility (Pearson correlation coefficient $r=0.8$ ), a prerequisite for the purpose to test for associations with the invariant genotypes.

In our study, the accuracy of measurements by flow cytometry turned out to be very accurate as confirmed by comparing the vitality and proliferation data in samples prepared in double. However, when evaluating the fraction of living cells it was not possible in all cases to distinguish precisely between dead cells and cell debris. As the fraction of living cells was referred to the total number of counted events, it was affected by varying amounts of cell debris. Thus, in the control samples without gemcitabine a broad range from about $30 \%$ to $80 \%$ of living cells was observed. It was estimated that initial deviations in the fraction of vital cells might affect the gemcitabine dose response curves of LCLs. However, no correlation with the EC50 value for cytotoxicity was seen in the final analysis.

The determination of the proliferation rate revealed consistently identical data between the samples prepared in double for each cell line, which indicates a very precise measurement method. The observation was that in some cases the initial staining of CFSE was varying between cell lines. It has to be considered that different initial CFSE loads might affect cellular functions as cell cycle process according to the supplier. Since substantial interday reproducibility for a subset of LCLs was observed, the inaccuracy was considered to be tolerable.

\subsection{General Considerations about GWAS}

In principle, GWAS is an extremely powerful approach to identify genetic markers in the entire genome. It is especially attractive since no priori knowledge is needed, which makes the analysis much more open-minded and allows the identification of genes so far unrelated to the considered phenotype (HIRSCHHORN and DALY 2005).

However, genome-wide association studies face some limitations. The most important issue in GWAS are problems adherent to multiple testing. In addition, this approach is 
constraint by the fact that mostly haplotypes related to a phenotype are identified and low frequent markers often stay undetected. In addition, all correlated SNPs in a respective haplotype have to be further evaluated since they all come into consideration for functionality. Noteworthy, the GWAS results just suggest associations with certain phenotypes, but do not reveal a direct functional link. All these limitations for clinical GWAS also hold true for functional GWAS, albeit herein the phenotypes could, in most cases, be determined more precisely.

In the recent years, whole genome sequencing has steadily become cheaper, which enlarges the data for GWAS. In the future, it is estimated that this method might be affordable for routine clinical applications. In my thesis, I had access to LCLs which are part of a large resequencing project. Thus, the used genotype data represent almost completely the genetic variability in the considered ethnicity except for rare variants for which the sequencing coverage is not yet sufficient. Consequently, the typical detection failure of SNPs which are not tagged by a haplotype in array-based GWAS is no more an issue for complete resequencing data. However, the higher marker density for the latter parallels with an increase in multiple testing. 


\section{Conclusion}

In my thesis, I investigated the molecular mechanisms of two SNPs in the equilibrative nucleoside transporter (ENT1), which were recently identified in our institute to affect overall survival of patients treated with a gemcitabine-based therapy for pancreatic cancer. The first SNP (rs1057985) is located in a promoter region of ENT1 and is hypothesized to modulate ENT1 transcription. Gemcitabine-induced ENT1 transcription was more pronounced in presence of the variant compared to the wild type allele of rs1057985. Electrophoretic mobility shift assay (EMSA) demonstrated protein binding only for the wild type allele of rs507964, the only polymorphism in perfect linkage disequilibrium with rs1057985 in Caucasians. EMSA experiments further suggested a member of the Sp-family to be the interacting protein. The mechanistic idea is that the Sp-family protein binds only in presence of the wild type allele thereby decreasing ENT1 transcription resulting in reduced cellular uptake of gemcitabine accompanied by worse therapeutic efficacy. Identification of the actual SP-family protein and its detailed functional cross-talk with the rs507964 should further clarify this issue.

The second ENT1 SNP rs45573936 derived from the association study represents an amino acid exchange (Ile216Thr). The suggested poor outcome for Thr216 was supposed to reduce gemcitabine uptake. Transport experiments with radio-labeled gemcitabine did not show uptake disparities between Ile216 and Thr216. Alternatively, this polymorphism might affect the efflux since ENT1 acts bidirectional what has to be further investigated.

In addition, picking up currently published GWAS data in relation to the outcome of gemcitabine-treated patients with pancreatic cancer the relevance of the polymorphism WWOX rs11644322 was confirmed. Expression induction of the tumor suppressor gene WWOX by gemcitabine was mitigated by the variant allele of rs11644322 which was associated with worse prognosis. In EMSA, this allele exhibited attenuated protein binding, putatively again belonging to the SP-family. If the hypothesized effects of this polymorphism on mRNA transcription translates into protein remains to be elucidated. An own functional GWAS for gemcitabine sensitivity revealed reproducibly enhanced resistance toward gemcitabine in presence of the variant allele of rs6898780. As this polymorphism and its genetic environment have not been functionally explored further studies may elicit new promising insights in the context of gemcitabine sensitivity and possibly pancreatic cancer. 


\section{References}

Abbruzzese, J. L., R. Grunewald, E. A. Weeks, D. Gravel, T. Adams et al., 1991 A phase I clinical, plasma, and cellular pharmacology study of gemcitabine. Journal of clinical oncology : official journal of the American Society of Clinical Oncology 9: 491-498.

Abdulla, P., and I. R. CoE, 2007 Characterization and functional analysis of the promoter for the human equilibrative nucleoside transporter gene, hENT1. Nucleosides Nucleotides Nucleic Acids 26: 99-110.

Abecasis, G. R., A. Auton, L. D. Brooks, M. A. DePristo, R. M. Durbin et al., 2012 An integrated map of genetic variation from 1,092 human genomes. Nature 491: 56-65.

Achiwa, H., T. Oguri, S. SAto, H. MaedA, T. NiImi et al., 2004 Determinants of sensitivity and resistance to gemcitabine: the roles of human equilibrative nucleoside transporter 1 and deoxycytidine kinase in non-small cell lung cancer. Cancer science 95: 753-757.

Ahlgren, J. D., 1996 Epidemiology and risk factors in pancreatic cancer. Seminars in oncology 23: 241-250.

Aqeilan, R. I., F. Trapasso, S. Hussain, S. Costinean, D. Marshall et al., 2007 Targeted deletion of Wwox reveals a tumor suppressor function. Proc Natl Acad Sci U S A 104: 3949-3954.

ArCher, R. G., V. Pitelka and J. R. Hammond, 2004 Nucleoside transporter subtype expression and function in rat skeletal muscle microvascular endothelial cells. Br J Pharmacol 143: 202-214.

Ashida, R., B. Nakata, M. Shigekawa, N. Mizuno, A. SAwaki et al., 2009 Gemcitabine sensitivity-related mRNA expression in endoscopic ultrasoundguided fine-needle aspiration biopsy of unresectable pancreatic cancer. Journal of experimental \& clinical cancer research : CR 28: 83.

Baker, C. H., J. Banzon, J. M. Bollinger, J. StubBe, V. SAmano et al., 1991 2'Deoxy-2'-methylenecytidine and 2'-deoxy-2',2'-difluorocytidine 5'-diphosphates: potent mechanism-based inhibitors of ribonucleotide reductase. Journal of medicinal chemistry 34: 1879-1884.

Bardeesy, N., and R. A. DePinho, 2002 Pancreatic cancer biology and genetics. Nature reviews. Cancer 2: 897-909.

BednareK, A. K., C. L. Keck-Waggoner, R. L. Daniel, K. J. Laflin, P. L. BERGSAGEL et al., 2001 WWOX, the FRA16D gene, behaves as a suppressor of tumor growth. Cancer Res 61: 8068-8073.

Belt, J. A., N. M. Marina, D. A. Phelps and C. R. Crawford, 1993 Nucleoside transport in normal and neoplastic cells. Advances in enzyme regulation 33: 235-252.

Bengala, C., V. Guarneri, E. Giovannetti, M. Lencioni, E. Fontana et al., 2005 Prolonged fixed dose rate infusion of gemcitabine with autologous haemopoietic support in advanced pancreatic adenocarcinoma. British journal of cancer 93: 35-40.

Bergman, A. M., P. P. EijK, V. W. Ruiz van Haperen, K. Smid, G. Veerman et al., 2005 In vivo induction of resistance to gemcitabine results in increased expression of ribonucleotide reductase subunit M1 as the major determinant. Cancer Res 65: 9510-9516.

Bergman, A. M., H. M. Pinedo and G. J. Peters, 2002 Determinants of resistance to 2',2'-difluorodeoxycytidine (gemcitabine). Drug resistance updates : reviews and commentaries in antimicrobial and anticancer chemotherapy 5: 19-33. 
Bergman, A. M., H. M. Pinedo, G. Veerman, C. M. Kuiper and G. J. Peters, 1998 Increased sensitivity to gemcitabine of P-gP and MRP overexpressing human non-small cell lung cancer cell lines. Advances in experimental medicine and biology 431: 591-594.

Bergquist, A., A. EKBom, R. Olsson, D. Kornfeldt, L. LoOf et al., 2002 Hepatic and extrahepatic malignancies in primary sclerosing cholangitis. Journal of hepatology 36: 321-327.

Berlin, J. D., P. Catalano, J. P. Thomas, J. W. Kugler, D. G. Haller et al., 2002 Phase III study of gemcitabine in combination with fluorouracil versus gemcitabine alone in patients with advanced pancreatic carcinoma: Eastern Cooperative Oncology Group Trial E2297. Journal of clinical oncology : official journal of the American Society of Clinical Oncology 20: 3270-3275.

Bhutia, Y. D., S. W. Hung, B. Patel, D. Lovin and R. Govindarajan, 2011 CNT1 expression influences proliferation and chemosensitivity in drug-resistant pancreatic cancer cells. Cancer Res 71: 1825-1835.

Bogdanovic, O., A. Fernandez-Minan, J. J. Tena, E. de la Calle-Mustienes, C. HidALgo et al., 2012 Dynamics of enhancer chromatin signatures mark the transition from pluripotency to cell specification during embryogenesis. Genome research 22: 2043-2053.

Brune, K. A., B. Lau, E. Palmisano, M. Canto, M. G. Goggins et al., 2010 Importance of age of onset in pancreatic cancer kindreds. Journal of the National Cancer Institute 102: 119-126.

Burris, H. A., 3RD, M. J. Moore, J. Andersen, M. R. Green, M. L. Rothenberg et al., 1997 Improvements in survival and clinical benefit with gemcitabine as firstline therapy for patients with advanced pancreas cancer: a randomized trial. Journal of clinical oncology : official journal of the American Society of Clinical Oncology 15: 2403-2413.

CAnO-Soldado, P., and M. PAstor-Anglada, 2012 Transporters that translocate nucleosides and structural similar drugs: structural requirements for substrate recognition. Med Res Rev 32: 428-457.

Carmichael, J., U. FinK, R. C. Russell, M. F. Spittle, A. L. Harris et al., 1996 Phase II study of gemcitabine in patients with advanced pancreatic cancer. British journal of cancer 73: 101-105.

Chaudary, N., Z. Naydenova, I. Shuralyova and I. R. Coe, 2004 Hypoxia regulates the adenosine transporter, mENT1, in the murine cardiomyocyte cell line, HL-1. Cardiovasc Res 61: 780-788.

Chen, H., and M. C. Hung, 1997 Involvement of co-activator p300 in the transcriptional regulation of the HER-2/neu gene. The Journal of biological chemistry 272: 6101-6104.

Choi, D. S., M. Handa, H. Young, A. S. Gordon, I. Diamond et al., 2000 Genomic organization and expression of the mouse equilibrative, nitrobenzylthioinosinesensitive nucleoside transporter 1 (ENT1) gene. Biochemical and biophysical research communications 277: 200-208.

Clarke, M. L., V. L. Damaraju, J. Zhang, D. Mowles, T. TACKaberry et al., 2006 The role of human nucleoside transporters in cellular uptake of 4'-thio-beta-Darabinofuranosylcytosine and beta-D-arabinosylcytosine. Molecular pharmacology 70: 303-310.

Colucci, G., R. Labianca, F. Di Costanzo, V. Gebbia, G. Carteni et al., 2010 Randomized phase III trial of gemcitabine plus cisplatin compared with singleagent gemcitabine as first-line treatment of patients with advanced pancreatic 
cancer: the GIP-1 study. Journal of clinical oncology : official journal of the American Society of Clinical Oncology 28: 1645-1651.

Conroy, T., F. Desseigne, M. Ychou, O. Bouche, R. Guimbaud et al., 2011 FOLFIRINOX versus gemcitabine for metastatic pancreatic cancer. The New England journal of medicine 364: 1817-1825.

Cunningham, D., I. Chau, D. D. Stocken, J. W. Valle, D. Smith et al., 2009 Phase III randomized comparison of gemcitabine versus gemcitabine plus capecitabine in patients with advanced pancreatic cancer. Journal of clinical oncology : official journal of the American Society of Clinical Oncology 27: 5513-5518.

Damaraju, V. L., A. N. Elwi, C. Hunter, P. Carpenter, C. Santos et al., 2007 Localization of broadly selective equilibrative and concentrative nucleoside transporters, hENT1 and hCNT3, in human kidney. American journal of physiology. Renal physiology 293: F200-211.

Davidson, J. D., L. MA, M. Flagella, S. Geeganage, L. M. Gelbert et al., 2004 An increase in the expression of ribonucleotide reductase large subunit 1 is associated with gemcitabine resistance in non-small cell lung cancer cell lines. Cancer research 64: 3761-3766.

De Jesus-Acosta, A., G. R. Oliver, A. Blackford, K. Kinsman, E. I. Flores et al., 2012 A multicenter analysis of GTX chemotherapy in patients with locally advanced and metastatic pancreatic adenocarcinoma. Cancer chemotherapy and pharmacology 69: 415-424.

De LA, O. J., and L. C. Murtaugh, 2009 Notch and Kras in pancreatic cancer: at the crossroads of mutation, differentiation and signaling. Cell cycle 8: 1860-1864.

Decosterd, L. A., E. Cottin, X. Chen, F. Lejeune, R. O. Mirimanoff et al., 1999 Simultaneous determination of deoxyribonucleoside in the presence of ribonucleoside triphosphates in human carcinoma cells by high-performance liquid chromatography. Anal Biochem 270: 59-68.

Deshane, J., J. Kim, S. Bolisetty, T. D. Hock, N. Hill-KapturczaK et al., 2010 Sp1 regulates chromatin looping between an intronic enhancer and distal promoter of the human heme oxygenase- 1 gene in renal cells. The Journal of biological chemistry 285: 16476-16486.

Dhayat, S., W. A. Mardin, S. T. Mees and J. Haier, 2011 Epigenetic markers for chemosensitivity and chemoresistance in pancreatic cancer--a review. International journal of cancer. Journal international du cancer 129: 1031-1041.

Doehring, A., W. P. Hofmann, C. Schlecker, S. Zeuzem, C. SARrazin et al., 2011 Role of nucleoside transporters SLC28A2/3 and SLC29A1/2 genetics in ribavirin therapy: protection against anemia in patients with chronic hepatitis C. Pharmacogenet Genomics 21: 289-296.

DrAZNIN, B., 2010 Mitogenic action of insulin: friend, foe or 'frenemy'? Diabetologia 53: 229-233.

Dumontet, C., K. Fabianowska-Majewska, D. Mantincic, E. Callet Bauchu, I. TIGAUD et al., 1999 Common resistance mechanisms to deoxynucleoside analogues in variants of the human erythroleukaemic line K562. British journal of haematology 106: 78-85.

El-Khoueiry, A. B., R. K. Ramanathan, D. Y. YANG, W. Zhang, S. Shibata et al., 2012 A randomized phase II of gemcitabine and sorafenib versus sorafenib alone in patients with metastatic pancreatic cancer. Investigational new drugs 30: $1175-1183$. 
Eltzschig, H. K., P. Abdulla, E. Hoffman, K. E. Hamilton, D. Daniels et al., 2005 HIF-1-dependent repression of equilibrative nucleoside transporter (ENT) in hypoxia. J Exp Med 202: 1493-1505.

Emerich, D. F., R. L. DeAn, J. MArsh, M. Pink, D. LAfReniere et al., 2000 Intravenous cereport (RMP-7) enhances delivery of hydrophilic chemotherapeutics and increases survival in rats with metastatic tumors in the brain. Pharmaceutical research 17: 1212-1219.

ERRASTI-MurugarRen, E., and M. PASTOR-ANGLADA, 2010 Drug transporter pharmacogenetics in nucleoside-based therapies. Pharmacogenomics 11: 809841.

Farre, X., E. Guillen-Gomez, L. Sanchez, D. Hardisson, Y. Plaza et al., 2004 Expression of the nucleoside-derived drug transporters hCNT1, hENT1 and hENT2 in gynecologic tumors. International journal of cancer. Journal international du cancer 112: 959-966.

Farrell, J. J., H. Elsaleh, M. Garcia, R. LAi, A. Ammar et al., 2009 Human equilibrative nucleoside transporter 1 levels predict response to gemcitabine in patients with pancreatic cancer. Gastroenterology 136: 187-195.

Fine, R. L., D. R. Fogelman, S. M. Schreibman, M. Desai, W. Sherman et al., 2008 The gemcitabine, docetaxel, and capecitabine (GTX) regimen for metastatic pancreatic cancer: a retrospective analysis. Cancer chemotherapy and pharmacology 61: 167-175.

Fukuchi, Y., T. Furihata, M. Hashizume, M. Iikura and K. ChiBA, 2010 Characterization of ribavirin uptake systems in human hepatocytes. Journal of hepatology 52: 486-492.

Fukunaga, A. K., S. Marsh, D. J. Murry, T. D. Hurley and H. L. McLeOd, 2004 Identification and analysis of single-nucleotide polymorphisms in the gemcitabine pharmacologic pathway. Pharmacogenomics J 4: 307-314.

Galmarini, C. M., X. Thomas, F. Calvo, P. Rousselot, A. El JafaAri et al., 2002 Potential mechanisms of resistance to cytarabine in AML patients. Leukemia research 26: 621-629.

Gandhi, V., J. Legha, F. Chen, L. W. Hertel and W. Plunkett, 1996 Excision of 2',2'-difluorodeoxycytidine (gemcitabine) monophosphate residues from DNA. Cancer research 56: 4453-4459.

GANDHI, V., and W. PlunKetT, 1990 Modulatory activity of 2',2'-difluorodeoxycytidine on the phosphorylation and cytotoxicity of arabinosyl nucleosides. Cancer research 50: 3675-3680.

Garcia-Manteiga, J., M. Molina-Arcas, F. J. Casado, A. Mazo and M. PastorANGLADA, 2003 Nucleoside transporter profiles in human pancreatic cancer cells: role of hCNT1 in 2',2'-difluorodeoxycytidine- induced cytotoxicity. Clin Cancer Res 9: 5000-5008.

Gati, W. P., A. R. Paterson, L. M. Larratt, A. R. Turner and A. R. Belch, 1997 Sensitivity of acute leukemia cells to cytarabine is a correlate of cellular es nucleoside transporter site content measured by flow cytometry with SAENTAfluorescein. Blood 90: 346-353.

Ghaneh, P., E. Costello and J. P. Neoptolemos, 2007 Biology and management of pancreatic cancer. Gut 56: 1134-1152.

Gidekel Friedlander, S. Y., G. C. Chu, E. L. Snyder, N. GiRnius, G. Dibelius et al., 2009 Context-dependent transformation of adult pancreatic cells by oncogenic K-Ras. Cancer cell 16: 379-389. 
Giovannetti, E., M. Del Tacca, V. Mey, N. Funel, S. Nannizzi et al., 2006 Transcription analysis of human equilibrative nucleoside transporter-1 predicts survival in pancreas cancer patients treated with gemcitabine. Cancer research 66: 3928-3935.

Gloeckner-Hofmann, K., E. Guillen-Gomez, C. Schmidtgen, R. Porstmann, R. ZIEGLER et al., 2006 Expression of the high-affinity fluoropyrimidine-preferring nucleoside transporter hCNT1 correlates with decreased disease-free survival in breast cancer. Oncology 70: 238-244.

GoAn, Y. G., B. ZhOU, E. Hu, S. Mi and Y. Yen, 1999 Overexpression of ribonucleotide reductase as a mechanism of resistance to 2,2difluorodeoxycytidine in the human KB cancer cell line. Cancer research 59: 4204-4207.

GRIFFITH, D. A., and S. M. JARVIS, 1996 Nucleoside and nucleobase transport systems of mammalian cells. Biochimica et biophysica acta 1286: 153-181.

Griffiths, M., N. BeAumont, S. Y. YaO, M. Sundaram, C. E. Boumah et al., 1997 Cloning of a human nucleoside transporter implicated in the cellular uptake of adenosine and chemotherapeutic drugs. Nature medicine 3: 89-93.

Gusella, M., F. Pasini, C. Bolzonella, S. Meneghetti, C. Barile et al., 2011 Equilibrative nucleoside transporter 1 genotype, cytidine deaminase activity and age predict gemcitabine plasma clearance in patients with solid tumours. $\mathrm{Br} \mathrm{J}$ Clin Pharmacol 71: 437-444.

Gysin, S., M. SAlt, A. Young and F. McCormick, 2011 Therapeutic strategies for targeting ras proteins. Genes \& cancer 2: 359-372.

Hart, A. R., H. KenNedy and I. HARVEY, 2008 Pancreatic cancer: a review of the evidence on causation. Clinical gastroenterology and hepatology : the official clinical practice journal of the American Gastroenterological Association 6: 275-282.

Hassan, M. M., M. L. Bondy, R. A. Wolff, J. L. Abbruzzese, J. N. Vauthey et al., 2007 Risk factors for pancreatic cancer: case-control study. The American journal of gastroenterology 102: 2696-2707.

Heinemann, V., L. W. Hertel, G. B. Grindey and W. Plunkett, 1988 Comparison of the cellular pharmacokinetics and toxicity of 2',2'-difluorodeoxycytidine and 1-beta-D-arabinofuranosylcytosine. Cancer research 48: 4024-4031.

Heinemann, V., D. Quietzsch, F. Gieseler, M. Gonnermann, H. SchoneKas et al., 2006 Randomized phase III trial of gemcitabine plus cisplatin compared with gemcitabine alone in advanced pancreatic cancer. Journal of clinical oncology : official journal of the American Society of Clinical Oncology 24: 3946-3952.

Heinemann, V., L. Schulz, R. D. Issels and W. Plunkett, 1995 Gemcitabine: a modulator of intracellular nucleotide and deoxynucleotide metabolism. Seminars in oncology 22: 11-18.

Heinemann, V., Y. Z. Xu, S. ChubB, A. Sen, L. W. Hertel et al., 1990 Inhibition of ribonucleotide reduction in CCRF-CEM cells by 2',2'-difluorodeoxycytidine. Molecular pharmacology 38: 567-572.

Heinemann, V., Y. Z. Xu, S. ChubB, A. Sen, L. W. Hertel et al., 1992 Cellular elimination of 2',2'-difluorodeoxycytidine 5'-triphosphate: a mechanism of selfpotentiation. Cancer Res 52: 533-539.

Herrmann, R., G. Bodoky, T. Ruhstaller, B. Glimelius, E. Bajetta et al., 2007 Gemcitabine plus capecitabine compared with gemcitabine alone in advanced pancreatic cancer: a randomized, multicenter, phase III trial of the Swiss Group for Clinical Cancer Research and the Central European Cooperative Oncology 
Group. Journal of clinical oncology : official journal of the American Society of Clinical Oncology 25: 2212-2217.

Hertel, L. W., G. B. Boder, J. S. Kroin, S. M. Rinzel, G. A. Poore et al., 1990 Evaluation of the antitumor activity of gemcitabine (2',2'-difluoro-2'deoxycytidine). Cancer research 50: 4417-4422.

HIGUCHI, R. FOCKLER, C. DOLlingER, G. WATSON, R., 1993 Kinetic PCR analysis: real-time monitoring of DNA amplification reactions. Biotechnology (N Y) 11: 1026-1030.

HirschHORN, J. N., and M. J. DALY, 2005 Genome-wide association studies for common diseases and complex traits. Nat Rev Genet 6: 95-108.

Hruban, R. H., A. D. van Mansfeld, G. J. Offerhaus, D. H. van Weering, D. C. ALLISON et al., $1993 \mathrm{~K}$-ras oncogene activation in adenocarcinoma of the human pancreas. A study of 82 carcinomas using a combination of mutant-enriched polymerase chain reaction analysis and allele-specific oligonucleotide hybridization. The American journal of pathology 143: 545-554.

Huang, P., S. Chubb, L. W. Hertel, G. B. Grindey and W. Plunkett, 1991 Action of 2',2'-difluorodeoxycytidine on DNA synthesis. Cancer Res 51: 6110-6117.

HuAng, P., and W. PlunketT, 1995 Induction of apoptosis by gemcitabine. Seminars in oncology 22: 19-25.

Huguet, F., N. Girard, C. S. Guerche, C. Hennequin, F. Mornex et al., 2009 Chemoradiotherapy in the management of locally advanced pancreatic carcinoma: a qualitative systematic review. Journal of clinical oncology : official journal of the American Society of Clinical Oncology 27: 2269-2277.

Hunsucker, S. A., J. Spychala and B. S. Mitchell, 2001 Human cytosolic 5'nucleotidase I: characterization and role in nucleoside analog resistance. The Journal of biological chemistry 276: 10498-10504.

InNOCEnTi, F., K. OWZAR, N. L. Cox, P. Evans, M. KuBo et al., 2012 A genome-wide association study of overall survival in pancreatic cancer patients treated with gemcitabine in CALGB 80303. Clinical cancer research : an official journal of the American Association for Cancer Research 18: 577-584.

Jemal, A., R. Siegel, J. Xu and E. WARD, 2010 Cancer statistics, 2010. CA: a cancer journal for clinicians 60: 277-300.

JimENO, A., and M. HidALGO, 2006 Molecular biomarkers: their increasing role in the diagnosis, characterization, and therapy guidance in pancreatic cancer. Molecular cancer therapeutics 5: 787-796.

Jones, J., A. TAKEDA, S. C. TAN, K. COOPER, E. LOVEMAN et al., 2009 Gemcitabine for the treatment of metastatic breast cancer. Health technology assessment 13 Suppl 2: 1-7.

Jones, S., X. Zhang, D. W. PARsons, J. C. Lin, R. J. LeARy et al., 2008 Core signaling pathways in human pancreatic cancers revealed by global genomic analyses. Science 321: 1801-1806.

Katz, M. H., P. W. Pisters, D. B. Evans, C. C. Sun, J. E. Lee et al., 2008 Borderline resectable pancreatic cancer: the importance of this emerging stage of disease. Journal of the American College of Surgeons 206: 833-846; discussion 846-838.

Kichenin, K., G. Pignede, F. Fudalej and M. SEmAn, 2000 CD3 activation induces concentrative nucleoside transport in human T lymphocytes. Eur J Immunol 30: 366-370.

Kim, J. H., V. M. KarpyaK, J. M. Biernacka, H. W. Nam, M. R. LeE et al., 2011 Functional role of the polymorphic 647 T/C variant of ENT1 (SLC29A1) and its association with alcohol withdrawal seizures. PLoS One 6: e16331. 
Kindler, H. L., T. IOKA, D. J. Richel, J. BennounA, R. LetOURneAu et al., 2011 Axitinib plus gemcitabine versus placebo plus gemcitabine in patients with advanced pancreatic adenocarcinoma: a double-blind randomised phase 3 study. The lancet oncology 12: 256-262.

Kindler, H. L., D. NiedzWiecki, D. Hollis, S. Sutherland, D. Schrag et al., 2010 Gemcitabine plus bevacizumab compared with gemcitabine plus placebo in patients with advanced pancreatic cancer: phase III trial of the Cancer and Leukemia Group B (CALGB 80303). Journal of clinical oncology : official journal of the American Society of Clinical Oncology 28: 3617-3622.

King, K. M., V. L. Damaraju, M. F. Vickers, S. Y. YaO, T. Lang et al., 2006 A comparison of the transportability, and its role in cytotoxicity, of clofarabine, cladribine, and fludarabine by recombinant human nucleoside transporters produced in three model expression systems. Molecular pharmacology 69: 346353.

Ko, A. H., 2011 FOLFIRINOX: a small step or a great leap forward? Journal of clinical oncology : official journal of the American Society of Clinical Oncology 29: 3727-3729.

Kroep, J. R., G. GiAccone, C. Tolis, D. A. Voorn, W. J. Loves et al., 2000 Sequence dependent effect of paclitaxel on gemcitabine metabolism in relation to cell cycle and cytotoxicity in non-small-cell lung cancer cell lines. British journal of cancer 83: 1069-1076.

Kroep, J. R., W. J. Loves, C. L. VAN DeR WiLt, E. Alvarez, I. TAlianidis et al., 2002 Pretreatment deoxycytidine kinase levels predict in vivo gemcitabine sensitivity. Molecular cancer therapeutics 1: 371-376.

Kuroki, T., S. Yendamuri, F. Trapasso, A. Matsuyama, R. I. Aqeilan et al., 2004 The tumor suppressor gene WWOX at FRA16D is involved in pancreatic carcinogenesis. Clin Cancer Res 10: 2459-2465.

KusCHEL, C., 2012 Functional and genetic variability in the cytotoxic action of nucleosid analogues, pp. in Medical Faculty, Institute of Clinical Pharmacology, Göttingen.

LAI, Y., C. M. TSE and J. D. UnADKAT, 2004 Mitochondrial expression of the human equilibrative nucleoside transporter 1 (hENT1) results in enhanced mitochondrial toxicity of antiviral drugs. J Biol Chem 279: 4490-4497.

LeE, E. W., Y. LAI, H. Zhang and J. D. UnADKAT, 2006 Identification of the mitochondrial targeting signal of the human equilibrative nucleoside transporter 1 (hENT1): implications for interspecies differences in mitochondrial toxicity of fialuridine. J Biol Chem 281: 16700-16706.

Li, D., K. XIE, R. WolfF and J. L. AbBruzzese, 2004 Pancreatic cancer. Lancet 363: 1049-1057.

Li, L., B. Fridley, K. Kalari, G. Jenkins, A. Batzler et al., 2008 Gemcitabine and cytosine arabinoside cytotoxicity: association with lymphoblastoid cell expression. Cancer Res 68: 7050-7058.

Li, L., B. L. Fridley, K. Kalari, G. Jenkins, A. BAtzler et al., 2009 Gemcitabine and arabinosylcytosin pharmacogenomics: genome-wide association and drug response biomarkers. PLoS One 4: e7765.

Li, L., D. J. Schaid, B. L. Fridley, K. R. Kalari, G. D. Jenkins et al., 2012 Gemcitabine metabolic pathway genetic polymorphisms and response in patients with non-small cell lung cancer. Pharmacogenet Genomics 22: 105-116. 
LoOS, M., J. KleEfF, H. Friess and M. W. Buchler, 2008 Surgical treatment of pancreatic cancer. Annals of the New York Academy of Sciences 1138: 169180.

Louvet, C., R. Labianca, P. Hammel, G. Lledo, M. G. Zampino et al., 2005 Gemcitabine in combination with oxaliplatin compared with gemcitabine alone in locally advanced or metastatic pancreatic cancer: results of a GERCOR and GISCAD phase III trial. Journal of clinical oncology : official journal of the American Society of Clinical Oncology 23: 3509-3516.

Lowenfels, A. B., P. Maisonneuve, G. Cavallini, R. W. Ammann, P. G. Lankisch et al., 1993 Pancreatitis and the risk of pancreatic cancer. International Pancreatitis Study Group. The New England journal of medicine 328: 14331437.

Lynch, H. T., R. E. Brand, C. A. Deters, T. G. Shaw and J. F. Lynch, 2001 Hereditary pancreatic cancer. Pancreatology : official journal of the International Association of Pancreatology 1: 466-471.

Lyon, J. L., M. L. Slattery, A. W. Mahoney and L. M. Robison, 1993 Dietary intake as a risk factor for cancer of the exocrine pancreas. Cancer Epidemiol Biomarkers Prev 2: 513-518.

LyOns, A. B., and C. R. PARISH, 1994 Determination of lymphocyte division by flow cytometry. J Immunol Methods 171: 131-137.

MACK, T. M., M. C. Yu, R. HANisch and B. E. Henderson, 1986 Pancreas cancer and smoking, beverage consumption, and past medical history. Journal of the National Cancer Institute 76: 49-60.

Mackey, J. R., C. M. Galmarini, K. A. Graham, A. A. Joy, A. Delmer et al., 2005 Quantitative analysis of nucleoside transporter and metabolism gene expression in chronic lymphocytic leukemia (CLL): identification of fludarabine-sensitive and -insensitive populations. Blood 105: 767-774.

Mackey, J. R., L. L. Jennings, M. L. Clarke, C. L. SANTOS, L. DabBagh et al., 2002 Immunohistochemical variation of human equilibrative nucleoside transporter 1 protein in primary breast cancers. Clinical cancer research : an official journal of the American Association for Cancer Research 8: 110-116.

Mackey, J. R., R. S. Mani, M. Selner, D. Mowles, J. D. Young et al., 1998 Functional nucleoside transporters are required for gemcitabine influx and manifestation of toxicity in cancer cell lines. Cancer research 58: 4349-4357.

MACKey, J. R., S. Y. YAO, K. M. SMith, E. KARPinsKi, S. A. BALDWIN et al., 1999 Gemcitabine transport in xenopus oocytes expressing recombinant plasma membrane mammalian nucleoside transporters. J Natl Cancer Inst 91: 18761881.

MacMahon, B., S. Yen, D. Trichopoulos, K. Warren and G. Nardi, 1981 Coffee and cancer of the pancreas. The New England journal of medicine 304: 630-633.

MALFERTHEINER, P., and K. SCHUTTE, 2006 Smoking--a trigger for chronic inflammation and cancer development in the pancreas. The American journal of gastroenterology 101: 160-162.

Mangravite, L. M., J. H. Lipschutz, K. E. Mostov and K. M. Giacomini, 2001 Localization of GFP-tagged concentrative nucleoside transporters in a renal polarized epithelial cell line. American journal of physiology. Renal physiology 280: F879-885.

Mani, R. S., J. R. HAMmond, J. M. Marjan, K. A. Graham, J. D. Young et al., 1998 Demonstration of equilibrative nucleoside transporters (hENT1 and hENT2) in 
nuclear envelopes of cultured human choriocarcinoma (BeWo) cells by functional reconstitution in proteoliposomes. J Biol Chem 273: 30818-30825.

Marce, S., M. Molina-Arcas, N. Villamor, F. J. CASAdo, E. CAmpo et al., 2006 Expression of human equilibrative nucleoside transporter 1 (hENT1) and its correlation with gemcitabine uptake and cytotoxicity in mantle cell lymphoma. Haematologica 91: 895-902.

Marechal, R., J. R. Mackey, R. Lai, P. Demetter, M. Peeters et al., 2009 Human equilibrative nucleoside transporter 1 and human concentrative nucleoside transporter 3 predict survival after adjuvant gemcitabine therapy in resected pancreatic adenocarcinoma. Clinical cancer research : an official journal of the American Association for Cancer Research 15: 2913-2919.

Matys, V., E. Fricke, R. GefFers, E. Gossling, M. Haubrock et al., 2003 TRANSFAC: transcriptional regulation, from patterns to profiles. Nucleic acids research 31: 374-378.

Mey, V., E. Giovannetti, F. De Braud, S. Nannizzi, G. Curigliano et al., 2006 In vitro synergistic cytotoxicity of gemcitabine and pemetrexed and pharmacogenetic evaluation of response to gemcitabine in bladder cancer patients. British journal of cancer 95: 289-297.

Michalski, C. W., M. ERKan, D. SAuliunaite, T. GieSe, R. Stratmann et al., 2008 Ex vivo chemosensitivity testing and gene expression profiling predict response towards adjuvant gemcitabine treatment in pancreatic cancer. British journal of cancer 99: 760-767.

Miksad, R. A., L. SChnipper and M. Goldstein, 2007 Does a statistically significant survival benefit of erlotinib plus gemcitabine for advanced pancreatic cancer translate into clinical significance and value? Journal of clinical oncology : official journal of the American Society of Clinical Oncology 25: 4506-4507; author reply 4508.

Mini, E., S. Nobili, B. Caciagli, I. Landini and T. Mazzei, 2006 Cellular pharmacology of gemcitabine. Ann Oncol 17 Suppl 5: v7-12.

Molina-Arcas, M., G. Moreno-Bueno, P. CANO-Soldado, H. HernandezVARGAS, F. J. CASADO et al., 2006 Human equilibrative nucleoside transporter-1 (hENT1) is required for the transcriptomic response of the nucleoside-derived drug 5'-DFUR in breast cancer MCF7 cells. Biochemical pharmacology 72: 1646-1656.

Moore, M. J., D. Goldstein, J. Hamm, A. Figer, J. R. Hecht et al., 2007 Erlotinib plus gemcitabine compared with gemcitabine alone in patients with advanced pancreatic cancer: a phase III trial of the National Cancer Institute of Canada Clinical Trials Group. Journal of clinical oncology : official journal of the American Society of Clinical Oncology 25: 1960-1966.

MoskaluK, C. A., R. H. Hruban and S. E. Kern, 1997 p16 and K-ras gene mutations in the intraductal precursors of human pancreatic adenocarcinoma. Cancer research 57: 2140-2143.

Murray, R. H., and A. J. RuBEL, 1992 Physicians and healers--unwitting partners in health care. N Engl J Med 326: 61-64.

Myers, S. N., R. K. Goyal, J. D. Roy, L. D. Fairfull, J. W. Wilson et al., 2006 Functional single nucleotide polymorphism haplotypes in the human equilibrative nucleoside transporter 1. Pharmacogenet Genomics 16: 315-320.

NaKano, Y., S. Tanno, K. Koizumi, T. NishiKawa, K. NaKamura et al., 2007 Gemcitabine chemoresistance and molecular markers associated with 
gemcitabine transport and metabolism in human pancreatic cancer cells. $\mathrm{Br} \mathrm{J}$ Cancer 96: 457-463.

Nakayama, S., S. Semba, N. Maeda, R. I. Aqeilan, K. Huebner et al., 2008 Role of the WWOX gene, encompassing fragile region FRA16D, in suppression of pancreatic carcinoma cells. Cancer science 99: 1370-1376.

NefF, T., and C. A. Blau, 1996 Forced expression of cytidine deaminase confers resistance to cytosine arabinoside and gemcitabine. Experimental hematology 24: $1340-1346$.

Neoptolemos, J. P., D. D. Stocken, C. Bassi, P. Ghaneh, D. Cunningham et al., 2010 Adjuvant chemotherapy with fluorouracil plus folinic acid vs gemcitabine following pancreatic cancer resection: a randomized controlled trial. JAMA : the journal of the American Medical Association 304: 1073-1081.

NGO, L. Y., S. D. PATIL and J. D. UnADKAT, 2001 Ontogenic and longitudinal activity of $\mathrm{Na}(+)$-nucleoside transporters in the human intestine. American journal of physiology. Gastrointestinal and liver physiology 280: G475-481.

Oettle, H., and P. Neuhaus, 2007 Adjuvant therapy in pancreatic cancer: a critical appraisal. Drugs 67: 2293-2310.

Olive, K. P., M. A. Jacobetz, C. J. Davidson, A. Gopinathan, D. Mcintyre et al., 2009 Inhibition of Hedgehog signaling enhances delivery of chemotherapy in a mouse model of pancreatic cancer. Science 324: 1457-1461.

Osato, D. H., C. C. HuAng, M. Kawamoto, S. J. Johns, D. Stryke et al., 2003 Functional characterization in yeast of genetic variants in the human equilibrative nucleoside transporter, ENT1. Pharmacogenetics 13: 297-301.

Paige, A. J., K. J. TAylor, C. TAYlor, S. G. Hillier, S. Farrington et al., 2001 WWOX: a candidate tumor suppressor gene involved in multiple tumor types. Proc Natl Acad Sci U S A 98: 11417-11422.

Paproski, R. J., F. Visser, J. Zhang, T. TACKABerry, V. DAmaraju et al., 2008 Mutation of Trp29 of human equilibrative nucleoside transporter 1 alters affinity for coronary vasodilator drugs and nucleoside selectivity. Biochem J 414: 291300.

Pauwels, B., A. E. Korst, G. G. Pattyn, H. A. Lambrechts, J. A. Kamphuis et al., 2006 The relation between deoxycytidine kinase activity and the radiosensitising effect of gemcitabine in eight different human tumour cell lines. BMC Cancer 6: 142.

Pennycooke, M., N. Chaudary, I. Shuralyova, Y. Zhang and I. R. Coe, 2001 Differential expression of human nucleoside transporters in normal and tumor tissue. Biochem Biophys Res Commun 280: 951-959.

Petrovic, V., S. Teng and M. Piquette-Miller, 2007 Regulation of drug transporters during infection and inflammation. Mol Interv 7: 99-111.

Philip, P. A., J. Benedetti, C. L. Corless, R. Wong, E. M. O'Reilly et al., 2010 Phase III study comparing gemcitabine plus cetuximab versus gemcitabine in patients with advanced pancreatic adenocarcinoma: Southwest Oncology Groupdirected intergroup trial S0205. Journal of clinical oncology : official journal of the American Society of Clinical Oncology 28: 3605-3610.

Poplin, E., Y. Feng, J. Berlin, M. L. RothenberG, H. Hochster et al., 2009 Phase III, randomized study of gemcitabine and oxaliplatin versus gemcitabine (fixeddose rate infusion) compared with gemcitabine (30-minute infusion) in patients with pancreatic carcinoma E6201: a trial of the Eastern Cooperative Oncology Group. Journal of clinical oncology : official journal of the American Society of Clinical Oncology 27: 3778-3785. 
Pourquier, P., C. Gioffre, G. Kohlhagen, Y. URASAKi, F. GoldWASSER et al., 2002 Gemcitabine (2',2'-difluoro-2'-deoxycytidine), an antimetabolite that poisons topoisomerase I. Clinical cancer research : an official journal of the American Association for Cancer Research 8: 2499-2504.

Puebla, C., M. Farias, M. Gonzalez, A. Vecchiola, C. Aguayo et al., 2008 High D-glucose reduces SLC29A1 promoter activity and adenosine transport involving specific protein 1 in human umbilical vein endothelium. Journal of cellular physiology 215: 645-656.

Raimondi, S., A. B. Lowenfels, A. M. Morselli-Labate, P. Maisonneuve and R. PEZzILLI, 2010 Pancreatic cancer in chronic pancreatitis; aetiology, incidence, and early detection. Best practice \& research. Clinical gastroenterology 24: 349358.

Ritzel, M. W., A. M. NG, S. Y. YAO, K. GRAhAM, S. K. LOEWEN et al., 2001a Recent molecular advances in studies of the concentrative $\mathrm{Na}+$-dependent nucleoside transporter (CNT) family: identification and characterization of novel human and mouse proteins (hCNT3 and mCNT3) broadly selective for purine and pyrimidine nucleosides (system cib). Molecular membrane biology 18: 65-72.

Ritzel, M. W., A. M. Ng, S. Y. YaO, K. Graham, S. K. Loewen et al., 2001b Molecular identification and characterization of novel human and mouse concentrative $\mathrm{Na}+$-nucleoside cotransporter proteins (hCNT3 and mCNT3) broadly selective for purine and pyrimidine nucleosides (system cib). The Journal of biological chemistry 276: 2914-2927.

RocKWELL, S., and G. B. GRINDEY, 1992 Effect of 2',2'-difluorodeoxycytidine on the viability and radiosensitivity of EMT6 cells in vitro. Oncology research 4: 151155.

Ross, D. D., and D. P. CudDy, 1994 Molecular effects of 2',2'-difluorodeoxycytidine (Gemcitabine) on DNA replication in intact HL-60 cells. Biochemical pharmacology 48: 1619-1630.

Ruiz van Haperen, V. W., G. Veerman, E. Boven, P. NoOrdhuis, J. B. Vermorken et al., 1994 Schedule dependence of sensitivity to 2',2'-difluorodeoxycytidine (Gemcitabine) in relation to accumulation and retention of its triphosphate in solid tumour cell lines and solid tumours. Biochemical pharmacology 48: 13271339.

Ruiz van Haperen, V. W., G. Veerman, B. J. Braakhuis, J. B. Vermorken, E. Boven et al., 1993a Deoxycytidine kinase and deoxycytidine deaminase activities in human tumour xenografts. European journal of cancer 29A: 21322137.

Ruiz van Haperen, V. W., G. Veerman, J. B. Vermorken and G. J. Peters, 1993b 2',2'-Difluoro-deoxycytidine (gemcitabine) incorporation into RNA and DNA of tumour cell lines. Biochemical pharmacology 46: 762-766.

Sandler, A. B., J. Nemunaitis, C. Denham, J. von Pawel, Y. Cormier et al., 2000 Phase III trial of gemcitabine plus cisplatin versus cisplatin alone in patients with locally advanced or metastatic non-small-cell lung cancer. Journal of clinical oncology : official journal of the American Society of Clinical Oncology 18: $122-130$.

Sankar, N., J. Machado, P. Abdulla, A. J. Hilliker and I. R. Coe, 2002 Comparative genomic analysis of equilibrative nucleoside transporters suggests conserved protein structure despite limited sequence identity. Nucleic Acids Res 30: 4339-4350. 
Santini, D., G. Perrone, B. Vincenzi, R. LAI, C. Cass et al., 2008 Human equilibrative nucleoside transporter 1 (hENT1) protein is associated with short survival in resected ampullary cancer. Annals of oncology : official journal of the European Society for Medical Oncology / ESMO 19: 724-728.

SAntini, D., G. Schiavon, B. Vincenzi, C. E. CASs, E. VAsile et al., 2011 Human equilibrative nucleoside transporter 1 (hENT1) levels predict response to gemcitabine in patients with biliary tract cancer (BTC). Current cancer drug targets 11: 123-129.

Santini, D., B. Vincenzi, M. E. Fratto, G. Perrone, R. LAi et al., 2010 Prognostic role of human equilibrative transporter 1 (hENT1) in patients with resected gastric cancer. Journal of cellular physiology 223: 384-388.

SCHAUDINN, A., 2013 Variability of therapy response in gemcitabine treated pancreatic carcinoma: Identifying relevant gene polymorphisms, pp. in Medical Faculty, Institute of Clinical Pharmacology, Göttingen.

Schreiber, E., P. Matthias, M. M. Muller and W. Schaffner, 1989 Rapid detection of octamer binding proteins with 'mini-extracts', prepared from a small number of cells. Nucleic Acids Res 17: 6419.

SchrumpF, E., and K. M. Boberg, 2003 Hepatic and extrahepatic malignancies and primary sclerosing cholangitis. Gut 52: 165.

Schy, W. E., L. W. Hertel, J. S. Kroin, L. B. Bloom, M. F. Goodman et al., 1993 Effect of a template-located 2',2'-difluorodeoxycytidine on the kinetics and fidelity of base insertion by Klenow (3'-->5'exonuclease-) fragment. Cancer research 53: 4582-4587.

ShaiB, Y. H., J. A. DAVILA and H. B. EL-SERAG, 2006 The epidemiology of pancreatic cancer in the United States: changes below the surface. Alimentary pharmacology \& therapeutics 24: 87-94.

Smith, P. K., R. I. Krohn, G. T. Hermanson, A. K. Mallia, F. H. Gartner et al., 1985 Measurement of protein using bicinchoninic acid. Anal Biochem 150: 7685.

Soler, C., A. Felipe, F. J. Casado, A. Celada and M. Pastor-Anglada, 2000 Nitric oxide regulates nucleoside transport in activated B lymphocytes. J Leukoc Biol 67: 345-349.

Soler, C., A. Felipe, J. Garcia-Manteiga, M. Serra, E. Guillen-Gomez et al., 2003 Interferon-gamma regulates nucleoside transport systems in macrophages through signal transduction and activator of transduction factor 1 (STAT1)dependent and -independent signalling pathways. Biochem J 375: 777-783.

Soler, C., J. Garcia-Manteiga, R. VAldes, J. Xaus, M. Comalada et al., 2001a Macrophages require different nucleoside transport systems for proliferation and activation. FASEB journal : official publication of the Federation of American Societies for Experimental Biology 15: 1979-1988.

Soler, C., R. Valdes, J. Garcia-Manteiga, J. Xaus, M. Comalada et al., 2001b Lipopolysaccharide-induced apoptosis of macrophages determines the upregulation of concentrative nucleoside transporters Cnt1 and Cnt2 through tumor necrosis factor-alpha-dependent and -independent mechanisms. The Journal of biological chemistry 276: 30043-30049.

Spano, J. P., C. ChOdKIEWICZ, J. MAUREL, R. WONG, H. WASAN et al., 2008 Efficacy of gemcitabine plus axitinib compared with gemcitabine alone in patients with advanced pancreatic cancer: an open-label randomised phase II study. Lancet 371: 2101-2108. 
Spratlin, J., R. Sangha, D. Glubrecht, L. DabBagh, J. D. Young et al., 2004 The absence of human equilibrative nucleoside transporter 1 is associated with reduced survival in patients with gemcitabine-treated pancreas adenocarcinoma. Clinical cancer research : an official journal of the American Association for Cancer Research 10: 6956-6961.

Stathopoulos, G. P., K. Syrigos, G. Aravantinos, A. Polyzos, P. Papakotoulas et al., 2006 A multicenter phase III trial comparing irinotecan-gemcitabine (IG) with gemcitabine $(\mathrm{G})$ monotherapy as first-line treatment in patients with locally advanced or metastatic pancreatic cancer. British journal of cancer 95: 587-592.

Storniolo, A. M., S. R. Allerheiligen and H. L. Pearce, 1997 Preclinical, pharmacologic, and phase I studies of gemcitabine. Seminars in oncology 24: S7-2-S7-7.

SugiYama, E., N. Kaniwa, S. R. Kim, R. HasegawA, Y. SAito et al., 2010 Population pharmacokinetics of gemcitabine and its metabolite in Japanese cancer patients: impact of genetic polymorphisms. Clinical pharmacokinetics 49: 549-558.

Suzuki, Y., M. HommA, M. ABEI, I. Hyodo and Y. KoHDA, 2013 Impact of solute carrier family 29 member 1 (SLC29A1) single nucleotide polymorphisms on mRNA expression in peripheral blood mononuclear cells. Biol Pharm Bull 36: 144-146.

Tanaka, M., M. Javle, X. Dong, C. Eng, J. L. Abbruzzese et al., 2010 Gemcitabine metabolic and transporter gene polymorphisms are associated with drug toxicity and efficacy in patients with locally advanced pancreatic cancer. Cancer 116: 5325-5335.

Tsubota, A., N. Shimada, K. Yoshizawa, T. Furihata, R. Agata et al., 2012 Contribution of ribavirin transporter gene polymorphism to treatment response in peginterferon plus ribavirin therapy for HCV genotype 1b patients. Liver Int 32: 826-836.

Turati, F., C. Galeone, V. Edefonti, M. Ferraroni, P. Lagiou et al., 2012 A metaanalysis of coffee consumption and pancreatic cancer. Annals of oncology : official journal of the European Society for Medical Oncology / ESMO 23: 311318.

Van Cutsem, E., W. L. Vervenne, J. Bennouna, Y. Humblet, S. Gill et al., 2009 Phase III trial of bevacizumab in combination with gemcitabine and erlotinib in patients with metastatic pancreatic cancer. Journal of clinical oncology : official journal of the American Society of Clinical Oncology 27: 2231-2237.

van Haperen, V. W., G. Veerman, J. B. Vermorken, H. M. Pinedo and G. Peters, 1996 Regulation of phosphorylation of deoxycytidine and 2',2'difluorodeoxycytidine (gemcitabine); effects of cytidine 5'-triphosphate and uridine 5'-triphosphate in relation to chemosensitivity for 2',2'difluorodeoxycytidine. Biochemical pharmacology 51: 911-918.

VeltKamp, S. A., D. Pluim, O. van Tellingen, J. H. Beijnen and J. H. Schellens, 2008 Extensive metabolism and hepatic accumulation of gemcitabine after multiple oral and intravenous administration in mice. Drug Metab Dispos 36: 1606-1615.

Vincent, A., J. Herman, R. Schulick, R. H. Hruban and M. Goggins, 2011 Pancreatic cancer. Lancet 378: 607-620.

Visser, F., L. Sun, V. DAmaraju, T. TACKABerry, Y. Peng et al., 2007 Residues 334 and 338 in transmembrane segment 8 of human equilibrative nucleoside transporter 1 are important determinants of inhibitor sensitivity, protein folding, and catalytic turnover. J Biol Chem 282: 14148-14157. 
von der MaAse, H., S. W. Hansen, J. T. Roberts, L. Dogliotti, T. Oliver et al., 2000 Gemcitabine and cisplatin versus methotrexate, vinblastine, doxorubicin, and cisplatin in advanced or metastatic bladder cancer: results of a large, randomized, multinational, multicenter, phase III study. Journal of clinical oncology : official journal of the American Society of Clinical Oncology 18: 3068-3077.

Wang, L., B. Munch-Petersen, A. Herrstrom Sjoberg, U. Hellman, T. Bergman et al., 1999 Human thymidine kinase 2: molecular cloning and characterisation of the enzyme activity with antiviral and cytostatic nucleoside substrates. FEBS letters 443: 170-174.

Warshaw, A. L., and C. Fernandez-del Castillo, 1992 Pancreatic carcinoma. N Engl J Med 326: 455-465.

WEISS, A. J., and L. JACKSON, 1961 The effect of 5-fluorouracil upon carcinomas of the gastrointestinal tract and related organs. The American journal of gastroenterology 35: 138-146.

Xiros, N., P. Papacostas, T. Economopoulos, G. Samelis, E. Efstathiou et al., 2005 Carboplatin plus gemcitabine in patients with inoperable or metastatic pancreatic cancer: a phase II multicenter study by the Hellenic Cooperative Oncology Group. Annals of oncology : official journal of the European Society for Medical Oncology / ESMO 16: 773-779.

XU, Q., Y. ZhANG and L. A. TRISSEL, 1999 Physical and chemical stability of gemcitabine hydrochloride solutions. Journal of the American Pharmaceutical Association 39: 509-513.

XU, X., A. S. STRIMPAKOS and M. W. SAIF, 2011 Biomarkers and pharmacogenetics in pancreatic cancer. Highlights from the "2011 ASCO Annual Meeting". Chicago, IL, USA; June 3-7, 2011. JOP 12: 325-329.

Zimmerman, E. I., M. Huang, A. V. Leisewitz, Y. WANG, J. YAng et al., 2009 Identification of a novel point mutation in ENT1 that confers resistance to Ara-C in human T cell leukemia CCRF-CEM cells. FEBS letters 583: 425-429. 


\section{CURRICULUM VITAE}

\section{PERSONAL INFORMATION}

Name: $\quad$ Sebastian Roppel

Address: $\quad$ Schöne Aussicht 20, 34376 Immenhausen

Date of birth: $\quad$ December $13^{\text {th }}, 1981$

Place of birth: Rotenburg a.d.Fulda

\section{SCHOOL EDUCATION}

$\begin{array}{ll}1988-1992 & \text { Primary school, Kassel (Herkules Grundschule) } \\ 1991-1998 & \text { Academic high school, Kassel (Wilhelmsgymnasium) } \\ 1998-1999 & \begin{array}{l}\text { Academic high school, Kassel } \\ \text { (Jakob-Grimm- Schule, Oberstufengymnasium) }\end{array} \\ \mathbf{1 9 9 9 - 2 0 0 0} & \text { Magnolia High School, Houston, Texas, USA } \\ \mathbf{2 0 0 0 - 2 0 0 2} & \text { Academic high school, Kassel } \\ & \text { (Jakob-Grimm- Schule, Oberstufengymnasium) }\end{array}$

School-leaving qualification: High school diploma

(Allgemeinbildendes Abitur)

\section{PROFESSIONAL EDUCATION}

2002 - 2003 Military service (Fritz Erler Kaserne, Fuldatal, Kassel)

2003 Work experience in hospital, Department of Cardiology

(Burgfeldkrankenhaus, Kassel)

2004 - 2009 Studies in biology, George August University, Göttingen

University qualification: Diploma in biology

2010 - 2013 Scholarship from DFG Research Training Group (GRK1034), PhD student in the Molecular Medicine Study, Department of Clinical Pharmacology, University Medical Center of the George August University, Göttingen 


\section{ADDITIONAL QUALIFICATIONS:}

- Certificate in laboratory animal science

(Zertifikat in Versuchstierkunde, den FELAS-B-Richtlinien entsprechend)

- Qualification certificate in radiation protection

(Fachkunde im Strahlenschutz für die Fachgruppen: S1, S2, S4.1,S5,

S6.1,S6.2 und S6.3 sowie R2)

- Radiation protection commissioner in the Department of Clinical Pharmacology, George August University, Göttingen

\section{LIST OF PUBLICATIONS}

- Florez, L. A., S. F. Roppel, A. G. Schmeisky, C. R. LAMMERS and J. STULKE, 2009 A community-curated consensual annotation that is continuously updated: the Bacillus subtilis centred wiki SubtiWiki. Database (Oxford) 2009: bap012.

- Lammers, C. R., L. A. Florez, A. G. Schmeisky, S. F. Roppel, U. MADER et al., 2010 Connecting parts with processes: SubtiWiki and SubtiPathways integrate gene and pathway annotation for Bacillus subtilis. Microbiology 156: 849-859 


\section{Appendix}

Table 17: Transcription factor binding prediction on hENT Promotr-SNP rs507964

\begin{tabular}{|c|c|c|c|}
\hline 1. V\$P300_01 & 2. V\$MZF1_02 & 3. V\$CDP_01 & 4. V\$AP2_Q6 \\
\hline 5. V\$SP1_Q6 & 6. V\$EGR1_01 & 7. V\$NGFIC_01 & 8. V\$EGR3_01 \\
\hline 9. V\$EGR2_01 & 10. V\$GC_01 & 11. V\$MSX1_01 & 12. V\$HOXA3_01 \\
\hline 13. V\$ZIC2_01 & 14. V\$AP2REP_01 & 15. V\$HOXA4_Q2 & 16. V\$MAZ_Q6 \\
\hline V\$ETF_Q6 & 18. V\$ZF5_01 & 19. V\$EGR_Q6 & 20. V\$SP1_Q6_01 \\
\hline V\$SP1_Q4_01 & 22. V\$CHCH_01 & 23. V\$LRF_Q2 & 24. V\$RBPJK_01 \\
\hline V\$KID3_01 & 26. V\$ELK1_03 & 27. V\$ELK1_04 & 28. V\$CKROX_Q2 \\
\hline V\$SREBP2_Q6 & 30. V\$MAFB_01 & 31. V\$LHX5_01 & 32. V\$NKX25_03 \\
\hline V\$NKX23_01 & 34. V\$GLI3_Q5_01 & 35. V\$KLF15_Q2 & 36. V\$ING4_01 \\
\hline V\$AML2_01 & 38. V\$ZBP89_Q4 & 39. V\$GKLF_Q4 & 40. V\$FKLF_Q5 \\
\hline V\$EGR1_Q6 & 42. V\$EGR1_02 & 43. V\$WT1_Q6_01 & 44. V\$EGR2_Q6 \\
\hline V\$NFE4_Q5 & 46. V\$ZFP740_03 & 47. V\$ZIC1_04 & 48. V\$EGR1_○4 \\
\hline V\$GCM1_04 & 50. V\$SMAD4_04 & 51. V\$SP4_04 & 52. V\$TCFAP2C_04 \\
\hline
\end{tabular}

Table 18: Lymphoblastoid cell lines from Coriell Cell Repositories (http://ccr.coriell.org)

\begin{tabular}{|c|c|c|c|c|c|c|}
\hline GM07000 & GM11831 & GM12892 & GM12347 & HG00096 & HG00130 & HG00236 \\
\hline GM11839 & GM11832 & GM06984 & GM12348 & HG00097 & HG00131 & HG00237 \\
\hline GM11840 & GM11881 & GM06986 & GM12383 & HG00099 & HG00133 & HG00238 \\
\hline GM11993 & GM11882 & GM06989 & GM12399 & HG00100 & HG00134 & HG00239 \\
\hline GM12003 & GM11992 & GM07037 & GM12400 & HG00101 & HG00135 & HG00240 \\
\hline GM12005 & GM11994 & GM07051 & GM12413 & HG00102 & HG00136 & HG00242 \\
\hline GM12056 & GM11995 & GM07346 & GM12414 & HG00103 & HG00137 & HG00243 \\
\hline GM12154 & GM12004 & GM07347 & GM12489 & HG00104 & HG00138 & HG00244 \\
\hline GM12716 & GM12006 & GM11829 & GM12546 & HG00106 & HG00139 & HG00245 \\
\hline GM12750 & GM12043 & GM11843 & GM12716 & HG00108 & HG00140 & HG00246 \\
\hline GM12760 & GM12044 & GM11892 & GM12718 & HG00109 & HG00141 & HG00247 \\
\hline GM12762 & GM12057 & GM11893 & GM12749 & HG00110 & HG00142 & HG00249 \\
\hline GM12763 & GM12144 & GM11894 & GM12775 & HG00111 & HG00143 & HG00250 \\
\hline GM12812 & GM12145 & GM11918 & GM12776 & HG00112 & HG00146 & HG00251 \\
\hline GM12814 & GM12146 & GM11919 & GM12777 & HG00113 & HG00148 & HG00252 \\
\hline GM12873 & GM12155 & GM11920 & GM12778 & HG00114 & HG00149 & HG00253 \\
\hline GM12875 & GM12156 & GM11930 & GM12828 & HG00116 & HG00150 & HG00254 \\
\hline GM10854 & GM12234 & GM11931 & GM12830 & HG00117 & HG00151 & HG00255 \\
\hline GM10859 & GM12239 & GM11932 & GM12889 & HG00118 & HG00152 & HG00256 \\
\hline GM06985 & GM12248 & GM11933 & GM12890 & HG00119 & HG00154 & HG00257 \\
\hline GM06993 & GM12249 & GM12045 & GM12282 & HG00120 & HG00155 & HG00258 \\
\hline GM06994 & GM12264 & GM12046 & GM12283 & HG00121 & HG00156 & HG00259 \\
\hline GM07022 & GM12717 & GM12058 & GM12286 & HG00122 & HG00158 & HG00260 \\
\hline GM07034 & GM12751 & GM12272 & GM12748 & HG00123 & HG00159 & HG00261 \\
\hline GM07055 & GM12761 & GM12273 & GM12827 & HG00124 & HG00160 & HG00262 \\
\hline GM07056 & GM12813 & GM12275 & GM12829 & HG00125 & HG00231 & HG00263 \\
\hline GM07345 & GM12815 & GM12287 & GM12842 & HG00126 & HG00232 & HG00264 \\
\hline GM07357 & GM12872 & GM12340 & GM12843 & HG00127 & HG00233 & HG00265 \\
\hline GM11829 & GM12874 & GM12341 & GM12340 & HG00128 & HG00234 & HG01334 \\
\hline GM11830 & GM12891 & GM12342 & GM12342 & HG00129 & HG00235 & \\
\hline
\end{tabular}




\section{Coding sequence of ENT1 (SLC29A1) used for transfection}

The hENT1 clone was obtained from SourceBioscience (Nottingham UK ; Clone 3051441, IRAUp969A097D; http:/www.lifesciences.sourcebioscience.com/ genomecube? $\mathrm{kw}=3051441$ )

\section{Sequence:}

3 ' CTGCAGCGAGAGCGCGCGGATCTCAGCGCGGGAGCAGTGCTTCTGCGGCAGGCCCCTGAGGGAGGGAG CTGTCAGCCAGGGAAAACCGAGAACACCATCACCATGACAACCAGTCACCAGCCTCAGGACAGATACAAA GCTGTCTGGCTTATCTTCTTCATGCTGGGTCTGGGAACGCTGCTCCCGTGGAATTTTTTCATGACGGCCA CTCAGTATTTCACAAACCGCCTGGACATGTCCCAGAATGTGTCCTTGGTCACTGCTGAACTGAGCAAGGA CGCCCAGGCGTCAGCCGCCCCTGCAGCACCCTTGCCTGAGCGGAACTCTCTCAGTGCCATCTTCAACAAT GTCATGACCCTATGTGCCATGCTGCCCCTGCTGTTATTCACCTACCTCAACTCCTTCCTGCATCAGAGGA TCCCCCAGTCCGTACGGATCCTGGGCAGCCTGGTGGCCATCCTGCTGGTGTTTCTGATCACTGCCATCCT GGTGAAGGTGCAGCTGGATGCTCTGCCCTTCTTTGTCATCACCATGATCAAGATCGTGCTCATTAATTCA TTTGGTGCCATCCTGCAGGGCAGCCTGTTTGGTCTGGCTGGCCTTCTGCCTGCCAGCTACACGGCCCCCA TCATGAGTGGCCAGGGCCTAGCAGGCTTCTTTGCCTCCGTGGCCATGATCTGCGCTATTGCCAGTGGCTC GGAGCTATCAGAAAGTGCCTTCGGCTACTTTATCACAGCCTGTGCTGTTATCATTTTGACCATCATCTGT TACCTGGGCCTGCCCCGCCTGGAATTCTACCGCTACTACCAGCAGCTCAAGCTTGAAGGACCCGGGGAGC AGGAGACCAAGTTGGACCTCATTAGCAAAGGAGAGGAGCCAAGAGCAGGCAAAGAGGAATCTGGAGTTTC AGTCTCCAACTCTCAGCCCACCAATGAAAGCCACTCTATCAAAGCCATCCTGAAAAATATCTCAGTCCTG GCTTTCTCTGTCTGCTTCATCTTCACTATCACCATTGGGATGTTTCCAGCCGTGACTGTTGAGGTCAAGT CCAGCATCGCAGGCAGCAGCACCTGGGAACGTTACTTCATTCCTGTGTCCTGTTTCTTGACTTTCAATAT CTTTGACTGGTTGGGCCGGAGCCTCACAGCTGTATTCATGTGGCCTGGGAAGGACAGCCGCTGGCTGCCA AGCCTGGTGCTGGCCCGGCTGGTGTTTGTGCCACTGCTGCTGCTGTGCAACATTAAGCCCCGCCGCTACC TGACTGTGGTCTTCGAGCACGATGCCTGGTTCATCTTCTTCATGGCTGCCTTTGCCTTCTCCAACGGCTA CCTCGCCAGCCTCTGCATGTGCTTCGGGCCCAAGAAAGTGAAGCCAGCTGAGGCAGAGACCGCAGGAGCC ATCATGGCCTTCTTCCTGTGTCTGGGTCTGGCACTGGGGGCTGTTTTCTCCTTCCTGTTCCGGGCAATTG TGTGACAAAGGATGGACAGAAGGACTGCCTGCCTCCCTCCCTGTCTGCCTCCTGCCCCTTCCTTCTGCCA GGGGTGATCCTGAGTGGTCTGGCGGTTTTTTCTTCTAACTGACTTCTGCTTTCCACGGCGTGTGCTGGGC CCGGATCTCCAGGCCCTGGGGAGGGAGCCTCTGGACGGACAGTGGGGACATTGTGGGTTTGGGGCTCAGA GTCGAGGGACGGGGTGTAGCCTCGGCATTTGCTTGAGTTTCTCCACTCTTGGCTCTGACTGATCCCTGCT TGTGCAGGCCAGTGGAGGCTCTTGGGCTTGGAGAACACGTGTGTCTCTGTGTATGTGTCTGTGTGTCTGC GTCCGTGTCTGTCAGACTGTCTGCCTGTCCTGGGGTGGCTAGGAGCTGGGTCTGACCGTTGTATGGTTTG ACCTGATATACTCCATTCTCCCCTGCGCCTCCTCCTCTGTGTTCTCTCCATGTCCCCCTCCCAACTCCCC ATGCCCAGTTCTTACCCATCATGCACCCTGTACAGTTGCCACGTTACTGCCTTTTTTTAAAAATATATTTG ACAGAAACCAGGTGCCTTCAGAGGCTCTCTGATTTAAATAAACCTTTCTTGTTTTTTTAAAAAAAAAAAA AAAAAAAAA ' 5 


\title{
Cloned Region Upstream of Transcription Start Site (TSS) of ENT1
} -1945/+141 According to (FUKUCHI et al. 2010)

\author{
Primer \\ ENT1_Prom_f AGAGTGGAAGCTTGCCTGGAGAGGAGGGAGAGGTTA \\ ENT1_Prom_r CCCCGCCCCGGGCACCTGCTGAGACTTTGGAGTGAGCATC
}

\section{Promoter Fragment Ahead of hENT1 Long Transcripts (2122bp)}

3 ' AGAGTGGAAGCTTGCCTGGAGAGGAGGGAGAGGTTAGGCCCCCAAAAGTGAGGCCACAAGTCCTGGCA GCAGCTGTATCCACAAAATGCTTTCTTTTGGAGTAGGATAATCCTGGCACCAGCACTGACCGAAGCCTGC CCAGTGGACAGAAGATATAGTGAGGGTTGTGCATGAGAGGGATCTGCCACAGACATGCCTCTCCACTCCC AACAGAAATGTCTTTCTGGAAGAATGCCTTGCATCTAGCACAAAACTGATTATTGCCCCTCTGTCCTCCA GCAGTTCCTCCCAAAGACCACTCCTAATCACCTCTGGCCTCAGGCGGGAGGGGAACTAACACCCACCCAC CCCTGCCCTCCCTGCAAATGGGAACATCAAGGTTCCCAGTGCTTAACTGAGGGACAAGTGACAATTTAGC AGAGAGGCAAGATTTGAATCCAGACTGTCTTCCAGACTCAGGACCTACCTTAAAATAATATCTGAGTTGC TTATGGAGGCAGACCTGCCTGCAAAGCCCAGCACTCAGCAAGTGCTCAATAAATATTTGATTTGAATTCT TTCCATGGCTTTGAAAGTCTAATCACCCAGACTGCTGCTCTGCAAAACAGTTTAACCTGGCCTGGCAGTT GGTGGGGGTGGGGGAGAGGAGAGATGGACAATTGTACAAGGGTTTATTTTGCTACCTATTCCATCGTGGT TTCAGTCCTCACAGCCTGGAAGTTGTTTCCCCCTGCTAAGTTTCGGTCAGTATGTCACACTGTGACCCAG AAATGGCTTGAGTCCATCTAGGAGGAAGTTTGCCTGGCTAGCTCACAGTAGGGAGGAAAATATCCTCCAG CGAGTTTGAGGACTTCTCAGCTAGTGGTGGTGGGAAGAGGGGTGATACGTTTGCTAAGAGACTGGGTGGG AGGCCACCCAGGGAGGCAGTGCAGAAATGCATCCCCTTGAGGGTCATCCCACCCTAGAAGAGACTAGGGT TGGGTGAGTTGCCTTAAGAACTGACTTCATCATTTCCTCCTCCCTAGTGGGAGGCCCCTCAGGGGTCAAA TAAGAGCCTCAGAAGAGTCAACATGCTTAAGGAAACACAGTTAGAAAGTGCAGTCTGGGCAGGGCGCGGT GGCTCACGCCTGTAATCTCAGCACTTTGGGAGCAGAGGCAGGAGGATCACCTGAGGTCGGGAGACCAGCC TGACCAACATGGAGAAACCCCGTCTCTACTAAAAATACAAAATTAGCCGGGCGTGGTGGCGTATGCCTGT AATCCCAGCTCCTACGGAGGCTGAGGCAGGAGAATCGCTTGAATCCGGGAGGCGGAGGTTGCAGTGAGCC GAGATCGCGCCATTGCTCTCCAGCCTGGACAACAAGAGCGAAACTCCGTCTTAAAAAAAAAAAAAAAAAG AGTTAGACACATTTGCATCCCAGCCTCCGGATAATTTGCTTATTGTTCCCAGGCAATAATCCTCTCTCTC TGGGTGACTCTTGGGCTCTATCTAGGTTCAGACGAGGACAGTGAGGAGTACAGGATCCAATTGGGATTCC AGTCCCCTCCCCACACCCGTCAGAAGGCTTGGTTGGGAAAGAAGTGAGCCCCAAGCTATCCGCCCCACCC CCAGCCCTGCGGGGCTTTCTGCCTGCCACACGCCGTCCCTGCTCACTACCCCATCGGTTTCCTTCGGGAG TCTTCAAAGCCAGTGCACGTGCTCCCAGGTCTCAGGGAGGCGACCCAGGGGGAGGGGCAGAGAGAAGGGG GTCCGAGCCCTTGGGCCCCTAACCCCGTCCCTTTCCGGAGCCTCGGGTGCCCAAAGGCGCCGGCCGCCAG TCCCAGGCCCGAAGGGCCCCTCCCACTGAGTCGGCTCTGGTCTCCCCGCCCCTGAGCCGCGAGGACTGGA CGCAGCTGGCTGCGGAGCTCTGGGCGGGCGCTGGGGTCGCCTGTTGCAGCCTCTCTTCCGCCCGGCGGCC CACACCGGTCAGGCCCGGCGCGGGCTGCGCTCTCCAGCTGTGGCTATGGCCCCAGCCCCGAGATGAGGAG GGAGAGAACTAGGGGCCCGCAGGCCTGGGAATTTCCGTCCCCCACCAAGTCCGGATGCTCACTCCAAAGT CTCAGCAGGTGCCCGGGGCGGG ' 5 